Portland State University

PDXScholar

\title{
Wherefore by Their Fruits Ye Shall Know Them: An Actor-Network Theory Analysis of Mercy Corps' Peaceful Communities Initiative in Central Asia
}

John Thomas Westerman

Portland State University

Follow this and additional works at: https://pdxscholar.library.pdx.edu/open_access_etds Let us know how access to this document benefits you.

\section{Recommended Citation}

Westerman, John Thomas, "Wherefore by Their Fruits Ye Shall Know Them: An Actor-Network Theory Analysis of Mercy Corps' Peaceful Communities Initiative in Central Asia" (2011). Dissertations and Theses. Paper 286.

https://doi.org/10.15760/etd.286

This Dissertation is brought to you for free and open access. It has been accepted for inclusion in Dissertations and Theses by an authorized administrator of PDXScholar. Please contact us if we can make this document more accessible: pdxscholar@pdx.edu. 
Wherefore by Their Fruits Ye Shall Know Them: An Actor-Network Theory Analysis of Mercy Corps' Peaceful Communities Initiative in Central Asia

by

John Thomas Westerman

A dissertation submitted in partial fulfillment of the requirements for the degree of

\author{
Doctor in Philosophy \\ in \\ Urban Studies
Dissertation Committee:
Sy Adler, Chair
Charles Heying
Ellen Bassett
Margaret Everett
Michael Flower

Portland State University

(C) 2011 


\begin{abstract}
The motivation for this research comes from the belief that an over reliance on a social constructivist perspective has caused development studies in general, and post-development in particular, to under-theorize the role of discourse in development. A key issue in post-development studies concerns whether or not development organizations depoliticize their interventions. The notion of depoliticization provides a perfect occasion for examining more deeply the role of discourse in development. This research uses the actor-network theory constructivist framework to analyze a USAID funded development program in Central Asia (Kyrgyzstan, Tajikistan, and Uzbekistan): Mercy Corps' Peaceful Communities Initiative (PCI). The research approach used in this study involved both traditional ethnographic methods and document analysis. The ethnographic case material comes from multiple field visits to PCI offices in Central Asia and multiple visits to a variety of PCI community sites. The documentary evidence comes from a variety of organization and project specific documents. The embedded case studies demonstrate that materiality cannot be easily separated from sociality and that indeed the two are inseparable. Thus development discourse cannot be solely understood as a social phenomenon but could instead be understood as an assemblage of material elements through which both power and sociality flow.
\end{abstract}




\section{Dedication}

In loving memory of my father and grandmother,

Robert E. Westerman and Helen H. Westerman

And also to

Brandy Westerman

For providing the love to see this through 


\section{Acknowledgements}

This dissertation would not have been possible without the support and guidance of several individuals who in one way or another contributed valuable assistance in the preparation and completion of this study.

First and foremost I would like to express my utmost gratitude to my dissertation Chair, Sy Adler, without whom this dissertation would not have been possible.

I am truly indebted to my advisor Charles Heying for his wisdom and insight during my time doing course work in the $\mathrm{PhD}$ program.

I owe a particular debt of gratitude to Michael Flower who first introduced me to actor-network theory while I was an undergraduate in Portland State University’s Honors program.

I would like to express my gratitude to Margaret Everett for her patience and insight as well as her thoughtful critique of post-development studies;

To Ellen Bassett for agreeing to join the dissertation committee at the last moment and for her keen analysis of my research.

I owe a deep debt of gratitude to the entire Mercy Corps organization and specifically to all those involved in the Peaceful Communities Initiative.

To my good friend and advisor, Dr. Lisa Walker, without her help and encouragement this dissertation would have never been finished.

To my dear friends Dr. Matthew Witt and Dr. Carlos Vilalta without your sage advice I would have dropped out and become a bicycle mechanic.

Last but not least, I owe everything to the love and support of my family. 


\section{Table of Contents}

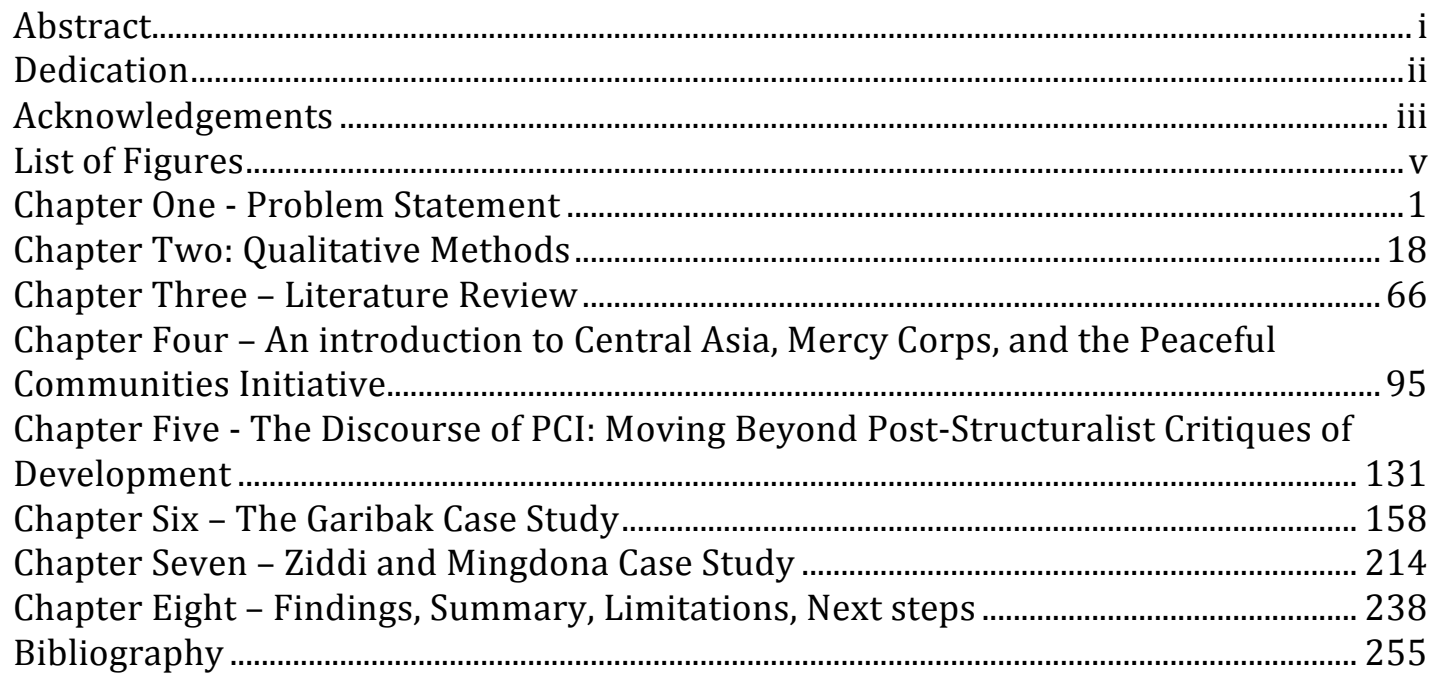




\section{List of Figures}

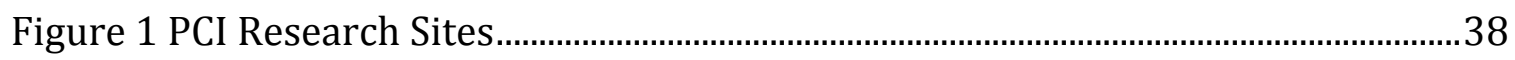

Figure 2 Mercy Corps' Civil Society Mandala .......................................................................114

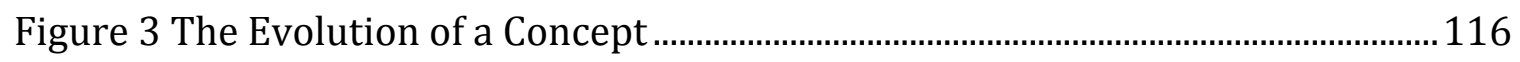

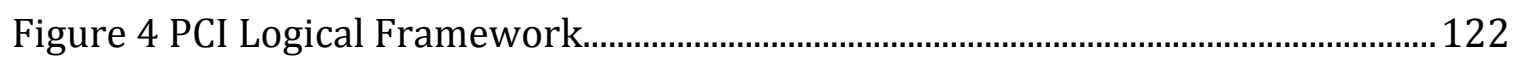

Figure 5 Description of a Community Cluster...................................................................199

Figure 6 Description of a Community Cluster......................................................................219 


\section{Chapter One - Problem Statement}

The research question posed by this dissertation had originally been concerned with understanding the sociological concept of power as it related to the context of a particular community development program. The question originally was simply: "What is the power of development?" The hypothesis was that the power of development was related to discourse but that existing theories of development, particularly postdevelopment, had so far under-theorized the notion of discourse. Post-development authors simply assumed a kind of social constructivist perspective that privileged a social conception of the idea of discourse and thus also privileged a social constructivist view of the world. This question of power still persists but it has been reworked to reflect a perspective that is more consistent with actor-network theory and also more at odds with the post-structuralism of post-development studies.

Post-development is a school of thought that can be traced back to a handful of authors (Escobar 1995, Ferguson 1990, Sachs et al 1999) who hold the position that the entire notion and practice of development. As Pieterse (2010) describes it, "postdevelopment is a radical reaction to the dilemmas of development. Perplexity, and extreme dissatisfaction with business-as-usual and standard development rhetoric and practice, and a disillusion with alternative development are keynotes of this perspective" (p.110). Pieterse explains that post-development is to some extent an incorporation of the absolute rejectionist standpoint of anti-development and the hopeful aspiration of beyond development, what Pieterse refers to as "looking over the fence" (ibid, p.111). These perspectives are combined with the post-structural perspectives of Foucault's archaeology of knowledge along with his focus on power/knowledge, along with the tools 
of discourse analysis. One of the key features of post-development is the adoption of the post-structuralist privileging of discourse as a means of constructing reality. Another key feature of post-development is the way in which the theoretical perspective dislocates agency to larger actors such as capitalism, the development apparatus, society, and culture.

This research proposes two interrelated hypotheses. The first is that power rather than being an actor in some sociological drama, is actually an effect or an outcome of a process. The second hypothesis is related to the first and suggests that our understanding of power is confused by theories of discourse that treat discourse as merely social while simultaneously ignoring the material basis of both power and sociality. Put differently this second hypothesis can be understood as the general hypothesis put forward by actornetwork theory: the social is not a building block of construction but rather something that flows through materiality. The null hypothesis in either case is that the postdevelopment description of the world is in fact accurate.

The research question derived from these hypotheses is as follows: to what extent did Mercy Corps' PCI program attempt to depoliticize its development activities? Following the work of James Ferguson (1990), depoliticization is understood as the process whereby development institutions or organizations, operating as 'anti-politics machines' render development in purely exogenous and technical terms which has the result of removing politics from the discourse of development. Additionally, it has been argued by Ferguson (1990) and others (Escobar 1995, Horky 2011) that development actors "are held in an illusio" (Horky 2011; p. 120), presumably by the development apparatus. Which is to say that development actors themselves, according to post- 
development, do not fully appreciate or even grasp the extent to which their various discourses operate as anti-politics machines. Thus the notion of depoliticization implicates two interrelated elements: Development must be understood in some sense as an imminent actor that works to depoliticize its interventions and also over-determines other actors to the extent that they are rendered, as in Althusser's (1965) writings, as mere träger, or supports for an overarching system. In Latour's wording depoliticization renders actors not as mediators that have the capacity to affect both process and outcomes but rather as mere intermediaries who faithfully relay the intentions of powerful others.

The research question posed in this dissertation relates to the question of power but does so by first focusing on understanding the construction of the assemblages through which power and sociality flow. The question also attempts to relate two disparate intellectual traditions in order to challenge one (post-development studies) and in a sense substitute it with another (actor-network theory). Many of the assemblages in the PCI program are documents and thus discourse forms an important component in building an understanding of development. However, this research proposes that post-

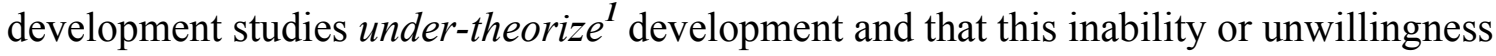
to elaborate a fuller theory of discourse leads post-development scholars to make a number of fundamental mistakes in their evaluation of development practice.

The hypothesis is that depoliticization refers to a failure of politics that is better understood as a premature closure of what should be a wider discussion engaging a wider array of actors. Instead of relying on a series of black-boxed facts development in these

\footnotetext{
${ }^{1}$ Under-theorization simply means that by focusing on only the social aspects of discourse, postdevelopment scholars overlook the materiality of discourse. A fuller theory of discourse must attempt to understand it as both material and social. Importantly, however, there are many different ways beside discourse that things/actors/propositions can be articulated.
} 
cases should proceed on the basis of opening those black boxes to scrutiny, or in Latour's language development should proceed based not on matters of fact but rather on matters of concern (Latour 2005, p.87).

There are a number of other inter-related problems with post-development. Postdevelopment tends to be extremely reductionist in its analysis and thus offers an oversimplified account of the assumed monolithic power of development. Postdevelopment fails in one other important respect: the critical perspective it offers is fundamentally flawed. First, it depends on absolute series of divisions: subject/object, nature/society, and Western/Other. Second, because of its overemphasis on an undertheorized understanding of discourse it relies too much on vague contextual explanations that are themselves left unexplained: capitalism, social relations, and power relations. Third, post-development, because of its reliance on these overarching categories of discourse and a kind of theory of embeddedness, can lead the proponents of this perspective to be anti-empirical. For example, local discourses simply become so many local examples of an overarching discourse such as capitalism and development. Because of this bias towards empiricism, post-development scholars often fail to account for the ways in which discourses are produced and used and more importantly, they fail to account for what sorts of things get added to these master discourses.

The effect is that post-development offers an untenable mereological ${ }^{2}$ model of the relationship between local discourse and global discourse and ends up offering a kind ironclad path-dependency. Post-development lacks a convincing theory of change. Because post-development insists on its own privileged perspective while simultaneously

${ }^{2}$ From the Greek word for 'part', $\mu \varepsilon \rho \varsigma$, mereology is the study of the relationship between part and whole, and part and part. 
insisting on the false consciousness of development actors and furthermore relying on the emergence of an unaffected grass-roots movement that should be fundamentally opposed to the existing and dominant categories of discourse, post-development denies the possibility of what Latour calls the progressive composition of the common world. Postdevelopment scholars are themselves barred from engaging in helping development because that would effectively mean their capture by the discourses they criticize, so they are essentially a Greek choir yelling at the actors from the sidelines. Development professionals are also disqualified from helping to positively change the world because they have already been captured and are mere cultural dupes laboring under a false consciousness that they are not even capable of recognizing. Finally, the grass roots saviors will not help form a common world either, but a world that is for them. Because of these things post-development can be said to operate with an extremely narrow conception of politics.

For post-development, politics must be both revolutionary and pure. But oddly enough they have no model for what one might call real politics. Which is to say that the post-development model of politics is both abstract and idealistic. What is also remarkable about this particular conception of politics is the extent to which it is asymmetric. Asymmetry is a common feature of all post-development writing. The postdevelopment scholar occupies a privileged position from which to exercise his judgment.

Actor-network theory, on the other hand, offers a strong challenge and a thorough going corrective to the problems and misperceptions of post-development. What is refreshing about actor-network theory is that it proposes a robust perspective that carries with it a defensible metaphysical/philosophical position that simultaneously challenges 
the traditional division of the world into subjects and objects. Actor-network theory also overcomes, or at least bypasses, the persistent and violent oscillation between subject and objects, nature and society, actor and system of older models. Actor-network theory offers a theoretical perspective on the nature of groups, action, objects, facts, and politics and it does so in a way that is not asymmetrical and does not privilege the view of a few well-placed scholars over the views of sociological informants.

Because of the robust and rigorous nature of actor-network theory as both theory and methodology it offers a fundamentally different perspective on the notion of critique and in many ways it saves the spirit of critique: the desire to challenge the oppressive and destructive nature of the apparently powerful structures of our common world. Actornetwork theory also does something that post-development has found notoriously difficult: rendering a considered judgment that has the capacity to assess whether or not something was done well or poorly. Actor-network theory also offers a theory of change that has a sound philosophical basis, whereas post-development offers a kind of entropy, a cold death of concretized identity and discourses that in the end rebuff any grassroots challenge. The unique contribution of actor-network theory to development studies is that it offers a methodology for making scholarship politically relevant and strongly suggests that there can exist a political project that involves the collective and progressive composition of a common world.

The problems with post-development theory are many: discourse is undertheorized, power relations and other contextual explanations are offered without explanation, and that which needs to be explained - sociality, power relations, and context - is instead offered as the explanation. The explanandum is confused with the 
explanans. Politics are narrowly defined, and the collective and progressive composition of the common world is rendered impossible.

Actor-network theory informed ethnographic methods are uniquely positioned for understanding the relationship between the discourse and practice of community development due in part to these methods' unrelenting focus on local interactions. Discourse and practice remain at the heart of the problem of development studies. And ethnographic methods offer the best chance at gaining some leverage on these questions.

This research will demonstrate that the power of development is rooted in the ability of a development organization to write the story of a development program. When looking at the PCI project one can ask a very simple question. Who controls the discourse about the project? The answer is likewise very simple. Mercy Corps' development professionals have had privileged access to the means for writing the narratives associated with the PCI program. From the initial set of studies designed to set the stage for the development program to the community development methodologies designed to increase Mercy Corps' understanding of beneficiaries, their needs and circumstances, to the constant flow of information coming out of the project in the form of field reports, quarterly reports, annual reports, field studies, to the final report and eventually to the sustainability study (Mercy Corps 2007) that forms a kind of capstone for the project. From start to finish those documents represent settlements about the meaning of the development project and are written by Western development professionals.

From the perspective of post-development studies there are a number of immediate problems that arise from this state of affairs. The first problem with Western 
Development discourse is precisely that, it is Western, it pertains to development and it forms a discourse. For Escobar development discourse involves a process of abstraction that follows the internal logic of professional discourse and institutional needs and as he explains,

It is crucial to unveil ....aspects of discourse and organization by investigating the documentary practices of development institutions. We must analyze how peasants are constituted by work practices of development professionals; that is, how the former's concrete experience is elaborated upon by the professional discourse of the latter, separated from the context in which the peasants' problems arise and shifted to that in which institutions speak and act. This work of abstraction is a necessary condition for development to work in the process of describing, inquiring into, interpreting, and designing treatment for their clients or beneficiaries. Although most times this process of abstraction and structuring -which goes on in large part unconsciously -- take place at the top (international or national levels), it inevitably works its way down to the local situation, where most of the work is done. The local level must reproduce the world as the top sees it, so to speak (Escobar 1995; p111 emphasis added).

There is a lot to unpack in this statement. First, it will be important to distinguish between what Escobar refers to as institutional development and development work done by an American NGO, Mercy Corps, on behalf of USAID. Perhaps we can forgive Escobar for characterizing all of development in this way when what he meant was merely institutional development. Perhaps when Escobar speaks of development it may be that he only means to indict institutions such as the World Bank, IMF, or the various United Nations' agencies and not NGOs. Sadly, Escobar makes no such distinction, for him,

The invention of development necessarily involved the creation of an institutional field from which discourses are produced, recorded, stabilized, modified, and put into circulation. This field is intimately imbricated with processes of professionalization; together they constitute an apparatus that organizes the production of forms of knowledge and the deployment of forms of power, relating to one another. The institutionalization of development took place at all levels, 
from the international organizations and national planning agencies in the Third World to local development agencies, community development committees, private voluntary agencies, and non-governmental organizations (Escobar 1995; p46, emphasis added).

What Escobar has given us is a monolithic version of an all-powerful field of development, and in conceiving of it in this way Escobar, and post-development studies in general, is incapable of understanding differences. Second, what does it mean to unveil, and why is Escobar given the power to do so but development professionals' carry on their own work unconsciously? This is part and parcel of the arrogance of a critical stance that claims to hold a god's eye view of what other mere mortals can only respond to from some fundamentally flawed position. What does an institutional field look like? Discourses are produced, often at a desk, in an office, in an actual place with fully conscious individuals writing on computer keyboards, referencing older documents, and checking their emails for comments from the field or HQ depending on from where they happen to be writing.

This is not to say that development does not have a shared discourse. Writers of development grants borrow heavily from their own repositories of documents and these documents tend to carry with them sets of ideas that do serve in some way to delimit the discourse of development. Writers also quote from the available literature, but that literature is not transported whole and intact but is instead translated and transformed to meet the current need. At every step the writers subtract or add something to their work and they often do so based on the extant professional literature, whether that is comprised of documents from Mercy Corps' own archives or borrowed from other aid organizations, or borrowed from scholarship about development. 
The mechanism for distribution of knowledge is not through the constitution of a macro level field but from the actions of a localized author sifting through the available detritus of previous programs, ideas, donor wishes, etc. Writing is a kind of negotiation aimed at eventually arriving at some sort of closure that will only be temporary. This research will demonstrate in part that, following Latour, writing is not an all-powerful social means for constructing worlds, but a tentative, difficult, risky proposition.

Post-development deploys two very general critiques of development. One, because development discourse is bound up in Western ideologies and self-referencing institutional demands it forms a kind of fetish and, two, for that very reason development institutions fundamentally get their facts wrong. Because of these demands development institutions are, as a matter of course, incapable of rendering honest judgments or producing faithful re-presentations of the world within which they operate. Oddly enough this is the same critique that is implied in much of what we would consider as the worst excess of development, namely that it treats its beneficiaries as cultural dupes clinging to fetishized knowledge and in desperate need of modernization through the application of actual facts.

For post-development studies, Western development discourse is ethnocentric and relies almost entirely on Western conceptions of development, communities, economy, etc. Because the discourse is, according to post-development studies, prima facie ethnocentric it represents an imposition on the culture and values of those it seeks to engage. Furthermore, such a discourse is deeply embedded in Western values and Western ways of seeing and understanding others. For instance the extent such development discourse engages in arguments about economy and democracy it becomes 
a tool for the deployment and further entrenchment of a neoliberal understanding of the role and importance of economy and democracy. As Berthoud, a contributor to the "Market" chapter in The Development Dictionary, explains it, "development implies, explicitly or implicitly, that the Western way of life is the only means to guarantee human happiness" (Berthoud 1993, p72). More recently this emphasis on neoliberal economic doctrine and democracy theory has been described as "the new policy agenda" (Hilhorst 2003, p144). Additionally, a recent study of cross border programs in the Ferghana valley of Central Asia asserts that their underlying rationality "locates [the projects] in the 'new policy agenda' for Central Asia (Bichsel 2009). The twin pillars of this new policy agenda are comprised of an adherence to neoliberal economic theory and democratic ideals.

Can we simply dismiss the PCI texts as tools of Western hegemony? Are the various PCI documents ethnocentric? Do they conform to some variation of neo-liberal economic doctrine or liberal democratic theory? If these documents are guilty as charged do they also attempt to replace more traditional and cultural local understandings of development with Western development thinking? There are a number of problems with the critique of development as it has been rendered by post-development studies. The first problem is that post-development can prima facie dismiss any development document or documentary practice as ethnocentric. But such a dismissal relies upon reified notions of what it means to be Western and also what it means to be non-western. Additionally, and perhaps more damning, post-development relies on a modernist understanding of a persistent set of dichotomies: West/East, subjectivity/objectivity, nature/culture etc. That is to say, the critique offered by post-development is only 
accurate and applicable if one first takes a large number of things as already given in the order of things.

Both post-development studies and modernity bifurcate the world between fetishes and facts. The reason they are able to do this has to do with what Latour calls the 'modern constitution' (Latour 1993, p.13) which insists that the world is ontologically divided with nature and her facts on one side and society, culture, and subjective understanding on the other. It is this premature division of the world that makes a particular kind of critique possible and allows post-development studies to declare Western development knowledge an institutional fetish while marshaling social facts to explain why development is destined to fail.

According to Harman, Latour understands modernity as something that "tried to purify the world by dissecting it into two utterly opposed realms. On one side we have the human sphere, composed of transparent freedom and ruled by arbitrary and incommensurable perspectives. On the other side we have nature or the external world, made up of hard matters of fact and acting with objective, mechanical precision" (Harman 2009; p57). Harman explains that Latour rejects this modernist vision since “there are not two mutually isolated zones called 'world' and 'human' that need to be bridged by some sort of magical leap. Instead, there are only actants, and in most cases it is impossible to identify the precise sphere ('nature, or culture?') to which any given actant belongs" (Harman 209; p57). Accepting that the world is divided into separate spheres also means accepting that modernity has somehow purified the world; however, as Latour says, "we have never been modern" (Latour 1991). This is a powerful and humbling lesson "for we ourselves, just like Neanderthals, sparrows, mushrooms, and dirt 
have never done anything else than act amidst the bustle of other actants, compressing and resisting them, or giving way beneath their blows" (Harman 2009; p58).

What would it mean, precisely, to say that cross-border development programs in the Ferghana Valley find their rationality in 'the new-policy agenda?' (Bichsel 2005). If we are deploying 'the new policy agenda' as a context meant to explain some action then our next step would be to draw the actual connections between these programs and that so-called agenda. How does the 'the new policy agenda' exist as an explanatory factor in the Mercy Corps' PCI program?

Latour reminds us that "a factor is an actor in a concatenation of actors instead of a cause followed by a string of intermediaries" and when researchers begin to treat their research subjects as mediators strung together "to their great surprise, the practical details of the case at hand seem to provide some explanation of the context that was supposed to explain it" (Latour 2005, p.107). To be an actor a thing must have an effect, it must leave some sort of trace. Without this the thing either doesn't exist or it is simply an intermediary that can easily be substituted with the cause. Instead of having a development project populated with faithful intermediaries, such as an American NGO faithfully transmitting the social force of a post-cold war ideology, or local villagers misperceiving their own sense of scarcity due to being subjective dupes of their own culture, there exist development projects that are a concatenation of actors where no social force is transmitted without transformation.

This is Latour's "principle of irreduction" (Harman 2009, p.14). Projects of all sorts are complicated by the fact that they are concatenations of actors and cannot be reduced to simple catch phrases. Simply juxtaposing the PCI program, or any 
development program for that matter, next to a concept that is meant to provide an explanation (neoliberal economic theory, democratic theory, Western hegemony, etc) does very little to explain the actual discourse and workings of the particular project. In an actor-network theory based methodology this move from local to global contextual explanations is strictly forbidden unless the researcher first pays the costs of tracing every link from the local to the global. The argument here is not that a particular development intervention doesn't broadly follow 'the new policy agenda' (Edwards and Hulme 1996), or any other broad concept but rather that it remains to be seen how and in what way the projects resemble or differ from these global explanations. The idea put forward here is that there are uncertainties that attend the deployment of concepts in development. Development projects face the possibility that their particular set of discursive commitments might fail upon introduction into the messy world of project implementation.

Furthermore, the successful deployment of a set of discursive commitments is dependent upon the construction of a durable actor-network and the construction of such a network implies two things. First, network building implies that a host of actors, not all of which are human, will need to be enrolled into the network; and second, the cost of enrolling actors into the network is paid in a series of successive translations. Thus, perhaps more important than pre-existing global contexts are the contexts which are locally produced in the interaction between NGO staff, discourses, community development methodologies, local knowledge, and existing relations. It may well be the case that after tracing the work of building this actor-network that the researcher can then demonstrate the links between the local context and what might be considered global 
contexts but these are never given beforehand. To pretend that they are is to insist on a world populated not with actors, but with merely faithful intermediaries.

\section{Understanding the Context of Development in Central Asia}

There are a myriad of different contexts or contextual issues that intersect with Mercy Corps' Peaceful Communities Initiative implemented in the Ferghana and Zarafashon valleys of Central Asia. A short and non-exhaustive list could include the following elements:

- The Post-Soviet context

- Decaying Soviet infrastructure

- Corruption

- The history and policy goals of Mercy Corps

- Conflict

- The history/histories of Central Asia

- The institutions of development in Central Asia

- The various levels of government in each Republic

- The policy goals of the U.S. Government through the auspices of USAID

- Culture - identity - ethnicity

Obviously, there are a great number of things that could be included as candidates for inclusion on this list of contexts. For instance we could add the standard sociological actors to this list: class, family, household, nation-states, etc. Thus we could try to explain the machinations of the PCI project through the lens of class-conflict, household economics, globalization, capitalism, or any other overarching framework. However, any move towards such a framework would immediately remove the inquiry from the local 
sites of interaction: writing a grant in a back office of Mercy Corps' Headquarters in Portland, Oregon; developing a survey tool to be used as baseline data; writing a quarterly report and trying to determine if project activities still fit into the logical framework; introducing the project to 'beneficiaries' in a village in Kyrgyzstan; or perhaps writing project reports meant for the donor whose office is in Almaty and who will then forward her own report on to bureaucrats in Washington, D.C..

The point of this exercise is to raise the issue of the status of the concept of context in sociological inquiry in general and in development studies in particular. Is there an overarching context that could be used as an explanation of the PCI development program? Instead of an overarching context or an explanatory frame of reference what is needed is a careful tracing of the creation and evolution of the PCI program. To make any of the other contextual factors work as more robust explanations it will be necessary to show how any possible candidate for inclusion as context are actually connected to the project. More importantly, actor-network theory requires its researchers to let the concepts of its informants rise to the surface instead of substituting the judgment of the analyst for those of the informants.

Actor-network theory also requires that the research maintain a tight focus on local activities. This focus on local sites of interaction is what Latour has recommended as the first move in a 'sociology of associations', namely "localizing the global" (Latour 2005, p173). As Latour says, "Capitalism... may be an intractable entity endowed with a 'spirit', but a Wall Street trading room does connect to the 'whole world' through tiny but expeditious conduits of millions of bits of information per second, which, after having been digested by traders, are flashed back to the very same place by Reuters or 
Bloomberg trading screens that register all of the transactions and are then wired to the 'rest of the (connected) world' to determine someone's net worth (Latour 2005, p178). Rather than a situation where development happens behind our backs and which leaves each and everyone of us a witless 'informant' that merely serve as blind intermediaries for the transmission of power, culture, or society, Latour envisions a world in which everything is out in front of us, everything is rendered traceable. Which is another way of saying that it might still be possible for all of us to engage in the progressive composition of the common world. In Isabelle Stengers' formulation we might still achieve cosmopolitics (1996, quoted in Latour 2005, p.262). 


\section{Chapter Two: Qualitative Methods}

A paradigm may be viewed as a set of basic beliefs (or metaphysics) that deals with ultimates or first principles. It represents a worldview that defines, for its holder, the nature of the "world," the individual's place in it, and the range of possible relationships to that world and its parts, as, for example, cosmologies and theologies do. The beliefs are basic in the sense that they must be accepted simply on faith (however well argued); there is no way to establish their ultimate truthfulness. If there were, the philosophical debates reflected in these pages would have been resolved millennia ago (Denzin 1994, p. 107).

Put simply, the research in this dissertation is comprised of a combination of qualitative methods: Actor-network theory, ethnography, and document analysis ${ }^{3}$. The methodological point of departure between this research and other research in development studies is the use of actor-network theory (ANT) as both a method ${ }^{4}$ and a form of analysis. George Ritzer (2004) explains that "ANT is considered as much a method as a theory; anti-essentialism informs both the conceptual frame used for interpretation and guides the processes through which networks are examined" (p.2). Additionally, Ruming (2009) argues that many scholars have advanced the argument "... it is more a method for studying the world rather than a theory" (453). Which is to say that actor-network theory is not a theory that predicts why things happen, but rather a theory of how things are put together. The reason that actor-network theory can be mobilized as both a method and a form of analysis is that it contains both methodological

\footnotetext{
3 The documentary analysis is, strictly speaking, not discourse analysis which has its own intellectual history, its own infra language, as well as its own sets of theories (discourse as language and discourse as a system of power/knowledge). Additionally, Content analysis is also not a good descriptor since it hints that content can be separated from its material conditions of existence. The method for textual analysis used in this research is simply referred to as document analysis and is derived from ANT's methodological principle of generalized symmetry.

${ }^{4}$ For in deeper understanding of actor-network theory as both a method and a form of analysis see Latour, B. (2005) Reassembling the social: an introduction to actor-network theory, Oxford University Press, Oxford.
} 
principles (Ritzer 2004) as well as a suite of analytical considerations (Latour 2005), and these both form interrelated but ultimately separate kinds of intellectual activity. In an important way the methodological principles of actor-network theory are derived from philosophical and metaphysical starting points for understanding the nature of reality. Both of these will be explained at length in the course of this chapter.

\section{Research Design}

To summarize the research design, the particular case was chosen so as to provide an occasion for the elaboration of a particular theoretical approach (ANT) to development, in contradistinction to other prevailing theories of development, and particularly, Post-development which, as will be explained in the next chapter, uses a conceptually different notion of discourse. Within this research context, actor-network theory, ethnography and document analysis are the most appropriate methods and are also, in an important sense, interdependent. The organization of the rest of this chapter will be as follows: First, it will be important to explain the unique qualities of the chosen methods and their interdependency; second, there will be a series of sections explaining the researcher's role, data sources, data collection, and data analysis; third, the chapter will conclude with a discussion of validity.

\section{Qualitative Methods: Actor-network theory - Ethnography - Document Analysis}

Understood in its most basic terms methodology is simply the way in which research data is collected and analyzed or interpreted (Ruming 2009). The research in this dissertation has relied upon a complimentary set of methods. These are actor-network theory, ethnography, and document analysis. Each of these will be explained in order. 
The primary reason actor-network theory is considered more a method than a theory is because it does not predict why things happens but rather how. Actor-network theory offers a series of philosophically and metaphysically connected insights that render it as more of a research stance than a theory. Three methodological principles form the basis of actor-network theory as a method.

\section{Agnosticism}

The first is agnosticism (Ritzer 2004, 2), or the idea that actor-network theory is both ontologically relativist and also empirically realist (Lee and Hassard 1999). Latour explains, "The solution, once again, is to learn how to feed off uncertainties, instead of deciding in advance what the furniture of the world should look like" (Latour 2005, 115). Thus actor-network theory is agnostic about which things will count as an actor. This agnosticism is not, however, limited to possible actors, but also extends to notions of scale and context. Actor-network theory does not assume that one thing is smaller than another or one thing is embedded in another, but attempts to flatten the landscapes of our inquiry and problematize such basic concepts as actor, size, context (class, culture, etc.), local, or global.

\section{Generalized Symmetry}

The second principle is generalized symmetry and according to Bjiker and Law (1992) was first developed by Bloor (1976, quoted in Bjiker and Law, 1992, p.14) as a principle of methodological symmetry and formed part of the sociology of scientific knowledge. Bloor's idea is, essentially, that both true and false knowledge is open to sociological inquiry. It would be Callon (1986a) who extends the notion of symmetry to objects and argues that nature and society can be understood by the same terms. While 
the researcher may pick from a variety of methods to explain various elements, Callon

(ibid) explains that

Having opted... for a vocabulary of translation we know that our narrative is no more, but no less valid, than any other. But given the principle of generalized symmetry, the rule which we must respect is not to change registers when we move from the technical to the social aspects of the problem studied. Our hope is that the translation repertoire, which is not that of the actors studied, will convince the reader (4).

What actor-network theory means by translation ${ }^{5}$ is the idea that scholars and others do not simply represent things as they are, or build correspondence between the world and words, but they transform the things that they encounter. The researcher does not represent a particular reality but translates that reality via a method into data that is later written into a report of some kind. Latour explains that translation "in its linguistic and material connotations, it refers to all the displacements ${ }^{6}$ through other actors whose mediation $^{7}$ is indispensable for any action to occur. In place of a rigid opposition between context and content, chains of translation refer to the work through which actors modify, displace, and translate their various contradictory interests $(1999,311)$.

\footnotetext{
5 Translation forms an important part of the ANT theory of action. As Latour says "action is always dislocated, articulated, delegated, translated" $(2005,166)$. The metaphysical argument is that actants are able to displace themselves (dislocate, delegate, translate) into more durable elements such as documents, spreadsheets, logical frameworks, etc, that themselves must be treated as mediators, actants, or obligatory passage points. Thus dislocation is not a kind of hand \& clay model of social reality since the clay resists modeling and acts on the hand as well.

${ }^{6}$ Apart from John Law's (2003) article the manager and his powers there is no better demonstration of the idea that we displace ourselves into more durable material things (documents, spreadsheets, canals, etc) than Latour's discussion, in his book Reassembling the Social, of the work of the primatologist Shirley Strum. Strum provides a view of baboons as having to continually reenact and re-perform their social structures and in Latour's opinion it is because they can only inscribe that social order onto their own bodies, they are unable to build temples, write documents, hand out degrees, plant a flag, or any other of the useful ways that humans engage objects in order to secure what are seen as social settlements.

${ }^{7}$ Latour differentiates between intermediaries that simply and faithfully transmit an effect and are therefore not actors and mediators which are other actors who transform plans and programs as they are included within them. As Latour says, "If an intermediary is fully defined by what causes it, a mediation always exceeds its condition" (1999, 306).
} 


\section{Free Association}

The third principle relates to the relationship between nature and society. Callon calls this third principle, "the principle of free association" and that "the observer must abandon all a priori distinctions between natural and social events" (Callon 1986b, 4). It is worthwhile to note that neither Callon nor Latour take this last principle lightly. The above quote from Callon is drawn from his paper which is subtitled "domestication of the scallops and the fishermen of St.Brieuc Bay" where Callon proceeds to put this methodology to the test with both fishermen and scallops, both considered by Callon as being full fledged actors (ibid). Callon explains this third principle thusly,

[The observer] must reject the hypothesis of a definite boundary which separates [society and nature]. These divisions are considered to be conflictual, for they are the result of analysis rather than its point of departure. Further, the observer must consider that the repertoire of categories which he uses, the entities which are mobilized, and the relationships between these are all topics for actors' discussions. Instead of imposing a pre-established grid of analysis upon these, the observer follows the actors in order to identify the manner in which these define and associate the different elements by which they build and explain their world, whether it be social or natural (ibid, p.4).

This third principle cannot be over-emphasized since so much of what follows in actornetwork theory is based upon this particular understanding of the relationship between nature and society. What is at stake in this third principle is the very nature of reality. Under the traditional formulation, what Latour calls the modernist constitution (Latour 1993, 13), the world is divided into parts; on the one side exists nature and her facts and on the other society and its subjectivity. , Graham Harman (2009) explains, in regard to Latour's 1993 book, We Have Never Been Modern, that while he considers this book to be Latour's magnum opus, 
...its major themes are simple. First, Latour advances the most powerful definition of modernism of which I am aware. Modernity tries to purify the world by dissecting it into two utterly opposed realms. On one side we have the human sphere, composed of transparent freedom and ruled by arbitrary and incommensurable perspectives. On the other side we have nature or the external world, made up of hard matters of fact and acting with objective, mechanical precision. As Latour puts it later in his Politics of Nature, a pluralistic multiculturalism is always opposed to a homogeneous mononaturalism. We are told that nature is one, but that humans have numerous diverse perspectives on it. Not surprisingly, Latour rejects this modernist vision. There are not two mutually isolated zones called 'world' and 'human' that need to be bridged by some sort of magical leap. Instead there are only actants, and in most cases it is impossible to identify the precise sphere ('nature, or culture?') to which any given actant belongs (p.57, emphasis in original).

What follows of course is that this division between Nature and her Facts and Society and its Values is meaningless because it is based on an idea that the moderns had somehow been able to purify the world into these zones. Hence the title of Latour's book We Have Never Been Modern. Harman explains, "we are unable to separate between the natural and cultural realms — not because they are hopelessly intertwined, but because the dualism of nature and culture is groundless in the first place" $(2009,38)$. What follows from this seemingly simple observation is that most of the dualisms of the last three centuries are as John Law puts it, "rubbished" $(1997,2)$. Subject - object, large - small, global - local, structure- agency, all of these dualisms are cast aside, but with one important caveat.

As Law reminds us, it is not as if they do not exist at all, but rather that such dualisms are made. Even though many of our most cherished dualism have been trashed "the scandal may sometimes be more metaphysical than practical. For this precise reason: it is not, in this semiotic world-view, that there are no divisions. It is rather that such divisions or distinctions are understood as effects or outcomes. They are not given in the 
order of things" (ibid, 2 emphasis in original). Thus the third principle leads back to the first and second principles. Actor-network theory is agnostic because it problematizes the making of dualisms as ready-at-hand categories of existence. Actor-network theory treats subjects and objects symmetrically because there is no natural division between the two, but rather made distinctions that again are not a part of the order of the things. John Murdoch (2001) explains that Latour's position involves a significant reworking of the notion of action. For Murdoch it is not so much an extension of action to objects but action becomes a kind of relational property held between objects and humans. Murdoch explains that.

This relational (and symmetrical) view of action follows from the idea that 'nature' and 'society' are co-constructed.... Such a perspective has the methodological consequence that no a priori assumptions about who or what will act in any particular set of circumstances can be made.... Action will be the result of network construction and networks are constructed out of all kinds of bits and pieces, some of which we might label 'social', others 'natural', others 'technical' and so on...(2001, p.119).

While tracing or 'following the actors' is not listed by any author as a codified principle in the same way as the previous three principles, it still forms an important element of actor-network theory as method. As Stewart Lockie (2007) describes it, "the theoretical and empirical arguments of actor-network theory are drawn from what is presented as a highly open-ended ethnographic approach to social research based on 'following the actors' - whoever and whatever they may be — as they engage in processes of translation and enrolment" (p.792).

\section{Actor-Network Theory as Material Semiotics}

Finally there is another sense in which actor-network theory can be thought of as forming a research methodology and this has to do with the material semiotic (Law 2007) 
nature of actor-network theory. ANT is the only method available for doing research into the relations between objects and humans that doesn't reduce the former to some element of sociality. Also, because of the principle of symmetry and the principle of free association ANT is profoundly post-human. The principle of symmetry suggests, in part, that researchers analyze objects and humans in the same way. ANT also extends the notion of articulation to objects in their capacity to exist as actants. Finally, the notion of free association reinforces the idea that there is not a fundamental gap between humans and objects. Ethnography, however, is by its very definition a method that privileges the human, or the ethnos, "̌ $\theta$ vos. Actor-network theory extends 'ethnos,' 'folk,' or even more broadly, 'group' to include non-humans. For example, when a person uses an automated bank teller (ATM) there are both semiotic components and material or technological components, but there is also a relation, or even a series of relations. In this account the person using the ATM is articulated as a 'bank customer' (itself a particular proposition) with a specific account and a card with a code that accesses that account. The person, the card, the code, and the ATM are implicated in a larger banking network that is also articulated into an economy. It's not turtles all the way down, but rather objects and relations and ANT is the methodology par excellence for researching material-semiotic relations and the PCI program is quite literally an exemplar case of the way in which development proceeds via the construction of hybrids.

\section{Ethnography}

Given the way in which actor-network theory privileges the richness of data at various local sites it is no surprise then that its preferred method for research should involve ethnography. Ethnography here is seen as an extension of the actor-network 
theory notion that researchers should trace or follow the actors. Brewer (2000) explains "ethnography is not one particular method of data collection but a style of research that is distinguished by its objectives" (11). The objectives in this research have been informed by the particular theoretical and methodological stance of actor-network theory and the selection of an overall case. But in the main, both actor-network theory and ethnography share a common concern for the semiotics of action, a concern for meaning. While Brewer treats meaning only in terms of being social, and in doing so recapitulates a modernist divide between things and words, actor-network theory is interested in meaning as a relational phenomenon. So while ethnography is interested in meaningmaking activities by particular people in particular places, actor-network theory adds the caveat that the researcher include both objects and people and that the particular site is itself problematized. The reason for questioning the actual sites of ethnographic research relates back to Latour's methodological concern that the research should not, by rejecting the global (either as an actor or a context as in globalization) as a privileged explanation, in turn, privilege the explanatory powers of the local. The point is not that these sites do not exist or that they are not important but only that neither should be used as a ready made explanation. Latour does not reject tout court the role of context in social theory, but rather exhorts the actor-network theory researcher to carefully trace the connections from one site to the next and by doing so provide a richer explanation. This means asking questions of the research site itself, why are these particular arrangement of things and people here, at this particular time, and what are the connections to other places, and how were various things brought here from other places.

So while ethnography often takes its sites for granted, as places populated with 
interesting people, actor-network theory takes things one step further and problematizes the notion of site. The way in which actor-network theory problematizes sites is very much in the spirit of ethnomethodology (Garfinkel 1967). This involves building an understanding of how actants work together to create both places and meaning.

Thus when PCI articulates a particular community as a 'PCI community' it involves a number of different elements. Choosing a community is not a value-free activity and involves establishing the existence of a particular community. Is it on the map? Does it have a name? Does it fit a set of predefined criteria? Is the community willing to participate? Is the local government willing to let Mercy Corps work in a community? Part of this process of choosing communities involves drawing on the knowledge of locally hired staff; part of the process involves engaging in quasi-social scientific research; and finally the process will eventually involve a very particular method of articulating the relationship between communities and PCI and this involves various community mobilization strategies.

\section{Ethnography's Naturalism}

The traditional understanding of ethnography is defined as a kind of naturalist study of particular people in their natural setting and involves collecting data that can provide some leverage for understanding what are, for the informant, ordinary activities (Brewer, p.189). Brewer recommends that in order "to access social meaning, observe behaviors, and work closely with informants and perhaps participate in the field with them, several methods of data collection tend to be used in ethnography, such as in-depth interviewing, participant observation, personal documents and discourse analysis...." (ibid, p.11). The researcher has followed Brewer fairly closely in his recommendations 
and has used all three of his suggested methods, though with some modification. The modifications in this research have been in the category of discourse analysis that this researcher has modified into an actor-network theory informed study of documents.

\section{Document Analysis}

Document analysis is used partly as a means of escaping the history and theoretical implications of the largely post-modern concept of discourse analysis. As Potter and Wetherell (1994) explain, discourse analysis has a varied history and various ways of being employed. They recognize at least four ways in which discourse analysis has been used in social science research, the first two are broadly speaking concerned with linguistics and psychology (p.47). The next two identified by Potter and Wetherell relate to fairly broad approaches to knowledge. As they explain it, " the third type of discourse analysis was developed within the sociology of scientific knowledge, partly as a response to methodological difficulties with other ways of studying science" (p.47). This third way is taken up by David Bloor and the so-called 'strong programme' in the sociology of scientific knowledge an is distinguished from actor-network theory, in part, by the latter's focus on construction as a social-material process whereas for the former construction is always first and foremost a social phenomenon (Barnes et al, 1996). The last method for the deployment of discourse analysis comes from "continental social philosophy and cultural analysis" (Potter and Wetherwell 1994, p.47), and is, broadly speaking, comprised of post-modern and post-structuralist understandings of discourse and semiotics. As such these perspectives are also dependent to a greater or lesser extent on a social constructivist notion of reality.

\section{Articulation}


Actor-network theory differs from these traditions in that it does not privilege humans in their capacity to speak. Instead, actor-network theory uses the notion of articulation and does not delimit the notion as something of which only humans are capable. Latour explains that articulation, “...occupies the position left empty by the dichotomy between the object and the subject or the external world and the mind. Articulation is not a property of human speech but an ontological property of the universe" and furthermore "The question is no longer whether or not statements refer to a state of affairs, but only whether or not propositions are well articulated" $(1999$, p.303).

\section{Proposition}

A proposition, in the actor-network theory sense of the word, "is used... in a metaphysical sense to designate not a being of the world or a linguistic form but an association of humans and non-humans before it becomes a full fledged of the collective..." (Latour 2004, 247). Thus while PCI may now be punctualized as a crossborder, community development program that was implemented in Central Asia, it did previously exist as an as of yet unsecured proposition that was vulnerable to various failures and reversals.

Cressman (2009) explains that in actor-network theory, punctualization "refers to the process by which complex actor-networks are black boxed and linked with other networks to create larger actor-networks" (p.7). For Callon (1991) it is the process through which more or less complex networks are converted "into a single point or node in another network" (Callon 1991, p.153). For instance, PCI may now be used as an example that demonstrates (to potential donors) Mercy Corps' ability to implement similar programs. 
The actor-network theory notion of proposition is closely linked to another actornetwork theory notion, that of articulation. Latour explains that articulation is

that which connects propositions with one another; whereas statements are true or false, propositions can be said to be well or badly articulated; the connotations of the word (in anatomy, law, rhetoric, linguistics, and speech pathology) cover the range of meanings that I am attempting to bring together, meanings that no long stress the distinction between the world and what is said about it, but rather the ways in which the world is loaded into discourse (Latour 2004, p.237).

Thus it is with both notions of articulation and proposition that this research used document analysis. Documents are seen not as punctualized and coherent but rather the outcome of the work to articulate particular propositions. How, and perhaps more importantly, which documents were used will be covered later in the sections on data sources and data collection.

\section{Data Sources and the Research Site(s)}

The sources of data for this research come in three general categories: participant observation, interviews, and documents. In regard to the first category Latour argues, the moment research begins "everything is data" $(2005 ; 133)$. Thus the researcher's participant observations conducted at a variety of sites in Central Asia form an important dataset. Participant observation, in this research, meant that the researcher occupied a role within a particular community of practice (Lave and Wenger 1991). In this case the community of practice was primarily composed of a few expatriate managers who each managed one of the PCI regions (Penjikent, Tajikistan; Khujand, Tajikistan; Osh, Kyrgyzstan; Andijon; Uzbekistan) and the national staff who worked in the community mobilization teams. In terms of the researcher's role, the researcher, because of his long association with Mercy Corps, was already a known entity among the expatriate staff. 
Amongst the national staff the researcher made efforts to stress that this research was not an appraisal of their work and as can be expected, it took time to gain their trust and respect.

\section{Participant Observation}

The actual activities of participant observation were split between time spent in Mercy Corps PCI offices and times spent visiting communities and infrastructure projects in the field. The researcher carried with him a series of notebooks used for writing descriptions of various settings; taking notes for the many non-recorded and impromptu interviews that were an every day occurrence during field work; and for writing theory related notes as part of a continual process of cross-comparison between documents, interviews, site descriptions, etc. In addition to the PCI offices the researcher visited many different communities and project sites throughout Central Asia. These were variously villages, pump-stations, work sites, canals, roads, and flood protection schemes. Since the community mobilization teams coordinated these visits as part of their own duties, it often meant that the researcher had an opportunity to visit with community initiative groups ${ }^{8}$. Visits to villages and project sites were always conducted in concert with PCI community mobilization teams. The reasoning was that this would be the best way to actively participate with the teams. Oftentimes visits would require the services of a translator. Sometimes a member of the community development team would provide translation and other times the researcher would provide his own translator. Translation was a constant necessity and forms one of the fundamental limitations of this research.

\footnotetext{
${ }^{8}$ Community Initiative Groups (CIGs) were the community based groups that had been formed during the initial community mobilization by PCI teams. Mercy Corps attempted to make these groups as broadly representative as possible in terms of ethnicity, age, and gender.
} 
It's helpful to remember that PCI was implemented in each of its regions by a single expatriate manager, working with one or two community mobilization teams which were composed of five or six members, more or less evenly divide in terms of both gender and ethnicity ${ }^{9}$. It should be noted that the community of practice was not limited to only the managers and their community mobilization teams but also included the wide variety of support staff, such as, finance, procurement, administration, security, logistics and translation staff that worked directly or indirectly for PCI. For instance, the Khujand Mercy Corps office housed at least two other programs in addition to the USAID funded PCI program and these programs shared support staff. However, in Penjikent, Tajikistan the PCI office was only PCI as there were no other Mercy Corps programs in the Penjikent region at the time. In addition to the support staff, the community of practice must also include Mercy Corps staff working at the national level in their respective countries as well as people working at Mercy Corps Headquarters in Portland, Oregon. While the research made every effort to be inclusive, in practice this has meant prioritizing those who had some direct contact with PCI. Consequently, inclusivity begins to fade or at least become more difficult to achieve the further one moves away from the Project Managers and their direct staff.

More so than the other two categories, the data derived from participant observation also serves to delineate the boundaries of the research site, which in this case stretched some 800km from Dushanbe to Northern Kyrgyzstan but also some 13,000km from Portland, Oregon to Dushanbe, Tajikistan. The importance of travel and the work

\footnotetext{
${ }^{9}$ Many of the paired or clustered PCI communities differed in ethnic origin and Mercy Corps felt it was important that there community mobilizations teams reflected this diversity.
} 
of managing such a large research site will be dealt with in the section titled: the researcher as instrument.

\section{Interviews}

The second source of data came from interviews. The research included 20 unstructured, in-depth, open-ended interviews and another 20 informal, ad hoc interviews conducted in the field (e.g. away from the office, in the villages, or in some less formal

setting). In every interview the potential interviewee was given both a written and verbal explanation of the purpose of the research. At this point the potential interviewee could decline the interview without prejudice on the part of the interviewer or the interviewee's employers, or if the interviewee accepted he or she had the choice of whether or not they wanted their names used in the final write-up of the research. The researcher decided at a later date that it was much simpler to protect the interviewees by changing the names of everyone in involved with the exception of expatriate staff. The reason for this is 1) all expatriate staff agreed to be interviewed with the inclusion of their full names, and each signed a document stating this preference, and 2) because they were so few in number it wouldn't be difficult for their colleagues to place them. The details regarding how informants were chosen and the way in which interviews were conducted will be dealt with in depth in the section on data collection.

At first the interviews were fairly broad in scope though delimited in terms of always being related back to PCI in some way. Thus the first round of informal interviews consisted of questions meant to help the researcher understand the informant's understanding of their work in PCI; what did that work consist of? Were there documents that explained how they should do their work? Had there been specific kinds of training? 
What did they use to guide the process of community mobilization? How did they work with communities? During subsequent interviews usually following a field visit the researcher would ask question about specific events: what was that particular project we visited? How does it work? How did the community choose a particular project, and so forth. Most of the interviews were informal but semi-structured. Every interview was conducted to fill a particular hole in the researcher's knowledge or to elaborate on a process that was not fully understood. The interviews relate to the research question very broadly by providing the researcher with information about how project were put together; with which kinds of materials; with which people; with which resources; and, importantly, with which documents.

\section{Documents}

The third main source of data for the research came from documents. The documents used in this research do not fall into easy categories of either primary or secondary documents. Brewer explains this distinction, "primary documents are original sets of data compiled by the writer, like a letter, tape recording of a conversation or transcript of a court trial." Secondary documents on the other hand "contain data obtained at second hand from someone else's primary document, like a newspaper report of a court trial, an edited transcript of someone's letters or an edited transcript of a conversation" (Brewer 2000, p.73). Brewer adds to this a second dimension that asks if the document is contemporary or retrospective. This research limited itself to two kinds of documents: primary documents such as field reports which contained contemporary accounts of field visits and various events, and secondary documents such as quarterly reports, annual reports, published field studies, grant documents, etc. Depending on 
one's perspective, however, the quarterly reports can be considered as primary or secondary, and both contemporary and retrospective. As a researcher or employee of the PCI program one sees a lot of what might be called supporting documents that managers may or may not use as a resource for writing quarterly reports and these are clearly contemporary and primary. However, a donor like USAID would likely think of the quarterly reports which are derived from these supporting documents, that were written during the course of events, as being more primary than secondary. Authorship in the case of the quarterly reports is always attributed to Mercy Corps as an organization and this has the effect of including necessary but unseen (by most outside viewers) steps in the process. This last category then is classified in this research as quasi-public ${ }^{10}$ documents (quarterly reports, annual reports, field studies, etc.) Which taken together form an important and nearly complete record of the entire program.

\section{The Archives}

This research also included documents that were kept in two physical archives housed in Mercy Corps country offices in Osh, Kyrgyzstan and in Dushanbe, Tajikistan. These archives were comprised of some $60-100$ boxes of documents that covered the entire period of the PCI program. For the most part the archive was divided roughly evenly between a variety of financial statements that ranged from things like fuel purchase requests and office supplies to more complex documents related to various contractors bidding on particular jobs within the program. In addition to the financial documents there were also many documents that related to specific infrastructure projects, these included many project description files, memoranda of understanding

\footnotetext{
10 The reason I am calling these documents quasi-public is that one needs to go through a gatekeeper to access them, but then once permission is granted one had access to the entire range of documents.
} 
(MOU) between Mercy Corps and the community, environmental memorandum, government approvals, technical drawings, estimates of costs, statements of work (SOW), and project sustainability plans. The great majority of these were written in Russian, Tajik, or Kyrgyz and were thus beyond the ability of this particular researcher to read without assistance. In spite of the differences in languages the researcher conducted an exhaustive review of the archives. In some instances the researcher was able to find research reports, trip reports, and other miscellaneous documents that had been used as part of Mercy Corps' efforts to choose communities for inclusion in the program.

Overall, however, there was very little in the way of narrative documents in these archives and very little of which was in English. In spite of some of the obvious difficulties presented by the archives, they were nonetheless important sources of information. Even though ascertaining content of the archival documents was difficult they would still prove useful in two ways: they provided an important validity check as they formed a part of the researcher's attempt to triangulate data through both methods and sources. The second way in which these archival documents were useful was in demonstrating the extent to which displacement occurred. Thus these documents form not only an important data set for understanding sociality, they form at the same time an important material data set. The documents demonstrate the degree to which PCI codified and collected the many different moves made during the course of the program.

\section{A Highly Distributed Research Site}

As already mentioned, the research site (see Figure 1) was highly distributed in both time and space. In terms of space the research site included the main offices of Mercy Corps in Portland, Oregon, but also the Mercy Corps Tajikistan office in 
Dushanbe, the regional office in Khujand, Tajikistan; the PCI specific office in Penjikent, Tajikistan, and the Mercy Corps regional office in Osh, Kyrgyzstan. From each of these sites in Central Asia the research site also included the many different villages and project sites visited as part of the researcher's participant observation. Participant observation also took place in a variety of miscellaneous places as I attended wedding parties of the staff in Penjikent, watching World Cup Soccer with staff in Khujand, and dinner parties and picnics with both PCI managers and their staff in all four of the main sites (Dushanbe, Penjikent, Khujand, and Osh). For a time the researcher's home in Dushanbe was a site for conducting interviews with staff transiting out of the field and onto other assignments.

Part of what made PCI particularly challenging was the way in which it was spread out across both time and space. In terms of time, the researcher came into the project at a particular point in the lifecycle of the project, and even though actor-network theory operates from a perspective grounded in the idea that one is always in medias res, and that there are no natural starting points, it is also true that like many other things the question of start, middle, or end points should really be left up to our informants. In much the same way as informants perform their own versions of scale, so to do they perform their own versions of starting points, etc. Thus, the researcher came into this program at the very end, just as all the projects were being wrapped up. This gives the researcher a unique view of the way in which an NGO, like Mercy Corps engages in the activities of summing up, of providing coherence to the overall project and building what Latour calls panoramas. Again, writing panoramas involves a variety of activities that range from field visits, end of project ceremonies, writing the final report, the building of 
a separate field studies, etc. The point is that there is something unique about the life cycle of a project, no matter how artificial though from an actor-network theory perspective it is interesting precisely because of the artifice involved.

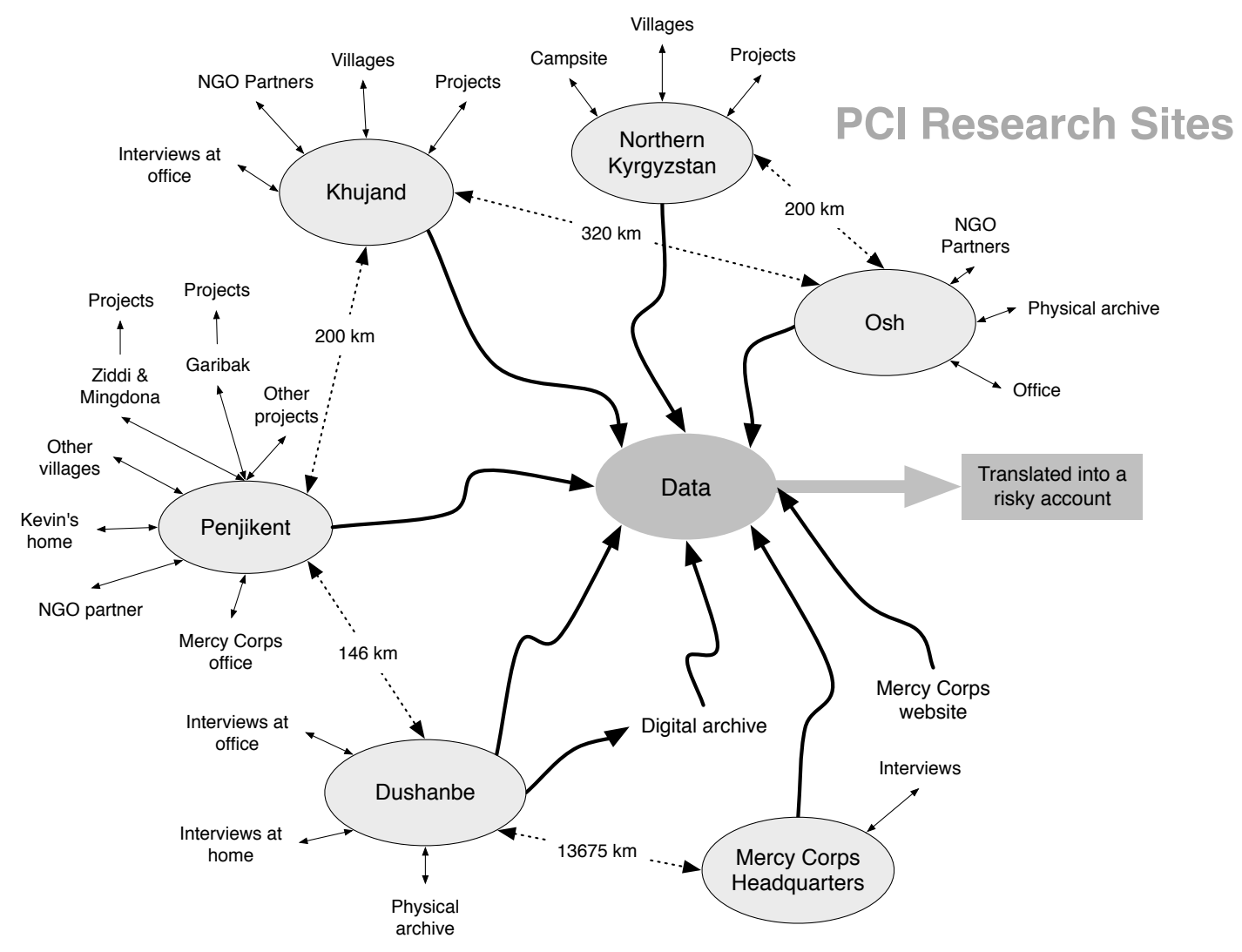

Figure 1 PCI Research Sites

\section{The Researcher as Instrument}

Before moving on to questions of data collection and data analysis it will first be important to elaborate on the idea that the researcher is a research instrument (Brewer 2000, 59; Burgess 1982, 1). Hammersley and Atkinson (2007) argue that this understanding of the role of the researcher, "as has long been recognized by ethnographers, [the researcher] is the research instrument par excellence" (17). What this 
focus on the researcher as instrument accomplishes, at least in part, is to draw attention to the role of the researcher and in some sense to problematize it in a way that is productive. For Hammersly and Atkinson "the fact that behaviour and attitudes are often not stable across contexts and that the researcher may influence the context becomes central to the analysis" (ibid, 17). In many ways this particular notion that the researcher is the best kind of instrument, and that her influence should be central to the research, informs this particular research in very important respects. First, the researcher is the most appropriate instrument and is a central figure in actor-network theory methodology. It's difficult to imagine how one would do quantitative research using actor-network theory. When actor-network theory exhorts its researchers to follow the actors or to trace things, the exhortation is meant literally. Indeed as the researcher pursues his study, he slowly begins to bring together a variety of resources from both fieldwork and the available literature to build a new proposition: the research paper. And so it's not only the researcher but his activities, the way he adds one account to another, the allies he enrolls to make his case, that should also be, if not central, than at least foregrounded.

Consequently, in this research the researcher conducted, transcribed, read, and coded all interviews; kept meticulous field notes that were likewise coded; traveled between research sites on numerous occasions; engaged in research both of Mercy Corps' PCI physical archives in Osh, Kyrgyzstan and Dushanbe, Tajikistan; reviewed the digital archive; read numerous documents including but not limited to the original field study, the original grant documents, the quarterly and annual reports, the final report, the sustainability field study, etc.; Many of these documents were likewise coded based on 
the researcher's own coding system ${ }^{11}$. The coding system used in this research formed a kind of minimal framework for categorizing information; there was not an attempt to develop a larger thematic coding system. This is not to say that the researcher didn't keep track of thematic issues, but that much of that work was done while writing up notes and writing up the research paper. The rather obvious point is that there is no other instrument used apart from those created and maintained by the researcher. Yet it's also clear that the researcher can only conduct research with the assistance of a methodology, a set of techniques that allow the researcher to make sense of the data.

Methodologies in and of themselves do little to help the researcher navigate the social landscape of fieldwork. To do this the researcher relied upon a variety of things. First and foremost was that the research could not have been conducted without access to the project and yet access is never simply granted but must be dealt with on a continual basis. If this research were a play or a novel it would be safe to say that 'access' becomes a character in the researcher's ongoing drama. While access was granted at the highest levels of Mercy Corps management, the researcher's own personal and rather long relationship with the organization made the granting of such access somewhat easier as the researcher was not a complete outsider. The researcher has worked with Mercy Corps in Kandahar, Afghanistan in 2002 in the wake of the US bombing campaign, in

\footnotetext{
11 The point of a coding system is maintain a clear separation between informants and the researcher, but also to document the different ways that the researcher addresses the same data so as to make clear those times when the researcher is merely commenting, making references to theory, paraphrasing, questioning, etc. The coding system in this research was derived from Bryman and Burgess (1994) and greatly modified by the researcher. The researcher's interview log, the researcher's notebooks, and the researcher's documentary analysis utilized the following coding system: "direct quotes" (paraphrase), [general corrections or adding information implied by the informant] [my comments], my questions, \{theory, literature, etc connections\}, [important names, contacts, etc]. If no indication given it will generally be my comments about the interview as paratext.
} 
Pakistan in 2005 in the wake of the October, 10th earthquake, and as a 'fill-in' desk officer at Mercy Corps headquarters in Portland. The researcher's wife, Brandy Westerman, has worked for Mercy Corps since 1999 and was instrumental in helping Mercy Corps realize its goal of securing funding from USAID for the PCI program. Additionally, the research would have represented an almost insurmountable financial obstacle were it not for the fact that the researcher was able to travel with his family to Tajikistan as an accompanying spouse as his wife, Brandy Westerman, was employed by the Mercy Corps Tajikistan office ${ }^{12}$. Even with the kind of access that comes with such a close relationship with a development organization, access was imperfect, partly because of the constant negotiation of insider/outsider status. The researcher has to be inside enough to see what is happening, but not so inside that he cannot ask questions. Thus it sometimes suites a researcher's purposes to be the ignorant outsider so that something about the way the organization operates can be learned. At other times, one can't get close enough to the action without being an insider. There is no doubt that the researcher's experiences with Mercy Corps in Kandahar, Afghanistan, or Mansera, Pakistan went a long way towards providing some credibility with seasoned expatriate staff. At the same time the researcher is never able to cross the line of complete insider since most of the work of creating documents is hidden.

Access was also affected by logistical concerns, as traveling in Central Asia, while always an adventure, is never easily done. The researcher's need to visit the field would sometimes result in the displacement of a valuable community mobilization team member since many of the vehicles used lacked enough seating. In spite of the

12 At the time of this writing Brandy Westerman was the country director (cd) for Mercy Corps Tajikistan. The $\mathrm{CD}$ is the senior most expatriate staff. 
researcher's explanations both written and verbal many people assumed he was engaged in some kind of high level program analysis that could potentially put employees, partner NGOs, or community members in a bad light. While in villages the researcher was often referred to as 'our dear guest from America' and there was an assumption that he was some kind of government official, and this in spite of constant explanations to the contrary.

Questions about negotiating access also lead to questions about the effect that a researcher has on their own research, and on the particular and peculiar ways in which individual researchers are always "situated" (Haraway 1988). Englestad and Gerrard (2005) argue,

Researchers' own experiences, roles and statuses, as well as their disciplinary perspectives impact on the production of knowledge, particularly when it comes to theory building, methodologies, and research practices. Today, many years after Donna Haraway first introduced her concept "situated knowledges", it is obvious that all aspects of the production of knowledge are situated and this situatedness must be taken into account (p.1).

Engelstad and Gerrard (2005) make the argument that the rise of the notion of situatedness was coextensive with a greater degree of interest in "constructivist thinking" (ibid p.1). However, there are at least two different ways of thinking of situatedness. First, there is the general sense that the researcher has a particular history, a set of ideas to which he/ or she is partial and these things raise the question of the researcher's objectivity. The second way to think about being situated is to question the way in which a researcher actually interacts with their site and informants. Both these question require a kind of mixed response. 
First the researcher must make clear her theoretical/philosophical perspective so as to situate himself in regard to the literature and academia in general. Second is to make as clear as possible the relationship between the researcher's personal life and his research. Finally, the researcher must use a combination of methods for ensuring the validity and thus objectivity of the research. Question of validity, verification, and triangulation will be taken up in more detail a later section of this chapter.

\section{Data Collection - Case Selection, Sampling, Following the Actors, Access}

There are two primary and related questions about research that precede actual data collection. These questions relate to case selection and sampling. Thus this section of the chapter will first discuss case selection and sampling before moving on to an in depth discussion of data collection.

The overall case study in this research was chosen by the researcher because of its obvious relational properties. The PCI program brought together a particular approach to knowledge embodied by the original three part assessment, The Heart of Central Asia (Mercy Corps 1998) as well as a particular development methodology: community mobilization. The program was considered relational for two other reasons: Mercy Corps through its vision for change ${ }^{13}$ has operationalized a particular approach to civil society that is itself a relational model for how communities should interact with other actors. Secondly, the program committed itself to working with local NGO partners,

\footnotetext{
13 The vision for change is a "living document" (Mercy Corps 2011, 8) that outlines Mercy Corps' ongoing and iterative commitment to civil society. The vision for change places "secure, just, and productive communities" at the center of its vision of civil society. Communities, in Mercy Corps' formulation, are surrounded by the concepts of "accountability, participation, and peaceful change" which intersect with the "private sector, public sector," and "civil society," and those are in turn surrounded by "good governance, economic opportunity, health and well-being, sustainable resource management, access to information" and "respect for human rights" (Mercy Corps 2011, 5).
} 
communities, various levels of government, and local businesses as part of its overall methodology. Finally, there is also the relationship between Mercy Corps and its donor, and in this case both bring their own set of values and interests to the program. Thus PCI was an exemplar of two major trends in development: networks/civil society and community mobilization. Quite simply the researcher chose to study the PCI program because in many ways it was the paradigmatic case for understanding a relational model of community development. The PCI case also offered a kind of perfect test case for applying actor-network theory. To put this in more methodological terms the criteria for case selection pursued a logic of sampling that is, following Palys (2008), a combination of paradigmatic case sampling, criterion case sampling and theory-guided case sampling. In regard to theory-guided sampling Palys explains,

Researchers who are following a more deductive or theory testing approach would be interested in finding individuals or cases that embody theoretical constructs. As this could be considered a particular type of criterion sampling, it also illustrates the overlaps that can exist between these categories (e.g., theorybased sampling might also lead the researcher to look for particularly intense or extreme cases) (p.698).

On the other hand, the embedded case studies were chosen based on a mix of what one might call theory-guided sampling and critical case sampling. The Garibak ${ }^{14}$ and Mingdona and Ziddi case studies were chosen because they represented both political closure $^{15}$ (Mingdona and Ziddi) and the breakdown of the political process (Garibak).

\footnotetext{
${ }^{14}$ The Garibak case study was produced by reference to a variety of documents, and interviews with PCI managers and staff. While the researcher visited the community, those visits came before the breakdown of the pump. At the time it wasn't clear to the researcher that this particular case would be central to the research. The point is that the events depicted in the Garibak study are all second-hand.

${ }^{15}$ Closure here signifies the successful end of the projects in question. For Ziddi this meant the finishing of the canal and to some extent the end of poor relations with Mingdona vis a vis the canal. For Garibak closure was achieved through the process of closing holes in the pipes and signing a new agreement for the monitoring of the irrigation system. Closure is not a permanent state and can be potentially undone at any
} 
The elaboration of these points also allowed the researcher to provide a substantive answer to the central research question: to what extent did Mercy Corps engage in a process of depoliticization as it implemented the PCI program? The choice of documents followed a modified criterion sampling methodology.

Because the researcher had limited access to personal documents including employee records, and emails, the choice was made to focus the document analysis on three broad categories of documents. The researcher defined supporting documents as those which were produced during the day to day work of implementation and which would eventually be used in support of writing reports to the donors. The second broad category was comprised of the semi-public, published documents produced by PCI over the course of the program. These included the original field study, other field studies, quarterly and annual reports. While it could be argued that these kinds of documents only present the best face of the organization, it would have been a mistake not to include them. The semi-public, published documents are all examples of settlements reached regarding the meaning of PCI. Each quarterly report is its own panorama that attempts to account for the complexity of fieldwork through the reductionist heuristic of a set of reporting standards. The researcher also felt that participant observation, along with interviews, would help to triangulate these documents and if necessary fill in the missing pieces. So while it is true that these documents place Mercy Corps and its activities in the best light possible it is also true that 'the best light possible' must also contend with reporting requirements, as well as the availability, quality, and interpretation of data. So it would be a mistake to see these documents as only constituting a best face approach.

point. For Mercy Corps closure would mean literally signing the projects over to the community and ending their relationship with those communities. 
These documents must also be seen as the outcome of a difficult process and perhaps better represented by the Latourian notion of risky accounts. When thinking of this notion of risky accounts one must also recall the actor-network theory principle of symmetry. Thus what is true of the researcher can also be true of the informants. In this case both researcher and informants are constantly engaged in their own projects of writing risky accounts. The researcher pursues his dissertation and the informants pursue their reports. The two kinds of writing are very similar in that both are gathering data in order to demonstrate that something happened. Latour explains,

In order to trace an actor-network, what we have to do is to add to the many traces left by the social fluid through which the traces are rendered again present, provided something happens in it. In an actor-network account the relative proportion of mediators to intermediaries is increased. I will call such a description a risky account, meaning that it can easily fail - it does fail most of the time-since it can put aside neither the complete artificiality of the enterprise nor its claim to accuracy and truthfulness (p.133 emphasis in original).

Thus another good reason for maintaining a focus on the representational work done by PCI managers was that they too must negotiate the relationship between the artifice of their particular kind of writing (reports follow an agreed upon format that is derivative of the logical framework) and the accuracy and truthfulness of their account. Thus an analysis of these documents is also an analysis of the way in which PCI constructs truthfulness in relationship to its forms and standards for writing.

\section{Choosing Participants}

Finally, it will be important to say a few words about the way in which participants were chosen for inclusion into the study. Choosing which people to interview and spend time with was in many way delimited by the choice of cases. Participants were chosen based on their relationship to PCI. Thus interviewing as many 
of the past and present PCI managers as possible was critical to the success of the research. It was also of critical importance to speak with those responsible for writing the original field study report as well as the original grant document. Next in order of priority were the other employees of PCI and this included support staff like those people in charge of finance, public relations, and office management as well as every member of the community mobilization teams. It was also important to include Mercy Corps staff who were not directly related to PCI but worked for the Mercy Corps regional or national offices and shared some responsibility for the program. Mercy Corps engaged with a number of local NGO partners and thus interviews were conducted with all four of these $\operatorname{organizations}^{16}$, finally it was important to get the perspective of the community interest groups ${ }^{17}$ or CIGs from the various PCI communities that were visited. Community members were chosen for ad hoc interviews based on a kind of snowball method.

The community members were in many ways the most difficult group to include. First, one of the goals of the research was to develop a kind of ethnomethodological account of how those responsible for implementing PCI came to understand their work. Thus the communities were already in some sense tangential to the focus of the research. In other ways though, the community members offered potentially one of the better checks on the entire program. Consequently, if one receives one account of PCI from a field manager and then upon visiting the field encountered a number of dissatisfied

\footnotetext{
16 Mercy Corps' local partner NGOs in Tajikistan consisted of Ittifok and The Institute of Cultural Affairs: Farhang va Tarakkiyot (ICA:EHIO. ICA is an international network of organizations in some 35 countries, Thus EHIO is the name designation of the partner NGO i) in Khujand, and Buzurg in Penjikent. In Kyrgyzstan Mercy Corps worked with Foundation for Tolerance International (FTI), as well as Lawyers Without Borders both with offices in Osh, Kyrgyzstan.

${ }^{17}$ These were the groups organized by PCI staff to be responsible for the various development activities in their communities. They are essentially spokespersons for their communities.
} 
community members, this would be a rather obvious indicator of a serious disconnect between discourse and practice.

There was also a serious problem of communication with village members who often spoke in Russian or just as often only spoke their local language (Kyrgyz, Tajik, or Uzbek). The researcher has some foreign language skills but they were not up to the task of interviewing, even casually in a foreign language. This meant that the researcher had to rely upon translators, which in turn meant that the quality of interviews would largely depend on the quality of translation and this varied tremendously from one translator to the next. In spite of these difficulties many villagers were included as participants in a ad hoc fashion. Essentially if they were on hand and willing to talk with the researcher than they were included. The researcher did make an attempt to not only talk with the village elders, but this was often impossible to avoid given the researcher's status as "important guest from America". Additionally, there were time constraints that militated against spending the kind of time in villages that would be necessary to break down cultural barriers and win trust. Thus much of what was expressed by villagers was incorporated into the study as examples of an emerging narrative about each development project, and as such they too were attempts to secure the meaning of development. The reader will recall that the actor-network theory method resembles semiotics but not at the level of language but rather at the level of association. Therefore, each kind of data was useful to the extent that it could be understood as a crucial piece in the Mercy Corps' PCI assemblage. Given the centrality of the overall case (PCI) to the research, the researcher felt it was important that the samples (documents, persons, sites) be as representative as possible. In practice this meant that the researcher attempted at least two visits to every 
PCI office in Central Asia. The major exception to this case was Uzbekistan. The researcher was informed that it would be impossible to get a visa that would allow for actual research. At the time of the study, however, most PCI activities in Uzbekistan had been seriously curtailed and the cross-border aspect of the PCI program had effectively ended in 2005 after the events in Andijon in May 2005 ${ }^{18}$. The researcher was, however, able to visit every other PCI office in Central Asia. This included, as already mentioned, Dushanbe, Khujand, and Penjikent in Tajikistan and Osh in Kyrgyzstan. Additionally, the researcher was able to visit many different project sites while visiting each of the main offices.

The primary means by which the researcher was able to follow the actors in PCI was through travel (see Figure 1). This last point is not trivial since it speaks directly to Latour's idea that movement between sites is always in some sense costly; it takes some work and therefore the work done by Mercy Corps of building the PCI assemblage throughout Central Asia was by no means simple or easy. By the same logic, the work of reassembling PCI for the purpose of research was likewise neither simple nor easy.

The reason of for the difficulties in either case are that the social aspects of development are not realized somehow in advance, through the current trends of development discourse or via a sedimented, archaeological connection (in the sense of Foucault's archaeology of knowledge) to the history of capitalism and development and all that might entail. Rather the social is built with the materials at hand and to the extent that PCI did rely on past ideas either from the enlightenment, capitalism, or some other

\footnotetext{
${ }^{18}$ For information on the massacre that took place in Andijon in May of 2005 see International Crisis Group. "Uzbekistan: The Andijon Uprising." Asia Briefing No 38, 25 May 2005 available at http://www.crisisgroup.org/en/regions/asia/central-asia/uzbekistan/B038-uzbekistan-the-andijonuprising.aspx. Last accessed June 9, 2011.
} 
font, those very same ideas do not escape the fact they must be again reassembled, rearticulated, redeployed. Consequently it is the social that is what flows through the performances at play in a program like PCI as well as in the many displacements of ideas into various sorts of material elements. The social is what eventually flows through the very things that PCI, together with their target communities, built and used in the day to day work of implementation: canals, drinking water systems, refurbished schools, documents, spreadsheets, community descriptions, memoranda of agreement, canals, roads, automobiles, project signs, contracts, standards for contracting, community mobilization strategies, computers, paycheck, administrative systems, local government representatives, buildings, offices, visas, agreements, grants, studies, household surveys, logical frameworks, telephones, satellites, conflict, ethnicity, livelihoods, etc. These are things that are brought together in a particular proposition via a method of articulation that make sociality possible. Everything on the list is also an actor, a proposition, a concatenation of actors, that is itself composed of disparate elements gathered from other places. However, Post-structuralism in general, and post-development in particular, not only assume that the world is socially constructed, they also assume an understanding of what constitutes 'the social'. In a very real sense actor-network theory re-problematizes the very notion of the social by drawing both the reader and the researchers' attention to the minute details of what it costs to bring something like PCI into the world. The actornetwork theory methodology significantly changes the way in which research is understood. As Latour says,

There is as much difference in the two uses of the word 'social' as there is between learning how to drive on an already existing freeway and exploring for the first time the bumpy territory in which a road has been planned against the 
wishes of many local communities. There's no question that ANT prefers to travel slowly, on small roads, on foot, and by paying the full cost of any displacement out of its own pocket (2005, p.22-23).

\section{Validity - Triangulation - Verification.}

The primary means of ensuring validity and reliability in this research was methodological triangulation. Which is to say that the researcher was able to develop a number of different methodologically informed perspectives and also that different kinds of data were used to provide both validity and reliability. The researcher also attempted to triangulate data with multiple visits with PCI offices, villages, NGO partners, various projects sites, together with multiple interviews, and multiple sources of documents. The documentary analysis serves as good example of how the researcher operationalized a method for triangulation. In the case of documents there were three primary sources of documents. First, the two physical archives, in Osh, Kyrgyzstan and Dushanbe, Tajikistan, contained a number of technical documents relating to PCI projects in terms of contracts, finances and various project descriptions. The other primary source of documents was the informants and the various PCI offices. The informants were able to give me a variety of unpublished reports that were written as part of their day-to-day work of documenting community mobilization activities. Many of these documents would form the basis of the quarterly and annual reports written for USAID. Finally, these quasi-public, published documents were located in a number of places. A unique feature of these documents is their portability. Most of these documents were saved as “pdf” files. Thus, some had been given to the researcher while he was still in Portland, others had been given to him at various points during the course of research. Finally, all 
of these documents could be found in the Mercy Corps Digital Library that was available over the Internet.

Triangulation was achieved by utilizing a number of different sources. Thus while it could be said of the quasi-public, published documents that they are examples of Mercy Corps representing itself in the best possible light, the supporting documents are contemporary and primary sources that reflect communication between villages and community development teams and PCI management. It is only later that they are fully translated into donor reports. Triangulation was also achieved through the comparison of different sources of data: documents, interviews, and participant observation. The two case studies in Chapters Six and Seven were constructed by analyzing data from these three sources. In both cases the researcher was able to visit the communities in question, interview a variety of informants from managers to community development teams to community members. The researcher could also look at plans, community descriptions, and quarterly reports, to name but a few. Together these various sorts of data were used to provide a thorough description of two infrastructure development projects.

Additionally, one could look at the interviewing strategy in terms of reliability and validity achieved through the gathering of multiple perspectives. Within the interview data there are high-level country managers, PCI managers, community development team members, NGO staff, CIG members, and community members. Also, participant observation was conducted in a wide variety of settings from the more formal office settings, to the many less informal settings such as riding together with teams to visit communities and project sites. Other interviews were conducted with NGO partners at their own offices, government officials, and on a few occasions, end of project 
ceremonies. Thus every type of method is a check against the other types of methods and every different type of data is also a check against the other forms of data. The difficult work of the researcher is to be engaged in a process of constant comparison between data types and methods. The only effective way to keep notes on all of these types of data was to meticulously code the data as already mentioned. While the research makes no pretensions towards grounded theory (Glaser and Strauss 1967), the method of constant comparison is similar. Constant comparison was used to compare types of data, but it should also be noted that every type of data collected was also measured against the researcher's theoretical outlook both in terms of ANT's methodological principles but also against ANT's analytical framework with its concerns for uncertainty and scale.

\section{Data Analysis - Uncertainty and Scale}

Data analysis in this research was almost exclusively informed by actor-network theory and followed Latour's recommendations for analysis very closely. Analysis in this case was largely limited to two sets of questions; the first has to do with uncertainties and the second with scale. In regard to uncertainty Latour comments that he has,

chosen 'uncertainties' - in a weak allusion to the 'uncertainty principle'because it remains impossible to decide whether it resides in the observer or in the phenomenon observed. As we will see, it's never the case that the analyst knows what the actors ignore, nor is it the case that the actors know what the observer ignores. This is the reason why the social needs to be reassembled (ibid, p.22).

Latour's five sources of uncertainty along with his recommendations for keeping the social flat form the structure of analysis and will be explained briefly. This last section of this chapter will deal with some of the practical elements of analysis and a discussion of the theoretical basis of analysis. 
In practical terms analysis was ongoing from the moment the researcher decided to study this particular program. The primary method for this was a modified version of constant comparison (Strauss 1987). Methodologically this meant that coding was a key technique. However, coding was not used in the sense of doing grounded theory, but rather it was used a means of keeping track of who was speaking, various ideas, relationship of data to theory, questions, etc. In this way, interview data was compared against the documentary data, and against participant observation data (notes which were also coded), and then in an iterative process the researcher would include the results of this constant comparison into the next round of research. Depending on the situation this iterative process might take place over the course of a few weeks, a few days, a few minutes, or even from taking one note to the next.

The method of constant comparison also included an ongoing and iterative process of comparing all the data (interviews, notes, documents) against both the methodological principles and analytical framework of actor-network theory. Was agnosticism rigorously maintained? Was symmetry observed and objects taken into account? Were relations rigorously questioned, examined, and analyzed in regard to the third principle of free association? Furthermore data was constantly compared against Latour's five sources of uncertainty and efforts were made to keep the social flat (Latour 2005).

\section{Analyzing Data: Latour's Five Sources of Uncertainty and Keeping the Social Flat}

Latour's five sources of uncertainty form the basis of the analysis of data in this research. The sources of uncertainty are as follows:

- the nature of groups: there exist many contradictory ways for 
actors to be given an identity;

- the nature of actions: in each course of action a great variety of agents seem to barge in and displace the original goals;

- the nature of objects: the type of agencies participating in interaction seems to remain wide open;

- the nature of facts: the links of natural sciences with the rest of society seems to be the source of continuous disputes;

- and, finally, about the type of studies done under the label of a science of the social as it is never clear in which precise sense social sciences can be said to be empirical (p.22).

\section{Groups}

PCI was very much about getting groups right. The actor-network theory perspective suggests, however, that groups do not come pre-packaged but must be in some way assembled. This follows from actor-network theory's principle of agnosticism; we cannot decide before hand what groups exist, but we must instead follow the actors and describe the way in which they articulate and perform various groups. Groups like Mercy Corps, PCI, CIG, etc. hold together because some effort is expended in doing so. If one were to visit one of the former PCI communities in Central Asia they would not necessarily find the community interest group assembled for them, and if they wanted to meet with that now defunct group then it would have to be assembled. The theoretical point is that the work of assemblage involves a translation and is therefore a new articulation of a new proposition and it will require more than simply words to hold it together. Therefore if there is no performance or articulation then there is no group. However, this is not to say that there is no memory. Rather it is to say that groups require a performance in order to exist and each performance, depending on how it is being organized, represents a different articulation and thus a different proposition. This doesn't mean, however, that the individuals or other components of the group don't exist. 
One can visit these individuals and one can gather together again those various documents that contain references to the groups. For example, if a student read this dissertation and wanted to write about Garibak she might first see if she can't find it on a map; once located on a map she might see if anyone else has written about that community. Eventually she might produce a paper that brings together bits of this dissertation, the map, and other elements. She will have articulated a different proposition that relates to Garibak.

\section{Action}

Action is also re-problematized within the actor-network theory framework. Deciding who or what is action is not something that can be done without empirical research. Actor-network theory deploys two very interesting ways of dealing with action and actors. Actor-network theory's unique metaphysical position is that it abolishes the notion that there is a tremendous gap between Nature and her facts and Society and its second-order interpretation of facts. For ANT the modernist notion of such a fundamental separation is untenable. Latour explains,

In the modern perspective, Nature and Society allow explanation because they themselves do not have to be explained. Intermediaries exist, of course, and their role is precisely to establish the link between the two, but they establish links only because they themselves lack any ontological status. They merely transport, convey, transfer the power of the only two being that are real, Nature and Society. ... Their competence is not their own. At worst, they are brutes and slaves; at best, they are loyal servants (Latour 1993, p.80).

However, if the divide between nature and society is abolished the effect on what were previously thought of as mere intermediaries is profound. Latour explains "they stop being simple, more or less faithful, intermediaries. They become mediators - that is, 
actors endowed with the capacity to translate what they transport, to redefine it, redeploy it, and also to betray it. The serfs have become free citizens once more" (ibid, p.81). This problematization of action has two effects. The first is that actor-network theory multiplies the number of actants within any assemblage. The second effect is this opens the door for the inclusion of objects in sociological accounts and it gives ANT a decidedly post-human form. In actor-network theory anything that leaves a trace becomes an actant. Thus readers will encounter in Chapters Five through Seven actants as diverse as a gap between two geographical points, a recalcitrant community, a broken water pump, and holes in a water pipe. Each is an actant in the drama that unfolds around them. The reader will also find that documents are actants as well. Documents do more than merely represent, they also authorize or limit action; they bring together things that quite literally do not fit together, communities, celebrations, governments, school buildings, water supply systems, electrical grids, and people into a relational space that does some of the work of holding those relations together.

Another important aspect of ANT's understanding of action is that it is always dislocated or displaced by other actants. In ANT there is no simple formulation of simple cause and effect and this is so because both sides of the equation are treated as mediators. If only one side of the equation were granted agency then the number of agencies at play in the world would be much reduced. However, ANT multiplies and increases the number of agencies by granting anything that affects anything else the status of actant and mediator. Instead of deciding beforehand that the important actors are class or productive forces, actor-network theory problematizes those stable categories and asks whether or not it can multiply the number of mediators by virtue of following the actors. 
Latour says, "Thus, the key question for a social science is to decide whether it tries to deduce from a few causes as many of the effects that were there 'in potentia', or whether it tries to replace as many causes as possible by a series of actors — such is the technical meaning that the word 'network' will later take" (2005, p.59).

\section{Objects}

The third source of uncertainty has to do with the agency of objects. There are two important points to be made in regard to objects. The first point has to do with why ANT has allowed objects back into the realm of sociological analysis, and the reason is fairly simple. The rejection of a divide between nature and society extends to other divides as well, between subject and object, human and non-human. ANT should not be taken as a sociology of two distinct realms of materiality and sociality, since it is precisely this distinction that is being set aside. Thus when ANT talks about the relations between humans and non-humans what it is really talking about is the creation of hybrids. As Latour says, "There exists no relation whatsoever between 'the material' and 'the social world', because it is this very division which is a complete artifact" (2005, p.76). ANT is thus not interested in privileging material causality over social intention but rather to abolish the line between the two. Human intentions are only realizable because humans are able to enter into relations with objects, to displace themselves into something more durable.

In terms of analyzing PCI the researcher cannot start his analysis by only granting agency to the managers, or to USAID, or to the development apparatus. Agency becomes an open question. It is opened agnostically with a strong measure of relativism but it is closed empirically via an account of the various agencies at play. Thus the agencies at 
play in PCI include not only USAID and Mercy Corps, but also managers, community mobilization teams, various other Mercy Corps staff, quarterly reports, logical frameworks, water pumps, pipes, rivers, flood protection schemes, automobiles, computers, local governments, memoranda of agreement, villagers, and community intiative groups. The list of actors that can be included is potentially quite long. In this research the list of actors has been delimited, to a certain extent, by the artifice of choosing particular case studies.

\section{Objects and Power Relations}

The second important point to be made about objects is that by including them in sociological accounts replaces the ghost-like quality of traditional accounts of power relations. What is replaced is an unknown agency or quantity with the means by which power is secured. Latour explains,

There exists, however, an even more important reason for rejecting adamantly the role given to objects in the sociology of the social: it voids the appeals to power relations and social inequalities of any real significance. By putting aside the practical means, that is the mediators, through which inertia, durability, asymmetry, extension, domination is produced and by conflating all those different means with the powerless power of social inertia, sociologists, when they are not careful in their use of social explanations, are the ones who hide the real causes of social inequalities $(2005, \mathrm{p} .85)$.

Thus objects are re-introduced by virtue of ANT's metaphysics but doing so provides the researcher with the means for providing more powerful explanations of social relations and power. By foregoing the many different ways in which action is displaced into objects, sociologists run the risk of leaving power relations un-explained. 


\section{Matters of Fact/Matters of Concern}

The fourth source of uncertainty is perhaps the simplest and relates to the possibility of politics. This is the uncertainty of factual accounts or what Latour draws out as a difference between matters of fact and matters of concern. For Latour there are very few things that are simple enough to stand on their own as matters of fact. This is not to deny the efficacy of science but simply to draw attention to the idea that facts rarely stand on their own, they must be constructed or made, but this making activity should not automatically cause one to doubt the truthfulness of the thing made. But it is precisely this quality of having been made that renders these things problematic and makes them open for study. Made things should not be merely accepted as natural elements in the order of things How was it made? Was it made well or not? The tension between matters of fact and matters of concern affect sociological inquiry in two ways. First, Latour's understanding of laboratory science has led him to the conclusion that facts are constructed. The caveat, however, is that facts are not socially constructed but rather are hybrids of humans and objects. Second, the making of facts does not make them less real; in the estimation of actor-network it actually makes them more real. Facts would not be known without the intervention of scientists, their laboratories, and their various tools. However, such a model does make facts a bit less iron clad, and more susceptible to politics. This should not, however be taken as an indictment or debunking of science, but rather a pragmatic view of the way in which science and technology must operate. The problem with facts is when they are used to short circuit politics. Latour writes 
So, when people doubt the existence of 'nature' and 'outside reality', you never know if they are contesting the premature unification of matters of concern under the hegemony of matters of fact, or whether they deny the multiplicity of entities revealed by the sciences. The first is indispensable, the second is plain silly (2005, p. 254).

In the research setting, the distinction between matters of fact and matters of concern can be a useful guide for understanding how knowledge is used and deployed. Additionally, such a distinction is useful for understanding the politics of a development intervention. Thus in the case studies to follow the reader will have the opportunity to see how, especially in Chapter Six, various actors (PCI managers, community mobilization teams, government) negotiate the question of 'what is to be done?' In Chapter Five the reader has an opportunity to see the researcher's account of how Mercy Corps negotiated and built its understanding of community needs in the Ferghana Valley and used that knowledge to secure funding from USAID for the PCI program.

\section{Writing Risky Accounts}

The fifth and last source of uncertainty concerns the question of risky accounts and has been discussed earlier in this chapter. However, it bears repeating that the notion of risky accounts is a useful heuristic for understanding documents. Many of the documents in the PCI program form a kind of artifactual account of the power of development. While this dissertation has generally eschewed the various extant theories of power, it still remains an important concept in understanding development. Much of the analysis in this dissertation concerning power is essentially implicit as ANT tends not to distinguish the social from power. Both are things that flow through the built assemblages of development, and these assemblages can be done well or poorly. That is, they can clearly violate our sense of right and wrong, or they can be used to support what 
might be understood as a fairly forward thinking progressive agenda. Either way, it is clear that the assemblages of development are in fact made to do things, and it seems that by providing a thick, actor-network theory analysis of development that this research goes some way in preparing the ground for judgment.

The final two analytical points concerning actor-network theory deal with the ways in which actor-network theory attempts to flatten out pre-existing scales so that certain sites where action takes place are not privileged over other sites, and as previously mentioned, it's important for the ANT researcher to problematize sites whether they are considered global, local, or in-between. The basic insight of ANT is that the informants will generally do the work of scaling themselves, and it's important for the ANT researcher to not do this kind of scaling before hand. To paraphrase Latour, contexts are fine as long as we can trace the connections between the sites and register the cost of transport without falling into the trap of thinking one site or actor is somehow embedded in another site or actor.

\section{Problematizing Scale}

Latour's fives sources of uncertainty and actor-network theory's three methodological principles of agnosticism, generalized symmetry, and free association, together with the exhortation to follow the actors, leads to a set of analytical considerations that have to do with the way in which actor-network theory scholars deal with questions of scale. An example will help to explain this particular methodological stance. Globalization is one of the better examples of a commonly used explanation for complex phenomena. As Nick Srnicek (2010) explains, there are three common understandings of the notion of global: "(1) the global as container, (2) the global as the 
top position in a hierarchy, and (3) the global as a level of a detail" (p.36). According to Srnicek, these conceptions "are incapable of accurately explaining the relations between levels and ignore that when we go to look for the global's operations, we only find more local levels" (ibid, p.36).

\section{Localizing the Global - Redistributing the Local - Connecting Sites}

Actor-network theory substitutes the phrase global with a series of intermediaries that move from one local site to another in some way. Latour uses, as an example, the idea of Capitalism and a Wall Street trading room floor; he says,

Capitalism, for instance, may be an intractable entity endowed with a 'spirit', but a Wall Street trading room does connect to the 'whole world' through the tiny but expeditious conduits of millions of bits of information per second, which, after having been digested by traders, are flashed back to the very same place by the Reuters or Bloomberg trading screens that register all of the transactions and are then wired to the 'rest of the (connected) world' to determine someone's net worth (2005, p.178).

Latour goes on to explain that at this point the researcher has a choice between two different routes. Latour says the researcher can still believe that capitalism continues to act as a kind of immanent, giant actor that "acts surreptitiously as the 'infrastructure' of all the worlds transactions" or the researcher can instead insist on examining where things lead from the trading site and how things move between one site and the next. The first choice involves a jump away from the local scene towards a contextual explanation that is itself unexplained. The second choice involves following the actors to see where they might lead. The 'so what' of this methodological imperative to follow the actors is that, as Latour explains it, "the landscape drawn in both cases, using these two definitions of tracers, will be completely different" (ibid, p.178). What Latour has described here is essentially his method for "keeping the social flat" (Latour 2005). This involves three 
critical moves: "localizing the global..., redistributing the local..., and connecting sites"

(Latour 2005, p.173). Latour explains that

The first corrective move looks simple enough: we have to lay continuous connections leading from one local interaction to the other places, times, and agencies through which a local site is made to do something. This means that we have to follow the path indicated by the process of delegation or translation... this deployment might take the shape of a network on the condition that every transport be paid in transformations, that is, if we make sure to pave the whole way from one site to the next not with intermediaries but with full-blown mediators. If we do this, we will render visible the long chains of actors linking sites to one another without missing a single step. It might be empirically hard but we should not expect major theoretical hurdles (p.173).

Even in this first move towards flattening the social landscape there is an obvious tension between local phenomena and context. The people and objects of our respective studies are constantly engaged in a perpetual reassessment of their own work, and the way in which it fits into a larger picture.

\section{Oligoptica and Panoramas}

Latour suggest that the researcher use two different "clamps" to hold the flatness of the landscape and to foreground the work of one's 'informants'. These are "oligoptica" and "panoramas" and of the first Latour says,

We, however, are not looking for utopia, but for places on earth that are fully assignable. Oligoptica are just those sites since they do exactly the opposite of panoptica: they see much too little to feed the megalomania of the inspector or the paranoia of the inspected, but what they see, they see it well-hence the use of this Greek word to designate an ingredient at once indispensable and that comes in tiny amounts $(2005, \mathrm{p} .181)$.

The reader will recall that panoptica come from the work of Foucault (1979) and it is used as way to describe an ideal prison, the panopticon, designed by Jeremy Bentham in the late 18th century. This is by now a famous example of the way in which Foucault 
privileges the power of sight. However for Latour, comparing panoptica to oligioptica is a way of highlighting the limited sight of a researcher. Researchers do not occupy a position similar to that of the panoptica that allows them see everything, but instead they have a powerful but localized ability to see what is around them at any given moment. The larger point is that any jump away from the myopic activity of tracing actors will involve a great deal of blindness.

Latour, however, introduces the concept of panoramas as a means towards building an understanding of the manner in which those we study build their own scale, put things into context, and mobilize coherent (though risky ${ }^{19}$ ) accounts of their work. Again, this last point takes the reader back to the first methodological principle of agnosticism. The point is that it is not the job of the researcher to put the informants' worlds into some kind of order, but rather the job is to resist ordering (agnosticism) and instead examining the process (tracing) by which those under study engage in the activity of ordering, all the while not privileging (generalized symmetry and free association) any particular actor.

\footnotetext{
${ }^{19}$ In many ways Latour's notion of risky accounts is at the center of the research presented in this dissertation. The reason accounts, or texts, are considered risky is that they can be written badly, they can misrepresent the data, or represent the data poorly, they can be challenged by others, they can fail to do that for which they are intended, and they include objects and actors that are not mere set pieces in a drama written elsewhere but full blown actors who can and do resist attempts at representation. Risky accounts stand in stark opposition to their more powerful cousin discourse, or hegemonic discourse in postdevelopment studies. While accounts are certainly part of the building blocks of reality they remain problematic and whatever power they have to structure reality is derived from whether they are done well or not. A poor quarterly report could mean rejection by the donor and an end to funding. The communities could refuse to participate and leave the writer with only failure. Accounts can be both artificial and accurate and such accuracy is a result of their artifice (Latour 2005, 124). While many may simply reject texts as nothing more than transparent social phenomena, ANT treats texts as mediators, which is to say as actors/actants that articulate a more ore less complex proposition. Thus, a text is always also in some sense a gathering of disparate elements and it must do the seemingly impossible task of making the incommensurable commensurable. A village, a project, a pump, these things are not made of ink and paper, but they are more or less faithfully represented and by being represented they are transformed (ibid 149) into paper and ink, or digital documents. But it must also be remembered that documentation is never easy or simple and always involves some work that in the end could be reversed or undone.
} 


\section{Chapter Three - Literature Review}

The general purpose of this dissertation has been to critique the theoretical stance of post-development, and to do so via the introduction of a different theoretical stance, that of actor-network theory. One of the claims made here is that part of the problem with post-development theory and other post-structuralist schools of development studies is that they leave discourse under-theorized and that which is mobilized to explain development is left unexplained. ANT is thus offered as a means to explain what postdevelopment leaves unexplained. Fittingly, this research poses a very direct question in regard to these two theoretical positions, which makes more sense? However, this project of substituting one set of theories with yet another theory must do more than demonstrate that it is a good candidate, it must also in some sense deliver on the promises of the failed theory. The point should not be to merely pit one set of ideas against another but rather to take what is valuable from one and import it into the other. One of the claims of this research, indeed the central theoretical claim, is that ANT is a robust and rigorous theoretical position that is supported by a sophisticated philosophical and metaphysical argument about the nature of reality and that it forms a challenge not only to post-development but to development theory in general. Given the tremendous points of difference between these two theoretical stances, the claim is that ANT significantly alters the social landscape, and in doing so provides both scholars and practitioners a new perspective on old problems. Some of these old problems have already been addressed by post-development studies. What is the nature of the relationship between the West and Others? Does the discourse of development and capitalism form a ruthless kind of 
hegemony? What is the relationship between discourse and practice? If we live in a capitalist society how does that manifest itself in development? These are all excellent questions and they should be addressed. The contention here, however, is that these questions have not been properly addressed and that post-development has been somewhat blinded by its ideological preferences and is coming dangerously close to becoming an anti-intellectual and anti-empirical endeavor.

The argument then is that ANT can do a better job of answering these questions. ANT can provide thicker descriptions and more sophisticated explanations for the relationship between development ideas and practice as well as between the West and others. But first, it is important that actor-network theory can answer the most basic question that post-development studies has asked, and it's a question that goes directly to the heart of the matter because it involves discourse, practice, and power. The question is to what extent do the agents of development depoliticize their interventions? Given this set up, this interplay between two theoretical perspectives with reality hanging in the balance, it should come as no surprise to the reader that this literature review will follow the direction of the research and provide an overview of development theory with an eye towards placing post-development into its proper intellectual context. This will be followed by a brief history of ANT and an explication of its theoretical content.

The status of development theory

The last 40 years can be called the age of development. This epoch is coming to an end. The time is ripe to write its obituary.... The idea of development stands like a ruin in the intellectual landscape. Delusion and disappointment, failures and crimes have been the steady companions of development and they tell a common story: it did not work (Sachs 1992, p.1). 
Thus does Wolfgang Sachs begin his indictment of development in the Development

Dictionary, and of course he was not wrong in his assessment of the overall impact of development. As David Simon relates,

Overall, the available evidence suggests that, despite debate about how best to implement development, success has at best been uneven, both within and between countries. While average incomes and the quality of life for a substantial proportion of people have been rising over the last two or three decades in much of Southeast Asia, and parts of Latin America, for example, the reverse is true in most of Africa, parts of South Asia, the Caribbean and latterly also Central and Eastern Europe. Within many countries, as well as between countries in particular regions, disparities have been widening rather than narrowing, with little evidence that this trend will shortly be reversed in line with predictions of conventional modernization (Simon 1999, p.22).

Leys (1996) argues that in spite of these failures, or perhaps in part because of them, there is much at stake in the elaboration of development theory. Ley's argues, “... what is at stake is —or rather was, since the practical ambitions of 'development theory' have been progressively reduced over the years - nothing less than whether human beings can act, collectively, to improve their lot" (p.3). Leys sets up this question as a kind of tension between intentional action versus various forces (market forces) "over which [humans] have, in general, little or no control" (ibid, p.3). Partly because of the so-called "impasse in development theory" (Schuurman 2004) development theories response has been less than satisfactory. Thus, for development studies at least, the question of what is to be done, and how to theorize such action, remains largely unanswered.

Schuurman (2004) argues that the impasse in development was a combination of "the lost decade" of the 1980s understood in terms of the failure of development and in particular the acute failure of an emphasis on economic growth. He argues that the "major factors contributing to this impasse were post-modern criticism of theory 
formation in the social sciences, the growing awareness that the emphasis on economic growth... resulted in an insupportable burden on the natural environment, and loss of the socialist paradigm as the link between theory and development praxis" (Schuurman 2004, p.1).

\section{Economic Theories of Growth}

While Escobar (1985) and others see 1949 as the year that development was born, economic theories of growth enjoy a much longer intellectual history. Thus Peet (1999) divides the history of economic thought into five distinct 'epochs' that begin with "preclassical, classical, marginalist, Keynesian, and post-Keynesian theories" (p.18). Thus medieval economic thinking finds its origins in Greek philosophy and Aristotle's concern that market prices be fair and equitable. As Peet notes, "for the leading lights of the medieval period, thinkers like Albertus Magnus (c. 1200-1280) or Thomas Aquinas (1225-1274), prices were a matter of justice and the law had a duty to fix them and punish individuals who exceeded the just price" (p.19). Peet also makes clear that medieval notions of economy, such as they were, reflected God's will and thus the early history of economic thinking is bound together with religious thinking. It is in some way no surprise then that challenges to this way of thinking economics emerged in the seventeenth century in "Protestant mercantile and manufacturing circles" (p.21). Thus Thomas Hobbes, John Locke, and David Hume were three thinker who were "especially important in forming the philosophical basis of classical economic theory: in many ways the three form steps along the path from mercantilism to modern capitalism" (ibid, p.21).

Classical economic theory would eventually cement the status of economics as a science. Thus John Stuart Mill (1806 -1873) in his major work Principles of Political 
Economy could argue on behalf of economic laws as the basis for competition and that these laws could be "outlined with precision and given universal validity by an abstract science (Peet 1999). Having said that, classical economics was still very much tied to questions of morality, and much economic thinking of the period is characterized by this concern. Thus both John Stuart Mill and Friedrich List (1789-1846) shared a concern with the negative effects of economic activity and the need for state intervention as a sort of guide for progress. While the focus of the two men was quite different, Mill was concerned in part with capitalist and labor relations and the positive role that could be played by the government, and List was concerned with the unevenness of economic development and advocated for the protection of national economies, both remained committed to the idea of state intervention (Peet 1999, p.31).

Near the end of the nineteenth century, Peet argues, "economics changed from political economy, part of a moral philosophy critically involved with social issues, to a specialized scientific discipline fascinated by calculus, algebra, and plane geometry, and increasingly removed from social concerns (ibid, p.31). Eventually neoclassical economics, led in part by it concern with marginal utility and the attainment of "maximum total enjoyment" (ibid, p.31), could be seen as a justification for the status quo of economic status. Peet explains,

Altogether, neoclassical economic theory asserted that, under conditions of perfect competition, price-making markets yielded a long-run set of prices that balanced, or equilibrated, the supplies and demands for each commodity in production and consumption. Given certain conditions, such as the preferences of consumers, productive techniques, and the mobility of productive factors, market forces of supply and demand allocated resources efficiently, in the sense of minimizing costs, and maximized consumer utilities, in the long run. And finally, all the participants in production received incomes commensurate with their 
efforts. Capitalism was therefore the best of all possible economic worlds (Peet 1995, p.34).

It is against this laissez faire attitude that Keynesian economic theory would validate and legitimate the notion of state intervention into the market economy. Keynesian economic theory rejected the notion that capitalism was the best of all possible worlds. Thus the free hand of neoclassical economics would be set against the guiding hand of the government. Hunt and Lautzenhieser (2011) argue that "given the stagnation and near disintegration of capitalism in the 1930 s, it may be said that for over seven decades Keynesian policies have worked tolerably well" though the authors go onto argue that result of this is "a structural change to a permanent military or warfare economy and the creation of a precarious debt structure" (p. 416-417).

Finally we arrive at the epoch of post-Keynesian economic theories. This period, which extends to the present, is marked by the post-war elaboration of development economics and more recently a kind of counterrevolution in development economics that represents a return to neoclassical models of economic theory. Peet writes that "the 'counterrevolution' in development theory, part of a more general neoliberal or even conservative reaction, opposed Keynesianism, structuralism, and radical theories like dependency in the name of renewed faith in classical, Smithian economics" (Peet 1999, p.47).

There are two policy areas where a retrospective analysis of development economics reveals at as having been particularly harmful to the so called third world, this is the area of trade strategy and agricultural policy. The former often appears to be little more than a justification for extracting cheap resources and goods while the latter is 
responsible for the spectacular failures of the so called green revolution. Thus, this paper is in some agreement with the general critique of theses practices but it should be noted that as a critique it is shared amongst a variety of development theorists and is by no means the sole domain of post-development.

\section{Sociology and Theories of Modernization}

Towards the end of the 1950s it had become apparent that whatever optimism there had been about the rapid development of newly emerging states based on "raising rural productivity and transferring underutilized labor out of agriculture and into industry" was quickly dissipating in the face of tremendous failure (Leys 1996, p.8). This raised a question regarding the supposed inability of these countries, most of them previously colonies, to respond to development. Leys writes that "'modernization theory" was an American response to this question. It was constructed by sociologists and political scientists involved in the rapidly expanding research and teaching programmes established by the US government to equip the country with the regional expertise it needed to exercise its new role as superpower" (ibid, p.9).

These emerging scholars believed in a kind of teleological advancement of societies from traditional to modern forms. Consequently, they took the West as the exemplar and height of Modernist development. Thus they began the project of tracing connections between social change, economic development and politics using the “structural-functional analysis and a typology of social structures derived from Weber and Talcott Parsons.... Practically, the modernization theorists envisaged modern values being diffused through education and technology transfer to the "elites' of the periphery" (ibid, p.9-10). There is a great deal more that could be said in regard to sociological 
theories of modernization, however, the most salient feature of this line of inquiry, following Baidya Varma (1980) is the privileging of Western society as the pinnacle of modernism and then measuring other societies and cultures based on that metric (p.28).

\section{Marxist and Neo Marxist}

There is a great deal of ground to cover when one introduces both Marxist and neo-Marxist theories of development. This section will be a painfully short oversimplification of an area of theory that deserves a closer reading but, unfortunately, it isn't directly pertinent to this study. In the main there are three theories of development that can be said to be neo-Marxist and these are underdevelopment (Baran 1960, Frank 1969a), dependency theory (Fernando Cardoso and Enzo Faletto 1979; Chase-Dunn 1975;), and world system theory (Wallerstein 1979). Peet explains that

Between the mid-1960s and the early 1980s, critical thinking about development was dominated by Marxist and neo-Marxist theories. Dependency theory and world systems theory were primary areas of debate in the late 1960s and for much of the 1970s. Marxist structuralism and articulations of modes of production were particularly important for radical thinking about development in the AngloAmerican intellectual world of the late 1970s and early 1980s. With the easy wisdom of hindsight, we can see structural and systemic theories as culminating triumphs of radical modern social philosophy. These highly generalized theories tried to position every historical event, and place each social characteristic, as a component of some more general, overarching system, be it mode of production, world capitalist system, or global market. The aim was a systemic theory of social totalities and their parts with nothing unexplained or left to chance, although some aspects might have to be examined empirically. For the true structuralist, empirical analysis was an admission of failure (Peet 1999, p.123).

It is against this background that post-structuralist thought begins to emerge. Much of poststructuralist thought can be understood in a very general sense as a project that is meant to reintroduce language into discussion of theory and philosophy. It can be seen as 
an attempt to move decidedly away from the over-determination of language and meaning by structuralism.

\section{Post Structuralism}

If post-structuralism is a reaction to the over-determination of culture, language and meaning by various structures, then what it accomplishes seems to be the replacement of one kind of over-determination (by structures, by the economic infrastructure if you are a Marxist) with another. That is, post-structuralism raises language and discourse to the level of a determinant that Marxists, at least, had reserved for the economy. Thus, following Manfred Frank (1988), in an important sense poststructuralism is not necessarily opposed to structuralism but is what comes after structuralism. Frank argues, "Post-structuralism is a critique of Structuralism conducted from within: that is, it turns certain of Structuralism's arguments against itself and points to certain fundamental inconsistencies in their method which Structuralists have ignored" (Frank 1988; quoted in Peters 2002, p.17-18). The Marxist example that comes to mind is Louis Althusser's reworking of Marxist theory that would allow culture, art, law etc., to exist as their own semi-autonomous sphere determined only in the last instance by the economy (Wolfe 1993). This re-articulation of Marx, based on the notion that one had to read Marx, would open up a world of possibilities for Marxist theory. Peters (2001) explains that

Althusser's Reading Marx (1971), based around a seminar-a collective reading of Capital - he organized in 1964, permitted a return to Marx based upon a "symptomatic reading," a new practice of reading texts in structuralist terms that applied the insights of formal linguistics to treat the work as a discursive system based on its own inner logic. In performing this reading, Althusser not only linked up with and revitalized a connection to the aesthetic formalism that some christen as twentieth-century modernism, but he also made Marx's continuing 
relevance to an extent dependent upon the application of new practices and productions of readings (2001, p.26).

In moving decisively towards the sphere of language, post-structuralism abandons materiality and eventually embraces a social-constructivist version of the world where everything becomes social by virtue of its relation with humans. This renders poststructuralism as implicitly correlationist. Harman calls this the "Fichtean principle of no $X$ without givenness of $X$, and no theory of $X$ without positing of $X$ " $(2009, p .165)$. This point will become important when the chapter turns to a discussion of Latour and actor-network theory, but it should be at least mentioned that while ANT is thoroughly post-humanist in its perspective and proposes a solution ${ }^{20}$ to the correlationist argument, poststructuralism implicitly accepts the correlationist view, and to be fair, the argument at least seems powerful. The point is that post-development is only implicitly correlationist rather than being explicit.

\section{Post-Development}

During the 1980s a handful of scholars began questioning development and expressing their fundamental dissatisfaction with the entire enterprise (Escobar 1985, 1987, 1988; Esteva 1985, 1987, Latouche 1986). What was different in these expressions was that they were not expressed as part of an agenda to improve development, but rather it was a call to reject development in its entirety (Ziai 2007). Indeed, as early as 1971 Ivan Illich was already criticizing development. Illich argued, "Rich nations now benevolently impose a straitjacket of traffic jams, hospital confinements and classrooms

\footnotetext{
${ }^{20}$ Both Harman and Latour's solution to the correlationist problem is to appeal to a 'rich elsewhere' that cannot be simply reduced to a function of mind. Harman also argues "It is powerful evidence against correlationism that it arbitrarily treats the human/world relation as philosophically more important than any object/object relation (Harman 2009, p.176).
} 
on the poor nations, and by international agreement call this 'development' (Illich 1971, reprinted in Rahnema and Bawtree 2001, p.95). Certainly the emerging anti-development scholars of the 1980s were inspired in part by Illich's writing1980s. Ziai explains that the Development Dictionary (Sachs 1992), the first of three foundational post-development texts ${ }^{21}$ was the result of a collaboration of this emerging school of thought and it had been inspired not only by Illich but also Foucault, Gandhi, and Polanyi (Ziai 2007, p.4).

The key historical moment for post-development scholars was Truman's inaugural address on January 20, 1949. President Truman proclaimed,

More than half the people of the world are living in conditions approaching misery. Their food is inadequate, they are victims of disease. Their economic life is primitive and stagnant. Their poverty is a handicap and a threat both to them and to more prosperous areas. For the first time in history humanity possesses the knowledge and the skill to relieve the suffering of these people.... I believe that we should make available to peace-loving peoples the benefits of our store of technical knowledge in order to help them realize their aspirations for a better life.... What we envisage is a program of development based on the concepts of democratic fair dealing.... Greater production is the key to prosperity and peace. And the key to greater production is a wider and more vigorous application of modern scientific and technical knowledge (Truman 1949, quoted in Escobar 1995, p.3).

For Escobar, this elaboration of what became known as The Truman Doctrine, "initiated a new era in the understanding and management of world affairs" (Escobar 1995, p.4). Truman's speech forms a quintessentially modernist view of the world, and thus for Escobar this particular articulation of modernism would become the primary means through which the so-called third world would be socially constructed. Many have criticized post-development suggesting "the critique of 'development' is excessive, since a number of 'development policies' have yielded good results. It is therefore wrong to

\footnotetext{
${ }^{21}$ The other two foundational texts are Escobars's (1995) Encountering Development; and James Ferguson's (1994) The Anti-Politics Machine.
} 
“essentialize development” (Rist 2009, p.258). Rist responds to this criticism by arguing that post-development is essentially uninterested in the details of development or development projects, rather "their critique is mainly directed at a faith, and ideology, a vision of the world's future, an explanatory model, or a discursive formation that shapes certain practices tending towards 'universal commodification' with the consequences that we know" (ibid, p.258). So for Rist the success or failure of any particular development project is not at issue, but rather " a general way of envisaging harmonious and equitable cohabitation of all those living today...." (ibid, p.258 emphasis in original).

Rist argues that it is "presumptuous to speak for others" (ibid p.258), but Corbridge argues "an unwillingness to speak for others is every bit as foundational a claim as the suggestion we can speak for others in a unproblematic manner" (Corbridge 1994, quoted in Pieterse 2010, p.119). What becomes clear in reading post-development texts is that much of it is intended as a thoroughgoing critique of modernism. As Pieterse (2010) argues, "post-development [is]... combined with a Foucauldian methodology and a theoretical framework of discourse analysis and a politics inspired by poststructuralism. These positions are not consistent and besides, a recent approach, post-development is not theoretically developed" (p.111). Following Pieterse, it will be important to examine three aspects of post-development thinking: the problematization of poverty; understanding development as a mode of Westernization, and the critique of science and modernism. Finally it will be important to examine the preferred methodology of postdevelopment: discourse analysis. 


\section{The problematization of poverty}

One of the things that post-development draws our attention to are the relations between Western development institutions and particular articulations of the notion of poverty. As Majid Rahnema (1999) argues,

Destitution, or imposed poverty, no doubt hurts, degrades and drives people into desperation. In many places, hunger and misery cry out to heaven. Indeed, few development concepts find their proof in such a glaring reality. Yet poverty is also a myth, a construct and the invention of a particular civilization (p.158).

Vandana Shiva offers a more sophisticated argument and in doing so seems to distinguish between real poverty and created poverty. Shiva writes, "culturally perceived poverty need not be real material poverty" (Shiva 1988, p.10). There is a sense in these descriptions that the West simply mistakes subsistence for poverty, and one can at least imagine that happening. On the other hand there is a unmistakable romanticization of poverty. As Pieterse points out, there are number of issues being conflated here. One is the issue of how to recognize real poverty, the other has to do with the representation of poverty, and finally if market participation is a root cause of poverty it doesn't necessarily follow, as Pieterse suggests, "that less market participation does not... imply more social participation, lest we homogenize poverty and equate poverty with purity (and the indigenous and local with the original and authentic)" (Pieterse 2011, p.129).

The ANT critique of the problematization of poverty is that quite simply it puts the cart before the horse. Post-development assumes two things in this case that contradict each other, one that development institutions get poverty wrong, but that these same institutions are so powerful (at social construction) that what they say about poverty becomes a reality. As Escobar explains it, "peasants are socially constructed prior to the 
agents... interaction with them. Socially constructed here means that the relation between client and agent is structured by bureaucratic and textual mechanisms.... That does not deter the agent... from presenting the results of the interaction as "facts"" (Escobar 1995, p.107). Oddly for Escobar the notion of socially constructed is meant as way to obfuscate the really real, but its unclear how one would recognize the difference.

The danger here is that it might be entirely possible that development institutions, or development programs are in fact impoverishing people, but one would first have to distinguish between monolithic development and developments. This is a move that post-development is reluctant to make. The reader will recall that Rist (2009) has already shunned the idea that post-development should pay attention to development projects since its focus is on the entire development apparatus.

Finally, from an ANT perspective post-development makes the mistake of thinking that because poverty is constructed it must be untrue. What Latour has demonstrated in studies of laboratory science is that there is no place that relies to such a great degree on artifice as a laboratory. Latour's argument is that artificiality and objectivity go hand in hand. Latour writes,

Even more so than in art, architecture, and engineering, science offered the most extreme cases of complete artificiality and complete objectivity moving in parallel. There could be no question that laboratories, particle accelerators, telescopes, national statistics, satellites arrays, giant computers, and specimen collections were artificial places the history of which could be documented in the same way as for buildings, computer chips, and locomotives. And yet there was not the slightest doubt that the products of those artificial and costly sites were the most ascertained, objective, and certified results ever obtained by collective human ingenuity (2005, p.89).

Thus if one is to consider poverty as a construct, one cannot look at the effect that development has on the reality of poverty, rather one can only ever look from one case to 
the next, and ask the question, did this development institution create this poverty? Actor-network theory would suggest that by asking this question and pursuing answers following an ANT methodology, the answers would be telling. The ANT scholar should be able to look at any situation where poverty is used as an important construct and ask whether or not the development agency constructing this particular notion of poverty has done it well or poorly? While ANT is relativist and agnostic when it comes to saying what is a priori in the world, it is not so relativist as to believe that one can simply make things up.

Additionally, Pieterse makes the case that "poverty is not simply a deficit, for that is simply to adopt the commodity-based perspective of the north; 'poverty' can also be a resource" (Pieterse 2011, p.125). By making a poverty a 'resource' Pieterse is suggesting that this can be done by attributing agency to the poor and he points to the work of Robert Chambers and human scale development, Paulo Friere's conscientization, as well as participatory action research and what he calls the actor-oriented approach (ibid, p.125). It should be said, however, that agency is not simply something that can be given or taken away, either it is a feature of the landscape of reality or its not. ANT moves well beyond the simple attribution of agency and instead provides a philosophically, metaphysically, and theoretically based set of reasons for doing so. For post-development, the absence of agency is simply a feature of a world ruled by discourse and social construction. And this last brings us back to an earlier point, post-structuralism is not necessarily antistructuralism but rather a kind of corrective to it. 


\section{Westernization}

Wolfgang Sachs, one of the leading lights of post-development explains that

The philosophy underlying the UN Declaration makes little sense without the view of history as the royal road to progress upon which all peoples converge The conception of achieving 'one world' by stimulating progress everywhere betrays the evolutionary bias. It inevitably calls for absorbing the differences in the world into an ahistorical a delocalized universalism of European origin. The unity of the world is realized through its Westernization. By the mid 20th century the term 'underdeveloped' had taken the place of 'savages'. Economic performance had replaced reason as the measure of man. However, the arrangement of concepts remains the same - the world society ahs to be achieved through the improvement of the backward (Sachs 1999).

It is remarkable in some respects, how much the world has changed from 1993 when Sachs first published The Development Dictionary from which the above quote is taken.

Reading just about any development proposal today, one gets very little sense that there is a program of Westernization. As Pieterse says,

This view is as old as the critique of modernization theory. It calls to mind the momentum and pathos of decolonization, the arguments against cultural imperialism, Coca-Colonization, McDonaldization, Disneyfication.... The cultural homogenization thesis according to which western media, advertising and consumerism induce cultural uniformity. All this may be satisfying, like the sound of a familiar tune, but it is also one sided and old-fashioned (2011, p. 132).

Besides being 'old-fashioned' there are good philosophical reasons for problematizing, though not rejecting, this thesis. The main reason comes back to the question of agency and the ability of people to resist. Another objection is that, as Pieterse notes, "westernization is a lumping concept that ignores diverse historical currents" (ibid, p. 134). Other post-development authors like Latouche, however, maintain, "the Other is integrated into the West only to the extent that the former is represented by the image of 
the latter" (Ziai 2007, p.68). The extent to which such a view removes agency is

remarkable. As Sande Lie (2008) remarks,

post-development portrays development as a monolithic and hegemonic discourse that constructs rather than solves the problems it purports to address. Yet postdevelopment itself becomes guilty of creating an analysis that loses sight of individuals and agency, being fundamental to its development critique (2008, p.118).

For McKinnon (2008) this lack of focus on agency is a result of post-development's intellectual commitment to the Foucauldian notion of governmentality. McKinnon writes, "The focus, in other words, is on structure over agency - on the discourses that shape our becoming subjects, rather than how subjects might shape the discourses" (2008). For Kiely, "Post-development theory is guilty of homogenising the idea of development, thereby conflating all theories of development with the outmoded (and long discredited) theory of modernization (1999, p.30).

An ANT approach to the question of westernization would be to treat it as an empirical case. It may well be that certain institutions or powerful western actors still think in terms of westernization. ANT, however, would replace the terms of the inquiry with actual actors and attempt to multiply the actors. Who is westernizing? What does it look like in practice? How is it done?

\section{The Critique of Modernity}

Post-development's critique of modernity is also a critique of western science, where science is representative of enlightenment thinking, positivism, and Cartesianism. Science is seen as quest for mastery over nature. Alvares (1999) writes

from this side of the Suez... modern science appears akin to an imported brand of toothpaste. It contains elaborate promises and much sweetness and glamour. It 
can be used, is often used (many times pointlessly), yet can be dispensed with at any time precisely because it is still largely irrelevant to life (p.219).

The reason that, for Alvares, toothpaste can be dispensed with is that he has other endogenous means for cleaning his teeth. But this is a point that ANT would agree with. Science and Modernity have in some sense worked against the common people. Modernity has done so, in Latour's estimation, by constructing a divide between nature and society, leaving nature and her hard facts to one side, and society and its soft interpretations to the other and then using science and often development as a mediator between the two. Except there is little to be done when one side holds the facts and the other holds nothing. According to Alvarez, science devalued people's epistemological rights. Alvares writes, "once the ordinary people's epistemological rights were devalued, the state could proceed to use allegedly scientific criteria to supplant such rights with officially sponsored and defined perceptions and needs" (p.231). Science has been able to do this because it has abrogated the rights of citizens and taken unto itself the right to provide valid accounts of nature and her facts. But for post-development there is still a gap between nature and society, but there are multiple ways to cross the gap. Indigenous cultures can cross the gap. In this sense then, post-development preserves a very modernist view of the relation between nature and society.

Another way to view the critique of the use of science in development would be to look at it from Latour's perspective regarding the relationship between matters of fact and matters of concern. Latour explains that

Matters of fact do not describe what sort of agencies are populating the world any better than the words 'social', 'symbolic', and 'discursive' describe what is a human actor and the aliens overtaking it. This is no wonder since 'Society' and 
'Nature' do not describe domains of reality, but are two collectors that were invented together, largely for polemical reasons, in the 17th century (p.110).

From an ANT perspective facts, such as they are, must be socialized before they can before they can be brought into the collective. The problematization of facts renders them instead as matters of concern. Latour explains

The discussion begins to shift for good when one introduces not matters of fact, but what I now call matters of concern. While highly uncertain and loudly disputed, these real, objective, atypical and, above all, interesting agencies are taken not exactly as object but rather as gatherings (ibid, p.114).

What Latour means by this is that in order for a collective to assimilate a matter of fact it must first be rendered as a matter of concern which makes the question of assimilation a political question and politics from Latour's perspective is always about gathering the right people (i.e. stakeholders) together with the thing that can unite or divide them and within this gathering pose the question: what is to be done. This is something that development in general has been very bad at doing. The opposite of Latour's gathering is the simple assertion of a matter of fact which can only ever serve to short-circuit politics and bring an end to discussion. Thus, the two positions are generally in agreement though they differ on the status of modernity.

\section{Discourse Analysis}

There is much that can be criticized in development discourse. Ferguson's (1990) study of Lesotho might also be a study in how a development institution poorly represents the reality of a place. Additionally, Mitchell's (2002) magisterial volume concerning Egypt and the "object of development" (p.209) is another example of a development institution describing Egypt via a set of reductionist dimensions. Mitchell writes that "Objects of analysis do not occur as natural phenomena, but are partly formed 
by the discourse that describes them. The more natural the object appears, the less obvious this discursive manufacture will be" (ibid, p.230). The problem for Mitchell was not so much the description of Egypt but the way in which the World Bank and USAID absented itself from the Egyptian scene it describes. And yet, the US and the World Bank had been intimately involved with the Egyptian economy.

Mitchell's understanding of discourse is, however, not the same as his supposed colleagues in post-development; indeed Mitchell began his book on Egypt by granting mosquitoes agency in the tale of Egypt's "most powerful transformations of the twentieth century" (p.21). Pieterse includes Mitchell as part of the post-development school, but in reading Mitchell one comes away with the sense that Mitchell sees discourse as one of the actors on stage, but not by any means the only actor. For postdevelopment, however, discourse is the only actor. Pieterse explains that "Discourse analysis applied to development is the methodological basis of post-development" and Pieterse remarks that this is not unique to post-development, but he goes on to say "what is distinctive for post-development is that from a methodology, discourse analysis has been turned into an ideological platform" (Pieterse 2011, p.115). Kiely (1999) argues Post-development theory also suffers from methodological inconsistencies. In particular, its almost exclusive focus on discourse leads to ambiguities in its account of the agents of development, and its anti-essentialism is highly selective. In terms of the former, like all discourse analysis there is a certain ambivalence over the question of power (p.36).

Pieterse argues that Escobar's view of development "provides a broad and uneven mélange with exaggerated claims sustained by weak examples" (p. 115). According to Pieterse, Escobar achieves breadth by his ability to combine the vocabularies of development, poststructuralism, and social movement theory but, as Pieterse sees it, his 
approach is uneven since his "argument centres on anti-development but makes no clear distinction between anti-development and alternative development" which leads Pieterse to conclude that Escobar's view of development is "exaggerated in that his position hinges on a discursive trick, a rhetorical ploy of equating development with 'Development'” (p.116).

\section{Actor Network Theory - a Brief History}

Actor-network theory (ANT) has its beginning in Bruno Latour and Steve Woolgar's anthropological study (1979) of the Salk Institute. Thus its origins and the bulk of its practitioners are still firmly rooted in The Study of Science and Technology (STS) (Law 1992; Bijker and Law 1994; Latour 1987; Law and Singleton 2000; Brenna, Law, et al, 1998; Akrich and Latour 1992; Cussins 1998; Michael 1998; Suchman 2000; Ashmore 1993; Brown 1998; Anderson 1994; Berg 1997; Dugdale 1999; Mol 2001; Engstrom and Escalante 1994;). Outside of the STS group there have been ANT studies of politics (Barry 2001; Bloomfield and Vurdubakis 1994); development (deLaet and Mol 2000); organizations and work (Cooper 1992; Cooper and Law 1995; Gherardi and Nicolini 2000; Kaghan and Phillips 1998; Latour 1996; Star 1992); Gender (Berg 1996;) and economics (Callon 1998a; Callon 1998b; Callon 1999; Callon 2001); information science (IS) (Bloomfield 1991); Thus its clear that ANT can and has been applied in number of different areas, but all of them, perhaps with the exception of Callon's work in economics, tend to focus on either science or technology. In some ways then, ANT is somewhat innovative for traditional sociological fields. 


\section{We have never been modern}

The philosophical foundation of ANT comes from Latour's break from modernity in his work We Have Never Been Modern, first published in France in 1991. Harman (2009) makes the argument that "Latour advances the most powerful definition of modernism..."(p.57). Modernity cuts the world into two pieces, two halves that are completely opposed. On one side exists Nature or the external world and it is composed of hard facts. On the other side is Society and its subjectivities. Harman explains that this side, "the human sphere, [is] composed of transparent freedom and ruled by arbitrary and incommensurable perspectives" $(2009$, p.57). This act of cleaving the world in two is, according to Latour, an attempt to purify the world. Latour claims that the moderns "have cut the Gordian knot with a well honed sword. The shaft is broken: on the left, they have put knowledge of things; on the right, power and human politics" (1993, p.3).

Latour locates the cutting of the Gordian knot in the seventeenth century controversy between Robert Boyle and Thomas Hobbes over an air pump. In their study of this controversy the authors Shapin and Schaffer (1985) suggest that "solutions to the problem of knowledge are solutions to the problem of social order" (p.332). Essentially the debate over the air pump has Boyle arguing on behalf of science for the resolution of disputes and Hobbes arguing for power of society. Harman explains "When these historians conclude that 'Hobbes was right' to grant victory to the power of society over the reality of nature, Latour counters bluntly: 'No, Hobbes was wrong' (p.26). Latour's argument is that although Shapin and Schaffer had offered a "masterful deconstruction of he evolution, diffusion and popularization of the air pump. Why then do they not deconstruct the evolution, diffusion and popularization of 'power' or 'force'? Is 'force' 
less problematic than the air's spring? (p.27). The answer to why in this case

demonstrates the great difference between Latour's sense of constructivism and Simon

and Schaffer. Latour (1993) says

trained in the framework of the social study of sciences, they seem to accept the limitations imposed by the Edinburgh school: if all questions of epistemology are questions of social order, this is because, when all is said and done, the social context contains as one of its subsets the definition of what counts as good science (p.157).

The Edinburgh School, sometimes referred to as the 'Strong Programme,' is organized around the application of social constructivism to the explanation of science and technology. Hacking (1999) asks "Why is the Edinburgh school said to favor social construction? Because instead of reasons for belief, it offers social explanations for belief” (p.90). Latour explains

In other words, 'constructivism' should not be confused with 'social constructivism.' When we say that a fact is constructed, we simply mean that we account for the solid objective reality by mobilizing various entities whose assemblage could fail; 'social constructivism' means, on the other hand, that we replace what this reality is made of with some other stuff, the social in which it is 'really' built. An account about the heterogeneous genesis of a building is substituted by another one dealing with the homogeneous social matter in which it is built. To bring constructivism back to its feet, it's enough to see that once social means again association, the whole idea of a building made of social stuff vanishes. For any construction to take place, non-human entities have to play the major role and this is just what we wanted to say from the beginning with this rather innocuous word (2005, p.91).

What follows from the rejection of the modernist split is a multiplication of actors, or actants. Now that the world is united how does one account for action? Part of the answer to this question is implied in the reunification of subjects and objects. It's not they are now indissolubly joined together but rather that they had never been separated 
and thus there are no positions of privilege to occupy. The human is set down along side the object, the plant, the canal, the automobile, the road, etc. What counts in this version of the world is the ability to leave a trace or resist a trial. In brief, actants act - and an act must register.

\section{Relativism and Agnosticism}

The world is not divided between facts and values. Nature and Society are not given in the order of things but must be constructed. The material for construction is not the social but rather the social is what results from our construction. The material for construction can be anything, even actual bricks and mortar, but it cannot be 'the social'. The implications here are brought to the fore by Ritzer's elaboration of ANT's three methodological principles (1993) and these are agnosticism, generalized symmetry, and free association (2004 p.2). The reader will recall the discussion of these principles in Chapter two. Since the principle of free association relates to the overturning of the modernist divide of nature and society the first two principles actually follow from the third. Since there is no clear division between objects and subjects ANT proceeds with caution in its researches. Agnosticism refers to ANT's ontologically relativist but empirically realist stance. ANT refuses to decide beforehand, as a methodological principle, which things populate the world. Also, in regard now to the second principle of generalized symmetry, this refers to the idea that ANT does not exclude objects. Thus objects are included in ANT research accounts.

\section{Articulation and Propositions}

Harman believes that Latour is "probably the first thinker in history to invent a local option for occasional cause - one not passing through God (as in al-Ash'ari, 
Malebranche, and even Whitehead) or the human mind" (Harman 2009, p.82). In

Latour's cosmology every actor becomes a potential mediator. This notion of

occasionalism is closely related to the twin notions of articulation and propositions.

Latour explains that

What I have been groping toward... is an alternative to the model of statements that posits a world 'out there' which language tries to reach through correspondence across the yawning gap separating the two.... If my solution appears wooly, readers should remember that I am attempting to redistribute the capacity of speech between humans and nonhumans... they should also remember that we have abandoned as largely illusory, the demarcation between ontological and epistemological questions.... I'd like to establish an entirely different model for the relations between humans and nonhumans by borrowing a term from Alfred North Whitehead, the notion of propositions... Propositions are not statements, or things, or any sort of intermediary between the two. They are, first of all, actants... What distinguishes propositions from one another is not a single vertical abyss between words and the world but the many differences between them, without anyone knowing in advance if these differences are big or small, provisional or definitive, reducible or irreducible.... This is precisely what the word 'pro-positions' suggests. They are not positions, things, substances, or essences pertaining to a nature made up of mute objects facing a talkative human mind, but occasions given to different entities to enter into contact. These occasions for interaction allow the entities to modify their definitions over the course of an event...(Latour 1999, p.141).

Furthermore, Latour argues that the "relation established between propositions is not that of a correspondence across a yawning gap, but what [he] call[s] articulation (ibid, p.142). What cannot be overemphasized, however, is the potentially great amount of work that is implied in the articulation of any proposition. This work is multiplied by the fact that the worlds we occupy are inhabited not with faithful intermediaries who do our bidding, but mediators with their own goals and programs who must translate our goals as we translate theirs. There is thus tremendous room for surprise and very little for absolute mastery. Every move is a negotiation. One example from the research is a home in Central Asia 
that straddles the border between two countries. Running through the yard of the home and out the door, across the street and into the neighboring country are concrete fence posts that have iron bars bent in the shape of hooks that could accept barbed wire of some variety. At the moment there is no wire, only the posts. These posts are also a proposition. Change any element in the above description and one gets a new proposition. Adding razor wire to the posts running through the woman's front yard is a fundamentally different proposition than the previous one. ANT, however, is tricky. The words on the page are also a proposition involving the researcher, his computer, and a software program. Add to this proposition an attentive reader interested in critique, then one has yet another proposition. Each articulation is also a translation. The point here is not to be ridiculous, but rather to be thorough. The reader will recall that translation refers to "all the displacements through other actors whose mediation is indispensible for any action to occur. In place of a rigid opposition between context and content, chains of translation refer to the work through which actors modify, displace, and translate their various and contradictory interests" (ibid, p.131).

\section{Circulating Reference}

One point that needs to be made directly is that ANT is not a theory of the special case. That is, ANT does not rely on either science or technology in order to be effective. It is the contention here that ANT is applicable to a wide range of research situations where the most interesting technology is a computer used to write documents. Documents are pretty easy to overlook in terms of thinking about them as technologies, and of course they are technologies, but they are also ubiquitous and mundane. One of 
the more interesting ideas in Latour's work is the idea of a circulating reference. The notion tracks quite closely to the ANT imperative of following the actors.

Earlier in his career, Latour was asked to follow a team of soil scientists into the Amazon rain forest to a place where the rainforest meets the savanna. The question that the soil scientists are attempting to answer is simple: is the forest retreating or advancing? It's a simple enough question but its answer will be far from simple and draws our attention to the myriad ways in which the only way to answer a question is to enlist the support of a number of different devices, techniques, or technology. This is a case study in the relationship between artifice and objectivity, but it is also a case study in the limitations of knowledge. Latour tells us, in regard to the research question,

this is the question that interests Armand; this is why he has come from so far away. Edileusa believes the forest is advancing, but she cannot be certain because the botanical evidence is confused: the same tree may be playing either of two contradictory roles, scout or rear guard. For Armand, the pedologist, at first glance it is the savanna that must be eating up the forest little by little, degrading the clay soil necessary for healthy trees into a sandy soil in which only grass and small shrubs can survive. If all her knowledge as a botanist makes Edileusa side with the forest, all his knowledge of pedology makes Armand lean toward the savanna. Soil goes from clay to sand, not from sand to clay-everyone knows that. Soil cannot avoid degradation; if the laws of pedology do not make this clear, then the laws of thermodynamics should (1999 p.27).

To accomplish her task Edileusa must divide the forest/savanna boundary into units that will help her to recall where she has been. Thus she divides the boundary into a set of grid coordinates that each have their own number designation. The numbers will help her to keep track of what is happening in each grid and she can then transfer that information to her notebook. Latour notes that both scientists in his narrative need the boundary divided into grids in order to be able to gather data. Edileusa sets herself to the task of 
gathering plants that fit her taxonomic scheme, and each plant she picks has thousand of others that remain unpicked. The pedologist on the other hand is taking soil samples and comparing their color to a standard color chart and entering his data into his own notebooks. Each scientist has dozens of such experiments to perform and data to enter.

For Latour, what these two scientists are doing as they translate the forest/savanna into data is building a chain. Latour explains,

At every stage we have recognized a common operator, which belongs to matter at one end, to form at the other, and which is separated by a gap that no resemblance could fill. The operators are linked in a series that passes across the difference between things and words, and that redistributes these two obsolete fixtures of the philosophy of language: the earth becomes a cardboard cube, words become paper, colors become numbers, and so forth. An essential property of the chain is that remain reversible. The succession of stages must be traceable, allowing for travel in both directions. If the chain is interrupted at any point, it ceases to transport truth - ceases, that is, to produce, to construct, to trace, and to conduct it. The word "reference" designates the quality of the chain in its entirety, and no longer adequatio rei et intellectus. Truth-value circulates here like electricity through a wire, so long as the circuit is not interrupted (ibid, 1999 p.69).

Another feature of this "chain of elements" is that it has no end and no beginning. The transformation, or translation from the wild forest/savanna, to a demarcated research site, and then to the various transformation of field data that are compared against charts and taxonomies, or measured with various equipment and the results recorded are all part of a chain of translations that may later be reduced into the form of a report. Latour explains

From forest to expedition report, we have consistently re-represented the forestsavanna transition as if drawing two isosceles triangles covering each other in reverse. stage by stage, we lost locality, particularity, materiality, multiplicity, and continuity, such that, in the end, there was scarcely anything left but a few leaves of paper. Let us give the name reduction to the first triangle, whose tip is all that finally counts. But at each stage we have not only reduced, we have also gained or regained, since, with the same work of re-representation, we have been able to obtain much greater compatibility, standardization, text, calculation, circulation, 
and relative universality, such that by the end, inside the field report, we hold not only all of Boa Vista (to which we can return), but also the explanation of its dynamic. We have been able, at every stage, to extend our link with alreadyestablished practical knowledge... let us call the second triangle, which the tiny transect of Boa Vista has been endowed with a vast a and powerful basis amplification (ibid, p.71).

Latour argues that philosophy has mistakenly wanted to make phenomena the point of intersection between though categories and things-in-themselves. Rather than being the "meeting point" Latour argues that "phenomena are what circulates all along the reversible chain of transformations, at each step losing some properties to gain others that render them compatible with already-established centers of calculation" (pp.71-72). Thus what starts on the left hand side is the world and all of its complexity, and through successive translations a proposition, such as a research report might be articulated, that report represents all of the elements on the right hand side but it can also become enrolled in another program at which point it becomes another element on the left. It is in this way that accounts travel between sites. 


\section{Chapter Four - An introduction to Central Asia, Mercy Corps, and the Peaceful Communities Initiative}

\section{Central Asia: a Brief Overview}

From Peter Hopkirk's (1994) The Great Game to Colin Thurbon's (2004)

travelogue: The Lost Heart of Asia, or Pauline Jones Luong's (2004) edited volume, The Transformation of Central Asia this vast expanse of land sandwiched between Russia, China, and Afghanistan is invariably represented as either exotic and dangerous (Thubron 1994) or in a state of flux (Luong 2004). Central Asia has long been seen as a kind of chess piece in a proxy battle between great powers in the more distant past of Hopkirk's 'great game' (1994) when Russia and Great Britain fought for supremacy in Central Asia and control over India and its riches, as well as more recently in the so called "New Great Game" described by Lutz Kleveman (2003) as a pitched battle between the U.S. Russia, and China over energy resources. Kleveman describes this new great game as "the last oil rush in world history", a prospect that has "evoked a sense of euphoria" from the energy ministries of Western, industrialized nations" (p.4). Even scholars of Central Asia like Sahadeo and Zanca (2007) describe it as "a land of great promise and peril" (p.1).

There is in the literature surrounding Central Asia no mistaking the heavy reliance by scholars, journalists, and others containing this common trope that Thompson and Heathershaw (2005) refer to as a "discourse of danger" (p.1). Indeed, the academic journal Central Asian Survey published a special issue in March 2005 called Discourses of Danger in Central Asia (2005). The special issue was published just two months 
before Uzbek forces would massacre civilians in the Ferghana Valley town of Andijan (Human Rights Watch 2005). While the 'discourse of danger' trope has been applied to all of Central Asia ${ }^{22}$ it is perhaps in the Ferghana Valley where all of the elements plaguing Central Asia are forced together into one volatile place. Three of the poorest former Soviet nations, Kyrgyzstan, Tajikistan, and Uzbekistan share an uneasy peace in this poorly divided valley. As Reeves (2005) writes, "It has become commonplace, in a scholarly discourse dominated by accounts of Central Asia as the battle-ground of elemental forces and a focal point for 'civilizational clash', for the Ferghana Valley to be identified as the mythical epicenter of such contention. One gets the distinct sense that scholars like Reeves, Heathershaw, Thompson and others feel that the 'discourse of danger' trope is itself a dangerous and inaccurate representation of the Ferghana Valley. In their estimation the trope only serves as a kind of excuse to justify the involvement of Western interests in the private affairs of Central Asians. As Thompson and Heathershaw note,

Contrary to prevailing wisdom in the bourses of Europe and America, danger is good for business, at least when one's business is conflict, its possibilities and its prevention. While many will object to the crudity of such an assertion, 'danger' is a recurring trope in discussions of contemporary Central Asian politics, society and potentials, whether one is considering the rationale for NGO programmes, political developments, or academic research (2005; p.1. italics in original).

\footnotetext{
22 See for instance Dianne L. Smith’s (1996) paper, “Central Asia: A new Great Game?” United States Army War College, Strategic Studies Institute, available online at http://www.strategicstudiesinstitute.army.mil/pubs/display.cfm?pubID=117 accessed April 2011; or Rajan Nemon's (2003)"The New Great Game in Central Asia", Survival, 45:2, 2003, pp. 187-204; or Ahmed Rashid's book Jihad: the Rise of Militant Islam in Central Asia Yale University 2002; or Boris Rumer's edited volume (2002) Central Asia: a gathering storm? M.E. Sharpe New York 2002. There are dozens books, articles, and assorted papers that deal with the dangers of Central Asia.
} 
There is in this critique an important set of questions regarding theories of discourse and the way that language and documents are implicated in constructing reality. The important point about Central Asia, and specifically the Ferghana Valley, is that there has existed a fairly broad consensus regarding the dangers and the threats that the region poses to itself and others. However, in order to understand the implications for development and security it will first be important to understand a bit more about Central Asia and its history ${ }^{23}$ since the exit and eventual fall of the Soviet Union. For the purposes of this research the inquiry into the history of Central Asia and the Ferghana Valley will be limited to questions of identity, livelihoods, and conflict.

\section{Understanding Identity in Central Asia}

In order to understand what Roy (2000) refers to as The New Central Asia one must go back to the August 19, 1991 attempted coup in the USSR which threatened the rule of Mikhail Gorbachev. According to Roy "most of the leaders of the Muslim Soviet republics promptly approved the putschists' actions" (p.vii). Several days later those same leaders would declare their independence from the Soviet Union. Thus began a series of projects in the creation of nationalism as "competitions were organized for the writing of national anthems and the design of national emblems (p.vii). Leaders who had been integral parts of the Soviet nomenclature were transformed into demagogues propounding the virtues of nationalism. Roy describes how "in 1996, we saw the

\footnotetext{
23 There are many useful books for learning about the long history of Central Asia. Rafis Abazov's (2008) The Palgrave Concise Historical Atlas of Central Asia, New York and Beckwith, Christopher I. (2009). Empires of the Silk Road: A History of Central Eurasia from the Bronze Age to the Present. Princeton University Press are helpful starting places. For a review of the period of the Great Game there can be $n$ better starting place than Peter Hopkirk's (1994) The Great Game: The Struggle for Empire in Central Asia. Kodansha International, New York.
} 
seventy-year-old president of Azerbaijan, Haidar Aliyev, giving Moscow a hard time and upbraiding the only one of his ministers unable to express himself in Azeri. Was this not the same man who had been a former KGB officer, a member of the Soviet Politburo and the ruler of Soviet Azerbaijan for the best part of 18 years?" (p.vii). And so begins Olivier Roy's examination of the complexities of identity and politics in the former Soviet Republics. Roy asks one of the persistent questions that attended the sudden changes in Central Asia. Were these newly minted nationalists simply unrepentant communists who faced the realpolitik of the collapse of the Soviet Union with a kind of pragmatism, or was communism only ever able to drape a thin veil over a persistent traditional society that survived in spite of the modernizing power of the Soviet Union? The answer for Roy is that the Soviet Union in Central Asia had always acted as a kind of engine for the production of national identities. As Roy explains, "Soviet nationalities policy had been conceived first and foremost to break existing nationalisms.... To this end, a multitude of 'small' competing peoples was manufactured... thus nationalisms were brought into being where previously they had not existed" (p.viii). The purpose of this Soviet policy was not to create permanent or viable nation states but rather to "reduce them, along with all the others, to a purely administrative appearance, as a prelude to their fusion in the greater Soviet whole" (p.viii). Thus, borrowing the language of Deleuze and Guattari (1972) the Soviet Union acted as kind of deterritorializing machine that destroyed or in some cases enrolled or coopted existing identities in a project of reterritorialization. Old meanings of place and identity were given new meanings. The Soviets cut the Gordian knots of identity by producing new identities that could be more easily plugged into Soviet ideology and the logic of Soviet rule. However serious the 
Soviets were about creating new nationalities, and by all accounts they were quite serious, it was only ever meant as temporary part of a longer trajectory. The irony of the situation is obvious. The Soviets never managed to arrive at the point where the nations of Central Asia could be neatly brought into the fold of the Soviet people. In the meantime all of the Soviet efforts aimed at creating temporary nationalities took root in ways they had not imagined. Roy describes this as a habitus taking root. Roy explains that "this habitus took root not as an ideology but as a code, operating at several levels" (p.xiv). The situation that Roy describes is one where Soviet cultural technicians (my phrasing) working variously as linguists, ethnologists, and archaeologists managed to produce a code. Importantly for Roy, this code was not a national culture since it failed to produce much in the way of an intellectual body of work that could speak to the culture of its people. Roy gives the example that in this model 'translation has priority over literary production in the national language; ethnography... has priority over sociology" (p.xiv) since there was not yet a society but only a conglomeration of little rural cultures that had not yet been assimilated. Roy remarks that "the nationalist ideologues of the Europe of nations filled whole libraries with books in the national language, while the manufactures of nationalities in the Soviet era were content with just a few showcases (p.xiv). Thus for Roy "it is thus striking the extent to which the code, the form and the appearance have a reality effect equal to the far richer and more complex efforts of the nationalist ideologues of Europe in the nineteenth century and Turkey in the twentieth, as regards setting in place a national culture (p.xiv). This is part of the reason that it will be important to take seriously various claims of ethnicity and identity. Not because the thin descriptions of identity explain very much about people but 
precisely because they hide so much of the work that goes into making those simplifications possible. Roy explains, "what was stamped on the South was neither communism nor socialism but Sovietism: Sovietism is a form, and apparatus, a technique of power and an organisation of the social which is permanently out of step with the ideology on which it is supposedly based (p.xv).

What is important for this study is the lesson that identities and ethnicities in Central Asia have relatively long histories that are connected to place and livelihoods (via the kolkhozes or collective farms), and differentiated based on simplified notions of ethnic identity.

Madeline Reeves (2007) argues that we must not impose our own superstitions and simplifications of the world on a region that is essentially foreign to our simple, Western understanding of the world. In the popular imagination of the West, the fall of communism meant the elaboration of greater freedom, and thus it seems odd to us that independence from the Soviet Union, where travel was restricted, has meant less mobility rather than more for the residents of border regions such as the Zarafashon Valley of Tajikistan and the Ferghana Valley shared by Kyrgyzstan, Tajikistan, and Uzbekistan. The rather simple point that can be made about boundaries in Central Asia is that the seemingly arbitrariness of Stalin's borders became a lived reality once these three nations achieved independence. In order to secure their new national boundaries, these borders had to be performed in a way that gave them a reality they had never achieved in the Soviet era. In the Soviet era natural resources such as water and gas flowed across boundaries as if they did not exist. Energy and transportation networks were built as systems that provided energy and mobility to the Soviet state and thus crossed borders 
without regard. So while people may have been restricted in their movement, resources were less so. For Reeves the supporters of globalization fail to see the ways in which new freedoms have led to un-freedom. Reeves explains that

The collapse of communism has actually entailed a de facto decrease in mobility, whether through the vagaries of newly installed visa regimes, dramatic hikes in fuel prices, or the collapse of state-run transport systems. It has transformed travel within neighboring republics into a nervous attempt to avoid the document check (proverka). It has also meant that distant sites to which one formerly traveled as a citizen are now encountered in a different guise - as labor migrant, guest-worker... (2005 p.284).

Reeves says that "Nowhere is this more true than in Central Asia's Ferghana Valley" (p.284). While it is certainly true that Ferghana Valley is now a strange concatenation of not just borders, but border regimes - different systems of enforcing, performing, or otherwise governing the borders, that results, as Reeves points out, in particular kinds of demobilizations - it is not the only region to face this set of problems. The Ferghana Valley stands out because prior to disunification the region lived and operated as a single region whereas now it is not only three regions but also many more due to the strange persistence and existence of various national enclaves ${ }^{24}$ within the boundaries of foreign states. Border conditions like the ones Reeves and others describe are no less acute in other border areas they are simply concentrated into a large single area.

The Ferghana Valley forms the breadbasket of Central Asia. It is 22,000 square kilometers of arable, agricultural land bounded to the north, south, and east by the Tien Shan and Pamir Alay mountain ranges. This combination of fertile land and mountainous boundaries has created as Reeves explains a "highly populated ecological and cultural

\footnotetext{
24 Enclaves are essentially political islands of communities that are completely surrounded by the territory of a different state. Enclaves are one of the weird outcomes of Stalin's attempt to divide and conquer Central Asia by mapping out ethnic identities into the actual landscapes of Central Asia.
} 
zone. Inhabited by Uzbeks, Krygyzs, and Tajiks... the valley has historically been marked by a high degree of ethnic interdependence, with shared bazaars, trade routes, sacred sites, and canal systems, coupled with elaborate unofficial mechanisms for regulating water use between upstream and downstream communities" (p.284). Prior to the Soviet implementation of the "process of delimitation" (Koichiev quoted in EverettHeath 2003) in 1924 the valley was, according to Koichiev, "marked by extreme ethnic diversity" (p.46). Koichiev writes that "at the time of the Russian arrival, only the Sarts and Tajiks - and to a limited degree the Uzbeks - were sedentary people, and the controlled most of the valley floor" (p.47). The administrative division of the Ferghana Valley, initially between Kyrgyz and Uzbeks and eventually including the Tajiks ${ }^{25}$ as well, was always a difficult and contentious process as each side competed for land and resources. Reeves (2005) contends, however, that the process itself helped cement identities along ethnic lines (p.284).

The Sovietisation of Central Asia was, as Roy explains, the direct result of "the nationalities policy of the USSR" which had "three basic elements" (2000 p.62). Roy elaborates the three elements,

The first was a body of theory elaborated by Stalin on the basis of a notion of 'people' inherited from nineteenth-century anthropology and the Marxist vulgate, and systematized into what one can call the Soviet school of ethnography. The second was a system of administrative and political classification based on territorialisation and language status. The third was a real practice of dividing up populations and territories on the basis of political and strategic logic which had little to do with the above two principles, but which had to be expressed in their terminology (p.62 my emphasis).

\footnotetext{
25 Tajikistan would not be separated from Uzbeksitan and made into Soviet Republic in its own right until a few years later in 1929. Two of the more contentious moves involved first, giving Tajikistan the city of Leninabad (present day Khujand) in order to make the country more economically viable, and giving Uzbekistan the largely Tajik city of Samarkand (Roy 2000; 61). Ask almost any Tajik today and they will still express some degree of resentment against the Uzbeks for having stolen Samarkand.
} 
Roy explains that this process of creating nations based on ethnographic, administrative systems that were informed by the logic of Soviet politics and strategy would have three main consequences: The first consequence confirms what Reeves has already pointed out, that Soviet policy of territorial delimitation reinforced ethnic homogenization among the nations of Central Asia. Uzbekistan would be predominantly Uzbek, Kazakhstan would become mostly Kazakh, Tajikistan mostly Tajik, and so forth (Roy 2000; p.84). Roy cites figures from the 1989 census which show that " 80.3 percent of Kazakhs lived in Kazakhstan, 88 percent of Kyrgyz in Kyrgyzstan, 93.3 percent of Turkmens in Turkmenistan, 84.6 percent of Uzbeks in Uzbekistan and 75.1 percent of Tajiks in Tajikistan" (p.84).

The second outcome of this process is, as Roy notes, "that the societies of Central Asia are mainly rural, and therefore the mechanics of politics cannot be understood without looking at their roots in the kolkhoz (p.84). The impact of this reliance and dependence on old structures of rule are still felt in many rural communities today. The case of Ziddi and Mingdona in the Penjikent Raion ${ }^{26}$ of Tajikistan, which are dealt with in a later chapter of this study, will prove to be instructive in this regard. Reeves is largely correct in her analysis of the difficulties of daily life due to the border regimes of the three nations of the Ferghana Valley. However, her explanation that these difficulties are in due in some sense to what she calls "the Janus-face of globalism" rings hollow (Reeves 2007 p.297). One doesn't need to make a leap to the explanation of globalization for what has happened in Central Asia. Life is difficult because

\footnotetext{
${ }^{26}$ Tajikistan is divided into oblasts (provinces) that are further sub-divided into districts (Raion), municipalities (Jamoats), and villages which are further subdivided into neighborhoods (muhallas). The Hukumats are the political/administrative bodies that govern at the Jamoat level.
} 
independence and the administrative practices that are part and parcel of performing nationhood also involve performing the borders as well. Stalin's lines on the map were less meaningful and lacked reality as long as the Soviet Union continued to function. The moment that the Soviet Union failed and independence was in some way forced on the republics of Central Asia, those boundaries began quite literally gaining reality. As they did life could only become more difficult for those whose daily lives involve those borders.

In Osh, Kyrgyzstan I spoke with lawyers from the NGO Lawyers Without Borders $^{27}$ about the difficulties of crossing the border. The lawyers explained the costs involved for a Kyrgyz to get an Uzbek visa,

Yes of course, for example how can you obtain an Uzbek visa? For one month it is 4 dollars, for 6 months its 6 dollars, and for the one year its only 20 dollars... but for example people who live in Osh in order to obtain the visa they have to go to... Bishkek because the Uzbek embassy is only in Bishkek. We have done some research [and] we found out that in order to get the visa for 20 dollars you have to pay more than 100 dollars for it, because you have transport expenses, you have to live in Bishkek for 15 days waiting for them to make a decision, and the final cost of the visa will be more than 100 dollars. And of course nobody goes to the Bishkek... everybody crosses the borders and go to Tashkent without any visa, this is our reality, people cross the borders and go to Ferghana, Namangan, but they don't have visas but they must according to Uzbek law... the visa regime it doesn't work (Kanybek, Personal Interview August 2006).

I spoke casually with one woman in the Ferghana Valley along the Kyrgyz/Uzbek border whose property was divided between the two nations. When I asked her if I could record our interview she became very nervous and refused, but she seemed happy to talk with me person to person. Her nervousness is instructive as is her living situation. At the

\footnotetext{
${ }^{27}$ The Ferghana Valley Lawyers Without Borders (FVLWB) is an NGO with partners in all three of the republics in the Ferghana Valley and has a membership of approximately 30 judges, prosecutors, advocates, and law professors in all three nations. Established in 2003 their "mission is to prevent conflict in the Ferfghana Valley by protecting the rights and interests of citizens of Uzbekistan, Kyrgyzstan, and Tajikistan" (Kanybek personal interview August 2006).
} 
moment of our conversation the border was represented by a series of concrete posts with iron hooks for hanging barbed wire. The posts were bare on the day I was there, but the possibility that it might not always be the case, that the Uzbeks or Krygyzs could come and add wire to those posts, would represent a significant change in the daily lives of this woman and her family members (personal observation August 2006).

My own journeys between Tajikistan and Kyrgyzstan are also instructive. Due to tensions between the US government and the Government of Uzbekistan over the American military base and Uzbek sensitivity about Western interest in the events of May 2005, in Andijan, I was never able to obtain an Uzbek visa. In practical terms this meant that when I needed to travel by car from Khujand, Tajikistan to Osh, Kyrgyzstan I would have to avoid crossing the Uzbek border. Prior to independence the quickest route to Osh from Khujand would be to take the two-lane blacktop highway that was located predominantly in Uzbek territory. After independence, and without an Uzbek visa I was forced to take what is called the black route (chorni darogi) that was an occasionally paved, occasionally unpaved road that is apparently the preferred route taken by smugglers and outlaws. Indeed there were a number of military checkpoints along the route. I am told that driving between Khujand and Osh on the Uzbek highway takes approximately four hours. My journey took at least 8 hours and very often as we made our way through the difficult unpaved sections we could actually see the Uzbek highway on the other side of the border (personal observation August 2006).

What is remarkable about the border between Uzbekistan and Krygyzstan is that in some places it simply does not exist. In spite of my not having a passport I often unknowingly entered Uzbek territory on a number of different occasions. On my final 
visit to Osh, Krygyzstan my PCI guides would often point out that, at this point or that point, the Uzbeks had decided to control the border at a point further into their own territory. The border served as a kind of constant reminder of the costs of making something real. To make the border real required the posting of border guards, guns, checkpoints, administrative systems, passport control, etc. In some ways these unmanned border areas are truly liminal spaces existing as a kind of living example of Schroedinger's cat both existing and not existing, gaining reality by the intervention of men, documents, and administrative systems, and losing that reality as those things are withdrawn from view.

\section{Mercy Corps}

It should be foregrounded that my own fate has been intertwined with Mercy Corps for some time. My wife, Brandy Westerman, is presently the Country Director for Mercy Corps Tajikistan. She has worked for the organization since 1999. I have also worked for Mercy Corps on and off over the years in various capacities. In 2003 Brandy and I were living in Islamabad, Pakistan for my wife's first overseas posting with Mercy Corps. I was on leave from graduate school and ended up taking a job with Mercy Corps in Kandahar, Afghanistan helping to manage a DFID (United Kingdom's Department for International Development) community development project in the Helmand Valley. Later I would work with Mercy Corps' GEO Team (Global Emergency Operations) in the Northwest of Pakistan in 2005 as part of their effort to respond to the earthquake disaster in that region. I have also worked at Mercy Corps HQ in Portland Oregon as a temporary desk officer for programs in the Balkans. When my wife, Brandy Westerman, began working with Mercy Corps, before we were married, she started in 1999 as the 
receptionist and has since worked her way up the level of director. Brandy was instrumental in securing funding for the PCI program and made several trips to the region during the period of the program's infancy. She helped plan the program and she was one of the unnamed authors of the field study that would become critical in securing funds for the project.

According to their mission statement, "Mercy Corps exists to alleviate suffering, poverty and oppression by helping people build secure, productive and just communities $^{28} . "$ The organization is fairly explicit in terms of both its interest in economics and justice. Mercy Corps was originally founded as Save the Refugees Fund in 1979 and operated as a kind of task force to respond to the "plight of Cambodian refugees fleeing the famine, war, and genocide of the 'killing fields ${ }^{29}$ ". At that time the organization was called the Save the Refugees Fund and had been organized by founder Dan O'Neill. The Save the Refugee Fund became Mercy Corps in 1980 after Dan met Els Culver while they both attended a relief and development conference. Dan recalls "I looked behind me and saw a very elegant looking man with reading glasses, wearing a blue blazer, blue pinstripe shirt and red tie... and I remember thinking 'this man must be a senator' he was very impressive $e^{30}$." Mercy Corps' website explains that the two men became friends and then discovered that they had shared a link. Els Culver was the vicepresident of an organization called Food for the Hungry that had been given grants from The Save the Refugee Fund. According to Mercy Corps' the two men shared a "much stronger bond - a commitment to provide more innovative, sustainable aid and

\footnotetext{
${ }^{28} \mathrm{http} / / / \mathrm{www}$. mercycorps.org/whoweare accessed April 11, 2011.

${ }^{29} \mathrm{http}: / /$ www.mercycorps.org/10638 accessed April 11, 2011.

${ }^{30} \mathrm{http}: / /$ www.mercycorps.org/10638 accessed April 11, 2011.
} 
development to poor communities - that united the two men in a singular purpose ${ }^{31}$. Els and Dan together went on to found Mercy Corps in 1982 with the goal of not only providing relieve but engaging in more long-term solutions for the problems of hunger and poverty. Mercy Corps first development project was located in Honduras. Since that time Mercy Corps has grown in both size and stature.

Today, Mercy Corps helps more than 16.7 million people each year recover from disasters, build stronger communities and find their own solutions to poverty. We have been an international leader in responding to the massive tragedy of the Indian Ocean tsunami, wars in Afghanistan and Iraq, food crisis in Niger, displacement in Congo and earthquakes from China to Haiti (ibid).

On the main page of the Mercy Corps home website visitors can click links that will tell the reader "who we are", "what we do", and "where we work". When one clicks on the 'who we are' tab the reader is taken to a page with the organization's mission statement and the option to view 7 more slides that provide the explanation for 'who we are'. I am not a media scholar or critic but my guess is that this is done pretty well. Each page has a short passage and a moving photograph. After the Mission statement comes "The People We Serve" the accompanied text reads,

No one is more motivated or better equipped to create change than the person whose life and future is at stake. We help communities catalyze the change they want to see. It is their potential, their energy, and their ideas that ultimately will turn crisis into opportunity (ibid).

With the accompanying text is a photograph of young boy in a school, to his side is a black board covered with what must be the day's lesson. Behind him the viewer can see daylight through the hand woven bamboo mat that is being used to shutter out the light from outside. The boy is wearing an Abercrombie \& Fitch sweatshirt over a white

\footnotetext{
${ }^{31} \mathrm{http} / / /$ www.mercycorps.org/10638 accessed April 11, 2011.
} 
collared polo shirt. The point is both obvious and effective and it's clear that the boy is wearing the best school clothes he has and that they have likely been donated. It is almost certain his family has never seen the inside of an Abercrombie and Fitch store. The boy does not, however, look needy; rather he looks ready to cheerfully take his place among the educated people of the world.

The next section the reader is led to is called: "The People of Mercy corps", the text reads, "Around the world, 95 percent of our team members are nationals of the countries where they work. Some are even former beneficiaries themselves. They personify our core belief in local solutions to local problems" (ibid). The photograph is of a Muslim woman with her head covered and she is gathered together with other women in a courtyard perhaps it is Afghanistan as some of these women have covered both their head and their faces. The message is clear; to work in difficult cultural contexts you need people who understand that context. The next section (4 of 8 ) is "Where We Work" the text reads,

Since 1979, Mercy Corps has provided \$1.7 billion in assistance to people in 107 nations. Our global programs are supported by headquarters in North America and Europe and field offices in some of the world's most troubled and challenging regions. Last year, we helped 19 million people in more than 36 countries turn crisis into opportunity (ibid).

In the photograph that accompanies the text there are 22 people standing in courtyard. They are obviously gathered together for a group photo. What is striking about the group is that they are such a mixed group of ethnicities and nationalities but the all exhibit the same kind of youthful professionalism. What is the message here? It seems to be that this mixed group of professionals is changing the world. Next up is slide (5 of 8) simply 
entitled "Our History" and the text reads "For 32 years, in the midst of economic collapse, political transitions, armed conflict, and natural disasters, Mercy Corps has been helping millions of individuals, families and communities turn crises into opportunities for sustainable, positive change" (ibid). The photograph here is of a group of young Chinese people, they look like students, gathered together in a public square and in the distance the viewer can see the Chinese flag. Once again the message seems clear and there is a strongly implied resonance with the events of Tiananmen Square. The picture is asking the viewer to remember another moment in the past where young Chinese gathered in a square. The other message is that Mercy Corps is ready and willing to work anywhere. And it is a truism that the organization does in fact seek out the most dangerous places on the planet.

The sixth slide reads "building back better" and is accompanied by the following text:

Where people are thrown into the chaos of war, economic collapse or natural disaster, Mercy Corps provides immediate, sustaining humanitarian assistance, always with the goal of hastening recovery. As the most urgent needs are met, we immediately move toward programming that pursues longer-term stability and prosperity (ibid).

I can attest from personal experience of working with the organization in the earthquake ravaged areas of Northwest Pakistan and the war torn region of Kandahar that the notion of moving quickly out of the relief phase and into long term development is a kind of mantra for the organization. In many ways, this is what the organization is known for, programming emergency relief with an eye towards the future livelihoods of those they are helping. The photograph that accompanies this slide is of an elderly East Asian 
woman stringing up and displaying dozens of fish. The message here also seems clear: livelihoods are important. It also seems clear the woman is an entrepreneur, perhaps catching her own fish and taking them to market. The economic lesson in the photograph is that Mercy Corps does not shy away from economic development but that it will focus that kind of development on individual livelihoods and also it will honor the entrepreneur.

The seventh slide is "innovating to reach millions" and the text reads "Mercy Corps believes that solving social problems in the developing world requires blending sustainable, entrepreneurial strategies with a deep knowledge of local culture and context" (ibid). The accompanying photo shows a group of African men huddled over computers in a classroom. These are not boys in this class room but men in their twenties. My strong suspicion is that these men are very likely veterans of civil war learning some new job skills. The eighth and last slide in the series is "Effective partners, Responsible Stewards" and the text reads, "Mercy Corps puts first the expressed needs of the people we serve, partnering to create durable solutions that make sense in the community context" (ibid). The photograph is of a group of dark skinned young boys, perhaps Indonesian, standing next to what appears to be a fully-grown field of rice. The notion of environmental stewardship is new to Mercy Corps and new to development organizations in general. The implied meaning is harder to interpret in this case. Mercy Corps could be thumbing its nose at environmentalist by juxtaposing the needs of the community with the notion of responsible stewardship. However, I don't believe that is the case. The reader must remember that for Mercy Corps, communities come first, everything else comes second. 


\section{Mercy Corps' Core Values}

One of the key documents for understanding Mercy Corps is their "Who We Are" paper. Mercy Corps writes, "This is a "living document" that is revised and updated as needed readers are encouraged to contact Mignon Mazique, Mercy Corps' organizational specialist at mmazique@mercycorps.org with comments or suggestions" (Mercy Corps 2010). Mercy Corps is an organization that certainly pays close and careful attention to its values and its mission. This evidenced by the existence of various publications like the "who we are" document, the study conducted by Sarah Wardell of the Vision for Change (Mercy Corps 2011) which is both a graphic that represents the organization's values and also a methodology for the design, monitoring, and evaluation of programs. Mercy Corps staff are expected to refer to this framework as a kind of check to compare existing programs against the "big picture" (Mercy Corps 2011). The Who We Are sets forth Mercy Corp's core values:

- We believe in the intrinsic value and dignity of human life.

- We are awed by human resilience, and believe in the ability of all people to thrive, not just exist.

- Our spiritual and humanitarian values compel us to act.

- We believe that all people have the right to live in peaceful communities and participate fully in the decisions that affect their lives.

- We believe that human imagination, goodness and energy can inspire innovative, entrepreneurial solutions to any problem, no matter how intractable.

- We value stewardship of the earth's health, pledging to accountably and efficiently preserve and manage its resources.

- We believe that it is our duty to be effective stewards of the financial resources entrusted to us (Mercy Corps 2011).

These are Mercy Corps' core values: the value and dignity of human life along with an appreciation for human resilience and their capacity to act. The belief that there is a moral imperative to act, and a belief not just in individual rights but the right to a 
peaceful community that involves meaningful participation and the capacity of humans to think and imagine solutions. Finally, Mercy Corps believes in both environmental and financial stewardship, which for them means allowing themselves to be held accountable in some way while embracing accountability as a core value.

Another key to understanding Mercy Corps' values is the emphasis they place on the capacities of those they help. As Mercy Corps writes, "we help... millions of people [who] are caught up in intolerable situations. But they are not today's victims; they are tomorrow's heroes who have the power to transform their own communities" (Mercy Corps 2011). This perspective stands in strong contrast to the images presented in the past by both NGOs and the American media, which has tended to treat poverty as the depiction of helplessness and a kind of abject victimhood ${ }^{32}$. Indeed when one views the photographs of people in Mercy Corps programs from around the world they do not seem helpless and they are certainly not depicted as victims but rather as fully capable human beings.

Finally, Mercy Corps defines its central methodology for working with poor communities in the so-called third-world. Mercy Corps writes,

In more than 25 years of experience on the ground, Mercy Corps has learned that communities recovering from war or social upheaval must be the agents of their own transformation for change to endure. Sustainable social change requires communities, governments and businesses to solve shared problems in a spirit of

\footnotetext{
${ }^{32}$ See for instance Susan D. Moeller's discussion of how the media portrays the third world in Compassion Fatigue: How the Media Sell Disease, Famine, War and Death (New York: Routledge, 1999); also much of post-development studies focuses on the way in which the poor are represented, see for instance The Development Dictionary (Sachs ed. 1992) which is essentially a compendium of misrepresentations. This is an area in which post-development scholars excel. Post-development tends to function fairly well when it offers what Latour (2005) would call panoramas, that is, a kind of big picture analysis of what happens when categories short circuit politics, the problem however, is that these same critiques tend to hobble future inquiry in exactly the same way, they short-circuit the scholarship of development, which is another form of politics.
} 
accountability and full participation. Secure, productive and just communities arise only when all three sectors work together in close cooperation (Mercy Corps 2010).

In Figure 2 below is a graphic of Mercy Corps' Civil Society mandala which is alternatively referred to as Mercy Corps' Vision for Change. Anna Young of Mercy Corps explains,

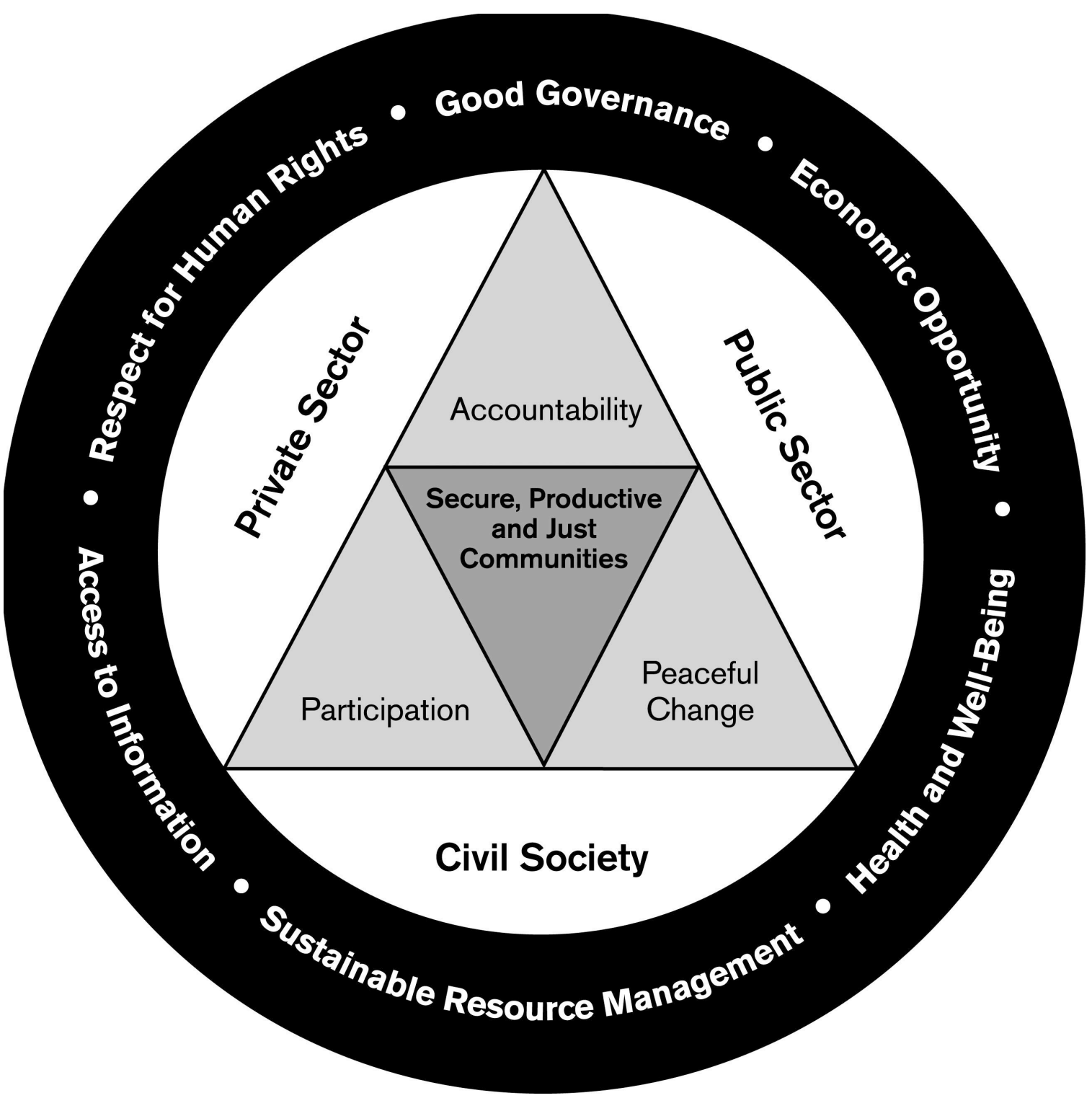

Figure 2 Mercy Corps' Civil Society Mandala 
The organization has managed its growth by creating the "Vision for Change", a framework designed to graphically represent the way in which key actors, operating principles, and external conditions interact in the service of the mission. The Vision for Change is intended to guide staff on how to carry out the Mercy Corps mission...(Mercy Corps 2011).

Mercy Corps believes that "when leaders are held accountable, when citizens participate meaningfully in the decisions affecting their lives and are equipped to negotiate change in a peaceful manner - poverty, violence and civil conflict are reduced" (Mercy Corps 2011 emphasis in original). Mercy Corp is not shy about mission nor is it shy about where it places its emphasis. "Secure productive and just communities" (2) are at the center of Mercy Corps' strategic vision. Anna Young explains that the current vision for change is rooted in the beginning of the organization. Young relates that in the early years, the organization "made a commitment to promoting peace and justice in the world, operating in regions of conflict from the Middle East to Afghanistan to Sudan" (p.3). When the current Executive Director, Neal Keny-Guyer first joined the organization in 1994 he made it his mission to help the organization define its institutional niche and began building a strategic vision for the future that was based on an elaboration of the structure of civil society. Mercy Corps writes,

Civil society was introduced as one of three historic program thrusts, alongside emergency relief interventions and sustainable development. By 1995, human rights had been integrated into a broader Mercy Corps vision, referred to as civil society. Later that year, Mercy Corps received an institutional strengthening grant from the United States Agency for International Development (USAID), Linking Civil Society and Sustainable Development. At this time, the Human Rights Desk was renamed the Civil Society Desk (ibid; p.2)

This brief overview of Mercy Corps' history and its commitment to civil society cannot really do justice to the organization. At best this brief review simply reinforces 
the fact that the organization has its ideological roots in notions of social justice and that its given this discursive commitment a life in the organization. Rather than being merely ideological the vision for change is incorporated into the work routines of the organization. The design of new programs must be written with the vision in mind and monitoring and evaluation must try to measure the extent to which the vision is being implemented.

\section{Evolution of the Civil Society Framework Visual Representations}

1995

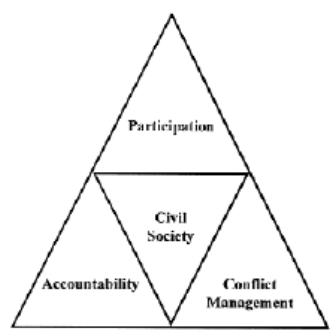

2000

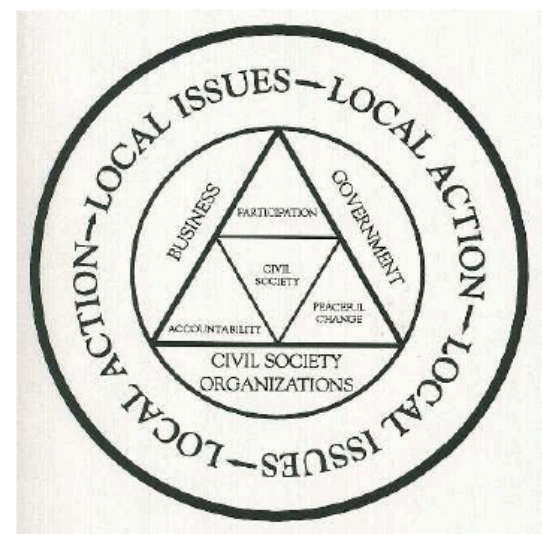

1998

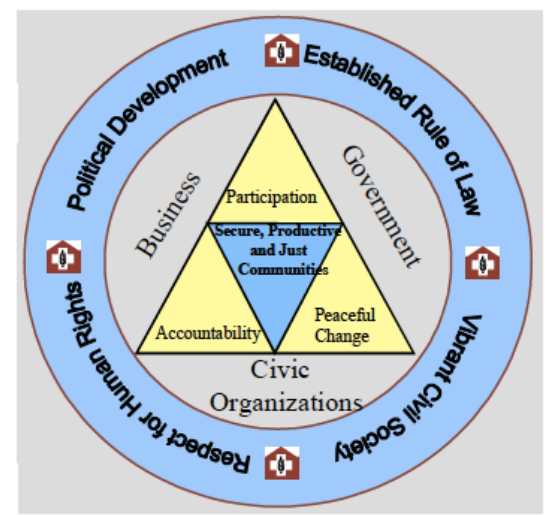

2002

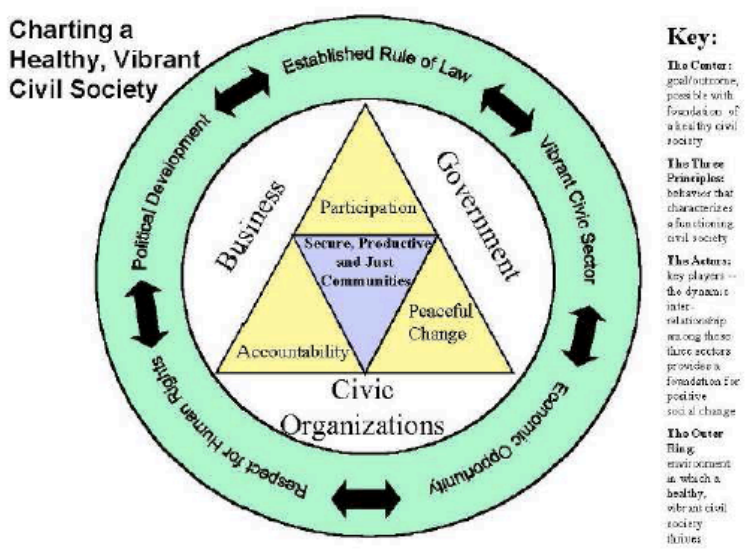




\section{The Mercy Corps' Timeline}

In many ways the history of Mercy Corps for the last 30 years is the history of natural disasters and man-made atrocities. The organization finds its beginnings in the 1979 killing fields of Cambodia. 1984 finds the organization responding the devastation of the famine in Ethiopia. 1984 is also the year Mercy Corps moves to Portland. In 1985 the world witnesses the Live Aid and Farm Aid concerts while Mercy Corps responds by delivering emergency food supplies to famine stricken Sudan and Ethiopia. 1993 would see the dismantling of Yugoslavia while Mercy Corps "provides critical assistance to 175,000 displaced people in war-torn Bosnia and Herzegovina, Kosovo and Croatia as Yugoslavia violently disintegrates" (http://www.mercycorps.org/timeline accessed on April 11, 2011). In 1998 hurricane Mitch devastated Honduras and Nicaragua. In the aftermath "Mercy Corps provides $\$ 3$ million worth of assistance to families in devastated areas of Honduras and Nicaragua" (ibid). 1999 brings the Kosovo/Macedonia refugee crisis that followed on the heels of the NATO bombing campaign in the former Yugoslavia. During the crisis "Mercy Corps delivers lifesaving food and vital household supplies to 250,000 people in besieged areas of Kosovo, while helping another 100,000 refugees in neighboring Macedonia (ibid). After the event of September 11th 2001 Mercy Corps would continue to work in Afghanistan. 2003 would bring the war in Iraq and in the aftermath of the initial conflict, "Mercy Corps rushes aid to thousands of internally displaced Iraqis, as well as Iraqi families who've fled to Jordan and Syria" (ibid). In 2004 the world witnesses the Indian Ocean tsunami that killed some 240,000 people. Mercy Corps was already working in Indonesia and was "one of the first on the ground in Indonesia's hard-hit Aceh Province, and launches programs ranging from 
cleanup to job recovery in the four of the countries most devastated by the tsunami:

Indonesia, Sri Lanka, India and Somalia” (ibid). In 2005 Mercy Corps would for the first time in its history respond to a domestic natural disaster: Hurricane Katrina,

Mercy Corps provides water, food, bedding and tools to communities along the Gulf Coast, as well as awarding grants to strained social-service nonprofits and neighborhood groups. Later, the agency promotes deconstruction of homes in New Orleans to preserve the city's unique culture, provide an environmentallyfriendly alternative to demolition, hasten rebuilding and create jobs.

2006 would find Mercy Corps responding to refugee crisis in Sudan. "Mercy Corps helps sustain 200,000 people in Darfur who've been displaced from their homes keeping camps clean, training health promoters, building and supplying schools, and providing skills training to women and other vulnerable people" (ibid). In 2007 Mercy Corps would respond with relief and development aid for the people of the Congo as fighting resumed in that already war-torn country. Left out of this time-line are all the other places where Mercy Corps is implementing ongoing long-term development programs.

\section{The Birth of PCI}

Mercy Corps' Peaceful communities initiative (PCI) was a $\$ 6.1$ million “conflict mitigation project" which officially began implementation in the three Central Asian Republics which share the Ferfghana Valley: Krygyzstan, Tajikistan, and Uzbekistan. The program officially began implementation on October 1, 2001 and finished on September 30, 2006 some five years later.

The original PCI program was focused entirely in the border regions of the The Ferghana Valley. The valley referred to by both Mercy Corp (1999) and others as the 
heart of Central Asia (Starr 2011). Weinthal (2002) explains, "within an area about 300 kilometers long and 20-70 kilometers wide, the Ferghana Valley has the highest population density in Central Asia" (p.95). Presently, the Ferghana Valley is divided unevenly between Kyrgyzstan, Tajikistan, and Uzbekistan with latter taking the lion's share of arable land while Tajikistan claims its more industrialized eastern edge and leaving the Kyrgyz a thin sliver of the Western valley floor as it abuts the Tien Shan and Pamir Alay mountain ranges. The aim of the five year, six million dollar program was to mitigate both cross-border and inter-ethnic conflict through the introduction of social and infrastructure projects that were to be designed and led by Community Interest Groups (CIGs).

PCI's social projects consisted of sports, cultural events, festivals (e.g. navruz), training seminars, and the opening and closing ceremonies for infrastructure projects. Infrastructure projects often involved repairing or updating old Soviet systems for drinking water, irrigation, gas supply, school repair, road repair, etc. In regard to the social programs, Anna Young explains,

For the PCI program, the social events were a key trust building exercise when teams started to work in the communities. Due to the limited amount of funds available and the sensitivities of cross border and inter-ethnic work, PCI felt from the outset that it was critical that the community mobilization process should be well under way before infrastructure projects began. However communities were often suspicious of yet another international organization conducting needs assessments and were concerned that PCI would leave without providing any results (Mercy Corps 2003).

Like many development NGOs Mercy Corps implemented the PCI program based on the organizing principles in the program's logical framework. A logical framework or $\log$ frame is a "goal oriented" approach to the design of programs that is itself designed to 
help program planners think through the relationship between goals and the various steps that will be necessary to achieve those goals. Mercy Corps explains, "a log frame is a chart that captures all the major steps in the life of a project and ensures that they each are logically connected" (Mercy Corps 2003). Additionally, Mercy Corps employs what it calls SMART indicators when staff members write $\log$ frames. SMART is an acronym that stands for specific, measurable, achievable, relevant, and time-bound.

For the first phase of PCI the log frame included two very broad SMART objectives with key outputs, major activities, indicators, and results for each objective (Figure 3). From reviewing the actual log frame what stands out is the successive translation of objectives until they are reduced to mostly numbers, such as the number of social projects, number of multi-community projects, and so forth. Log frames are emblematic of a kind of results oriented managerialism that is common throughout development organizations and such things as SMART objectives and logical frameworks form the metrology of international development. Indeed, rather than looking at ideology as the kind of binding force that holds "Development" together, scholars would do well to instead look at what the forms and standards that are shared and propagated across organizations. In answering the mereological question of 'how does "Development" hold together?' scholars should look not to capitalism or even governance but rather to metrology, the ways in which organizations use and share particular forms, standards, and measurements. One of the larger scale actors that such an exercise brings into relief are not the captains of industry or heads of government that are colluding to bring about a more perfect union of capitalism and governance, but 
rather sociology and its obsession with measuring all things. Mercy Corps' obsession with measurement is both a rational endeavor and a response to a shared set of practices.

Mercy Corps' log frame is useful for understanding the PCI program in the briefest of terms. In one quick glance it is possible to discern PCIs goals, methodologies and, in very simple terms, its outcomes. 


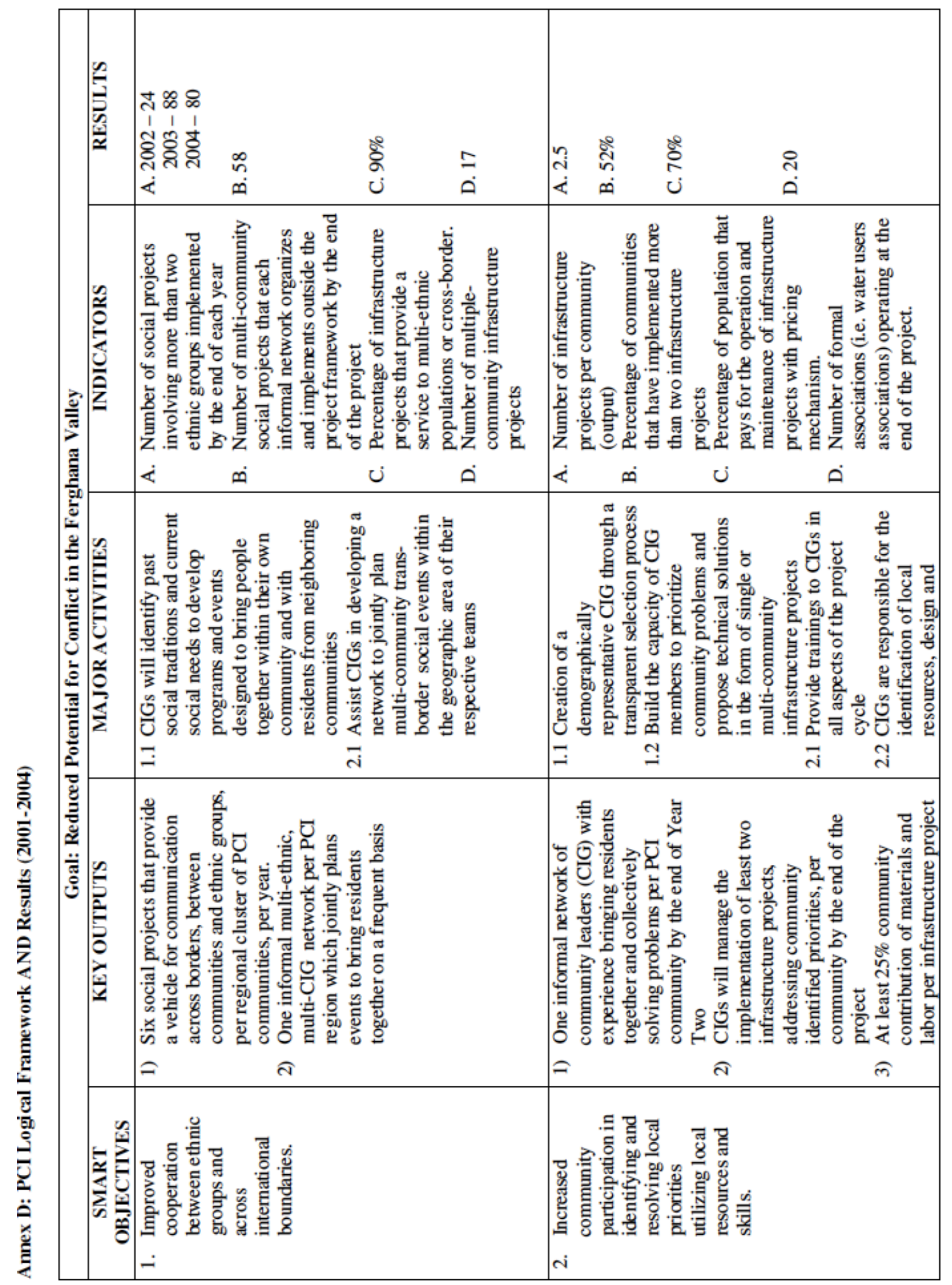

Figure 4 PCI Logical Framework 
Over the course of five years, Mercy Corps' PCI program would see some important changes. Probably the biggest change was the extension of funding by USAID so that Mercy Corps would be able to implement another round of programs. Within PCI the funding for this second round of implementation is often referred to as PCI II. It turns out that there are some important differences between PCI II and I. PCI I was a crossborder development program that chose communities that were ethnically different and actively involved in some kind of conflict or disagreement with another community over a shared resource that crossed an international border. However, various events in the region, from the so-called Tulip Revolution Kyrgyzstan to the Andijan Massacre in 2005 would effectively end cross-border programs between Kyrgyzstan-Uzbekistan, and Tajikistan-Uzbekistan. There were no Kyrgyzstan-Tajikistan cross-border programs, which brings into sharp relief the fact that the majority of difficulties in the region stem from the Uzbek border. Mercy Corps writes that

After the revolution in Kyrgyzstan in March of 2005, one of the most significant reactions came from neighboring Uzbekistan, which became extremely concerned with the potential for instability spreading into Uzbekistan. Borders became a very sensitive issue, and even as the situation stabilized in Kyrgyzstan, the notion of fostering the exchange of ideas or supporting interaction between border areas became very unpopular with officials in Uzbekistan. The events of Andijan in May, 2005 further concerned officials inside and outside of Uzbekistan who sealed borders to control the flow of information as much as anything. The issue of refugees from the Andijan events being harbored in Kyrgyzstan further compounded tensions between the neighboring states. By the summer of 2005, officials in Uzbekistan openly discouraged any cross-border movement (2007).

The government led massacre of civilians in Andijan and the international reaction to that massacre would effectively end all cross-border programs in the region. The effects of this situation surrounding the events of Andijan would eventually cause the third iteration 
of PCI (PCI III) to shut down completely. PCI III had been envisioned as the third iteration of PCI but would have only been operational in Uzbekistan.

After the events in Andijan, Uzbekistan in May of 2005 it became extremely difficult and ultimately impossible for Mercy Corps to carry on programming. The Uzbek government had, as Mercy Corps describes it, "become increasingly hostile towards international organizations operating in Uzbekistan" (Mercy Corps 2007). One of the manifestations of this hostility occurred when both the Uzbek Ministry of Justice and the Tax authorities began audits of various international development organizations. The outcome of these audits was often the complete shutting down and exit of these organizations from Uzbek territory. This would eventually be Mercy Corps' fate as well (Mercy Corps 2007).

Mercy Corps explains that,

In response to a Ministry of Justice (MOJ) audit finding (2005), Mercy Corps applied for registration as a Filial of an international organization, while maintaining its current registration as a Representative office of an international organization in the Republic of Uzbekistan. Per the MOJ, a Representative office may not directly implement programmatic activities in Uzbekistan, making Filial registration of Mercy Corps a pre-requisite for continued implementation of PCI activities. While the MOJ advised Mercy Corps to move forward with meetings with City Hokimiyats in target areas, Mercy Corps was asked to abstain from implementation of program activities till the registration as a Filial was completed. The filial registration was expected to be completed by December 2006. However at the time PCI termination in April of 2007, Mercy Corps was still facing bureaucratic roadblocks to the organization's registration as a Filial (p.4)

Mercy Corp would also face two lawsuits brought against them by the Yakkasaray District Tax Department. Mercy Corps reports that in both cases the judicial system actually ruled in their favor but by the fall of 2006 Mercy Corps' bank in 
Uzbekistan was ordered by the Tax Department to seize their bank accounts and turn the funds over to the Government of Uzbekistan. For these reasons Mercy Corps with the permission of USAID terminated PCI programming in Uzbekistan.

\section{Shift from Cross Border to Community and Community-Government Relations}

Under PCI II, USAID had requested the projects focus more explicitly on economic development. In 2006, Adrian Ouvry, the Assistant Country Directory for Mercy Corps Tajikistan recalls that "The most notable shift [from PCI I to PCI II] was USAID's shift to Economic Development ${ }^{33}$." Adrian explains that USAID's representative in Tajikistan, "Mark Hannefin... urged us to begin using economic indicators as a proxy for peace indicators — or well being — but generally as a replacement for traditional or community development indicators" (Adrian Ouvry personal interview March 2006). Adrian gives the example of having two projects, one for gas and one for water. In the gas project it's simpler to show how the program is connected or is connecting the community to a longer market-chain and is thus a both an economic as well as a well being indicator. However, have cleaner drinking water is an indicator of health and is more difficult to represent as part of a commodity or market chain, the question then becomes, as Adrian explains "how can we represent this [as an economic indicator]" (Adrian Ouvry personal interview March 2006). Justin Odum confirmed this shift in focus,

In terms of the infrastructure projects that we do, um whereas before we were doing just about anything in PCI I, now there's a requirement that projects be a little more narrowly focused around infrastructure projects that enhance economic development, obviously there are different ways you can define that, but the most contentious point for us would have been "schools" but you certainly can make an

33 See USAID white paper U.S. Foreign Aid: Meeting the Challenges of the Twenty-First Century, January 2004. 
argument that education is a prerequisite for economic development, um, but we've kind of veered away from schools and towards things that more directly impact economic development such as irrigation systems, electricity, things that we could do and almost immediately thereafter say 'look... this guy opened up and started selling ice cream because now he's got powerful enough electricity to do so' whereas schools the benefits are farther down the road" (Justin Odum personal interview July 2006)

Schools, however, were not entirely removed as an option for development. In many ways it remained up to the community to choose their infrastructure projects and a few still chose to do schools in the PCI II phase. The problem for Mercy Corps was not how to avoid doing schools but rather how to represent those projects as economic. Mark Goldenbaum, who in 2006 was still running the Krygyzstan portion of the PCI project, confirmed that they still had at least one school project in Kyrgyzstan in the village of Turkishstat (Mark Goldenbaum personal interview August 2006).

The shift in focus towards economic development also required the program to use a new set of indicators to measure program success. Mark Goldenbaum explains that in PCI II, "we moved into this economic infrastructure stuff, and we had pretty basic criteria, the criteria are [1] either provides a direct input for income generation or commercial activity such as electricity, ah we even thought that natural gas in some cases a case could be made, or [2] another criteria would be that it provides improved access to markets such as a road or a bridge or even an improved market such as a repair, and I think the $3^{\text {rd }}$ criteria [3] was that it was providing irrigation to water to privately owned lands...". Proving success in economic terms, however, was not always an easy task. 
In June of 2006 I traveled with Emily Hillenbrand. Emily was a young woman

working for the summer as an intern for the PCI program. Part of her tasks as an intern

was to collect success stories. The following is taken from my field notes,

Wednesday, 28 June, 2006 last stop of the day, in search of a success story. [We are in] Chigdalik Community [in Tajikistan south of Khujand]. (Emily says just now as I am writing this that it is a less active community). We stop at a farm complex I think there are two families here or at least two households of the same family. We are to meet a group of women, but when we arrive everyone is in the fields gathering apricots. The family has recently began to make rugs, both carpets and the flatter weave that I know as a killum. The electrification of the village through PCI... has allowed these women to work at night on carpets and rugs. [Emily was told by the CIG members that because of the electricity these families were making rugs and making money, this, however, is a bit of an exaggeration] Apparently they don't need to make any more rugs because they are out of daughters, which normally the daughters would need the rugs for their dowry. Its unclear [if they've stopped making rugs entirely] I wasn't getting English translations at this point as [my translator] I think was just simply done translating and felt it easier to translate in Russian for Emily who speaks Russian fairly well. At any rate the point is that they can make rugs if they want to as they have access to a yarn spinning machine, and they did speak quite a bit about their ability to make rugs but it is unclear if they are. They are certainly not making rugs for the market, but they already have a store of rugs and cushions, to which they referred to as their savings, but since they have no more marriageable daughters they have no reason to make more rugs. Additionally the cost of materials for a rug is right around 100 somoni, and they could sell the rug for 150 somoni, but there may be market taxes and other problems or access to markets [also] Tajiks are not buying [these] (killums) anymore [but] they could sell to other Kyrgyz. As they were telling Emily on our way out 'its not about the money, its about stature', the more rugs a girl has the higher her social standing (author's personal field notes; 28 June 2006).

In the end this particular narrative is not explicitly included as a success story. Indeed,

Emily actually was able to turn her project into a paper about PCI's impact on women.

The point is not to ridicule Mercy Corps for pursuing "success stories" but rather simply to point out that success is not always easily accounted for.

Also, the previous narrative should not be read as a program failure but as a recognition that development realities are often complex. The household in this narrative 
actually had quite a few rugs and other textiles on hand, and it was clear from talking with everyone involved in this particular visit that these things did in fact represent at least part of the families wealth or savings. For the moment, however, they were unable to translate these objects into actual currency. Hillenbrand writes "Even when they were not able to sell their work, group after group commented on the household savings they realized because of their sewing skills. 'Look, this is a huge benefit for the girls,' remarked one sewing trainer, 'The money that they would have had to spend on clothes, they can now spend on their families"” (Hillenbrand unpublished 2007).

PCI did however produce some obvious success stories in regards to its renewed focus on economic development. Hillenbrand reports that

There were exceptional success stories, such as a young woman in Ravot who opened a hairdressing salon and was able to make a living from her work. In Tojik-Okjar, the two best sewing students earned $\$ 13$ and $\$ 16$ per month from orders, which is roughly the equivalent of a teacher's monthly salary. In general, two to five out of the roughly 15 students trained in each community reported that they were actively using their skills to bring in occasional income (ibid, p.7).

The meaning of this kind of livelihood focused economic development remains an open question. It's difficult to imagine that these seemingly small and marginal gains, which do in fact make a difference in families' livelihoods, would have much affect on larger market realities. The truth is that there was never any real follow up on the request made by USAID that projects be more economic. This might certainly provide the basis for critiquing USAID's blind faith in markets, but the critique would not be applicable to Mercy Corps. The reason is that Mercy Corps did manage to complete these projects in a manner that satisfied their own internal criteria for success. Were youth positively engaged in activities that resulted in both the potential and actual betterment of their 
livelihoods? And, yes, that would seem to be the case. Unfortunately, this question of whether or not policy goals were met dose not form a part of this research. The question of whether policy goals are met remains an open question perhaps for some future research.

\section{FROM PCI I to PCI II}

In spite of dramatic changes in the region the goal of the project remained to "reduce... [the] potential for conflict through improved cooperation between ethnic groups, among communities and across international borders" (Mercy Corp 2007). Mercy Corps achieved its goal by adhering to four objectives:

- communities identifying, solving and addressing shared problems in a peaceful manner;

- youth engaged and committed to strengthening inter-ethnic relations among target communities;

- local governments understanding and supporting community-driven initiatives in target areas; and

- local NGOs providing support and leadership in bringing communities together (Mercy Corps 2007).

During its 5 years of implementing programs PCI is accounted as having over 150,000 "direct" beneficiaries. Direct in this case means those beneficiaries who lived in the PCI communities. Indirect beneficiaries are those in neighboring communities who Mercy Corps believes were positively affected. Mercy Corps counts these indirect beneficiaries in the thousands though no actual figures are given. Furthermore, in the PCI II phase in the Penjikent region, Mercy Corps sought to eliminate indirect beneficiaries in neighboring communities by selecting entire clusters of villages. This clustering approach worked, at least in the Penjikent region, to reduce the problem of creating animosity or jealousy in neighboring communities. While the bulk of this dissertation 
research has focused on infrastructure projects such as the irrigation system and pump station in Garibak and the canal repair in Ziddi and Mindona the PCI program balanced such infrastructure projects with what it called social projects. Since the start of the program PCI focused a lot of its "social and skill building projects" on young men and youth in general (Mercy Corps 2007). According to Mercy Corps, young men are one of "the most volatile populations in Central Asia" (Mercy Corps 2007). PCI's social programs consisted of organizing various sporting activities and teams, and offering various skill-building classes in basic vocational skills, journalism, healthy behavior and lifestyle, and tolerance. Through these youth focused social projects PCI was "able to address the needs and improved the potential of over 40,000 youth in Central Asia's Ferghana Valley and the Penjikent Raion of Tajikistan (Mercy Corps 2007). 


\section{Chapter Five - The Discourse of PCI: Moving Beyond Post-Structuralist Critiques of Development}

\section{Introduction}

This Chapter will review Mercy Corps' and the PCI program's discourse. The research presented here offers a different definition of discourse than what one normally finds in discursive studies of development. Ebrahim (2005) describes his approach to development discourse as referring "not only to how development is described and talked about, but also how it is thought about (i.e. its underlying assumptions) and practiced," he then argues that "these assumptions are reflected in text, conversation and in actual development projects and standard operating procedures" (p.11). Ebrahim goes on to provide a kind of scalar definition of the levels of development discourse: local, national, and international and these can be further divided into "development thought, development practice, and development policy" (p.11). Ebrahim here is offering a fairly standard post-structuralist model of development discourse. Discourse is seen as entirely social and ideational.

However, following Latour and actor-network theory this research will treat discourse as a kind of material technology that because it is material (paper and ink, digital) enables the social to pass through it. In fact without the materiality of language, or more broadly articulation, sociality would be barely possible. Documents then form a kind of material reality that makes forms of sociality possible. There are two further philosophical points that need to be made. One, discourse is a form of articulation, and articulation in ANT is not limited to only human actors nor is it limited merely to texts. 
Second, each document in the Mercy Corps archive that relates to PCI is both a proposition and a concatenation of other propositions.

To understand how these things fit together it's important to understand that, according to Latour (1999), "we have abandoned as largely illusory, the demarcation between ontological and epistemological questions" (p.141). When Mercy Corps makes reference to the concatenation of elements that describes the states of affairs of various villages and by extension the Ferghana Valley as whole, it is not on the one hand simply mimicking an observable reality or on the other hand providing an explanation that is adequate to that extant reality. Rather it is constructing, or articulating, a chain of translations or transformations that render that reality speak-able — and also render that reality actionable in a way that is amenable to the goals of both USAID and Mercy Corps. However, they are not bridging a divide between words and world, but rather linking together a series of statements, observations and objects so that they can say, 'this is the state of affairs in the Ferghana Valley.'

Mercy Corps faces a situation much like Latour's soil scientists in Boa Vista attempting to answer the question of whether the forest is advancing or retreating in the face of a similarly advancing or retreating savanna (Latour 1999). There the scientists could not simply gaze at the border of forest/savanna and render a judgment, but instead must, through some methodology, render the relevant data visible. The reason for this inability to simply see the world as it is, is that the forest/savanna present an infinite number of possible data points and not all of those would be relevant to the question of the forest/savanna's retreat/advance. In the same way, villages and regions in the Ferghana Valley likewise offer potentially infinite sets of information, practices, beliefs, 
identities, cultures, power-relations, land management techniques, local knowledge, administrative systems, social relations, etc. ad infinitum. Just as Latour's soil scientists had to, as Levi Bryant puts it, "prepare the object studied so that certain differences might come into relief ${ }^{34,}$ so too did Mercy Corps' researchers. Mercy Corps' approach to understanding the Ferghana Valley was to render it as a complex array of a finite set of issues: water and sanitation, agriculture, health, and the economy. Mercy Corps' methodology for constructing facts along these four dimensions was threefold: participatory rural appraisal, household surveys, and focus group discussions. The end result of this process is a document that one can hold in their hand: The heart of the Ferghana Valley: Mercy Corps' multi-sectoral assessment of the Ferghana Valley. The question then is what does the document gather together and how is that activity of gathering together made possible.

Within PCI what kinds of forms, standards, and metrics exist? First, the PCI program, once it was in full swing and implementing in communities, was awash in forms and standards. A review of the two physical archives in Osh, Kyrgyzstan and Dushanbe, Tajikistan, demonstrate this point rather well. The archives were an almost overwhelming collection of documents. Overwhelming because the majority of the documents were written in Kyrgyz, Russian, or Tajik and also because of the variety of documents.

The archives were, somewhat equally, divided between a variety of financial statements that included documents related to purchases such as fuel purchase requests and office supplies to more complex documents related to contracts between local

\footnotetext{
${ }^{34} \mathrm{http}$ ://arvalsubjects.wordpress.com/2009/07/12/the-factory-of-truth-towards-an-object-orientedepistemology/ accessed February 2011.
} 
businesses for various services. In addition to the financial documents there were also many documents that related to specific infrastructure projects, these included many project descriptions, various memoranda of understanding (MOU), environmental memorandum, government approvals, technical drawings, cost estimates, statements of work (SOW), and project sustainability plans. Within the archive there was very little that could be classified as narrative documents, and yet most of the critiques offered by post-development focus on narrative documents. Why are documents like the ones in the archive overlooked by development studies in general? It is clear from reviewing these documents that they form the nuts and bolts of implementation.

How do the archival documents represent forms and standards? Take for instance the idea of procurement within PCI. If PCI had to purchase goods and services from the larger community in order to implement its programs, it would do so in a manner that was governed. The reader might ask, governed by what? The answer is invariably found in documents. The process of procurement is governed by a set of documents, it proceeds via the production of documents, and it uses documents to bring the process to a close. This is true whether PCI was purchasing vehicles, buying petrol, or hiring a contractor to dig a 100-meter canal. In each case there are a set of administrative rules and practical procedures. These rules and procedures, forms and standards form the basis for the process of isomorphism, that is, the extent to which Mercy Corps forms and standards look like, or in some way, mimic the forms and standards of similar organizations. In the beginning, as the project was moving from ephemeral idea to reality, the number of forms and standards were fewer, as were the number of actual documents. The PCI program began as an idea, moved on to a series of published studies, and was 
eventually concretized in the form of a grant agreement between Mercy Corps and USAID. At each step Mercy Corps would add reality by adding knowledge, methods, and studies. These things were very often in the form of documents. Mosse (2005) reminds us "that all projects begin as systems of signs, text and language, and that the relationship between these and objects and events is uncertain. Latour writes "depending upon the informant and period... the project may shift from idea to reality or from reality to idea..." (Latour 1996 quoted in Mosse 2005; p.157). An example of this was when Mercy Corps first visited USAID with the idea of proposing a multinational, cross-border program. As Lynn Renken explained

Jim [White] was the one with this idea, he had the idea, but it didn't go anywhere, he didn't take the idea much further and then he went on to Bosnia or to Kosovo, But I remember having a meeting with Jim, myself, and two people at the USAID mission talking about cross border programming in the Ferghana Valley and the basically told us, ‘you're crazy, it won’t work”' (Lynn Renken Personal Interview October 2005).

After learning that USAID was generally set against the idea of a multinational cross-border development program, Lynn Renken and Jim White approached USAID again, but this time with the idea of having them fund a research program into crossborder development issues in the Ferghana Valley. Lynn reported,

So I remember Jim and I having that meeting and we were going to try and have them fund this Ferghana Valley survey and they totally were against it... they were like 'you can't do that, it wont work', ... it was a very negative meeting, and so we decided [to do the study ourselves] and Steve Zimmerman approved [the] funding for our assessment, and I think that assessment and the leg work that we did was critical for us 
securing PCI and without [it] we wouldn't have gotten it... it took a year, it was a huge amount of time and most of the work landed on Brandy [Westerman] and myself because Jim left, and he definitely was one of the chief spear-headers. Brandy and I were very much on board and it was driven from here [HQ] for a long time, because the nature in which MC works... we really had no regional programming before then, that I know of" (Lynn Renken personal interview October 2005).

While Mercy Corps at that time in 1999 had offices in Kyrgyzstan, Tajikistan, and Uzbekistan, they each operated entirely independently of one another. Strangely enough any connection between these three offices would have to be made through Mercy Corps HQ, half a world away. Thus doing a three-country study was in itself a kind of management challenge, as it would require coordinating three offices already quite busy with their own ongoing programs. However, what is interesting from an actor-network theory perspective is the way in which PCI would gain and lose reality as it gained or lost allies.

Mercy Corps would eventually engage in a research program in the Ferghana Valley that was comprised of three main methodological components: a rapid rural appraisal, a broader and more extensive household survey that would be administered throughout the three countries of the Ferghana Valley, and finally a series of focus groups interviews. These three research projects would be compiled into a single report: The Heart of Central Asia: Mercy Corps' multi-sectoral assessment of the Ferghana Valley (Mercy Corps 2000). This study would in turn become the basis for USAID request for 
applications $\left(\mathrm{RFA}^{35}\right)$. RFAs are a common form that is used for organizations that are funded by USAID.

What is interesting in this particular case is that the development of this particular RFA was led by an NGO. USAID, the reader will recall, was reluctant to consider programming or even research that might provide the basis for such funding. An idea and a set of personal relationships between USAID and Mercy Corps were insufficient to bring PCI into the world, but a three part study of the material conditions of daily life in rural villages in the Ferghana Valley provided enough properly formatted information to move USAID to write an RFA based on Mercy Corps' study.

The writing up of the first series of three research reports provides a good example of how reality is added to the project and the importance of forms, standards, and metrics for achieving this. The knowledge gained about communities in the Ferghana Valley is formalized, it follows a set of social science standards, and it provides a host of understandable measures by which others can assess both the needs of the communities in the study as well as the veracity of the truth claims made in the three research studies. Knowledge about these communities is first put into the form of a participatory rural appraisal $(P R A)^{36}$. This is a method which will be understood by

\footnotetext{
35 Investopedia (2011) defines RFA as "A type of solicitation notice in which an organization announces that grant funding is available, and allows researchers and other organizations to present bids on how the funding could be used. The Request For Application (RFA) will typically outline what type of programs are eligible, what the expectations are and how applications are submitted and reviewed" (http://www.investopedia.com/terms/r/request-for-application.asp accessed on April 16, 2011). A request for proposals (RFP) is essentially an invitation for bids to complete or implement a specific program that has already been designed. (http://www.investopedia.com/terms/r/request-for-proposal.asp accessed on April 16, 2011).

${ }^{36}$ Mercy Corps publishes an internal document for program planners and mangers called $A$ Guide to Community Mobilization Programming that explains "PRA helps groups analyze local problems and formulate tentative solutions with local stakeholders. It makes use of a wide range of visualisation methods and mainly deals with a community-level scale of analysis. These methods can be very effective for getting detailed information from large groups. The emphasis on ensuring community feedback broadens the group
} 
Mercy Corps’ professional audience: program managers at Headquarters, and administrators at USAID, as well as other development professionals - the efficacy and the limits of such an approach will be readily understood by Mercy Corps' peers.

In the research report the authors provide a concise description of their methodology. The researchers used three tools to conduct the PRA. They constructed a timeline that "identifies the most important events of the community's history.... it may include when roads were constructed, communications installed, schools established, medical services initiated, and when natural catastrophes or conflicts had occurred" (Mercy Corps 2000; attachment 6, p1). The researchers also used participatory mapping and as the document states, "this tool uses spatial analysis to gather information about a range of issues and concerns" and involves the community in a process of gathering information about their assets and mapping them" (ibid). Finally, the researchers used a problem-ranking matrix that "includes a list of problems on the vertical axis with categories of impact on the horizontal axis" (Mercy Corps 2000; attachment 6, p.1). The purpose of the matrix is to provide a network-like view of the main issues and their attendant issues.

In all three cases the researchers are involved in a process of translating local knowledge into a format that can travel, be easily understood by others, and that can be used as the formal basis for the development of a survey tool which would be implemented in a wider selection of randomly selected communities in the Valley. What should be noted here is that these particular forms and standards, research methodologies and community development methodologies link a number of diverse sites while they

of people involved, while keeping the facilitation of data-gathering and analysis manageable" 2009 Mercy Corps. 
simultaneously articulate a number of propositions into the overall proposition of comprehensive field study that will later be articulated into an RFA that will in turn be articulated into a program proposal. What is being articulated? Villages, borders, livelihoods, values, goals, money, and methodologies... the list is potentially quite long and each element, each proposition must be properly understood as a mediator.

Latour would implore us to ask if these forms and the process of developing them are either local or global? The answer is really neither since both local and global are outcomes rather than ontological features. Knowledge is gathered locally, but it uses a universal set of tools that have been created elsewhere and could be used, with some modification, anywhere. Local knowledge is then translated into data using the metrics and form of such things as PRA, household surveys, and focus groups each one articulating essentially the same sources of data in a unique way. Using this method Mercy Corps is able to provide rough data about its eight areas of concern: water, employment, food security, natural disasters, youth and recreation, education, health, medicine and sanitation, and agriculture. By dividing communities into these eight dimensions and translating local knowledge about these things into a form (the report), the authors of the research report are then able to produce a qualified statement about the communities, but the communities themselves are also formatted and stabilized.

Thus elements of these communities are transported through the vehicle of PRA to other sites where the data will be used to develop a survey instrument for the next phase of research. Mercy Corps' researchers can now carry the communities inside their laptops and transfer them via email to Headquarters in Portland. What is more important here than whether an item is local or global are the connectors and connections. What is 
being transported from one to site to the next, and how is such transportation made possible?

The PRA has become, in ANT parlance, an immutable mobile, a displacement of knowledge from the local sites of its production into a particular form. Latour explains that the word form "takes a very mundane practical meaning; it can be a paper slip, a document, a report, an account, a map, whatever succeeds in practicing the incredible feat of transporting a site into another one without deformation through massive transformations" and it is not a case, as Latour argues, of "displacement without transformation but displacement through transformation" (Latour 2005, p.223). Without this work of transformation into acceptable forms that meet some basic standards for the production of statements it would be impossible for Mercy Corps' audience of readers to take their findings seriously.

However, PRA was only part of a three-part research project. "Based on the results from this preliminary assessment, Mercy Corps developed a household survey that was conducted in 1,613 households in 18 communities within the Southwestern Valley regions to gather quantitative information on the issues and resources in these communities." In addition, Mercy Corps implemented a "third and final step in the process" which was to "conduct qualitative research through focus groups in these same communities" (Mercy Corps 2000; p.13).

Part of what makes these research projects interesting is that Mercy Corps did not set out to find out why communities faced these problems, though some of that information was available through the PRA and focus groups, but sought mainly to account for the existence of a finite set of problems. For Mercy Corp the answer to the 
'why' question was already known, thus they give four reasons for the purpose of the study and in doing so they provide the answer to the question of 'why' communities face these difficulties. First, "Mercy Corps recognized that throughout the 1990s, the living conditions of many in the Ferghana Valley worsened... due to economic decline, scarce natural resources, increased ethnic hostilities and ethnic conflict, and decreased access to markets due to border closures and/or difficulties with customs." Second, "Mercy Corps is uniquely positioned in Central Asia, as it possesses strong programs n Kyrgyzstan, Tajikistan, and Uzbekistan, and has operational satellite offices in four locations within the Ferghana Valley...." Third "the fertile Ferghana Valley is the heart and most densely populated area of Central Asia. Overpopulation severely stresses resources such as land and water. Stress on these resources has sparked conflict that has escalated into ethnic clashes, killing or injuring people on all sides of the border." And fourth, "Mercy Corps is confident that it has the capacity to contribute towards expanding economic development opportunities, improving water resources and sanitary facilities, decreasing morbidity and mortality at the community-level, and building the capacity of local organizations -- all of which help to build civil society, strengthen the mechanisms by which people can begin to solve their own problems and reduce the potential for resource-based conflict in the Ferghana Valley" (Mercy Corps 2000; p.12). These four reasons are essentially a reiteration of Mercy Corps' argument for the funding of their program and the research conducted is their vehicle for achieving that goal. The first field study is clearly a foundational document for Mercy Corps. It expresses the proposition that there is a need for the kind of programming Mercy Corps has in mind as well as the 
proposition that conflict could arise from local communities over the availability and quality of basic resources such as water and gas.

\section{Ethnicity and Conflict}

The reasons that Mercy Corps give for using ethnicity as one component of the organizing logic of the PCI program is they had established a connection or a relation between the potential for resource based conflict and the ethnic status of particular communities. The argument that this research makes is that this use of ethnic identity does not amount to a simple reification or an entirely reductionist use of the concept of ethnic identity and its relation to potential conflict in the Ferghana Valley. What it does amount to is a recognition on the part of Mercy Corps of an extant literature that recognizes ethnic identity as a component in conflict; a recognition of the ways in which ethnic identity is actually distributed in the Ferghana Valley; the relation of ethnic identities to international borders; and finally a recognition of local peoples' own assessment of the role that ethnic identity plays in their lives vis a vis Mercy Corps' multi-sectoral assessment. The extent to which Mercy Corps deploys Western notions and understandings of the role of ethnicity in the Ferghana Valley comes from their reading of the available literature on the Ferghana Valley. Admittedly, much of the research and writing available in 1999 regarding conflict and ethnicity in the Ferghana Valley was speculative in terms of its predictions for potential conflict (Nunn, Rubin and Lubin 1999; Tabyshalieva 1999; United Nations 1999). However, much of the information available was also empirical in its understanding of the ingredients or resources available for the escalation of conflict. For example, the division of ethnic minorities through a border system devised by the Soviet Union was not in contention 
(Roy 2000). Apart from differences in the choice of adjectives, one would find little to argue with in the following quote:

The ethnic composition in the region is problematic as all states have major minority groups that belong to one or several of its neighbors. The most extreme is Tajikistan where most of its titular people live either in Afghanistan or Uzbekistan. Uzbekistan on the other hand has the largest Diaspora groups in the other states. This is a result of the Soviet policy to divide and rule, which aimed at creating pockets of other people in different republics. These "islands" of minority groups are a central problem for the Central Asian states today. This is especially true in Tajikistan and Kyrgyzstan where large populations of Uzbeks live in compartmentalized regions in the border areas with Uzbekistan. (Swanström, Cornell, and Tabyshalieva 2005, p.6).

What these authors do take issue with is the meaning that particular researchers attach to this basic demographic information. Thus how one interprets this information forms the basis of controversy surrounding the notion of the potential for conflict in the Ferghana Valley. Authors such as Nick Megoran (2007), Christine Bichsel (2005), and Madelienne Reeves (2005), all of whom are loosely aligned in their theoretical perspective with post-development studies, take issue with the way both policy writers and development organizations like Mercy Corps have characterized the relation between conflict and ethnicity as well as the general status that they ascribe to the category of ethnicity. The argument put forward in this paper is that these authors fail to account for the actual ways in which Mercy Corps deploys both concepts of ethnicity and conflict and the relation that Mercy Corps posits between the two. A simple review of either the original Ferghana Valley Multi-Sectoral Study (Mercy Corps 1998), or The Ferghana Valley Field Study (Mercy Corps 2003) reveals a more nuanced understanding of these concepts than is generally recognized by this particular group of authors. As Latour is fond of saying both God and the Devil are in the details (2005, p.137.). However, the 
details are precisely what post-development must overlook in order that their arguments remain coherent.

To be fair however, authors like Megoran (2005) object to Western usage of the notion of ethnicity in precisely those terms, it is western usage and thus it can only be understood as an exogenous understanding of ethnicity. Even so, it seems foolish to argue against the importance of ethnicity in a region that still uses internal passports that specify the owner's ethnic background. The point is that ethnic identity remains a powerful feature of the social landscape of Central Asia; it is simply unavoidable. However, the question that needs to be asked is how did Mercy Corps use the notion of ethnic identity? The answer is that they used it as a potential marker of conflict since in their estimation ethnic identity could become a mask for resource based conflicts. Anna Young writes

To those living outside the region, conflict in the Ferghana Valley evokes images of cross-border scuffles between villages of different ethnicities or large-scale riots. Many analysts see the Ferghana Valley as a potential tinderbox, where one spark, or incident, might quickly become out of control and spread through the region. While people living along the border may express concerns about potential future disputes or refer to disagreements between villages, no one during the course of this study expressed concern about imminent violent outbursts (Mercy Corps 2003).

Young goes on to stress that "the two most obvious or visible causes expressed in secondary literature and by the communities themselves as the root of the problems in the Ferghana Valley are weak and corrupt governance structures and resource allocation between countries due to the borders" (Mercy Corps 2003, emphasis in original). Ethnicity appears to be a kind of empty category for Mercy Corps whereas relations between communities and governments and resources allocation takes center stage. 
In reviewing the many documents that were produced in the life of the PCI program what one finds is an organization that went to great lengths to discover useful information about the difficulty of daily life in Central Asia. Rather than focusing on ethnicity as an explanatory category, Mercy Corps focused instead on shared resources between communities and strained relations between communities and their local governments. But it is also the case that the existence of ethnic minorities remained a consistent part of the selection criteria for both PCI I and PCI II. Part of the reason for this is that Mercy Corps wagered that there would be a relationship between ethnic minority status and access to resources and government. But this wager appears to be made in relation to a seemingly intractable set of issues related to the borders. Mercy Corps writes in September of 2004 that

Of the 83 infrastructure projects to date, approximately $90 \%$ of them provide services to multi-ethnic populations, cross-border, or to mono-ethnic minority communities (i.e. an ethnic Kyrgyz community in Uzbekistan). In addition, there have been 14 multi-community infrastructure projects, such as irrigation, health clinic, drinking water, and natural gas projects. Since this type of project usually addresses a concrete source of tension (often transborder), these projects are clearly the most difficult, requiring villagers from neighboring communities to put aside their differences, and work together (Mercy Corps 2004)

The borders divide the region by ethnic groups and so it is not an accident that an ethnically Kyrgyz community in Kyrgyzstan is sharing a cross border resource with an ethnically Uzbek community in Uzbekistan. In those places where the border does not correlate to ethnic identity it simply reverses the problem and places Kyrgyz in Uzbekistan or Uzbeks in Kyrgyzstan who because of their identity exist as minorities. The point is that while ethnicity may be an empty category that does very little to explain the difficulties of daily life in the Ferghana Valley, it's still an important marker for 
potential conflict because of the way in which ethnicities have been distributed but also because as Roy (2000) points out these regions are still engaged in a process of national differentiation based on the now absent Soviet policies of ethnic and national differentiation.

\section{Economics and Livelihoods}

Development scholars such Kamat (2004) or Edwards and Hulme (1996) point out that there is a worrying relation between neoliberalism as a global policy agenda that and the way in which NGOs are complicit in the furtherance of neoliberal goals. Kamat (2004) argues that by focusing on the provision of needed services instead of politically mobilizing beneficiaries through a process of education, NGOs depoliticize the needs of communities while simultaneously privatizing the state by showing communities how to be self-reliant.

However, such a concept of depoliticization relies on a very narrow definition of politics. The question must be asked to what extent does the PCI program support a kind of neoliberal agenda in Central Asia? I want to suggest that this argument is bit ridiculous and can be easily turned on its head by simply reversing which actors are the important actors. To what extent does USAID support a community-first, livelihoodsonly approach in economic development that actively undermines the neoliberal agenda?

For actor network theory the way through the original question regarding PCI's complicity in a global neoliberal agenda is, again, to pay close and careful attention to what PCI actually says and does. It is also important to bear in mind Latour's question about the possibility of a progressive composition of the common world. First, what does PCI say about economic development? 
In the original three-part field study that became the basis for PCI programming Mercy Corps describes the economy of the Ferghana Valley, Mercy Corps says,

The Valley is responsible for $22 \%$ of the total industrial output and $26 \%$ of the agricultural production of the three republics.... American, Israeli, French, Indian and other companies are operational in Tajikistan's Sugd (formerly Leninabad) Province, engaged in a variety of businesses such as the production of animal fodder, textiles, and gold extraction. Tajikistan's largest foreign investment to date was by Nelson Gold Corporation, a Canadian firm, for over $\$ 54$ million (Mercy Corps 2000).

The study goes on to talk about foreign investment and the difficulties of such investment in the face of "customs controls, separate currencies and difficulty in obtaining parts and services across borders" (ibid). This portion of the study is essentially a recapitulation of the concerns expressed by Nunn et al in the book Calming the Ferghana Valley. As such it's a nod to the neoliberal agenda and says 'we recognize the importance of foreign investment'. The discussions of the difficulties of business give way to discussion of environmental degradation, the youth population, the rise of unemployment, the history of violent ethnic conflict and the prospect of future conflict. Mercy Corps writes,

Impoverishment, scarce arable land and ethnic homogeneity of the official leadership and economic elite, combined with the growth of spontaneous nationalism among various ethnic groups could eventually trigger a social explosion of immense proportions. The geographic interdependence of the Central Asian states necessitates cooperation to resolve water and land disputes, trade, internal migration and many other concerns. Water shortages, land degradation, overcrowded agricultural areas, and urban 
zones are potential factors of tension, often masked as ethnic rivalry. A cooperative inter-state approach is necessary to address environmental concerns and to manage resources that are distributed across border regions (Mercy Corps 1999).

Is this passage to be understood as a call for making the Ferghana Valley safe for capitalism? Does this passage speak to the neoliberal agenda? Most post-structuralist analysis would at this stage point out the similarities between this local expression of an element of capitalist discourse and a global capitalist discourse. What hold does the history of ideas have on the present and local elaboration of some smaller set of those ideas?

In ANT, while there is freedom of association, there are no free connections. If Mercy Corps' PCI program is to be understood as an element in capitalism it remains to be explained exactly how such a relation has been made. Post-development would make the above passage somehow do all of the work of association. The ANT point here is that Mercy Corps, with its study of livelihoods and infrastructure in the Ferghana Valley, is articulating a very unique proposition.

Consequently, it's important to ask the question what else is added to this discourse, and how does Mercy Corps propose and eventually implement its economic agenda? The answer is that Mercy Corps does two things that a neoliberal agenda would likely pass over. Mercy Corps focuses its economic analysis on the protection and well being of communities and the support of livelihoods. Mercy Corps writes, "As a result of its study in the Ferghana Valley, Mercy Corps has identified its programmatic goal as the prevention of potential resource-based conflict in the Ferghana Valley through improved and sustainable community livelihoods. This goal will guide all future Mercy Corps 
activities in the Ferghana Valley..." (Mercy Corps 2000, p.3). Thus the articulation of this particular proposition, that would eventually become PCI, has less to do with neoliberalism and more to do with Mercy Corps' commitments to those things the organization sees as its core values.

Mercy Corps' commitment to communities and livelihoods is enshrined in the organizations' civil society mandala, or Vision for Change. At the heart of Mercy Corps' vision of what constitutes a civil society are "secure, productive, and just communities". Also the charge of neoliberalism involves a both substitution of the NGO for the State (NGOs provide services where the state cannot do so) and also a process of accommodating communities to the gradual withdrawal of the state by providing services in its absence (NGOs providing services where the state simply refuses to do so) rather than organizing communities to demand that government provide such services in the first place.

This is really a difference of opinion regarding what NGOs should be doing. In Mercy Corps' vision of a civil society communities hold a privileged position at the center while the private sector, public sector, and civil society surround the community and are joined in the last ring by good governance, economic opportunity, etc. Mercy Corps' vision of a well-balanced society also includes the government as a partner for development. What makes Mercy Corps' Vision for Change interesting from ANT perspective is the degree to which the idea has been displaced into a variety of documents and practices. One cannot visit any of the Mercy Corps offices in Central Asia, and likely the rest of the world, without finding a poster of the civil society mandala hanging somewhere. Its presence is ubiquitous and serves as a constant reminder to staff and 
visitors that this comprises a part of the organization's core values. In a very real sense this version of civil society has become an obligatory passage point ${ }^{37}$, a standard against which programs and outcomes can be measured. Mercy Corps could no more forego the 'vision for change' in its Ferghana Valley field study than it could waive the requirement that surveys be recorded, or that communities be chosen via some criteria. Thus it's not the shadow of capitalism that renders a relation between Mercy Corps' work in the Ferghana Valley and capitalism but rather a few words written into the executive summary of its field report.

The connections between Mercy Corps' unique vision of civil society and the multi-sectoral field study (Mercy Corps 1998) and the eventual PCI program are numerous and replete. It is then by virtue of this modest obligatory passage point, that is itself composed of a few pieces of paper, several drops of ink, and a digital image on a hard drive, that ensures the future program will be organized around the logic of this unique view of civil society. What makes this particular view of civil society stronger or weaker are its relations. At the point at which Mercy Corps had originally published the Ferghana Valley field study the idea of civil society had been operationalized via the mode of three social scientific studies that specifically sought out answers to questions regarding the well being and livelihoods of communities. Every time Mercy Corps operationalizes this particular articulation of civil society it adds reality to that vision. However, the vision's point of weakness is in its deployment into a new setting. It is never an indisputable fait accompli that Mercy Corps will be able to deploy the concept in the way it wishes.

37 An obligatory passage point refers to when something acquires the status of being either indispensable or unavoidable. 
First, Mercy Corps will have to enroll more allies to help accomplish its goals. But one never simply adds allies as a collection of so many faithful intermediaries; rather one adds mediators, actants (which are again also concatenations of other mediators, goals, and programs) with their own goals and programs. This is the ANT meaning of translation and it is also an engine for change and surprise. By multiplying the potential number of agencies, ANT forces our attention towards accounting for relations and in doing so it also forces the researcher to be attentive not only to similarities, as in postdevelopment, but to actual differences. Thus development programs proceed on the basis of standards, objectives, and goals that are displaced into documents, grants, and plans.

For example, throughout the life of PCI Mercy Corps would go to great lengths to bring local governments into the development process in whatever capacity they could manage.

In 2004 during PCI I, Mercy Corp writes

Local governments have contributed to $95 \%$ of PCI's 83 infrastructure projects. This partnership during implementation is a step forward in breaking down the perception that government representatives are indifferent. In addition, 19 projects identified as community priorities were addressed with the support of local government as a result of CIGs advocating their needs to local government outside of the PCI project framework (these have included construction of child care centers, health clinics, and providing land for sports fields). Additionally, communities are now reaching out to local government representatives and inviting them to attend all social events. Of the 192 social projects that PCI has held, at least one local government representative has attended $76 \%$ of the projects. Though often symbolic, this is another sign of improved government support for these communities (2007).

Indeed the participation of local government was one of the four primary objectives of PCI overall. By the end of the program in 2007 Mercy Corps could report that, 
Including local government in the PCI process has been a focus of the project from its early stages and has been crucial in assisting beneficiaries to address and solve shared problems in order to limit or eliminate source of conflicts in their communities. One of the major sources of gaining government involvement, trust and buy-in has been including government officials and organs in the community infrastructure implementation. In all, a variety of government bodies-from community-based to oblast level - have contributed to two-thirds of PCI technical projects, a marker of their engagement in the project and, more importantly, of their cooperation with their constituents, and ultimately, the reduction of conflict between the two sides (Mercy Corps 2007).

In attempting to address the question of how and in what ways an NGO supports a neoliberal agenda or some other destructive capitalist formulation it is important to look at how an organization articulates its own notion of economics and politics and how that articulation compares to the core value of the organization. Organizational values are often left untouched and unremarked upon in the study of development and development scholars often decide on a model of politics beforehand, and then criticize NGOs for failing to implement whatever narrow version of politics had been imagined without ever inquiring into the actual composition of politics that unfolds as an organization engages in implementing programs. Consequently, scholars like Kamat (2004) are simply substituting their own desires for the desires that the community should have. Ironically, scholars like Kamat (2004), by deciding before hand what politics should be composed of, deny that opportunity to the NGOs and their beneficiaries. When do communities have the opportunity to articulate their position on neoliberalism, good governance, etc.? If a community accepts better livelihoods over the uncertainty of challenging a seemingly powerful and disinterested national government then are they complicit in depoliticizing their own lives? 
Latour re-specifies politics as "the progressive composition of the common world" (2004, p.86). For Latour, articulation is the mechanism for understanding whether or not politics are being achieved or short-circuited. Latour says,

We shall say of a collective that it is more or less articulated, in every sense of the word: that it "speaks" more, that it is subtler and more astute, that it includes more articles, discrete units, or concerned parties, that it mixes them together with greater degrees of freedom, that it deploys longer lists of actions. We shall say, in contrast, that another collective is more silent, that it has fewer concerned parties, fewer degrees of freedom, and fewer independent articles, that it is more rigid. We can even say of a two-house collective, made up of free subjects and indisputable natures, that it is completely inarticulate, totally speechless, since the goal of the subject-object opposition is actually to suppress speech, to suspend debate, to interrupt discussion, to hamper articulation and composition, to shortcircuit public life, to replace the progressive composition of the common world with the striking transfer of the indisputable - facts or violence, right or might (p.84).

In many ways the various post-structural critiques of development still depend for their analysis on this two-house collective that separates subjects and objects, nature and her objective facts against society and its subjective opinions. To engage Latour's version of politics in development would mean that organizations like Mercy Corps would have to gather together the right people: women, youth, community leaders, and local government, with the thing that unites or divides them: a water pump, a shared resource, or an electrical transformer, and then to ask the question 'what is to be done' and to proceed with the answers by way of rendering facts as matter of concern. Which is to say that instead of short-circuiting politics by mobilizing facts that cannot be argued with, such facts have to be opened and the various concerns aired. As will be shown, this is largely how Mercy Corps proceeded in the implementation of PCI. 


\section{Summary and analysis}

Consider for a moment Dimaggio's notion of isomorphism among organizations. This question strikes me as being very much a question of mereology, that is what is the relationship between wholes and parts, except that in this case its not a question of how do the parts of one organization relate to the organization itself but how do similarities between organizations help constitute groupings of organizations that can be understood as constituting 'Development,' understood in this instance as a kind of higher level object. DiMaggio and Powell (1983) ask "what makes organizations so similar?" and the answer they give is that "the engine of rationalization and bureaucratization has moved from the competitive marketplace to the state and the professions" (p.147) In order to understand why organizations are similar Dimaggio and Powell do not drill down into the minutiae of organizational practice but rather they jump outwards towards organizations as fields, and they then hypothesize that isomorphism is a function or outcome of large scale processes of resource centralization and dependency, goal ambiguity, and technical uncertainty.

Actor Network Theory via Bruno Latour, however, suggests that rather than jumping away from the local site to the global field where it is believed that structuration happens, the research should instead stick to the local, and should set those globalities down and for the time being assume that they sit side by side. Once they are flattened the ANT scholar can begin to look at what passes between these sites, between the local and global, through which office, in which particular documents that authorize what sort of behavior, that then travels to some other place. What Latour suggest that the ANT researcher will find is that there are a variety of forms and standards that connect these 
various sites. In business this might be something as mundane as accounting standards(Latour 2005). This is not to say that Dimaggio and Powell are wrong but rather that the structure of the argument needs to be stood on its head, the researcher interested in this particular question needs to build her data from local sites and back towards those sites that were assumed to be global. Research done in such a way will reveal an entirely different landscape. This is especially true in the field of postdevelopment studies that asserts that structuration happens at the level of discursive fields that then act downwards towards local discursive practices. For post-development what holds development together is a kind of social linguistic ideology that forces its practitioners to behave in ways they themselves are not entirely unaware.

Again ANT reverses the directionality of the cause and essentially says 'you can keep your high level discourse as long as you describe a chain of connections between sites that are real and involve some cost of transportation' otherwise all one has is the assumption of a connection without the benefit of being able to see the actual connections between things. Again, forms and standards will be among those things that connect various sites.

PCI offers many examples of this. The community mobilization methodology is a both a form and standard. The selection criteria for communities is a form and standard that connects communities to PCI, and various other control points (the PCI regional offices, connected to their country offices, connected to regional USAID offices, and out towards HQ and Washington DC), as long as the researcher recognizes and accounts for every transformation along the way. PCI II communities in the Penjikent Raion are first understood through a set of criteria that were field tested in the original three field studies 
that established a kind of baseline knowledge about communities in Central Asia. From out of the original studies, the original grant, with its SMART objectives and logical framework comes a template for including new communities. These new communities are brought into PCI based on the preceding criteria and checked against the experience and knowledge of local staff. Once the clusters of communities were picked it was necessary to follow up with participatory rural appraisals or PRA. The PRA methods are common from one organization to the next as there is a kind of professional standard that must be met. Indeed there are a handful of organizational practices that exist in the form of guidance documents that could be used by field staff to help establish what practitioners like to call best practice $e^{38}$.

The point here is that there exists an array of documents that have been indispensable to Mercy Corps' efforts to first establish the PCI program and its subsequent efforts to implement and represent the program. Under the rubric of actornetwork theory there are a variety of ways to understand all of this documentary activity. Documents can be seen as so many displacements that were necessary to literally add reality to the emerging PCI program. Thus documents are implicated in ongoing processes of articulation and they form an important propositional resource. Documents represent the work of PC as in the numerous Quarterly Reports that were produced during the life of the program. Documents also enact relations as in the example of contracts, and various memoranda of agreement. Documents are implicated in the production of infrastructure projects as these needed plans, drawings, seismic studies, water flow

\footnotetext{
${ }^{38}$ There are number of examples that could be cited here. Two obvious candidates for inclusion would be Mercy Corps' Guide to Community Mobilization Programming, or Mercy Corps' Design, Monitoring, and Evaluation Handbook (2003).
} 
measurements. Documents such as the 'vision for change' form important metrics for organizational behavior and also obligatory passage points. Documents, in all of their various forms, gather together a diverse group of objects, people, plans, desires, methodologies, and so forth. However, it is precisely all of this work that is done by and with documents that post-development overlooks. Again, the entire scenography of how development operates changes significantly within an actor-network theory framework. 


\section{Chapter Six - The Garibak Case Study}

\section{Background}

In May of 2006 the PCI program in Pendjekent, Tajikistan, in the remote ${ }^{39}$ Zarafshon Valley, was preparing to celebrate the end of one of their many projects in the valley. The community of Garibak had, it was believed, finished the final pieces of an irrigation project that would move water from a downhill source via two mechanical pumps up a hill through a maze of pipes and to a reservoir that would collect the water and then allow its flow to be managed back down the hill to family farms and homes.

The Garibak community is one of the many communities within a "cluster" of communities chosen for inclusion in the second round of funding for Mercy Corps' PCI program in what came to be known as PCI II. Due to conditions in Uzbekistan following the massacre in Andijon in May, 2005, Mercy Corps was forced to curtail most of its cross-border development programming (Mercy Corps 2007). Whereas the original PCI program focused on border communities that shared resources, PCI II focused its efforts on neighboring communities that shared resources within their titular nations. The program continued to maintain its focus on conflict and also continued to use ethnicity as a marker for potential conflict. The PCI II final report (Mercy Corps 2007) describes the Penjikent cluster by giving its readers "a snapshot of relations" in the valley. Mercy Corps explains

\footnotetext{
${ }^{39}$ The remote Zarafashon Valley is flanked on its Northern and Southern sides by 6000 meter mountains. In the winter the passes North to Khujand and South to the capital are often closed due to impassable roads. To the East the mouth of the Zarafashon Valley opens onto the plains of Samarkand in Uzbekistan though the way is blocked by the border and strict border restrictions enforced by the Uzbek Government.
} 
This cluster consisted primarily of ethnic minorities - Uzbeks and Turks in Jamoat Hurmi and a community of Roma on the edge of Penjikent city. In all cases, people felt that their ethnicities were a hindrance to economic development as the local government largely ignored them and their problems. Foremost among these problems was the deterioration of the irrigation infrastructure of the region, which was badly in need of repair so that rice harvests (the main economic activity) could reach their potential. Furthermore, relations between villages were not well developed, with frequent conflicts arising over access to water and grazing land. Relations between the Roma population and their neighbors were especially poor with the population of Navobod not developing any ties whatsoever with their neighbors (Mercy Corps 2007, p.14)

And Mercy Corps (2005) explains that the community of Garibak, in the Hurmi district of the Penjikent Region and part of the Soghd Viloyat ${ }^{40}$ or Oblast

is just across the river from Penjikent city. Garibak is a Tajik village and the largest village in the Hurmi jamoat. The primary source of local income comes from rice production and as well as some wheat. Other economic activity includes animal husbandry and the production of bread, which is sold in Penjikent. Some residents also rely on remittances from relatives working in Russia. Agricultural production has fallen in recent years. Rice is grown along the bank of the Zarafshon River, though due to the poor condition of the nearby dam, crops are often destroyed by minor flooding. There is also a significant section of land that is not sufficiently irrigated due to the poor condition of the pump station. This raises tensions with neighboring Sarikamar and Shingak, who own adjacent parcels of land. Frustrations often take on an ethnic dimension as well, as Garibak is the Hurmi jamoat's only majority Tajik village, and thus seen as favored by local authorities (Mercy Corps 2005, p.29).

The thing that most stands out in this description is Mercy Corps' tight focus on the economic conditions in the cluster. Thus we have a cluster of rural communities that are, in Mercy Corps' considered opinion, dependent for their livelihoods on agriculture and remittances. Like many communities throughout Central Asia, many of their working age men are in Russia seeking work. Kireyev (2006) notes "migration from Tajikistan and the consequent remittances have been unprecedented in their magnitude and

\footnotetext{
${ }^{40} \mathrm{~A}$ Viloyat is also referred to as an Oblast is analogous to a province or a state. Each Oblast is composed of one or more regions which in turn contain a number of districts or Jamoat in Tajik. Tajiks in general refer to the nomenclature of government in both Russian and Tajik.
} 
economic impact. No other country has seen its workforce decline by around 20 percent in a decade, nor flows of remittance reach around 50 percent of GDP" (Kireyev 2006, p3). As for the local infrastructure, Mercy Corps tells us that both the local dam and the local pump station are in poor condition. While Mercy Corps doesn't give the reason for the poor condition of the pump station and local dam the reason is widely known: most, if not all, of the local infrastructure throughout Tajikistan and Central Asia in general was built by the Soviets. Once the Soviets exited Central Asia the newly formed nations of Kyrgyzstan, Tajikistan, and Uzbekistan began to see their various infrastructures fall apart as the new governments lacked either the funding or the will to maintain them. The International Crisis Group reports that

Central Asia's basic human and physical infrastructure - the roads, power plants, hospitals and schools and the last generation of Soviet-trained specialists who have kept this all running - is disappearing. The equipment is wearing out, the personnel retiring or dying. Post-independence regimes made little effort to maintain or replace either, and funds allocated for this purpose have largely been eaten up by corruption (ICG 2011).

The problem of decaying infrastructure is widespread throughout the region and is not limited to "roads, power plants, hospitals, and schools" but affects nearly every single piece of Soviet infrastructure and this includes drinking water systems, irrigation systems, flood protection schemes, as well as less critical infrastructure such as play grounds and sports fields. This decay is particularly acute in Tajikistan, which is often described as being the poorest of the former Soviet Republics.

One purpose of this research has been to pay close and careful attention to the way in which Mercy Corps deploys ideas about communities and explicitly how they deal with the relationship between economic well being and ethnicity. Thus it's important 
to note that in Mercy Corps' short description of the communities, there is an implicit theory of conflict. Rather than relying on the common reductive narrative of ethnicity and conflict in Central Asia, Mercy Corps takes the non-reductive standpoint that the source of conflict has more to do with the material conditions of life in villages and a perception of favoritism among minorities than with ethnicity per se. The simple point here is that Mercy Corps has done the work of adding a depth of understanding to the category of ethnicity instead of relying on the category to do all the work in explaining potential conflict. This understanding of the mechanics of conflict was largely the same across a number of different informants and documents. When asking informants about conflict there was a tendency to downplay the notion and recognition that 'ethnicity' as such was a poor marker for potential conflict. Mercy Corps' primary focus in PCI was to deal with the sources of conflict ${ }^{41}$. In the "Ferghana Valley field Study" (Mercy Corps 2003) Mercy Corps explains that

Throughout the community selection process, potential for conflict was the primary consideration for the teams although the criteria varied depending on whether the setting was rural or urban. For PCI, community selection was based on the identification of communities that were located on one of the borders or that were an ethnic island within another majority population. The tensions identified were primarily resource-based or due to frustrations because of isolation from other communities and a feeling of alienation from the government (my emphasis Mercy Corps 2003).

While the above quote refers to the initial phase of PCI and not directly to the PCI II programs in the Zarafashon Valley, the selection principle remained roughly the same.

\footnotetext{
${ }^{41}$ Mercy Corps' Ferghana Valley Field Study (Mercy Corps 2003) provides an explicit theory of conflict with conflict arising out of the interplay between actors, underlying tensions (ethnicity being just one potential candidate among ten others), and root causes. According to this model the two root causes of conflict in Central Asia are "weak, corrupt governance structures" and "inequitable resource allocation" (Mercy Corps 2003, p.9).
} 
When I asked Kevin Grubb ${ }^{42}$, the expatriate manager for PCI, about the selection process he explained, in regard to the Mercy Corps expansion of PCI II into the Zarafashon Valley that,

The goal has kind of evolved as I guess you know, when I first got here it was still a little more geared towards conflict prevention and bringing different communities, and different ethnic groups, sometimes within the same community, ...together to kind of address the problems that were, specific problems that were a source of conflict between them and just generally build relationships in cases where there were no relationships between communities or even within communities sometimes, especially in cases where positive relationships would help to better their own lives.... Um and then it kind of altered.... I mean that never stopped, that is still PCI its still certainly a part of PCI in Penjikent, it's a huge part, but now were developing more relations at the village and government level kind of bringing government representatives to help so that they in partnership can solve problems together with community (interview July 15, 2006).

As discussed in earlier chapters "PCI's aim [was] to reduce inter-ethnic and transborder conflict through a combination of social and infrastructure projects driven by local Community Initiative Groups" (Mercy Corps 2007). The conflict in this case is between three neighboring villages, Garibak, Shingak, and Sari-Kamar. Shingak sits on the Northern bank of the Zarafashon River and roughly 15km Northeast of the region's largest city, Penjikent. Shingak is the easternmost village of the Hurmi Jamoat and is composed of both Turks and Tajiks. The majority of its income is derived from the agricultural production of rice and to a lesser extent wheat and livestock while as much as $40 \%$ of its income comes from remittances from abroad (mostly Russia and Ukraine).

The point of conflict between the villages of Shingak and Garibak concerned a large plot of arable but dry land adjacent to the Shingak village. The pump station was intended to

\footnotetext{
${ }^{42}$ At the time of this interview Kevin Grubb, an American employee of Mercy Corps, was the lone expatriate manager of the PCI II program in the Penjikent region of Tajikistan.
} 
irrigate this land. Mercy Corps explains "this land is adjacent to a plot of land allocated to Garibak which relies on the same pump station, further straining the limited water resources and raising tensions between the two villages" (2005). The project was meant to have an impact on ethnic tension between the two villages but perhaps more importantly on the livelihoods of these two communities. An intern hired to research and write success stories related to the impact of PCI on the lives of women relates that for Garibak the repair of the pump station had an immediate impact on women's lives by reducing the amount of money spent on purchasing food. A woman quoted in the Hillenbrand's case study says 'For the past two years, we couldn't grow anything at all, we've had to buy everything in the bazaar.... With the money that we're saving on produce [now], we can buy other things that we need.... already, that's economic development" (Mercy Corps 2007). According to this report the pump station project together with the flood protection schemes irrigated over 1800 hectares of land and protected 494 hectares from seasonal flooding.

In 2007 Mercy Corps published its "Sustainability Field Study: understanding what promotes lasting changing at the community level" (Mercy Corps 2007). The Garibak community was chosen for participation in that study and Mercy Corps provides the following quote from a community member, “The water pump didn't work for 30 years, now it is in good condition. People contributed to the pump repair and so they value and maintain it" $(2007, \mathrm{p} .16)$. What the reader is offered by these brief quotes and explanations is a success story. What is not related in these texts are the various trials and failures that are part and parcel of most community development projects. Unlike the monolithic and all-powerful "Development" presented to us in the post-development 
literature (Escobar 1995; Ferguson 1990) the development project this research describes is tenuous, precarious, and prone to failure and reversals of fortune. While it is heartening to hear that the project in question is still functioning in the years after its completion, it is important to keep in mind that such sustainability is not a foregone conclusion but is the result of a great deal of work.

Latour urges the ANT scholar to study innovations (2005). The reason for this is that actor-network theory is particularly well suited for inquiry into innovations, when things, people, and others are being put together in new associations. It is during the initial stages of programs when all of the elements and actors, both human and nonhuman, are visible and readily available for view. Once put into place and while in proper working order objects recede from view. Their trials and tribulations are not visible. All we can see as scholars is their seamless integration into a system. Because of the timing of my entry into the field my research has had to focus on the end of the PCI project.

Frequently my field visits consisted of driving for miles only to stop and park the car along the side of the road in order to spend a few moments gazing at a completed project. These were variously canals, road construction projects, flood protection projects, water pumps, or some other kind of built structure, or community infrastructure. These structures were the outcome of one or sometimes two years of community development work. The arguments that had been won and lost, the funding that had been allocated, the various enrollments that had been achieved and defections weathered, none of these things were visible in the built structure of a finished project. If they are then they are not readily apparent to the untrained eye. What the ethnographer sees as he or 
she gazes at the object is a thing where all of the interesting actions have already taken place. All that can be done with such an object is to note its existence, ask whether it works properly and move on. It is this last question, however, which provides a potential opening for the actor-network researcher. Innovations and controversies offer one kind of opening to the ANT scholar, but as Latour notes, "accidents, breakdowns, and strikes" offer another. When something breaks down, Latour says, "all of sudden, completely silent intermediaries become full blown mediators; even objects which a minute before appeared fully automatic, autonomous, and devoid of human agents, are now made of crowds of frantically moving humans with heavy equipment" (Latour 2005 p.63-68). This was precisely the case with the water pump station in the community of Garibak. This chapter takes up the question of what is at stake when a project, or some part of a project, fails. In particular this chapter will look at the PCI project in the village of Garibok in the Zarafshon Valley of Tajikistan. The capstone to the year long community development project involved the construction of an irrigation system designed to move water from a stream then up a hill to a reservoir and from there to irrigate the fields of the village below. Central to the functioning of this irrigation system were two water pumps, one large and one small. In this case both of these pumps failed at a critical moment in the life of the project, and that failure provided a crucial opportunity for the researcher to gain a more nuanced and in-depth understanding of the workings of the PCI project.

On the afternoon of May 26, 2006 I was in the PCI office in Penjikent. I had spent the previous four days visiting a variety of projects and interviewing members of the two community development teams. Many of these interviews were conducted in Russian with a translator, but a few of the younger community mobilization team 
members spoke English well enough that it was possible to conduct the interview in English. As usual I was also falling behind in transcribing the interviews and taking notes from my field notes. I needed a few hours to catch up and thus I turned down an opportunity to attend an end of project celebration in the PCI community of Garibak. I had previously attended a few of these celebrations and they always ended with the men convincing their foreign guests to drink a lot of vodka. At the last celebration I attended I was asked, as an official guest from the United States, to say a few words. I was shocked and embarrassed, my Russian is poor and my ability speaking either Uzbek or Tajik is non-existent. I had hoped to sit on the sidelines with my translator and simply take notes and hopefully go unnoticed. Afterwards, I asked my translator to ask one of the village elders "what will you do now that you have fixed your irrigation system?" He responded that they would of course grow cotton. The celebration seemed ironic in the face of the kind of oppression that growing cotton represented. Though, to be sure it was a poor community looking to gain some kind of economic traction and the battle over cotton wouldn't be won or lost in that one community. Perhaps because of my previous experiences with these parties I was happy to pass up an opportunity to witness another village celebrate its success. Mostly because it seemed there would be very little to learn. I was not in Tajikistan to study end of project celebrations after all, I was there to do an actor-network analysis of the politics of development. This celebration turned out to be different.

The PCI director for the Penjikent region, Kevin, related to me what happened when he arrived for the celebration. Kevin explains, 
So we're out there today and the first thing that happens is the Jamoat guy grabs me by the arm and he's like the 'pump burned out overnight at about 11 o'clock last night' so I'm you know, I'm not angry with anybody, I'm not blaming anybody, my only statement is... 'we can't hold the presentation' Meanwhile there are 3 or 4 old men there that are [saying] 'the big pump doesn't work, its not getting water up to our communities, or our lands right now, only the little one is working and its not strong enough to lift water all the way up there [from the source to the reservoir at the top of the hill] (Interview May 26 2006)

Kevin believes reason the little pump failed to work is because people in the community had drilled holes, as many as 14 , into the pipe in order to let the water out before it reached the reservoir. However, as long as the larger pump was operating it essentially masked the problems associated with the holes and the small pump. One could have assumed that as long as the big pump was operating that all was well. In fact, when I later interviewed the community mobilization team this was a constant refrain (Focus group interview May 26). However, the mechanical failure of the large pump revealed not only the inability of the smaller pump to deal with the holes, but also the weak points in PCI's community development methodology. Evidently those doing the puncturing either didn't believe that the water would make it to their lands or they didn't care. Their ultimate intentions, however, are not at issue. What is at issue it the apparent failure of the PCI program to properly enroll these people. But the facts surrounding the appearance of these 14 holes are at best unclear. As I was speaking to Kevin and getting more detail about the project he expressed his doubts that all of the holes were new. Kevin explained "While I couldn't get a complete answer today and I assume from what I heard from some people is that these holes have been there for a long time on some parts of the pipes, that they just have been there from 4 or 5 years ago. And now this pump, the bigger pump... now all of a sudden gives an opportunity to use these pipes again... 
that they're replacing... the pump that we're replacing can use these pipes that go up higher again, so all of a sudden it becomes an issue again”. This was confirmed by the members of the community mobilization team who later explained during a focus group interview with the entire group ${ }^{43}$, that the big pump made it possible to use older pipes that were much higher up, and that some of the holes have been there for years, but it was only when the water came that it was apparent where the holes were. As one of the team members said, “even before... people didn't know about all the holes, but then yesterday when they used the pump water flooded part of the community". When I asked him why it wasn't possible to know about these holes beforehand he replied "there wasn't any water so nobody knew about it” (Interview May 26 2006).

Kevin feels strongly enough about the pump failure that he felt it was necessary to call off the celebration. Kevin explains what happens next,

So ok, so the Jamoat guy pulled me aside 'you guys and the podratzi [the contractor] make a promise that you'll change that piece... 'of course we'll promise, its going to be changed and its not going to burn out any more once we get done with it' but [Kevin speaking for himself here] we're not going to hold this presentation without that. [The Jamoat Rayiz ${ }^{44}$ disagrees and says] 'no, no, no, no we'll hold the presentation its ok, its ok, lets just do it' and you know there is television there, there's the Jamoat people... 'no I can't get up here in front of the people and say great, thank you, wonderful job Mercy Corps, wonderful job contractor, and who knows how many', I said there were 4 old men down there and when I say 4 old men there were probably only 30 people of adult age down there overall. Plus 25 children so that's more than 50, so out of the whole population there are probably 200 people who are unhappy with the project the way it is, and people were still trying to get me to hold this saying 'that its just 4 old men, they haven't been involved, they don't know what's happening' My reaction is 'come on, are you asking me?' ... and so we're going back and forth and finally I just say... 'you know what? you are not going to convince me otherwise, I'm sorry' and the Rayiz of the Jamoat walks off all upset and

\footnotetext{
${ }^{43}$ This was a memorable interview as the entire community development team was given the opportunity to offer their version of events in this case. The interview was conducted without formal translators, but again a few of the other members were able to translate.

${ }^{44}$ The elected leader of the Jamoat.
} 
frustrated... I walked up to him and he is holding his side very upset and tells me 'you must promise to get this piece changed' and [Kevin speaking for himself] 'of course Rayiz we'll do so, without a doubt thank you for being honest with me and just having me come in here like a fool' which sometimes I am of course because they allow me to be ignorant for the sake of not showing a little problem... so this scandalized everything, obviously my saying that we're not holding it. 'we already paid, we already set this up, the presentation' [Kevin responds] 'I'm sorry we'll cover it double over with another presentation whatever we need to do, its not about the money right now, its about being honest with the people, especially those who are not happy with the project as it is... like again the team wasn't as involved as they should have been (Interview May 26, 2006).

For Kevin the question of cancelling the day's celebrations is not simply about having a party. There is at least one meaningful ceremony that is a central part of the celebration and it involves both the contractor who has supplied the pumps and Mercy Corps officially handing over responsibility and ownership to the community. But Kevin is not immune to the social pressure presented by all of those assembled for a celebration. Kevin explains,

in the end anyway I think rational heads prevailed in the given moment, and the leader of the $\mathrm{CIG}^{45}$ was the guy who was really offended was like "no were going to hold this presentation, I've organized this, I've paid money for this, I've gotten the community ready' and you know there are kids standing there with bread and salt and balloons and ribbons ready to cut you know? And, so the first 20 minutes of this thing I still see this girl holding this bread, and I'm like will you tell these kids that its ok were not going to be holding the presentation? So anyway and this again the leader of the CIG and his supporters sort of like were adamantly for holding this presentation... and of course initially the shock and the offense, they were saying 'we're offended, we're offended we've worked at this, we spent money on this, we're going to hold this presentation (interview May 26, 2006).

I ask Kevin how they managed to resolve the issue and he answers,

So anyway... we get clearer heads around the table and probably at the end maybe 15 people, including a few from Mercy Corps, from the contractor, from communities, from the CIG, from the higher up land that had not been getting water... and all of this is really... standard operating procedure, this is our job, this is great, this is interesting, this is what we deal with on a daily basis it just happened to be more bright today because it was supposed to be the presentation,

${ }^{45}$ Community initiative group. 
and everybody out there, and the cameras filming.. but otherwise this would have been normal (ibid).

I ask Kevin specifically what will be done about the holes in the pipe, he responds, ...from the side of the community of course now to get those 15 holes filled, or 14 holes filled, and to make an agreement, again a written agreement, its going to be great, its going to be in the Jamoat for not cutting more holes. They're still going to cut sometimes but at least we have that [agreement], the community has that. So again that was the one side, but from the side of the contractor to replace the part that didn't work that burned out last night, also another no-brainer its what we would have done in any case and they would have probably themselves come to the office and say 'hey, sorry you know we have a contract, please don't fine us, we haven't finished, its just this piece burned out.." [Kevin] 'ok, no problem take another few days you'll find the part' and then thirdly was that this was the one of the touchier moments also, the contractor says 'ok then we can hand over this obyect because if we do, they'll [the community] be running the smaller pump and if there is any problems or if the smaller pump has the slightest bit of screw loose or if they won't close those holes then it can't get water higher, then they're going to come back and blame us so we are not going to give over any of this project' and I said 'no, no, no, wait because the land up there is burning up, we need water to get up at least as high as it can for now, so lets come to agreement' so they agreed and they both signed this document 'ok the community is accepting the pump on their balance now... the smaller pump, its no longer the responsibility of the contractor, the community takes responsibility so that means that they're collecting funds, that means they're responsible for any maintenance, all the holes, etc' and then the contractor remains responsible for fixing the larger pump which will then work when they fix it...(ibid).

As Kevin points out, the trickiest bit of this event had to do with who still held responsibility for the pumps and the overall project. The contractor was still responsible for the condition of the large pump but they wanted to be absolved of responsibility for the smaller pump. Eventually all of these things would happen: the holes would be filled, at least temporarily; the community would consent via a written agreement between themselves and the Jamoat that would monitor the pipes for new holes; the contractor fixed the large pump; and eventually the water flowed uphill to the reservoir and back down to the villages. 


\begin{abstract}
Analysis
What can a broken pump tell us about social relations? More specifically, what does this narrative about a broken pump tell us about the question of politics in development? The answer to these questions requires a detour through the theoretical constructs of actor-network theory and more narrowly through the ANT methodology offered by Bruno Latour. The following sections of this chapter take up the task of providing a theoretical analysis of the broken pump narrative.

\section{The Five Sources of Uncertainty}

Latour (2005) argues that in order to trace or reassemble the social the ANT scholar must pay attention to five sources of uncertainty. These sources of uncertainty pertain to: groups, action, objects, facts, and written accounts. Following a review and analysis of these sources of uncertainty it will be important to add three critical moves that will make it possible to draw some conclusions regarding the political relevance of both this study and community development. The first of these three moves involves, as Latour says, "localizing the global"; the second move will be to "redistribute the local"; and the last move involves "connecting sites" (Latour 2005). When these five uncertainties and three moves are complete it will be possible to draw some conclusions about what the political implications of both the project under study and this research itself.
\end{abstract}

\title{
The First Source of Uncertainty: Groups.
}

To engage in research regarding a particular group, Latour enjoins us to look for the traces that are left by group formation. Rather than starting with our own pre-made groups or groupings such as class, culture, indigenous, foreign, professional, etc. we must 
look for the traces left by our informants and engage in a kind of ethnomethodology. As Latour says "ANT simply doesn't take as its job to stabilize the social on behalf of the people it studies; such a duty is to be left entirely to the actors themselves" (Latour 2005, p26). The question then is what are the major groups involved in the PCI program and how have they been stabilized? The groups involved in Garibak with PCI are Mercy Corps, PCI, community development team 4, the village of Garibak, neighboring villages, the community initiative group (CIG), the Jamaoat, the pump-station, the irrigation system, the contractors, and for lack of a better name, the hole makers. It should also be noted that these groups exists in at least a handful of different registers. Obviously some of the groupings existed prior to Mercy Corps' intervention. The point, however, is that the pre-existing Garibak is a slightly different place than the PCI community of Garibak.

There are no essential identities persisting over time but rather a complicated mixing of various relations. Identity itself is a kind of thin simplification that glosses over relations. Knowing that a person is Tajik or Uzbek or Turkic doesn't tell us very much about those people and their circumstances and yet there is no single word or concept that can simply stand in for their complicated lives. Calling them poor, disadvantaged, or disenfranchised tells us nothing about the content of those conditions. However, understanding the various relations that individuals and groups interact with gives us a great deal of data. And yet, this is not to say that PCI research methodologies in some way exhausted the possibilities for Garibak, that is clearly not the case. There is much that is, in Graham Harman's (2009) philosophical language, withdrawn. Withdrawn from view, or presence, or knowledge. The holes and their hole-makers were 
withdrawn from view; the knowledge that some members of the community were not enrolled or shared some distrust of the system was not known and was therefore also withdrawn. Up until the point of pump failure the hole-makers had no spokespersons working in relation to PCI.

Latour (2005) says that in order "to delineate a group, no matter if it has to be created from scratch, or simply refreshed, you must have to spokespersons which 'speak for' the group existence" (p.31). These can be anything, but in the case of this project the spokespersons are the PCI manager, myself, but also all the groups already mentioned with the exception of the hole makers. One way to understand the crisis that ensued after the failure of the pump is to see it as a crisis of group formation. Will the various groupings hold together? If they do hold, what exactly is doing the work of holding them together? What has held them together up to the point where the pumps failed? This last question regarding the stabilization of groups provides a good starting point for a more general enquiry into the ways and means of the PCI program and should provide a firm basis for answering these questions.

How did Mercy Corps come to pick the Garibak community for inclusion into PCI and what sort of work was necessary to translate this community into a PCI community? The answers to these questions are not particularly difficult to understand or explain but it should be noted that the selection of communities took place well before this research was conducted and the data for these explanations comes from either archival data or interviews. As part of the reporting requirements for USAID the PCI managers would write both quarterly and annual reports. These reports are the primary archival data for this research and really do represent the most public face of both PCI 
and Mercy Corps. One could argue that these documents form a kind of representational wall around the project and are mostly composed of fairly positive reviews of the project. That criticism is fair but it also misses the point. These documents, precisely because they are the most public face of the program, provide the researcher with a valuable resource. Each quarterly or annual report is the outcome of a sometimes long and painful process that involves gathering data, visiting projects, and talking with community development teams and managers about the relative value of their contributions and the documents also represent a kind of achieved settlement about the meaning of various activities within PCI. In as sense these are incredibly meaningful documents for that reason. Every statement is weighed, calculated, negotiated, and labored over to some degree before being decided upon. Unfortunately, what is not available to the reader or the researcher is the record of those negotiations and translations. However, understanding that the documents have been put through a more or less rigorous process lends them a certain authenticity. When reading these documents one is not presented with ephemeral opinions but rather settlements in regard to the meaning of the project. This distinction between opinion and reporting on project outcomes is important. The difference between the two is precisely the amount of work that is done in terms of the measurement of outcomes and processes. These documents operate as a kind of spokesperson for both the project and its beneficiaries. These reports also provide a valuable resource for understanding how PCI managed to stabilize its various groups. Research and community selection played a crucial role in the performance of these groups. 
In regard to the question of community selection, PCI published its "community selection criteria" in its Quarterly Reports. For example, in the October - December Quarterly Report for 2004, Mercy Corps writes,

PCI teams conducted research in over 80 communities throughout the Ferghana Valley and Penjikent raion[sic], employing their past experiences in assessments, as well as meeting with other international organizations, national NGOs, media, local government and community members. Initial community selection reached over $50 \%$, awaiting final approval from project managers and director. PRAs were initiated with community members and the process of selecting CIGs in the most active communities began (p.32)

\section{PCI Community Selection Criteria}

The criteria which were used to select the PCI communities are:

- Presence of conflict potential:

- among multiethnic communities within one country or across international borders

- within the community

- between minority ethnic communities and local government;

- Presence of disputes and tension due to mismanagement and unequal distribution of natural resources among cross-border communities;

- limited access to natural resources;

- Location of communities close to border or on the border;

- Multiethnic communities or minority ethnic communities;

- Occurrence of open conflict within the last ten years;

- Existence of the potential for establishing peaceful relations with neighboring communities, regional cooperation and improvement of trans-border trade;

- No programs or international organizations duplicating PCI; and

- Presence of common problems among two to three communities (Mercy Corps 2005).

The selection criteria for the communities also points to another feature of Latour's methodology for understanding how groups are performed. Latour says that "whenever some work has to be done to trace or retrace the boundary of the group, other groupings are designated as being empty, archaic, dangerous, obsolete and so on. It is always by contrast with other competing ties that any tie is being emphasized" (2005; p.27). In the case of PCI, communities are selected based on a set of criteria and 
conversely communities that fail to meet those criteria are left out by virtue of this methodology. There is no explicit denunciation of other possible groupings but only a privileging of this particular kind of grouping based on the very basic ideas of ethnicity, conflict, and material need. As Latour notes "when groups are formed or redistributed, their spokesperson looks rather frantically for ways to de-fine them (Latour 2005; p.28). The larger point that Latour is making is that the researcher does not occupy a privileged position from which to see or better delineate groups, but rather that the researchers' informants are always already engaged in this kind of world making activity. To do this, however, requires some work, some technology or technique that can help define the group.

Justin Odum, one of the key managers of the PCI program during its second iteration explained the process of picking communities in the Penjikent region thusly, "I did go in there with... a list of all the Jamoats... every community within the Jamoats and kind of some rough ideas of where the Uzbeks are, where the Tajiks are, no mention of any Turks at that point....” At this point I asked Justin where he had come by that information. Justin replied

Oh just from staff basically, they know all this stuff... so I went in there with some really basic population numbers, and really basic demographic numbers, and then we had basically a month to decide where to work, and I think we did pretty well, I think we did very well picking communities, um but no, if we could do it all over again? I would not pick the exact communities that we chose but it'd be pretty close" (interview Justin Odum July 12, 2006).

Justin explained the selection criteria used to pick communities in the Penjikent region, “well villages with specific conflicts were definitely candidates," I asked how would you know if a community had a conflict, Justin answered 
Well, we would ask. They weren't so secretive that they wouldn't tell you, but um, they weren't at that same time completely open to people just coming in and asking and our staff already had some good ideas going in... We were trying to go for clusters if possible so that we weren't here, there, and everywhere trying to join communities that had no kind of natural connections with each other and also kind of excluding neighboring communities, ah, from PCI activities (ibid),

I then asked Justin about his concerns regarding the notion of excluding neighboring communities. "We were trying not to [exclude], trying to avoid it, that's one of the things in cluster villages that you try to avoid. We were trying to get clusters of villages so as avoid excluding neighboring villages, where if you just randomly pick here, there, and there, and there, they've all got neighbors who would be like 'why did you pick them and not us?' were um..." Apparently during PCI I in the Ferghana Valley communities had been picked by adhering more strictly to the selection criteria and without much regard for neighbors or geographic dispersal. Justin explains

There was a lot of that, PCI 1 was much more geographically dispersed. I think they just looked more at the criteria, you know ok villages, ethnic minorities, and specific conflicts and if that meant picking 5 villages that were quite apart from one another then so be it, but in this one we tried to kind of do clusters. If you just pick one village out at random and say ok Sarkmar why did you pick Sarkmar, well there's nothing really specific about Sarkmar that led us to pick it apart from it being a minority Uzbek village, it was more that the region... was a large mostly Uzbek village that kind of, well we got expressions of, of [being] neglected by government officials because they were Uzbeks... and they had some resource squabbles amongst each other too, nothing huge, but definitely some points of tension between the villages and so we just picked the whole chunk, we didn't go village by village and say ok Changal yes, Chorbot no, Sarkmar yes, Hazak no, we just said ok all of it (Odum interview July 12, 2006).

As we have already seen much of the work of performing and stabilizing groups was accomplished through the selection criteria and then the follow on community development methodologies. It is through the artifice or technique of the "participatory rural appraisal' and the creation of a 'community initiative group' that a selected 
community becomes fully enrolled in the PCI project, not merely picked for inclusion but rather made a part of a new grouping. The PRA serves to establish the actionable needs of the community and the formation of the CIG accomplishes providing an official spokesperson for the community. It is through these techniques of selecting, discovering needs, and group formations that the community is given form as a PCI community. In James Scott's view (1999) these techniques could be understood as technologies of legibility that allow the PCI manager and her community development team to see these local communities. But these techniques also work to perform and stabilize the overall group and its constituent elements: $\mathrm{PCI}$ and the community.

Latour wants his readers to also recognize the complicity that social scientists and their particular methods play in forming, performing or otherwise stabilizing groups. The origin of the PCI program, as discussed in an earlier chapter, came out of a three-part field study involving rapid rural appraisals, household surveys, and focus groups, what Mercy Corps referred to as "three distinct multi-sectoral assessments" (Mercy Corps 2000; p.1). While Mercy Corps makes no claims to the scientific validity of their studies, in fact quite the opposite, one can only assume that scientific validity was their purpose. At the very least Mercy Corps had an interest in producing defendable statements about the condition of border villages in the Ferghana Valley. In the preface to the field study Mercy Corps writes that its "assessment goal was to better understand the socioeconomic dynamics and to make a strategic and unified contribution (through its three country programs and personnel) towards the improvement of community livelihoods in the Ferghana Valley" (Mercy corps 2000, p.12). That they chose to do so via the tools of social science reinforces Latour's argument regarding the complicity of 
social science in the work of stabilizing various groupings. The key difference in the case of PCI is that such activities are undertaken not by social scientists but by lay development professionals. The knowledge gained in Mercy Corps' original field studies would guide the work of PCI managers for the first phase of the program and would also become a template for expanding the program (PCI II) into the Zarafashon Valley of Tajikistan, though clearly there were some important differences. Latour argues that "if inertia, durability, range, solidity, commitment, loyalty, adhesion, etc. have to be accounted for, this cannot be done without looking for vehicles, tools, instruments, and materials able to provide such a stability... (p.30). All of this is not to say that the community of Garibak would not exist without the PCI intervention, that is a clearly ridiculous claim, but rather that these particular groupings would not be possible without the sets of relations between people, technologies, documents, techniques, etc. that are use to both define the group and hold it together.

In PCI what performs the groups and holds them together are all of the things previously mentioned but also money, administrative systems, office space, local knowledge, procurement procedures, computers, software, practical know-how, community development methodologies, salaries, vehicles, etc. It is the orchestration of these many elements that makes the Garibak pump station project a possibility. Based on our understanding of the kinds of ingredients that have been put into play with PCI is it possible to then make an assessment regarding the raw materials of its construction? What would it mean to now say that PCI is socially constructed? The answer is that it would be somewhat meaningless to insist on a purely social explanation for PCI and how it was both put together and how it managed to hold together. 
The Garibak PCI project did manage to hold together until almost the very end. The event of the large pump failing, and the smaller pump being unable to keep up due to holes drilled in the lines, revealed a major weakness in the project. While it seems clear that the overall project was never in danger of failing completely, but from the perspective of Kevin and others the outcome was by no means certain. Just as it took a great deal of work to form these groups in the first place, so too it would take a bit more work to get them to hang together long enough so that the project could be completed. What is of interest here, from a theoretical perspective, is the notion that the irrigation system and the pump station played their roles in both performing the group and holding it together. Essentially, a proper working pump station and irrigation system also meant that there were properly working social relations, and furthermore that various material elements helped to constitute the social elements. This brings me to Latour's "second source of uncertainty: action is overtaken" (Latour 2005, p.37).

\section{Second Source of Uncertainty: Action}

How is it possible to account for action? As Latour asks, "when we act, who else is acting?" Do we attribute action to some social force, or perhaps some unknown set of power relations? If those are indeed what is acting, then what does that look like? Latour's proposal is that whenever we attribute action to some contextual actor that is meant to envelope smaller actors, such as NGO managers being enveloped by capitalist or at the very least development discourse in Escobar's formulation, who is actually acting? For example, when a university grants a degree what happens, and who acts? Once we begin researching this question of who is acting we begin to see that a host of other mediators are present. A university cannot physically hand a degree to someone, 
but a professor can, and so the professor acts instead. The professor cannot conjure the degree out of thin air but must rely on the University's administrative practices, its accreditation, its departments, grades, enrollment forms, artists, printers, etc. Standing between our simple formulation 'the university' and its action 'granting a degree' are many other actors, not all of them human.

ANT's theory of action forms an important corrective to the misperceptions of both post-structuralism, social constructivism, and post-development. In many important ways ANT is a theory of research and as such it can also be understood as a methodology. Within this methodology one is not allowed to bring contextual actors into an explanation without first explaining how a local phenomenon is connected to that context. Society, culture, social relations, nature, and power structures; none of these are explanations and all of them are in need of explanation. In Latour's estimation contemporary social science has tended to reverse the explanandum with the explanans. Contexts, like society and power, are often mobilized as explanations but the notions themselves remain unexplained. One method for making this theoretical argument a bit clearer is to apply it to a real situation, preferably a situation that involves a bit of controversy. Latour suggests that in any given controversy over agency there are certain features that will always be present. One, agencies will be part of the accounts; two, agencies are given a figure; three, they will be opposed to other competing agencies; and four, they will be given alongside an explicit theory of action. In the Garibak case the broken pump serves as a controversy, and it is a controversy that reveals a variety of agencies and a variety of explanations. 
The central figures in the Garibak broken pump controversy are community development team 4 , the broken pump, the holes themselves, and the hole-makers. In this controversy we have a number of competing accounts of the broken pump. For the Rayiz of the Jamoat and Kevin's "4 old men" the broken pump is not a problem as it will be resolved. For Kevin, there has been a community development failure and he attributes this to the community development team assigned to Garibak. As Kevin describes it

I think... its symptomatic of this team in particular, not paying enough attention to the infrastructure project, the drinking water, and the potential for conflict and the effect we're having on the communities, and you know we've discussed this and you know and tried to get them more involved, and they sort of have this attitude... again you know its my fault, period, I'm not doing enough about it, they have this attitude to say like 'you know it's their problem in the community it's a Jamoat problem, you know, let them decide this, and then we will be there' and of course my question is like 'my friends we just had a great discussion about this... then why are we here, we're not here to build shit, if we wanted it could be me, finance, and procurement. If you like we could order a contractor to go out there and build a pump station for them'(Grubb interview July 152006$)$.

Kevin locates this failure in Team 4's refusal to do what he sees as their basic job and that is conflict prevention. Kevin also understands this issue of the holes in the system as the kind of conflict that his team should have seen. When the team complains to him that this is a community problem and thus between members of the community Kevin's reaction is to say:

Exactly! That's why we selected this community because they are so conflict loving, there's so many different issues, that's why we selected the whole Jamaal... but Team 4 insists that no it's like 'there was an election campaign and [one side] won election and another deputat that didn't win and so its kind of two sides' exactly that's why were here (interview with Kevin Grubb, July 15, 2006).

But Kevin's description of the problem in an interview wasn't limited to the community development team. Kevin also attributes the problem if not to Central Asian culture, then 
to individuals simply wanting the water closer to their homes and fields. Kevin explains

that

There were 14 holes bored into the pipes, which happens everywhere believe me its endemic, through Tajik - throughout Central Asia-- people decide like well the water pipes running by my land... instead of letting it go up to its reservoir, getting pumped into the reservoir, then comes down through the canals... so instead of having to walk 300 meters down to the capstan and get water... 'I'll just tap in right here and pay a guy to weld it up and run it right into my home on my own, or into my... garden you know and use it as field [irrigation] and for drinking water and there is just not enough pressure in the pipes of course. So in this case.. sometimes we've held the presentations without these issues being completely resolved because it is so endemic, and it is so difficult to fight with and you may get like, convince 5 neighbors to close theirs up while your conducting those negotiations another 33 have opened (interview Kevin July 15, 2006).

For Kevin there are any number of reasons why the holes are a problem. Also Kevin is not entirely unsympathetic to plight of people who because of their poverty must rely on water systems for irrigation and consumption that are to some degree out of their immediate control. Also, for Kevin the possibility exists that the very people he is trying to enlist in his efforts to stop drilling holes are often involved in the activity. Kevin describes his concerns in the abstract

so there's holes appearing all the time, and we're getting the Jamoat involved, and you know law enforcement basically, but again it's so unenforceable almost, it's so... its just so accepted and you know guys that we might be talking to [asking] 'can you help us make a decision on this and get people on board?' and the leader of the Jamoat or the leader of the police or the Hukamat and these guys are the ones that are taking 14 holes into their own land because they got the money to pay a welder to weld pipes for them... I'm not saying that's all of it. But... in all truth it happens in many cases people do police themselves, you know you'll see corks and sticks stuck in the pipes sometimes and you know it may not affect the water immensely adversely in this case because the big pump wasn't working only the small one was affected very adversely (Grubb interview July 15, 2006) 
This also can be seen as a failure to properly or fully enroll some people into the scheme. Perhaps there wasn't enough training, perhaps the system was never allowed the time needed to demonstrate its effectiveness, perhaps this is an age old practice of simply making do, faire faire as Latour might say. It is difficult to fully account for the defection, but one can imagine that development projects face a myriad of such problems. James Scott might call this a form of resistance and perhaps it is, but what is being resisted? Modernity? Local power structures? Development? Or others might write it off as the perennial culture vs. rationality problem (Crewe and Harrison 2000). However, none of these capture the problem in a completely satisfying way. Perhaps it is merely a case of a lack of trust of the technical system? It could also be active mistrust, and so perhaps they feel that someone down the line will do the same thing and thus they better get theirs while they can. It would seem to be dangerous work, however, to impute reasons without knowing more. And yet it is this very idea of knowing more that seems so elusive to the researcher, Kevin, and the community mobilization team. In the end the only account of this problem are the ones presented here. There are no narratives of these events in the Mercy Corps archive and that is unfortunate because community development professionals stand to learn a great deal from failures of these sorts.

\section{Third Source of Uncertainty: Objects}

It should be clear by now that the story of the broken pump and of PCI in Garibak cannot be understood in purely social terms. One of the unique features of ANT is its treatment of objects and its inclusion of objects along with humans as actors. There are a number of reasons for this. One of the first principles of ANT is its commitment to symmetry. Unlike modernism or post-modernism we do not inherit a world already 
divided into nature and her facts on one side and society and its subjective interpretations on the other. Latour's amodernism instead suggests that there is no separation between the two. They are not equal sides of a great divide that then needs social scientists to build bridges in order to cross. Our reality, such as it is, is always a kind of hybrid assemblage with material elements underwriting the social elements. In the case of Garibak the broken pump, the smaller pump, the irrigation system, the holes in the pipes, and the people who may have drilled those holes are all on equal footing in regard to their status as actors. In fact, the repair of the somewhat damaged social relations between Kevin and his community development team, between PCI and the Rayiz of the Jamoat, and between PCI and the community members depends on the repair of the pump and the resolution of the problem presented by the creation of the holes. What is interesting about this case from an ANT perspective is that the resolution of the problem is not entirely or only social. Holes have to be filled, a pump requires repair, and then a document representing an agreement to close any existing holes and to police the pipes for new holes is signed between the Jamoat and the community initiative group leaders. If reality was socially constructed one could expect a mere word to accomplish these things.

The importance of this document in securing a resolution should not be overlooked. The reason why is that it is a perfect example of what Latour means when he uses the word constructivism. Remember that for Latour there can be no social constructions. The social is not what things are made of but rather what flows through things. The social is not what holds things together, it is rather what is being held together by things. The agreement between the Jamoat and the CIG leaders is an attempt to 
reinforce the integrity of the irrigation system; it brings together in the space of a page the whole irrigation system, the community, the holes, the power of the government to compel, and it binds those in power as much as it binds the community. Remember that Kevin has a number of theories about the appearance of the holes in the pipe. One of his theories is that he worries that the holes could be the work of the most privileged members of these communities: the Jamoat leader, or the Hukumat leaders. Kevin is helping the community secure the sustainability of the project and he is doing so with what appears to be the weakest of all possible tools: a mere document. But these are the limited choices available to those who are attempting to construct something. They can attempt to build their settlement into the environment in such a way that its mere existence compels obedience, or they can revert to less guaranteed means of securing an agreement. The document may not succeed in these tasks; it is after all only a document, a piece of paper with ink. It is not much, but the remarkable thing is that it might just be enough.

It is possible to contrast the contract document with something a bit more concrete. Latour recounts a story told by the philosopher Langdon Winner about Robert Moses and the redesign of the New York parkways. With the redesign of the parkways, Moses made sure that the bridges giving access to the beaches were low enough to make it impossible for a bus to pass underneath. Thus the beaches were secured for those who could afford an automobile (Latour 2004). For both Latour and Winner the Robert Moses story is an account of how it was possible to build social injustice into built structures. Latour explains, 
Since, at the time, blacks were not rich enough to own private cars, this meant that Moses, without any apartheid laws, without even the appearance of impropriety, could maintain his beaches as free of any miscegenation as if he had created a racist police to enforce his edict: "For whites only". Hence Winner's conclusion: not only artifacts have politics, but it's the most perverse of all since they hide their biases under the appearance of objectivity, efficiency or mere expediency (p.51).

It now almost 60 years since Robert Moses built his politics into the bridges and causeways of New York. The world has moved on in those intervening years. Now those same bridges are discriminating against trucks and interstate commerce. Clearly it wasn't Moses' intent to discriminate against trucks and yet New York has inherited this settlement about who may and who may not pass. Importantly for Latour Moses' bridges are not simply pure embodiments of a particular ideology, but are capable of surprising us in their unintended effects. Additionally, those effects are not the product of intention and are in fact cut off from intention. It may have been Moses' intention to discriminate against blacks, but the bridges he designed to do that, do more than just that.

The case being made here is that no such strategy to build a settlement into the materiality of the irrigation system was possible and so Kevin and the CIG and the Jamoat leader pursued another alternative. At present there does not appear to be anything particularly ideological about this particular agreement regarding the pipes. It is possible, however, to imagine a situation where the document is no longer useful because of changes in the world. The document does not and cannot foresee new additions or the possible effects that new additions, whatever and whoever they might be, might have. It might be that an earthquake could destroy the irrigation system and thus render the documents entirely meaningless. However, as long as the document has some meaning it must be represented. The purpose of the document is that it literally can be re-presented 
in the case of a violation. The document now forms a part of the village's power relations with its local government.

An important finding at this point is that the work of repairing the pump stations was from start to finish a political project. This gets at an important question in this research. Of what are politics composed? Is it possible to know in advance, as postdevelopment scholars seem to, the nature of politics? The Robert Moses example is the example par excellence of a depoliticized development. The bridges silently enforced their social provisions. It is only with the passage of a time and with an accounting of the effects of these bridges that they are brought back into politics. Does the contract between the Jamoat and the village of Garibak represent a case of depoliticization? The answer to this questions depends on how politics are defined. To answer this question requires at least one more detour, this time through the uncertainty between matters of fact and matters of concern.

\section{From Matters of Fact to Matters of Concern}

The central hypothesis of this research is that far from depoliticizing its development program Mercy Corps was actually engaged in a form of politics from start to finish. Part of the problem with asserting, as post-development studies has, that development actors depoliticize development (Ferguson 1995), is that on the one hand, it treats development as a monolithic structure and substitutes one type of development knowledge and practices for all types. Development programs by the World Bank, the $\mathrm{UN}$ and other recognized institutions are not differentiated from development work done by NGOs; and on the other hand, post-development theory rests on an extremely narrow definition of what counts as politics, and that definition of politics in turns rests on very 
narrow understandings of what constitutes an actor and the role that discourse plays in development. Put simply, post-development theory rests very much on a social constructivist basis; it believes that discourse constructs the world but it only ever theorizes the social component of discourse and thus overlooks its most salient feature: materiality. The social is not what constructs a document but it is the material features of a document that allow the social to exist. Without some ability to displace our ideas into something less ephemeral than speech or thought we are simply reduced to being naked apes (Law 1997). However, humans are constantly displacing their settlements into documents that because of their materiality have the ability to persist and to travel. These are just a few of the features of the world that post-development insists on overlooking. However, in order to prove my hypothesis it is not enough to give a negative accounting of post-development's theory of politics. Thus it is important to provide some positive proof that Mercy Corps not only avoided depoliticization but also conversely engaged in a type of politics. Analyzing the Garibak pump station project in terms of the five sources of uncertainty makes it possible to provide some proof of Mercy Corps' politics in the PCI program. The fourth source of uncertainty: the difference between matters of fact and matters of concern will form a cornerstone for this proof.

Latour argues "A matter of concern is what happens to a matter of fact when you add to it its whole scenography, much like you would do by shifting your attention from the stage to the whole machinery of a theatre" (Latour 2008). The 'scenography' Latour is referring to is precisely what has already been covered in this chapter: groups exist as a performance; action is distributed through a variety of actants; and objects must be included in our account. The secondary hypothesis in this research states that 
depoliticization, to the extent that it can be verified to exist, will be a function of the way in which developers use knowledge in their programs, either through the strict mobilization of facts at the expense of matters of concern or through an opening up of the development process that leaves some room for local interpretations of a so-called fact. It may be that many organizations engage in a little of both behaviors depending on whether it suits them at the time.

It is the contention of this research that Mercy Corps, from the time it originally sought funds from USAID for a cross border development program in the Ferghana Valley, up through both phases of the implementation process, the mid-term field study, and finally to the sustainability field study which forms a kind of last word on the program, largely proceeded on the basis of matters of concern. This is not to say that the organization didn't mobilize, or in some cases such as the various field studies attempt to establish, their own sets of facts; indeed they did. The point is that when it came to time for Mercy Corps to roll out its programs in villages it did so in a way that did not privilege facts over process. This finding is based primarily on the ways in which Mercy Corps dealt with knowledge, in general, and more specifically knowledge related to ethnicity, conflict, and livelihoods. In each case it has been shown that Mercy Corps proceeded mainly in a non-reductionist way when dealing with these ideas.

This finding that Mercy Corps tended to approach implementation of its projects largely in terms of matters of concern is also demonstrated through their use of community development methodology. The rather simple point that has been confirmed through observation, interviews, and archival data is that at no point did Mercy Corps use factual data to convince a community to pursue one kind of project over another. While 
the only undisputable fact was that each of the chosen communities faced some severe infrastructure problems, their experiences were not universal. Thus in terms of both social and infrastructure projects there was not an attempt to apply a singular fix for each and every community. The types of social and infrastructure projects were largely left up to the community to choose. But looking at this question of facts versus concerns in the case of Garibak and its broken pump, which can be argued represented a kind of crisis in the life of the project, did PCI resolve the crisis through a quick mobilization of facts or did they proceed as they had been doing by treating the crisis as a matter of concern? Based on the interview data already presented it seems clear that for Kevin, the broken pump represented a kind of acute failure of the community mobilization process. It's a failure that Kevin attributes to both himself and his team. When I first spoke with Kevin about the broken pump station he began by saying,

well I'll open with the fact that if it sounds like I'm throwing blame or anything... there's nobody to blame, but me, period. That's understood alright? That's our baseline.... What we have is... I think... its symptomatic of this team in particular... not paying enough attention to the infrastructure project, the drinking water, and the potential for conflict and the effect were having on the communities, and you know we've discussed this and you know and tried to get them more involved, and they sort of have this attitude... again you know its my fault, period, I'm not doing enough about it, they have this attitude to say like 'you know it's their problem in the community it's a Jamawat problem, you know, let them decide this, and we'll be there' (Grubb interview July 15, 2006).

The reader will recall, however, that Kevin had a number of different theories about both the appearance of the holes in the pipes that ostensibly started the problem and more abstractly the problem that holes present for most water projects in Central Asia. The solution, however, was not to declare the holes an illegal infringement on the integrity of the project but rather involved, in the first place, reflecting on this failure and asking 
where the community mobilization process had failed, and second to gather together all of the stakeholders and put the question before them: what is to be done. Latour argues that politics is fundamentally about gathering the right people together with the right objects to discuss what is to be done. For Latour, a fact is, by its very nature, a failure to gather because a single perspective is substituted for multiple perspectives while it also refuses to allow new members into the discussion. Facts, as Latour has argued, are generally used to close down conversations prematurely (Latour 2005). Clearly, in the Garibak case there was a desire to bring closure to the problem, and the question was how to do so. As the reader will recall, the Rayiz of the Jamoat was hoping to carry on with the closing ceremonies and fix the problems afterwards. Kevin was not comfortable with papering over the reasons for the failure and together with his team, the CIG, the contractors, the land owners, and eventually with the participation of both the Rayiz of the Jamoat and the Hukumat leaders managed to put together a legally binding contract that set forth both rights and responsibilities in regard to the irrigation system. Closure was reached but it was achieved through re-gathering the participants and re-presenting the problem.

It could be argued, however, that communities only had the opportunity to agree or disagree and beyond that basic level of agreement they would have to endure the presence of strangers attempting to mobilize them. However, this participation-astyranny argument (Cooke and Kothari 2002) is a fairly narrow and weak argument that only recapitulates the main arguments of post-development theory: development discourse is wedded to capitalist imperialism and is therefore tainted from the start (Sachs 19990). This universalist argument against development fails on several fronts. Firstly, 
and most damning, is that the argument is anti-empirical in its one size fits all analysis. Because of this anti-empirical bias, the post-development approach is unable to perform the most basic function of analysis: it is unable to distinguish between good and bad development. Secondly, the post-development argument rests on an extremely thin, post-structuralist, theoretical basis that substitutes belief for inquiry and it is a belief in the social power of discourse to make the world. Finally, the post-development argument is primarily a critical approach to development, but this approach is fundamentally flawed since it privileges the knowledge of post-development scholars while treating development knowledge as either a fetish or factually incorrect. Thus, post-development treats its knowledge about development in terms of facts that can be mobilized to sustain its arguments, but it finds it both impossible and distasteful to engage in development as a matter of concern, since to do so would mean engaging development on the basis of improving development practice. As Pieterse argues "Postdevelopment articulates meaningful sensibilities but does not have a future programme" (Pieterse 1998; p.345). Tamas argues that this notion of practicality seems like a false choice for the post-development scholar, Tamas explains,

Post-structuralist critics are often asked how their 'approaches might be fed into a practical agenda'. Such statements assume that the measure of this practicality is to be taken against the standards of those who are making the demand. In this case the discourse of such authors recognises development as a way to help the poor and interventions are thought practical to the extent that they help developers to do their jobs. Post-structuralist critiques, however, target the discourses within which this notion of practicality is formed. This demand for practicality, then, is formed within a discourse whose foundations are the object of assault (Tamas 2004, p.650). 
ANT's point of departure, as will be demonstrated in the following sections of this chapter dealing with notions of context and scale, is that development does not exist inside of a discourse. However, before getting to notions of scale and context it will be important to mobilize the fifth and final source of uncertainty.

\section{Writing Risky accounts}

Following Latour's methodological recommendations this chapter has examined the case of Garibak in terms of four sources of uncertainty: groups, action/actors/actants, objects, and facts. This chapter has demonstrated that the work of creating and holding a group together is not simple and is not done with words alone. Even the documents one encounters in development cannot be reduced to only words or only ideas. These documents must be dealt with in terms of what they gather together, the groups they perform, the actions they represent or authorize, the objects they mobilize, and the way in which they deal with questions of knowledge and knowing. At this point I think it will be important to review the relationship between documents and actants. Actants can be understood as those things, human or non-human, that cause others to act, that leave a trace of their action. Quite simply, actors/actants act and action is by its nature traceable. Latour also discusses actants in terms of being what he calls propositions. Latour explains

Propositions are not statements, or things, or any sort of intermediary between the two. They are first of all, actants.... What distinguishes propositions from one another is not a single vertical abyss between words and the world but the many differences between them, without anyone knowing in advance if these differences are big or small, provisional or definitive, reducible or irreducible. This is precisely what the word "pro-positions" suggests. They are not positions, things, substances, or essences pertaining to nature made up of mute objects facing a talkative human mind, but occasions given to different entities to enter 
into contact. These occasions for interaction allow the entities to modify their definitions over the course of an event" (Latour 1999).

Understanding the various elements at play in the propositions of this development project, the various actors, the objects, the nature of action, the nature of facts and the way in which various groups and actors interact with those facts, brings home the reason why Latour refers to them as uncertainties and also brings home the fundamental lesson of this last source of uncertainty: risky accounts. The accounts that development managers, academics, and others write about development are composed of a tremendous variety of things. Latour argues that the role played by language forms the critical distinction between the ANT model of the world and the modernist or post-modernist model that still perceives a fundamental split between nature and society on the one hand and between epistemology and ontology on the other. In his discussion of Pasteur's discoveries, Latour explains that "In the first model, the only way for a statement to have a reference is for it to correspond to a state of affairs. But the phrase 'lactic acid ferment' does not resemble in any way the lactic acid ferment itself, any more than the word 'dog' barks or the sentence 'the cat is on the mat' purrs. Between the statement and the state of affairs to which it corresponds, a radical doubt always sets in, since there should be a resemblance where none is possible" (Latour 1998, p.142). Latour goes on to argue that relations between propositions should not be thought of as correspondence which functions like a bridge crossing a chasm, but rather as what he calls articulations. Thus Latour's "Pasteur 'articulates' the lactic acid ferment in the city of Lille" (p.142). This fundamentally changes the role of language. Instead of language being a property of humans alone, articulation "becomes a very common property of propositions, in which 
many kinds of entities can participate" (p.142). Articulation as such is not restricted to language but "may... also be applied to gestures, papers, settings, instruments, sites, trials" (p.142). The lesson here is almost non-intuitive. Words do not correspond to or resemble the things they represent, but it is this non-resemblance that makes it possible for on thing to articulate another. Mercy Corps' various reports do not resemble the villages and projects they have worked on, but rather they articulate a relationship between propositions. This is why the accounts written by development managers, academics, and others exist as risky accounts; they are risky because some or all of the relations they articulate may fail to obtain, or may change, or disappear. They are risky because these writers and implementers and others cannot know in advance which proposition will be the important proposition. This is as true for the development manager writing a quarterly report as it is for the researcher finishing his $\mathrm{PhD}$. It is worth quoting Latour at length here,

What do we do when we trace social connections? Are we not, in effect, writing down accounts? What is an account? ...At best, we add an account to all those which are simultaneously launched in the domain we have been studying. And this study, of course, is never complete. We start in the middle of things, in medias res.... And when you begin to write in earnest, finally pleased with yourself, you have sacrifice vast amounts of data that cannot fit in the small number of pages allotted to you. How frustrating this whole business of studying is. And yet, is this not the way of all flesh? (p.122).

Again, what is true for the researcher is also true for the so-called informant. Both are swimming in a world of data and must by necessity make choices about which threads to pursue, which bits of data to collect. This process of reduction is also why our respective accounts are considered risky. It is not always known which proposition will be the key proposition, and as it turns out there are a lot of propositions, a lot of data 
points and it is simply not possibly to swallow or regurgitate the world whole. For Latour this means that development, academic, or other types of writers must engage in a process of reduction and amplification. As the writer confronts choices about which bits of data to include some things are lost. According to Latour these are "locality, particularity, materiality, multiplicity, and continuity" but through a process of amplification (very often through published reports) Latour argues that we gain "compatibility, standardization, text, calculation, circulation, relative universality" (Latour 1998, p.71).

What Mercy Corps gains is quite simply results, impacts, progress towards goals, and possibly some measure of sustainability. Mercy Corps also extracts other 'goods' from its projects, and these are experience and demonstrations of its unique capacity to deliver measurable results. These results can be used in the form of various reports to donors to secure future funding from individual, government, or other donors. Successful programming is the lifeblood of organizations like Mercy Corps. The researcher in this case gains a step towards his $\mathrm{PhD}$ and possibly a few articles and the chance to do it all again as part of a career. This research, however, is less concerned with the shape and content of things gained than with the myriad ingredients that are used to get there, along with our unique ability to displace our thoughts, opinions, etc into more material elements and thus rendering them durable enough to travel to other sites. 
In the case of Garibak, very little of the complexities, or more precisely the complicatedness $^{46}$, of the project make it into Mercy Corps' texts. Below in Figure 5 is a table from Annex A of the Final Report (Mercy Corps 2007) describing the projects from the villages in Jamoat (district) Hurmi.

\footnotetext{
${ }^{46}$ This is another of Latour's ideas and I've since forgotten where it came from. The point about using the word complicated over complexity is that our research sites even if they extend to all of society, are not snowflakes or some other self-organizing thing. Rather they are made of intentions, programs, goals and intentionality. That unintended effects are often rampant shouldn't cause us to default to a position that ignores the agencies of the various actants involved and this is precisely what occurs when we replace agency with self-organization.
} 
Annex A

(uster Communities: Shingak (pop. 1079, 60\%-Turk, 40\%-Tajik), Garibak (pop. 2351, 100\%-Tajik), Sarikamar (pop. 935 , 99 25\%-Tajik), Havzak (pop. 1014, 99\%-Uzbek), Chot (pop. 800, 99\%-Uzbek), Changal (pop. 715, 99\%-Uzbek) Navobod Mahalla (pop 1050, 100\%-Roma) Snapshot of relations: This cluster consisted primarily of ethnic minorities - Uzbeks and Turks in Jamoat Hurmi and a community of Roma on the edge of Penjikent city. In a cases, people felt that their ethnicities were a hindrance to economic development as the local government largely ignored them and their problems. Foremost among these problems was the deterioration of the irrigation infrastructure of the region, which was badly in need of repair so that rice harvests (the main economic activity) could reach their potential. Furthermore, relations between villages were not well developed, with frequent conflicts arising over access to water and grazing land. Relations between the Roma population and their neighbors were especially poor with the population of Navobod not developing any ties whatsoever with their neighbors. Problem and Conflict before PCT

- Natural disasters regularly taking their toll on the region; irrigation water poorly distributed and disrupted by floods and landslides.

- No interaction or joint events among youth of the communities, despite their proximity to one another

- $80 \%$ of irrigation pumping stations broken

- Distrust between ethnic group

- Population's perception of government in problems.

- Poor ecological situation

- Widespread infectious diseases transformer replacement and electric lines installed in Navobod.

Irrigation Pump Station reconstruction and groundwater drainage canal cleaning in Shingak

Landslide protection channel was cleaned and irrigation water pump station rehabilitated in Garibak.

Drinking water supply system construction with a length of more than $4000 \mathrm{~m}$ and pump station rehabilitation in Sarikan Irrigation water pump station and transformer rehabilitated, roads improved and two landslide protection channels cleaned in Katta-Kishlok.

Construction of four additional classroom in Chubot.

Transformer replacement and irrigation water pump station repained in Havzak. Construction of drinking water supply system and construction of riverpank protection dam in Changal.

\section{Social Projects}

作

the opportunity to make friends across. ethnic lines and gain new skills in areas such as tolerance and leadership. Sport league-Young girls and boys from all communities participated in volleyball and football tournaments with youth from 8 communities

Jointly celebration of holidays Hundreds of community members and local government representatives participated in joint festivals such as Navruz and Children's Day. Together we are united family -Youth of four communities met to improve relations in formal and social settings to conduct joint meetings on strengthening relations following conflicts over grazing lands.

Professional training Youth gained skills in carpentry, welding and dressmaking

Taking Care of Nature -5000 members actively participated in this project to clean up their communities and learn about sustainable practices for preventing land degradation. rrigation and Drinking Water Capacity Rehabilitated five pump stations allowing for more than 250 hectares of land to be irrigated trained in establishing of Water User

Committees for the future sustainability of the projects.

More than 3,000 people are provided with clean drinking water and the number of infectious diseased was significantly reduced.

Neighbour Relations Improved - CIG leaders, community residents and especially youth now have strong relations and and regular interaction with neighboring communities and local government.

Public Services improved - Schools, electricity supply, healthcare and roads are improved as

well as the quality of drinking water.

Improved relationship with Government -

Government contribution to almost al

infrastructure projects and participation in almost all the stages of implementation of projects has improved the community-government

relationship, as well as strengthened the relations between communities.

Figure 5 Description of a Community Cluster 
In the table in Figure 5 the reader is offered in a rough idea of the location and demographics of this cluster of communities, a 'snapshot of relations'; the preexisting problems or sources of conflict; the various technical projects that took place as part of PCI; the important social projects; and the overall impact of the project. In Mercy Corps' reductionist description via the vehicle and format of its final report of activities to USAID in Garibak and other communities we see that a great deal of detail has been lost in favor of a standardized list of successful community mobilization projects. Again, locality, particularity, materiality is lost in favor of relative universality, standardization, compatibility, etc. It should be understood, however, that the Final Report covers a tremendous amount of ground as it must account not only for the last quarter of the program but the entire program from the start of PCI II to the finish. So it is not only the details of Garibak's trials and tribulations that are missing, but all similar narratives for every village in PCI II are missing.

This 'missing middle' of messy details is symptomatic of development projects in general. More often than not the energy and funding for programs are up front, at the beginning. As implementation nears completion there are not always funds available for writing narratives that do not fit neatly within the confines of either the 'logical framework' or the proposed activities in the original grant document. Writing narratives of the day to day tussle between beneficiaries, neighbors, local government, and NGO partners, was simply not an agreed to part of the PCI program. The day-to-day experiences of development managers are often just that, a personal experience that may well inform the individual's future perspective but does not affect the description of the project. 
When a development organization like Mercy Corps fails to account for these kinds of narratives, and also fails to displace them from the flow of daily experience and into the physical record, these experiences are largely lost. What substitutes for actual experiences and actual places, and as part of an actual project, is now an archival record of those projects and personal recollections. The archival record or some part of it can be retrieved and used as the basis of new projects. Indeed many of the documents produced in the years while PCI II and I were being implemented are available to Mercy Corps staff in the Mercy Corps digital library. But even the digital library is incomplete; it doesn't hold everything. The library only holds what is digitally submitted and one must assume that the digital librarian working with program staff makes some decisions about what goes into the library and what doesn't.

For PCI what one finds in the library are the grant agreements, all of the quarterly and annual reports, the original three part field study, the mid-term study, and the final sustainability field study. In essence the PCI program is re-presented through a series of published documents. The larger theoretical point is that this record now forms the primary means for articulating the PCI program. Correspondence to reality starts to seem a bit odd, because what one is corresponding to does not resemble that reality out there in the far reaches of Central Asia, rather it is only a series of printed pages, another re-presentation or articulation. Does one then make an attempt to correspond to those pages? The answer is that it is articulation all the way down. It wasn't as if field managers during the life of the program had some sort of primary access to reality. They too only had their articulations and re-presentations. Those managers who worked in the field, in their host villages, worked somewhat frantically to translate those "real" 
experiences into documents. Once translated those field documents became the basis for other documents that would eventually find their way into the physical record.

Garibak is also mentioned in Mercy Corps' Sustainability Field Study (Mercy Corps 2008) where it is noted as part of a list of communities included in the study. Garibak is listed as community \#45, part of the PCI project, community name: Garibak; Oblast (Region): Sugd, Raion (District): Penjikent (Zarafshan Valley), Country: Tajikistan, population: 2351. The Sustainability Field Study also includes this quote from one of Garibak's residents: “'the water pump didn’t work for 30 years, now it is in good condition. People contributed to the pump repair and so they value and maintain it.'- Isroilov Salohuddin of Garibak community in Penjikent" (Mercy Corps December 2007 Sustainability field study, p.16). The point here is not deride Mercy Corps for their failure to write a full and complete narrative of the events in Garibak, but rather to point out the degree to which certain elements are lost. The reasons for this have to do, to some extent, with where Mercy Corps focuses its efforts and also on what gets funded. The incident at Garibak was one fairly typical incident among literally dozens of other projects spread across a handful of regions and three separate countries. At the time this research was underway, Kevin Grubb, who was managing the PCI program in Penjikent, was being asked to fill in for another PCI expatriate splitting his time between Osh, Kyrgyzstan and Andijan, Uzbekistan. The entire PCI II program was rapidly coming to an end and the Garibak community apparently couldn't take priority over the thousands of other loose ends that Kevin and his staff were dealing with.

One key finding to emerge out of this analysis of the documents is that the way in which Mercy Corps chose to account for its activities provides the researcher with fertile 
ground for actual critique. This is the irony of post-development studies. In its desperation to show that local discourses are but a sub-set of, or are embedded in a larger, overarching discourse they miss the actual grounds upon which a development organization can be usefully critiqued. These grounds are not what a development organization's discourse resembles, but rather how does an organization constructs its discourse and with which materials, and in constructing their discourse in a particular way, what work is accomplished? What other things and activities are then authorized? But even with this resource the next person to come along and use it will not be captured by it, but rather will have to articulate a new relation. The divide between critique and practicality is as false a divide as that between nature and society. At best it is misguided to believe that one cannot help without being captured and thus rendered an unknowing dope or informant, at worst it is a pale excuse in the face of tremendous suffering for doing absolutely nothing. The ghost of Marx spins unhappily in his grave as postdevelopment fails to both describe the world, and to change it. Post-development fails to describe the world accurately as it insists that the world is socially constructed by discourses and that successive discourses are simply embedded within such "larger" discourses as capitalism and development. However, Mercy Corps' discourse is not embedded within or encompassed by another, larger, stronger discourse. Mercy Corps' discourse sits alongside those other discourses and other modes of articulation.

\section{Rendering the Landscape Flat}

There are number of features that distinguish ANT from other social theoretical perspectives. ANT is interested in networks but the metaphor of a network is extended well beyond its often technical definition. Essentially everything is a network in the 
same way that Gabriel Tarde argued that everything is a society (Candea 2010). The word assemblage might be more apt, but the acronym AAT was never going to go very far. ANT's definition of actors, actants, and propositions is also controversial when compared with other social theories. ANT's dismissal of the traditional divide between nature and society, subject and object is another of its unique traits. ANT proposes a relativistic and flat ontology (though ANT also demolishes the divide between ontology and epistemology). The flattening of the world involves a re-specification of our collective understanding of scale. Objects, actors, assemblages, and propositions are not nested within one another, embedded one in the other like a series of puzzle boxes. Objects, actors, assemblages, and propositions, sit alongside one another. The global is not a place, but a concept used to describe the linkages between localities. As such, the local is not a subset of the global, and is not sitting beneath something that overarches it. Like scale, context too is not a go-to source of explanations but must always be explained by tracing the connections between sites and asking how does something move from one site to another. What is the cost of such movement? With which vehicle is such a movement made possible? However, scale should not be dismissed out of hand, at least not by the researcher. Scale and scaling are not features of a natural world but achievements. Latour suggests that "The problem is that social scientists use scale as one of the many variables they need to set up before doing the study, whereas scale is what actors achieve by scaling, spacing, and contextualizing each other through the transportation in some specific vehicles of some specific traces" (Latour 2005; p.184 emphasis in original). In the case of Garibak and in PCI more generally in what ways did writers, managers, and staff members achieve scale? There is nothing terribly radical or even 
particularly interesting in the way PCI staff used scale. It has become cliché for development professionals to speak of beneficiaries and donors as existing at two ends of spectrum. Beneficiaries are downstream, donors are upstream, and the program stands between them. Mercy Corps also relied on an accepted Soviet/Tajik geographical nomenclature for locating their projects: village A in Jamoat B as part of Region C of country D in Central Asia. Again there is nothing particularly noteworthy or surprising in this. However, no matter how natural these divisions appear they are not the result of nature or society, but rather a product of daily use. These distinctions are re-performed daily by a multitude of various actors. Mercy Corps' use of this nomenclature simply reifies what are constructions. That they are constructed does not mean that they are false or wrong or evil, but only means that their continued existence is contingent on future performances and also displacements, such as maps, community descriptions, etc.

Latour explains that it is the way in which local interactions seem to overflow with agencies from other times and places that leads us away from them in order to seek out their source. This has to do with the way in which actors and actions seem displaced or dislocated. When the researcher comes on scene nearly every element on scene has come from some other place and there is thus a kind of natural reaction by researchers to want to visit these other places. However, the problem, for Latour, occurs when the researcher jumps too far away and attempts to explain local interactions via an overarching context, or by society, culture, etc. This movement away from an object of inquiry is recapitulated again once the researcher reaches these structuring sites. Suddenly she finds them too flimsy to use and is thus pulled back to the local site and to local interactions. Thus, for Latour, we have the recipe for the perennial "actor/system 
quandary or the micro/macro debate. The question is to decide whether the actor is 'in' a system or if the system is made up 'of' interacting actors" (2005). The solution to this quandary for ANT is to render the social world entirely flat and treat scale as the achievement of some work. To do this Latour proposes relocating the global to get beyond the reflex that causes social scientists to oscillate from local interaction to global context. Latour's next step is to "redistribute the local so as to understand why interaction is such an abstraction" and lastly the ANT scholar must learn to "connect the sites revealed by the two former moves, highlighting the various vehicles that make up the definition of the social understood as association.

\section{Relocating the global}

This first move is not tremendously difficult. Instead of jumping from local interaction to a context which substitutes as an explanation, the ANT scholar instead traces the continuous connections between various sites and in doing so the ANT scholar lays the global beside the local, the world is flat and every site is essentially side-by-side. What the ANT scholar and reader must keep in mind, however, is that every move from one site to the next requires some transformation or translation by some mediator rather than a mere intermediary that simply transports an effect without transformation. An example of the latter would be to treat Mercy Corps' discourse as but a subset of an overarching capitalist discourse. To treat discourse in this way is to reduce every actor to an intermediary.

In the case of Garibak there are a variety of mediators and transport vehicles that come from a variety of places and some of those places are quite far away. Originally it was Jim White, sitting in the Tajikistan country office, who thought of the idea for the 
PCI program (Lynn Renken Interview). That idea, however, had to travel back to Mercy Corps' HQ in Portland, Oregon (via email and telephone conversations) in order to enroll others (Lynn Renken and Steve Zimmerman) in the problematic presented by Jim's idea, namely how would Mercy Corp transform this idea into USAID a funded program in Central Asia. Once Lynn and Steve were brought on board, Jim's idea was then displaced and given a more durable form as a paper - though its unclear whether this was 'concept paper' or a simply a 'terms of reference.' In any case the idea is transformed into a document which can now travel from place to place. This document was then taken by Lynn Renken and presented to USAID where it was immediately shot down. Lynn Renken explains that they were laughed out of the USAID office (Renken interview 2005). What Mercy Corps needed, in order to enroll USAID, were more allies and these would initially come with the funding of the three-part field study that would itself eventually become the basis for the USAID request for applications that Mercy Corps responded to by writing a grant document that would eventually be approved and signed by USAID. Jim's idea has been transformed from into a document, from a document to a study, from a study to an RFA, from an RFA to grant proposal and from that to an actual project. The transformations have been immense and the additions have been many. What started as an idea ends up as a grant document that spells out in fairly elaborate terms just exactly what Mercy Corp will do, with who, when, for how long, with how much money, and with which results. PCI went from being an idea to a document, to a series of documents, to an assemblage of skills, money, documents, knowledge, and spread sheets. From its inception into the world as an idea it would, in its various transformations, eventually crisscross the planet before taking up residence in at least 
four different countries, three different Mercy Corps country offices, and a handful of villages spread across three countries. The program would begin as a cross-border development program but those cross border activities would eventually end due to the massacre in Andijan in 2005, as well as the various color revolutions in and around the region. So what began as a cross-border program would end as an inter-community development program that only dealt with borders somewhat tangentially. The point of this simple exercise is simply to focus on the number of locations, intermediaries, and transformations involved. The long arm of the US government is able to reach the Ferghana Valley via Mercy Corps but only through some very specific vehicles and for real costs. Getting PCI to Central Asia and back requires a great deal of material elements; stabilizing the new PCI groups also takes a great deal of time, money, people, offices, computers, telephone lines, local staff, hiring and other administrative systems, airlines, taxis, drivers, food, landlords, national government bodies, local government bodies, villages, villagers, youth, women, sports, soccer fields, engineers, pipes, pumps, canals, concrete, labor, etc, etc, ad infinitum. Each one of the elements in the this litany is itself also an assemblage that must be held together, that is itself overflowed with connections to other places and times. As Latour explains “... it is perfectly true to say that any given interaction seems to overflow with elements which are already in the situation coming from some other time, some other place, and presented by some other agency.... Action is always dislocated, articulated, delegated, translated" (Latour 2005, p.166. emphasis in original). In recognizing how various things sit side-by-side it becomes more difficult to imagine a world where local interactions are still explained by some distant context. 
The so-called post-soviet context is one of the common contextual explanations given for the poor state of infrastructure in Central Asia (ICG 2011; Sievers 2003). However it is not terribly difficult to draw a line from a failed pump station and its failed irrigation system to the poor community that does not have the means to repair this pump, to the various levels of government which are either too poor or too disinterested in repairing this particular pump, to the collapse of the Soviet Union and its affect on villages in the newly formed republics. The collapse of the Soviet Union has also had a tremendous impact on those in border areas as the various regimes have sought to enforce borders drawn by Stalin and his government (Roy 2000). However, one of the reasons why invoking this context is problematic is that communities will have experienced this decline in unique ways. One cannot predict how a particular community will respond to its own infrastructure problems. The relations that a particular community has with its broken infrastructure, its government, or its neighbors cannot be predicted or known without interacting with the community in question. Thus 'context' used outside of a research program that can verify the local connections that support it can only ever operate as part of what Latour calls a panorama. Panoramas are neatly painted pictures or expertly told stories that provide the viewer or reader with a kind of flawless, comprehensive, and coherent view of a particular subject. Two good examples would be Ahmed Rashid's book Taliban (2001) and Karly E. Meyer and Shareen Blair Brysac's Tournament of Shadows: the Great Game and the race for empire in Central Asia. Both books provide a kind of comprehensive view of subjects that do not easily lend themselves to such succinct coherency. The problem for the ANT scholar, or for any scholar, is that we cannot substitute panoramas for explanations at the local level. 
Panoramas may provide the research with a sort of general road map of what to expect but the details and peculiarities of particular localities cannot be simply glossed over.

\section{The Local is also an Achievement}

Latour explains that "Sticking obstinately to the 'localize the global' slogan does not explain what 'local' is, especially if action, as we have witnessed many times earlier, is so clearly 'dislocated' (Latour 2005, p.192). The answer for Latour is to treat both the local and the global symmetrically. The 'local' is just as much an achievement of some work as the 'global'. What Latour is attempting here is a kind of refocusing of our vision. Instead of looking at a place that is either or close or distant, he is suggesting the research focuses primarily on the connections between sites or what Latour calls "articulators and localizers" (p.193). The point is that the understanding that actors are shaped by things that are absent and withdrawn tells us nothing about where these things originate. All that has been established so far is that these elements do not originate in a context. Latour's solution is unique and has already been strongly hinted at. Latour explains "The meandering path through which most of the ingredients of action reach any given interaction is traced by the multiplication, enrollment, implication, and folding of non-human actors" (p.193). Garibak reduced to a basic description and written into a document can travel to Mercy Corps HQ in Portland, Oregon where it can serve as an example of a sustainable program in a discussion between development professionals debating whether or not to pursue a similar funding opportunity in the Sudan. This can only be accomplished by translating Garibak into a text as part of a digitized document that can be compressed or zipped and sent via email to a program officer sitting at her 
desk in Portland, Oregon. The social activity of discussing or debating sustainability or pursuing further funding is made possible by this displacement into some thing that is clearly asocial but just as clearly an association. Garibak's sustainability does not travel as an idea but as a file stored in various computers, entered into the digital library and possibly pulled out and rearticulated for some other purpose. This is how the world is made, with bricks and mortar but also with spreadsheets, computer programs, and flash disks. It is here where post-development and post-structuralism commit their greatest mistake: to believe that world is socially constructed out of discourse, without ever so much as a nod towards the materiality that makes such discourse effective.

Having followed Latour this far we can now ask the question, where are effects produced? Where are the power relations? How do they travel and in which vehicle dispatched by which agency? Rather than development happening behind our backs as Ferguson (1995) suggests, it is all before us. Certainly there may be unintended effects produced by development but that is now a function of our uncertainty, and those uncertainties can be pursued in exhausting detail if necessary.

\section{Political Relevance.}

The seemingly contradictory finding of this research into PCI and Garibak is that Mercy Corps engaged in a fairly robust form of politics vis a vis its development intervention but in its accounts of these activities the politics as such disappear. In a real sense every successfully finished project provided an important kind of political closure, 
at least for the moment. One could also argue that there are no politics in the account because of that closure. Mercy Corps is no more enthusiastic about re-visiting politics than are the people of Garibak; life moves on and what end would it serve? Mercy Corps quite clearly cannot engage in open and combative politics with either its donor or its various host governments without risking either its own funding or its welcome to stay and its permission to implement programming that benefits local communities.

The question regarding depoliticization is two-fold. Did Mercy Corps depoliticize its interventions and did they also depoliticize its accounts of development. The first question has already largely been answered. The second question is more difficult to answer since the question itself is political because it asks in what other politics should Mercy Corps involve itself? It can be seen that post-development only ever offers up a single type of politics and that type is always in a sense revolutionary and also outside of common experience. The lesson of ANT, however, is that politics cannot be known in advance of articulations. Instead, politics should be understood as what Latour calls the "progressive composition of the common world" (2004; p.247). Latour (2004) describes this composition as an "Expression that replaces the classic definition of politics as an interplay of interests and powers: the common world is not established at the outset... but must be collected little by little through diplomatic work done to verify what the various propositions have in common. Composing is always contrasted with short-circuiting, shortcut, arbitrariness..." (p.247). The problem faced when examining post-development is that it critiques one short-cut taken by people and institutions it does not favor by positing its own set of analytical short cuts for demanding a particular kind of politics. Importantly, from the perspective of post-development it is 
simply not possible to compose a common world. A common world simply does not exist; the world comes pre-composed of discourse, privileged scholars, those captured by the system, and those who escape because of their grass roots. Those that are captured by the system are the damned, those that offer a real alternative to development form the saviors, and the post-development scholars are the prophets. This research has demonstrated, however, that Mercy Corps did engage in a collective composition of the world in concert with local staff, USAID, beneficiaries, communities, pumps, canals, etc. The nature of good community mobilization essentially involves gathering together people, things, and others to ask a question of the collective: what is to be done. This much Mercy Corps accomplished via its community mobilization methodologies. Community mobilization, however, is not a panacea for good development. The test of whether or not community development lives up to its name comes from understanding the extent to which the organization mobilized facts or relied on matters of concern.

Thus the political relevance achieved by Mercy Corps was its demonstration that it could operate in good faith as a diplomat in the successful if ultimately short-lived experiment of forming a common world with strangers in a strange land. If there is something that Mercy Corps could have done better, it is that they could have represented the entire struggle in all of its complicated and hard-to-relate details. A fuller analysis of the political relevance of both Mercy Corps' program and this research will be taken up in the final chapter of the dissertation. 


\section{Chapter Seven - Ziddi and Mingdona Case Study}

\section{Description of PCI in Ziddi and Mingdona}

This embedded case study is an examination of PCI activities in the two neighboring communities of Mindona and Ziddi in the Penjikent region. One of the important changes in the second iteration of PCI was that the program was no longer a 'cross-border development program' and would instead focus its work on intercommunity relations on. Most cross-border activities between Tajikistan, Kyrgyzstan, and Uzbekistan ended after the massacre in the Uzbek city of Andijon ${ }^{47}$. Mercy Corps explains some changes from PCI I,

Although unique for its cross-border inter-ethnic peace building activities in the Ferghana Valley, in 2004, the PCI project expanded to encompass the Penjikent Raion of Tajikistan, an isolated, poverty-stricken region of the country with an ethnically diverse population and a hot spot of ongoing conflicts among villages and between communities and government. This expansion in the geographical reach of the project was the first of many changes to come in the project's fourth year and challenged PCI to adapt to the changing environment or suffer obsolescence. Such changes included the closing of international borders prohibiting the implementation of cross-border projects, once the bread and butter of the PCI project; the increased focus on economic development in target communities, thus more deeply addressing one of the root causes of conflict; and the difficult operating environment in Uzbekistan, leading the project to make quick and applicable shifts in its approach to adapt to the changes (Mercy Corps 2007).

Because of the move away from cross-border programming the Penjikent region and the

focus on clusters with opposing ethnicities would be a unique addition to the PCI

\footnotetext{
${ }^{47}$ See David Lewis, The temptations of tyranny in Central Asia. (Hurst London 2008); Holly Cartner, Uzbekistan: "Saving its secrets": government repression in Andijan, (Human Rights Watch United States 2008); or Crisis Group International “Uzbekistan: The Andijon Uprising," 2005 Asia Briefing N³8 25 May 2005 http://www.crisisgroup.org/en/regions/asia/central-asia/uzbekistan/B038uzbekistan-the-andijon-uprising.aspx; (Bishkek/Brussels 2008).
} 
program. Though there would be no "cross-border" villages one could argue that the Penjikent region is still very much affected by borders and border closures. The Zarafashon Valley is hemmed in on three sides. The valley is bounded on the north and south by 3000-meter tall mountain ranges whose passes are often closed for six or more months every year due to snow and poor road conditions. The Eastern end of the valley opens up fairly dramatically to the plains of Samarkand in Uzbekistan. The Tajik city of Penjikent was once a distant suburb of Samarkand. Now, however, during winter months, if Uzbekistan closes the border west of Penjikent on the only road leading out of the valley, the communities of the Zarafashon Valley find themselves completely cut off from the rest of Tajikistan (Jonson 2006). The IMF Tajikistan Country Report states that, "difficult relations with Uzbekistan remain the bottleneck for Tajik exports. All commercially viable export routes - the only railroad and a few highways - go through Uzbekistan. During the winter closure of the Anzob Pass, Tajik traders have to transit through Uzbek territory even for domestic trade between the south and the north of the country (IMF Country Report No. 05, 31 April 2005). This situation has been somewhat improved in recent years by the construction of the Anzob tunnel. According to a Tajik website the tunnel officially opened in March of $2006^{48}$. Indeed there is even a page on Facebook which refers to the Anzob tunnel as the "Tajik Tunnel of Death." The Facebook page has this to say about the tunnel,

If you're been to Tajikistan, chances are you passed through [the Anzob tunnel]. 20 minutes to 4 hours in length (depending on traffic and accidents). A foot of running water. No air but plenty of fumes. Broken down cars and equipment. Single lamps hanging down to give it that "abandoned coal mine" feel. The

\footnotetext{
${ }^{48}$ http://www.anzob-tunnel.tj/news.htm accessed April 5, 2011.
} 
president [Rahmon] refused to go through it at the opening. You get the idea. Anyway, you survived? You're in the club ${ }^{49}$

More recent rumors suggest that the tunnel has been somewhat improved, but the fact of its early opening is a testament to how desperate the transportation situation is for transiting in and out of the Zarafashon valley. My only experiences traveling the Anzob Pass occurred before the tunnel opened. Traveling from Dushanbe to Khujand and transiting through the Zarafashon valley meant crossing the Anzob Pass by road. The very top of the Pass was still covered with at least 6 meters of snow and a crude road had been cut through the snow. At the time I was told that every few weeks the entire snowfield would shift 100 meters downhill thus obliterating the road while taking with it any vehicles present on the Pass. The larger point to be made regarding the Zarafashon Valley is that it is isolated by both natural features and the Uzbek borders. Additionally, the ethnic composition of villages in the clusters chosen emulates the conditions between PCI I cross-border communities.

The villages of Mindona and Ziddi are ideal for Mercy Corps' PCI program. The criteria for selection into the PCI expansion program were based partly on the existence of tensions or conflict between villages. The reader will recall from the previous chapter that the following selection criteria were used in the PCI II program for the Penjikent region:

- the communities' proximity to a border;

- location in a "cluster" of communities across or in a border region;

- history of or potential for future conflict;

\footnotetext{
${ }^{49}$ http://www.facebook.com/group.php?gid=19529314027 accessed March 2011.
} 
- strained community relations with local government representatives;

- scarcity or mismanagement of resources;

- ethnic minority or mixed ethnic population;

- low economic standards and lack of employment opportunities;

- large population of disenfranchised youth; and

- isolation from government or commercial centers (Mercy Corps 2007).

The difficulty for PCI managers and staff in the Penjikent region was in finding 'clusters' of communities that shared these criteria (Mercy Corps 2007). The four communities of Jamoat Yori was formed by two pairs of neighboring villages, Mingdona and Ziddi and Veshist and Soi Veshist, that exhibited some or all of the above criteria. Mercy Corps describes this cluster in its "Snapshot of relations" that form Annex A of the final report to USAID:

This cluster consists of villages of Tajiks and Turks. Residents of Ziddi felt neglected by local officials, insisting that their ethnic Tajik neighbors in Mingdona were favored. They also had no access to irrigation water due to the destruction of the irrigation system that previously served the area. Soi Veshist cut off relations with Veshist primarily over a dispute over funding for their Uzbek-language school, a branch of the Tajik-language school in Veshist. Tension over access to resources exists in Veshist between resettled residents, including many Turks originally from Soi Veshist, and original inhabitants of Veshist. After the break up of the kolkhozes into Dekhkan farms, disagreements arose among villages over the redistribution of land (Mercy Corps 2007).

The projects and various problems associated with the villages of Veshist and Soi Veshist had been completed and resolved. However, the Zidd/Mingdona shared canal was in the final stages of completion and offered a small window of opportunity to discuss the project with the local villagers while it was still ongoing. 


\section{Ziddi and Mingdona a History of Conflict}

I had been told and had read in the various reports that the communities of Mindona and Ziddi were both marked by strained relations between themselves and also between Ziddi and its local government. According to Mercy Corps, "Ziddi residents have voiced frustration at being ignored by officials, something they attribute to their ethnicity. Furthermore, this whole region is an area where there has been very little activity on the part of international organizations, adding to overall feelings of resentment and isolation” (Mercy Corps QR Oct - Dec 2004).

Upon entering Mingdona one would not know by merely looking that the village was actually two villages. The larger village of Mindona (pop. 1527) sits near the bottom of a small river valley, running north and south, that branches off perpendicularly from the Zarafashon river valley that runs from east to west. The smaller village of Ziddi (populatoin 964) sits $2 \mathrm{~km}$ further north up the valley. Both villages are approximately 10 kilometers east of the administrative center in Yori town. Additionally, both villages are dependent on remittances from family members working abroad in Russia, though according to Mercy Corps, Mindona earns “... significant income ... through rice cultivation.” Ziddi also earns some additional income from livestock (Mercy Corps QR Aug 2005). 
Annex A

4 communities of the Jamoat Yori, Penjikent Region: Mingdona, Ziddi, Veshist, Soi Veshist

Cluster Communities: Ziddi (pop. 980, 80\% Turk, 20\% Tajik); Mingdona (pop.1541, 100\% Tajik), Soi Veshist (pop.256, 100\% Turk); Veshist (pop.1145, 85\% Tajik, 15\% Turk). Snapshot of relations: This cluster consists of villages of Tajiks and Turks. Residents of Ziddi felt neglected by local officials, insisting that their ethnic Tajik neighbors in Mingdona were favored. They also had no access to irrigation water due to the destruction of the irrigation system that previously served the area. Soi Veshist cut off relations with Veshist primarily over a dispute over funding for their Uzbek-language school, a branch of the Tajik-language school in Veshist. Tension over access to resources exists in Veshist between resettled residents, including many Turks originally from Soi Veshist, and original inhabitants of Veshist. After the break up of the kolkhozes into Dekhkan farms, disagreements arose among villages over the redistribution of land. Problem and Conflict before PCI

- Inability to secure water for 180 ha of land allocated mostly to the

- villages of Ziddi and Mingdona.

- A lack of water for land allocated to 70 young families living in

overcrowded conditions in Ziddi.

- Insufficient levels of electricity for the original residents of Vehsist and the new mahalla, consisting largely of relocated ethnic Turk residents.

- Yearly flooding and landslides overwhelmed the makeshift dam constructed by residents of Veshist, and threaten lands of Mingdona.

- Lack of clean drinking water for the residents of the newer parts of Veshist, including many ethnic Turks from Soi Veshist, resulting in high levels of infections and adding to tensions.

- Condition of school in Soi Veshist too decrepit to conduct classes in the winter, increasing tensions with Veshist, whose school is supposed to release funds for Soi Veshist's school.

- Frustration on the part of residents, especially ethnic Turks, directed perceived inaction of local officials.

\begin{tabular}{|c|c|c|}
\hline Tech & Key Social Projects & Impact \\
\hline $\begin{array}{l}\text { Irrigation System Construction in Ziddi } \\
\text { and Mingdona -irrigation system of } \\
\text { over } 1500 \text { meters constructed, providing } \\
\text { water for over } 100 \text { ha of land of the } \\
\text { village of Mingdona, } 30 \text { ha for Ziddi as } \\
\text { well as } 50 \text { ha of land for the Jamoat } \\
\text { center. } \\
\text { Mudslide diversion system in Mingdona } \\
\text { - to protect rice fields and the canal } \\
\text { supplying them with water. } \\
\text { Transformer Replacement in Veshist - } \\
\text { thereby improving the entire } \\
\text { community's electricity. Residents of the } \\
\text { new mahalla financed themselves } \\
\text { electric lines to from the transformer to } \\
\text { their mahalla. } \\
\text { Reinforcement of a dam in Veshist - } \\
\text { which provides irrigation water to local } \\
\text { rice fields. } \\
\text { Drinking water provided to the new } \\
\text { mahalla in Veshist - from a spring } 4.5 \\
\text { kilometers distant. } 11 \text { taps included. } \\
\text { Uzbek-language School Constructed in } \\
\text { Soi Veshist - The school was promoted } \\
\text { from a branch of the Veshist school to a } \\
\text { full school. It gives students the } \\
\text { opportunity to study year-round in warm } \\
\text { conditions. }\end{array}$ & $\begin{array}{l}\text { Youth from all } 4 \text { villages participated in } \\
\text { the Youth Forum held to provide youth } \\
\text { with training in leadership, teamwork, } \\
\text { conflict mitigation and gender issues in a } \\
\text { multi-ethnic environment. } \\
\text { Sports tournaments held for youth and } \\
\text { young adults of the } 4 \text { PCI villages, as } \\
\text { well as neighboring villages, bringing } \\
\text { together youth of different ethnic groups } \\
\text { for positive interaction. } \\
\text { Youth newspaper "Parastu"- Over } 4 \\
\text { months youths from all } 4 \text { villages of Yori } \\
\text { developed critical thinking skills through } \\
\text { the publication of this youth newspaper. } \\
\text { Vocational training held for youth in the } \\
\text { region - carpentry for boys and young } \\
\text { men, clothes-making for girls and young } \\
\text { women. } \\
\text { The } 4 \text { villages carried out joint holiday } \\
\text { celebrations throughout PCI } \\
\text { implementation, regularly bringing } \\
\text { together community leaders from all four } \\
\text { villages for positive, productive } \\
\text { interaction. } \\
\text { CIG members from all communities } \\
\text { participated in a series of CIG trainings } \\
\text { designed to improve their abilities to } \\
\text { develop their own communities. }\end{array}$ & $\begin{array}{l}\text { Water problems eased - } 180 \text { ha of land } \\
\text { provided with irrigation water, } 70 \text { young } \\
\text { families from Ziddi move to land newly } \\
\text { provided with water. Agreement, facilitated by } \\
\text { local government, signed by communities, } \\
\text { governing water usage. } \\
\text { Good relations fostered between villages - } \\
\text { Relations between villages improved through } \\
\text { addressing problematic infrastructure issues } \\
\text { (electricity, drinking and irrigation water, } \\
\text { school) and bringing community residents } \\
\text { together for positive interactions. } \\
\text { Understanding principles of mobilization - } \\
\text { Through significant community contribution } \\
\text { and technical projects completed without } \\
\text { donor support, community members show an } \\
\text { understanding of the need for community } \\
\text { mobilization. } \\
\text { Improved Government Relations - } \\
\text { Government officials negotiated water-use } \\
\text { agreement between Ziddi and Mingdona, } \\
\text { while raion officials provided inventory for } \\
\text { the school in Soi Veshist, establishing the } \\
\text { precedent of positive community-government } \\
\text { interaction. } \\
\text { Standard of living raised through improved } \\
\text { electricity, access to clean drinking water and } \\
\text { the construction of a new school. }\end{array}$ \\
\hline
\end{tabular}

Figure 6 Description of a Community Cluster 


\section{Success and Closure: Building a Strong Narrative.}

Ziddi, a community of Turkish-Uzbeks who trace their history in Tajikstan to the Varzob river valley near Dushanbe and also trace their ancient history to what is now modern day Turkey, has been in conflict with its geographically close but Tajik neighbors in the village of Mingdona since the breakup of the Soviet Union and Tajikistan's independence. In 1991 the Government of Tajikistan redistributed the lands held in common between the two villages as part of a privatization of what had been collective farms under Soviet rule and referred to locally as either a kolkhoz or Dekhan farms. According to Mercy Corps Mingdona is alleged to have used whatever relatively privileged access it had to local government as ethnic Tajiks to assure themselves access and rights to the most hectares of the fertile land it had previously shared in common with Ziddi and other neighbors. Olivier Roy confirms the importance in Central Asia of gaining access to resources through ethnically based networks. Roy explains that the first effect of Soviet collectivization was to terminate all forms of nomadism and semi-nomadism, and to bind rural communities to the land while at the same time limiting the possibilities for rural exodus. In the Soviet system one's social existence was constructed around belonging to a 'collective'... and this oliged the individual to identify with a group (in the countryside this group was the kolkhoz). The group acted as a social mediator for the individual: one's administrative existence (internal passport), the availability of basic social services, and the right to housing and travel were conducted through this group (Roy 2000, p.86)

Earlier in his book Roy speculates that Soviet system must have indirectly reinforced some identities and those identities that are still operative are those that are still, in some sense, represented by administrative or political categories which remain active, such as the collective farm (kolkhoz), the neighborhood group (mahalla), or their district 
$(\text { Raion })^{50}$ (Roy 2000, p.22). It is an open question whether or not this is the case with Mingdona's apparently privileged access to land, water, and government. Regardless of whether or not this can be proved it is certainly the impression of villagers living in Ziddi (group interview, community development team 5, 08 July 2006).

This apparently one-sided redistribution of land left Mingdona in possession of irrigated land that it could use for more than simple subsistence farming but left Mingdona with only rain-fed lands and limiting them to subsistence farming. One of the infrastructure projects that the communities agreed to involved the construction of an irrigation canal that would cross a gap some 400 meters wide between two cliffs. Prior to the start of construction the two communities were required by PCI to collect a community contribution of the equivalent in Somonis (TJS) of $\$ 6000$ US dollars. The community would add in-kind contributions of labor and food as the old canal was re-dug and the new canal was cemented. Mercy Corps writes "When water began flowing from one side of the valley to the other... not only was water restored to parched lands, but relations were restored between former adversaries" (Mercy Corps 2007). The completed project will provide irrigation water to 130 hectares of land dedicated to growing wheat and orchards for both communities. Mercy Corps notes that Ziddi had already begun construction of new homes on " 70 plots of land.... Filling a great need in this land-starved community" (Mercy Corps 2007).

Haji Holik explained that the opening of the canal in Ziddi, with its source being a spring in the mountains behind Ziddi, would allow them to trade water for land. Holik

\footnotetext{
${ }^{50}$ The reader will recall that Tajikistan is divided into oblasts (provinces) that are further sub-divided into districts (Raion), municipalities (Jamoats), and villages which are further subdivided into neighborhoods (muhallas). The Hukumats are the political/administrative bodies that govern at the Jamoat level.
} 
also explained that they will give Yuri access to the water and Yuri in return will give/lease them land for cultivation. While the economic benefits are not known in detail Holik believes they can be safely surmised: more land in cultivation means that Ziddi should be able to move away from rain-fed subsistence farming and perhaps be able to sell more produce at the market in Penjikent. Haji Holik was also quick to point out that the irrigation canal would, in addition to allowing the two communities to bring new land into production, also allow about 70 families from both communities to move out of homes they share with their parents and grandparents.

One resident of Ziddi, Nasim Boboev, is quoted by Mercy Corps, “"we are the happiest community in Yori Jamoat, because now we have water, which has been the dream of the entire community for the last 25 to 30 years. The water project has greatly impacted the livelihood of the community, both morally and materially. Also, now we have strong relations with Mindona, whereas before, due to the break-up of the Dekhan farm and the lack of water, we always had tensions between our communities"' (Mercy Corps 2007).

One of the striking differences between this case study and the previous Garibak case study is in the remarkable way that success has concretized a shared narrative between the spokespersons for Ziddi and Mindona and PCI staff as well. The point of this chapter will be to examine this success in terms of the kind of strong closure that was in evidence when speaking to literally anyone connected with the project. The purpose of this exercise is simply to demonstrate the political nature of this particular project and the power or efficacy of that this particular canal has in holding together a particular narrative about and between communities. Where in the previous case the research 
demonstrated that a failed pump simultaneously meant failed social relations, here we can see that a successful infrastructure project had, at least in the short term, cemented positive social relations.

\section{In Ziddi}

Prior to arriving at the PCI office in Penjikent for another round of interviews I had asked one of the PCI staff members if they could inquire with the village of Ziddi about the possibility of hosting me for a few days so that I could see the canal project for myself, ask a few questions, and also get at least a limited sense of village life. I had also asked Mercy Corps to find a translator who spoke Russian, Tajik, Uzbek and English, and surprisingly enough they did. On Tuesday Morning July 4th, 2006 I was met at the PCI office by my new translator, Umer, a young man of 17 years, and Haji Holik, a 78 year old farmer from the village of Ziddi who would act as my personal guide while in Ziddi. Haji Holik was traveling with a woman to whom I was not introduced. I suspect, but was never able to confirm, that they, or at least Haji Holik, had come to Penjikent specifically to meet me and bring me to the village. It was at Haji Holik's house that I would be staying. Before leaving for the village I spoke with Umer about what I needed for translation. I suggested that I needed as much of the conversation as was possible and he was only too eager to agree. While his English was much better than my Russian it was still far from perfect. However, given the time constraints I felt lucky to have a translator at all, as the trip would have been completely useless without him. Umer would become my research instrument and my only linguistic connection to the extremely odd world I was about to enter. 
I need to foreground this description by saying that my trip did not go as well as could be expected. The translator was less than optimal and I had failed to secure any time to interview members of team 5 . Team 5 had been with the Ziddi project from the start. Not getting any interviews with Team 5 about Ziddi, prior to this visit, would prove to be my biggest problem as they were privy to a lot of information that the community simply refused to talk to about with me. Also, had I been privy to some of the information that I later discovered, I believe I would have been able to push harder into some of the conflict related issues. However, the fact that I didn't get any interviews, and that I went in cold, would prove to be a lesson in both Tajik protocol and the power of a closed narrative. The lesson in protocol seemed to be, never air your dirty laundry to an outsider, especially if that outsider is a representative of the United States. It was later explained to me that most of the villagers had this vague notion that I was some strange sort of envoy from the United States Government. Given my status, my informants would successfully resist any and all attempts to get them to talk in any detail about conflicts or potential conflicts with other communities. In fact any questions not related to the technical specifics of the canal project were met with vague answers. After a day and a half I was not getting any more clarification or information on my questions about the project. One explanation for this reluctance was that the project was a success. The project was also, for all intents and purposes, finished. All that remained at the time of my visit was the organization of the final presentation where the project would be consecrated as one of the most successful PCI programs in the Penjikent cluster. The following is taken from field notes and interviews taken during my briefest of times in the village of Ziddi. 
When I first arrived at Haji Holik's home in the village of Ziddi I immediately began asking for details about the canal. He referred to the canal as the Kahlifi Hassan canal. Kahlifi Hassan had come in 1939 from what Holik explained as the original village of Ziddi in the Varzob river valley near Dushanbe. Kahlifi was an eshoni which is like a mullah or an imam, my translator says "like prayer" and suggests Mullah. Holik explains that they came to the present day location of Ziddi in 1931 just two years after Tajikistan was disconnected from Uzbekistan due to Stalin's redrawing of the boundaries between these two nations. Holik explains to me that as a young man he used to swim in the canal.

It was at this point in Holik's narrative that I thought to ask about the previous conflict with Mingdona, to which Holik replied, "Before there was not any conflict." (Holik, Haji. Personal Interview 04 July 2006). This turns out not to be true, although I don't believe that Haji Holik was lying. After my return to Penjikent I did get the opportunity to interview two members of Team 5, Jovid and Kameel. They explained that there was indeed some conflict or disagreement between the two villages, although there had not been open conflict, which is to say that no one had taken up arms. An important aside here is that the word 'conflict' has very strong connotations in Tajikistan and perhaps also the rest of Central Asia and it would have been better had I used the word disagreement. However, when I was faced with a non-answer I did use the word disagreement but then would only get little more than 'yes there was disagreement about the canal' and when I pressed them for details I got nothing. At any rate, the basis of the disagreement was land and water. Mingdona at the time had access to (enough) water and land and because of its connections to the local government had recently done very 
well in government land re-distribution scheme. When I spoke with Kevin Grubb about the project he provided some additional information regarding negotiations with Mingdona. According to Kevin, in order to get Mingdona to agree to the canal project, which was a shared project, they also asked Mercy Corps to fund a separate project exclusively for their community ${ }^{51}$. Additionally Mingdona believed that the canal could not provide enough water for both Ziddi and Mingdona and thus they were not convinced that it would be a useful project for them. It was not until Mercy Corps agreed to fund an additional and exclusive project in Mingdona and a water expert was brought in to measure the flow of water and declared that there was enough water, that they changed their minds. Holik also confirmed this. Holik explained that "Mingdona was not agree... they $[\mathrm{PCI}]$ begin this project and Mingdona was not agreed... First, Mingdona was not agreed and expats explained that it will be enough water for 2 communities.... Expats came from Khujand, a tall German, came and explained that there was enough [water]". Holik also explained that Ziddi and Mingdona paid for the project through PCI and both communities raised money and contributed labor for the project.

I ask Holik how much more land would be available for farming. At first Holik said $1 / 2$ hectare, but it was unclear if he meant per family. Holik then explained that 100 Siddik $=1$ hectare and that each family would receive 6 Siddik. At this point in our conversation I pulled out the three documents that I had with me, the Infrastructure Project Description, and the Project Selection document, and another document listing all of the social projects. Holik asked me through Umer "if his account is accurate with the papers that you have" and Umer urged me to stop writing. Holik was under the

\footnotetext{
${ }^{51}$ This is the "mudslide diversion in Mingdona" mentioned in Annex A in Figure 5.
} 
impression that I was some kind of auditor, even though I had explained that I was doing research for my PhD. From Holik's perspective, though, I was a stranger from the United States and the canal was being built by the United States Agency for International Development. The community had even embedded the acronym USAID into the side of the canal with shiny stones. Thus it was difficult to shake the impression that I was there to judge the project in some way. Even my own translator had begun to feel nervous with my questions. After this short initial interview Holik made his way to the side yard where a large black sheep was tied to a post. Holik butchered the sheep in my honor, though secretly I am somewhat horrified by the thought that my visit has cost them some of their personal wealth. However, hospitality is a kind of sacred value to the people in Central Asia and Hajik Holik is no different. Later, when I returned to Penjikent and asked about the sheep slaughter, I am told that it would have been tremendously rude to refuse and I am somewhat mollified.

The rest of my time in Ziddi was spent either at Haji Holik's modest home or walking through the two villages. I did attempt to interview a handful of other men about the conflict with Mingdona but I was given the same basic narrative: at first they did not agree to the project but later they did and now that it is done they are all good friends. I do not believe, as I wrote earlier in regard to Haji Holik, that any of the men I interviewed are lying. I do believe, however that their answers were tempered by their assessment of my identity and also the basic fact of the matter: the canal was largely finished, the water was flowing and life for them would be better. 


\section{Success and Uncertainty}

At this point it will be helpful to review the case in light of Latour's sources of uncertainty and his thoughts on scale and political relevance. Recall that for Latour there are five sources of uncertainty and these pertain to groups, action, objects, facts, and accounts. In addition to these sources of uncertainty Latour recommends a methodology for rendering the social world flat so as to reveal the topography of its connections. To do this Latour recommends making three moves: these moves involve understanding the global as local; reorganizing the local so as not to fetishize it in the way Latour believes the global has been fetishized; and finally retracing the connections between various sites.

The point is that phenomena are not embedded in one other in some bizarre recursive system where interdependent phenomena (actor/system, power/knowledge, nature/society) are ranked in orders of magnitude so that the further one travels from the center the more important the phenomena. Rather these phenomena sit alongside one another, each situated in a real place populated with real actors mediating the differences between themselves. Global isn't a place but rather the description of a set of relations and also a kind of achievement or outcome of some structuring activity. However, while the global does not offer a panacea for difficult-to-explain local interactions, neither do local interactions offer a stable space where questions can be finally answered. The reason for this is that locations are not perfectly bounded events with actors that are fully accounted for by their mere presence. Instead the researcher quickly realizes that local interactions are tremendously complicated due to the fact that every actor on scene has in some sense been compelled on scene for some unknown, perhaps unfathomable reasons 
(Latour 2005, p.166). Thus one can imagine any location as a kind of web connections with threads that lead elsewhere. Methodologically, we ought not leap to context, or society, or some other global explanation. The best a researcher can do is to pick up a thread and follow it from one site to the next. The notion of connecting sites replaces the sociological move of jumping back and forth between interactions and context.

Following the threads or traces left by real actors in real places will eventually lead us to real explanations, or at least to descriptions that provide a stronger basis for asking was something done particularly well or not. Actor-network theory descriptions then provide a basis upon which others can ask political questions. Additionally, the approach of actor-network theory is not only good at revealing the political relevance of our studies but also the political relevance of the work done by those who are studied.

\section{Groups}

At this point in the development process there is not a lot that can be said about groups. The hard work of choosing communities and clusters and then engaging those selected communities in various community mobilization methodologies is long past. Ziddi and Mingdona had been translated into PCI "cluster" communities almost two years previous to the start of this research. What is left is a nearly finished project that is in the final stage of closing down. By all accounts both communities (as well as the village of Yuri which turns out to be an indirect beneficiary of Ziddi and Mingdona having more water) are completely satisfied with the outcome. The satisfaction is so complete and pervasive that it seems the two communities have reached a kind of 
détente. Ziddi no longer feels 'blocked' from its ancestral home in Turkey ${ }^{52}$ but now has access to new lands that are unfettered by the accidents of history that had left the largely Tajik village of Mingdona holding all the best land.

In this scenario what then becomes of the various groupings left behind by PCI? Mingdona and Ziddi will again become non-PCI communities; the CIGs will melt back into the general population. What remains are water user groups charged with maintaining the canal, and these groups are held together by mutual consent, written documents, and the demands of the canal for cleaning and maintenance. But there is a kind of new group being performed. Identity and subjectivity should not be seen as fundamental essences but rather as an effect of the various relations that people and objects enter into. Gabriel Tarde, who Latour recognizes as the father of the sociology of associations, says this of identity,

To exist is to differ; difference, in one sense, is the substantial side of things, what they have most in common and what makes them most different. One has to start from this difference and to abstain from trying to explain it, especially by starting with identity, as so many persons wrongly do. Because identity is a minimum and, hence, a type of difference, and a very rare type at that, in the same way as rest is a type of movement and the circle a type of ellipse. To begin with some primordial identity implies at the origin a prodigiously unlikely singularity, or else the obscure mystery of one simple being then dividing for no special reason (Tarde quoted in Latour 2005, p.15).

Ziddi and Mingdona are complicated entities. Complicated by history, religions, ethnic identity, geography but also complicated by sets of materially based social relations. The two villages have different levels of access to the same material resources such as water,

\footnotetext{
${ }^{52}$ After explaining the village's Turkish origins Haji Holik pointed that the only road out of Ziddi went through Mingdona and thus he felt that Mingdona was blocking Ziddi from its ancestral home. The new lands, as Haji Holik pointed them out to me, actually sit on the western edge of Mingdona and offer the new residents an open view of the west and their ancestral homes beyond (interview July 5 th).
} 
and land, but also, and perhaps because of their identities, differential access to government and government services. If identity is relational and based on a concatenation of elements, both human and non-human, then this research must conclude that being a non-PCI community (not selected) is different than being a PCI or a post-PCI community. In the same way, Ziddi with a functioning canal and access to land is different from Ziddi with no functioning canal and limited access. Knowing the identity of the community does not help much for providing information or explanations about the relations of the community. Identity, even that provided by membership in a particular group, can never go very far without either displacing itself into some material reality, a bridge, a document, a wall, etc., or by continually re-performing and representing itself.

\section{Action}

One of the interesting phenomena that ANT draws attention to is the way in which closure tends to conceal action. A successful project eventually becomes a kind of authorless object in the landscape of the community. The political work that was necessary to put the project together, to get the project to hold together is no longer needed. If politics are defined, as Latour defines them, as a kind of gathering where what is brought together are not only the right people but also the thing that unites or divides them and assembled in such a way as to render facts as matters of concern, then this is what Mercy Corps' PCI project managed to do in concert with the people and things of Ziddi and Mingdona. This research found no evidence of Mercy Corps' deploying a set of facts to influence the groups into a pre-designed outcome. Neither did this research find Mercy Corps treating its interlocutors as anything but full-blown mediators instead 
of intermediaries. The data showing how Mingdona eventually agreed to the project after initially objecting and holding out for more concessions attests to the fact that they were not passive intermediaries but rather involved and active mediators translating PCI to meet their own ends even as they themselves are being translated and enrolled to meet PCI's ends.

Groups begin to fade from view or take on other concerns that are beyond the range of Mercy Corps' interest or capacity. Action too begins to fade as it is taken over by a completed canal and a strong narrative. Objects find their way into this narrative as the absolutely essential elements that make social agreements possible in the first place. There can be no denial of conflict or an esprit de corps without a functioning canal delivering enough water, or without Mingdona's flood protection scheme, or without the necessary drop in elevation from one side of the chasm to the next. Earlier in this paper it was mentioned that part of the canal project involved bridging a 400-meter gap between two cliffs. This technical difficulty, at one point, threatened the future of the project. Had the far cliff been a meter higher then the water would not have flowed through the pipes down one cliff and up through the pipes on the other side. Part of Ziddi and Mingdona's futures hung in the balance. In the end there was just enough drop in elevation to ensure the flow of water to the new lands. The positive social relations that were evident in my discussions with villagers were made possible, in part, by this 2 or 3 meter drop, and the canal, and the concrete, and the water, all working in concert to perform this irrigation system. Objects underwrite our sociality and secure our agreements. 
Groups are performed, action is displaced, objects are part of the account, and now facts are either deployed as a short-circuit to politics, or are rendered as matters of concern and laid open to examination by interested parties. This is what happened when the original project had been proposed. Mingdona attempted to short circuit politics and hit Ziddi and Mercy Corps's PCI program with the fact that there was just not enough water to make it worth their while. This objection was eventually overcome. Mercy Corps enlisted an ally, a German hydrologist, to test the flow of the water. Again, there is no evidence to suggest that PCI ever operated outside of this unarticulated boundary between facts and matters of concern. This is important because it is a typical feature of failed development projects, that they are often implemented based on matters of fact ${ }^{53}$. Basing development decisions on the facts at hand is typical of the kind of top-down, modernizing development that post-development studies rails against. However, when it comes to programs based on community development methodologies one must take a much closer look. It's certainly possible for organizations to deploy the ideas and methodologies of community development in order to reach an already decided upon outcome. This research does not find that to have been the case with PCI in Ziddi and Mingdona.

Before moving on to questions of scale and the importance of politics it will be necessary to deal with the last source of uncertainty: risky accounts. The most ubiquitous types of objects that appear again and again throughout this study are documents. Documents are piled one upon another as monitoring reports are added to community

\footnotetext{
${ }^{53}$ To my mind there is no better example of this than the case of the "Green Revolution" in Bali as explained by Stephen J. Lansing in his book Priests and programmers: technologies of power in the engineered landscape of Bali 1991 Princeton University Press.
} 
descriptions and other data so the PCI manager can write a Quarterly Report so that bureaucrats in Washington can see programs in places like Tajikistan. Accounts, however, do not have to take the form of documents. The canal itself is a kind of account that is inscribed in the landscape and which performs the settlement: good relations are dependent on Ziddi having access to irrigation and land. Thus it is much more powerful to have that settlement built into the landscape. Ironically, once the canal was finished, it became a kind of matter of fact and consequently to open it up, to reverse what had been set in place, one would have to break some bit of it, perhaps destroy a pipe, break some concrete, or divert the canal's water. One cannot simply write it out of existence, but must take up arms against it.

Documents are not as stable as concrete canals, but they are often all that is available. Here is a risky account: Mercy Corps made a kind of wager that conflicts were not based on ethnic identity but would form out of an actual conflict over actual resources. In order to hedge their bet Mercy Corps enrolled some allies. At first these allies were studies that produced more documents that would make their case for them. Later these allies became if not bigger then more intensely connected; USAID, USAID's request for applications, the winning grant, and funding which would then lead to actual employees doing actual work, using vehicles, writing reports, traveling to villages, selecting villages, hiring engineers, etc. The interesting thing is that PCI gained reality as it gained more allies and enrolled an ever-widening array of people and things. But then PCI began to lose some of that reality, or transform that reality as it began to shut down. PCI now exists as a handful of projects scattered throughout Central Asia and someday the foreign actors that made it possible will be forgotten. What remains are 
documents in archives both physical and digital. Ziddi and Mingdona and the Kahlifi Hassan canal now exist in several places, in the documents and archives of Mercy Corps, in a handful of research projects, in the material remains of the infrastructure projects they helped build, and in this thesis. In the following chapter this research will take up the question of the riskiness of PCI's accounts.

The questions of documents and risky accounts lead somewhat seamlessly into question of scale: globality and locality, context, society, nature etc. How does the PCI program fit into a larger framework, or it should it be fit into a framework at all? Does PCI fit, in some way, into an overarching discourse about development? Or is it simply another addition to a variety of discourses about development, some of them dominant for a time and perhaps falling out of favor at another time. Are the connections between Mercy Corps' own discourse and "big D" development discourse direct or are they rather convoluted, complicated, and indirect? For the previous explanatory order (macro-mesomicro, global/local) to make any sense at all, the local must be nested in the overarching contextual space of the global so that scholars are able to explain phenomena at the "local level' by making recourse to global explanations. The contention in this research is that such a view not only reverses the direction from which empirical research should begin its studies but also relies on upon empty explanations for complex events. PCI is poorly served by the explanation that it unwittingly supports a kind of capitalist imperialism. The evidence that it does such a thing is fairly weak. This is especially so when one begins to examine Mercy Corps' discursive starting places and then moves on to an analysis of what else has been added. This is where post-development studies fails as it cannot recognize what else has been added to a given discourse. 


\section{Political relevance}

In the case of Ziddi and Mingdona what has been added to discourse about conflict, community, and economic development is an unyielding respect for the community as the center of development decisions and the notion that livelihoods must play a pivotal role in decisions about economic development. Mercy Corps' PCI program placed communities and livelihoods at the forefront of its implementation efforts. While the organization never shied away from economic development as a category of development, it also never failed to place livelihoods at the core of its economic development. Certainly Mercy Corps didn't engage in a communist form of economic development, but then that would make very little sense for a USAID partner. It is the contention of this research that PCI's tight focus on livelihoods and communities fundamentally differentiates the program from the more general and universal discourses of either capitalism or development. But every development program does this by the mere act of implementation. The real question is did Mercy Corps, through PCI, implement the program in a way that is to be applauded or decried? Development scholarship should, at an absolute bare minimum, be able to differentiate between development done poorly or done well. Post development simply stacks the deck in favor of its own irreal, ideal, and revolutionary politics, which may well never obtain.

Did Mercy Corps engage in a depoliticization of its development efforts?

Certainly they avoided open conflict with the elite at the national levels of government, but does that necessarily mean that they avoided politics altogether? The charge of depoliticization only makes sense if one can decide beforehand, and perhaps once and for all, of what are politics composed. If politics (epistemology) is to remain open, then 
short cuts such as those proposed by post-development must be ignored. The clever trick of both modernism and post-modernism is to maintain a strict boundary between epistemology and ontology. Latour breaks that boundary. As long as epistemology can stand on it own then it is fair to decide in advance of which elements the world is composed. That is the grand assumption that epistemology makes, that it knows in advance of what the world is composed. The cost of such a move, however, is to agree that we cannot form a common world. This is really the poison at the center of the postdevelopment apple. The other remains absolutely other, while the development professional remains captured by a powerful world-making discourse that can only be seen by post-development scholars who must heroically implore someone (who?) to tie them like Odysseus to the mast so that they can hear but avoid the siren call of making the world better. Only the grass roots can save the day, but they can only do so by completely rejecting the West. The argument of this research is that because one cannot know in advance which propositions will be the important or crucial ones, one also cannot know in advance the content of politics. 


\section{Chapter Eight - Findings, Summary, Limitations, Next steps \\ Introduction}

This concluding chapter will review and summarize the key findings of this research, briefly discuss the limitations, and examine the possible next steps for research. While the three case studies presented in this research are each empirical studies of different aspects of the PCI development program, they also compose a unique contribution to the theory and philosophy of development. Consequently, this review will reflect some of those theoretical and philosophical concerns. It is hoped that the reader accepts this research as a unique but ultimately modest contribution to both development theory and practice.

\section{Findings}

There are four key findings in this research. The first and most central finding relates to the research question posed in Chapter One: to what extent did Mercy Corps' PCI program depoliticize its activities? The answer to this question, and the central finding of this research, is that Mercy Corps' PCI program did not depoliticize its development activities. There are, however, a number of implications that go along with this finding and those will be discussed shortly. In addition to this first key finding, there are three more. Following the first finding regarding depoliticization, the second finding is that ideology, and by extension discourse, is not the strong force of social construction but rather one risky account among others. The third key finding is that the mechanism for isomorphism in development, that is, the extent to which the parts of development differ or reflect development as a whole, what can be understood as the mereology of 
development, is not to be found solely, or even primarily, in the overarching discourses of capitalism and development, but rather in the forms and standards of development practice. Finally, the fourth key finding is that social relations do not exist, indeed cannot exist, at least for very long, without materiality. In Ziddi and Mingdona the two villages were able to literally concretize a new set of relations, a new social order, but they were only able to do so via the displacement of desire into the form of a canal and flood protection system. This is not to say that social relations may not yet deteriorate for some unknown and unrelated reason, but only that for the two projects in the case studies presented here, that hybridity was the rule and not the exception. It would be difficult to know where to cut off materiality and say that this part of the project is social, that part there is material.

\section{Depoliticization}

The research question that this paper has sought to answer has been to what extent, if any, did Mercy Corps' PCI project depoliticize its development intervention. However, the question, derived from post-development studies, is itself based on a narrow definition of what counts as politics. Even so, the spirit of the question aims at uncovering the political machinations of development actors who might deny and obfuscate the fact that their projects are fundamentally political. The central finding of this research is that Mercy Corps did not engage in depoliticization of its development activities. Mercy Corps' development interventions, especially as they related to the process of identifying, funding, and implementing infrastructure projects, were fundamentally and quite openly political. In order to understand this it will first be important to understand the way in which actor-network theory, especially as elaborated 
by Latour, has reworked the common understanding of politics. Politics from a Latourian perspective is constituted by the act of gathering the right people together with the thing that can either unite or divide them and then proposing the question: what is to be done? Thus in this sense politics can only ever be understood beforehand as a kind of methodology or a form. From the perspective of this model of politics it is not possible to know in advance the content of politics. The content of politics grows out of what Latour would describe as the collective and progressive composition of the common world (Latour 2005). This leads to another implication of this finding. Under the rubric of postdevelopment and more broadly of post-structuralism there is no possibility for the progressive composition of the common world. There are number of reasons for this. The first reason is that post-development still depends on a modernist division of the world between nature and society. The development professional cannot properly cross the gap between worlds and words because of the way in which the development professional is already, completely and utterly, captured by the dominant discourses of development.

Additionally there can be no real knowledge of the other because development knowledge is already tainted by its own fetishistic nature and cannot escape its own origins. Development professionals are forever trapped by knowledge that is always western, and also either a fetish or simply wrong. The only way to avoid capture then is to completely reject the offerings of the West. The grassroots other must reject the West in toto. Thus there is no common ground, no possibility of a mixed collective, and thus no possibility of a progressive composition of a common world. There can only be the destruction of one or the other. This leads to a related implication: the politics of post- 
development are both ideal and revolutionary. However, in a practical sense, they have no real politics at all, only an abstract meta-politics that literally has no bearing on reality. It in fact cannot have a bearing on reality, but can only ever refer to an ideal set of conditions and is thus irreal. One of the key lessons of the post-development perspective is the imperative for inaction. To engage in development is to be captured by it (Kiely 1999; Storey 2000). Thus there can be no active and practical engagement.

Post-development, despite its critical stance, is incapable of rendering a judgment about whether a development project is done well or poorly. A related problem with the post-development perspective is the way in which it mobilizes the notion of a 'powerful discourse.' In the case of development the overarching discursive regime is related to the power of the West and is described by post-development as a hegemonic ideology. This

powerful discourse is the discourse of capitalism. Thus when post-development scholars such as Bichsel (2005) and Megoran (2005) identify Mercy Corps as a purveyor or in some sense a support for that hegemonic discourse then anything that follows, as well as the meaning of anything that follows, is prematurely fixed by that privileged discourse of capitalism.

\section{Discourse}

The second key finding is that ideology, and by extension discourse, is not the strong force of social construction but rather one risky account among others. This is not to say that discourse is not implicated in the construction of reality, it certainly is, but rather it is implicated in a much different way than that imagined by post-development.

The consequence of post-development's reliance on discourse and powerful ideologies is that it renders post-development research somewhat anti-empirical. What 
post-development does is to split the object of discourse in two, the first is the privileged, hegemonic, discourse of capitalist ideology, and the second would be Mercy Corps' own discourse. The caveat for post-development is that by having already identified Mercy Corps with that privileged capitalist discourse, and by virtue of a post-development understanding of development as part of an overarching discursive field, it becomes unnecessary to take into full account the discursive productions of Mercy Corps because they have in a sense already been explained. Such a view does tremendous damage to the concept of agency and also leaves post-development in the odd situation of being anti-empirical. For post-development, the meaning of any additional discourse is already pre-explained by the fact that it is already part and parcel of a privileged discourse. All that remains for the post-development scholar is to minimally demonstrate the fetishized nature of Mercy Corps' discursive practices via the simplest intellectual exercise of noting the similarities between Mercy Corps' discourse and capitalist discourse.

This is how post-development sets aside differences at the start of its various research projects and it also explains how post-development analysis of discourse always proceeds on the basis of a comparison with a more privileged discourse. Any additional discursive work is reduced to being merely an exemplar of that privileged discourse and development agencies and their staff are reduced to mere intermediaries, which are not actors at all but simple relays. Part of the evidence for this is negative. Neither Bichsel (2005) nor Reeves (2005), both post-development scholars who have studied the PCI program, offer an examination of Mercy Corps' values as represented in a variety of available documents. For these authors, Mercy Corps exists as a kind of simple black 
box that is never opened and is assumed to hold the same values as USAID, which is, in turn, a kind of avatar for capitalism.

In addition to treating development knowledge as a kind of fetish, postdevelopment scholars will often make the simultaneous move demonstrating that any given development program has simply got its facts wrong. This puts development practice in the uncomfortable position of always being wrong. If they implement a development program on behalf of any group that is not a 'social movement' then they are working in support of a privileged discourse and their knowledge, all of their knowledge, is a mere fetish. Furthermore, if they attempt to work, as they must, in the complex reality of a location, they will inevitably misunderstand, misconstrue, or otherwise misapprehend the objects of their projects. Indeed this is much of what Ferguson (1990) has offered in his review of development in Lesotho. The point here is not that these kinds of things don't happen, they most certainly do. The question is whether or not they must always happen. With post-development, development is left with the useless tools of fetishes and bad facts but then is also acted upon by forces beyond its control. The post-development scholar working in this critical tradition enjoys a privileged view of the world that allows her to uncover these fundamental facts about development, while the misguided development practitioner is forced to work under conditions of false consciousness (Latour 2004). The privileged view of the postdevelopment scholar allows them to escape this fate. Thus post-development scholars have privileged access to reality that is denied to most others, and they have the enviable position of always being right (Latour 2004). 


\section{Modernist Divisions}

With this research I have suggested that both post-development and poststructuralist versions of development studies rely upon a particularly modernist conception of the relationship between objective nature and subjective society. For example Escobar reminds readers that

The historicized view of the relation between nature and culture constitutes a further critique of modernity's view of nature as an inert background for the unfolding of the human saga. Worldwide, societies have been ceaselessly constructing bridges between nature and culture (Latour 1993). As we shall see, what types of bridges are built, and how, makes all the difference. Modern capitalist societies link nature and culture in ways that contrast sharply with how black and indigenous communities do it (Escobar 2010, p.30 emphasis added).

While Escobar is a strong critic of modernism, he doesn't appear to disagree with its basic scenography: that of a bridge crossing a divide. This scenography is what Latour refers to as 'the modernist constitution.' In the above passage, Escobar suggests that the divide between nature and society is experienced and dealt with differently by different cultures. Consequently, his critique of the modernist constitution is that it posits the nature side of the divide as an inert background, he then asserts that other 'societies have been ceaselessly constructing bridges between nature and culture'. Escobar then goes on to add Latour as a reference to this bridge building activity. However, Escobar misses the point entirely. For Latour the scenography of a bridge that crosses a gap between society and nature is entirely rejected and this should be glaringly obvious to any astute reader of Latour since the publication of Latour's book We Have Never Been Modern (1991). However, here we have Escobar marshaling Latour in support of an argument that Latour has repeatedly defeated. For Escobar, the divide between nature and society 
still exists and must still be bridged. Thus if he understands actor-network theory as bridge building than he is misunderstanding what Latour and other actor-network theorists mean when they speak about societies, natures, and modernity.

Latour says, "the idea of a bridge between representation and the represented is an invention of visual art" (Latour 2007), and by extension not a natural feature of the order of things. For Latour, the gap between nature and society is an artifact of a particular modernist way of viewing the world. The social sciences, having proceeded from a desire to be like the hard sciences, have generally accepted this gap and thus accepted that their role has been to build bridges across that gap. What Latour proposes is to abandon the bridge building activity and move between the two sides to better perceive their hybridity. The point of this exercise is to foreground the idea that an actor-network analysis radically changes the scenography of development, and in terms of postdevelopment, it quite literally stands post-development, and with it post-structuralism, on its head. Discourse is a material reality that is implicated in processes of articulation that produce particular and unique propositions. Discourse is also an actant and it is absolutely implicated in processes of constructing reality, but this is so because of its materiality.

There are elements of discourse and the production of discourse that are not considered by post-development. The first rather simple point is that any discourse must be constructed, and rather than taking the process of production for granted our understanding of development is better served by investigating in as much detail as possible the production of discourse. The second point is that once the messy process of producing a discourse is examined our attention is drawn away from large-scale actors, 
hegemony, ideology, and context and the landscape of development begins to look very different. Post-development begins its inquiry with the finished products of discourse and then attempts to relate them, or demonstrate their relations to, a number of contextual issues. These include hegemony, and various ideologies associated with capitalism and democracy, along with various other vaguely understood concepts such as power relations.

Instead of relating the final product to the way in which it was produced, including an analysis of the relations that are drawn by the various authors of these discourses of development, post-development draws our attention away towards a powerful, hegemonic field of discourse and renders any individual contribution to that overall discourse as a sort of exemplar of what counts as knowledge for development, and it is a development that is inseparable from ideology.

\section{Theories of Change - Isomorphism - Mereology}

One of the unsatisfying aspects of post-structuralism is that it is difficult to discern the mechanism by which changes can occur. Additionally, one is moved to ask, what is the mereology of post-development? How does it account for the relationship between parts and wholes? The finding of this research is that changes occur at the point where other actants and elements are introduced into existing assemblages. Post-development on the other hand posits an overarching discursive field that somehow affects all of those who come into contact with it. Though, to be sure, the mechanism by which discursive fields act is left unspecified. Thus this lack of specification regarding a mechanism for change forms part of the reason for claiming, in this research, that post-development 
under-theorizes discourse. If discourse is implicated in the construction of reality, then it is important to specify how that happens.

The argument here is that discourse is implicated in processes of construction, but it has also been demonstrated that discourse is not merely a set of ideas but a material technology that supports the displacement of ideas (sociality) into something more durable (materiality). Thus it matters what form documents take; are they published? Which audience are they meant for? How do they circulate? What do they authorize? What do documents gather together? How do they delimit action? In the case of Garibak, and by extension every project in PCI, the project was being constantly documented by PCI staff members: expenditures were logged, communities were mapped, criteria were measured, contracts were drawn up, plans were devised, water flow was measured, agreements were signed, and so forth. There were quite literally very few moves that were left undocumented in some sense.

Consequently, documents form part of the mechanism by which change occurs, but they are also the mechanism by which isomorphism occurs. Thus it is possible to track changes in documents and also track changes in the relationship between PCI, capitalist discourse, USAID, and others. This is not difficult; it involves an examination of the similarities and differences between discursive formations. But importantly, actornetwork theory focuses our attention on not merely similarities but constantly asks the researcher to examine what else gets added to the assemblage. Since every addition is in a real sense a translation there can be no simple accounting of similarities; difference cannot be simply set aside. Thus, as the reader has seen, when Mercy Corps engages with concepts like capitalism, the Ferghana Valley, ethnicity and so on, they always seem 
to add something to these elements. To capitalism Mercy Corps adds an approach to livelihoods and civil society. To ethnicity, Mercy Corps adds a series of studies. To conflict, Mercy Corps adds a theory of conflict; that conflict is local and resource based. Forms and standards, these are the material mechanisms by which differentiation and isomorphism occur. These are shared between organizations and between parts of the same organization. Something as mundane as 'cutting and pasting' becomes, in actornetwork theory, a socio-material process of imitation and translation.

\section{Social Relations are Inseparable from Material Relations}

In many ways the finding that social relations are inseparable from material relations informs the writing of the entire dissertation. This is the point of actor-network theory, objects too have agency. This is, however, the most contentious finding since its implications are immense. It is this understanding of reality that makes actor-network theory profoundly post-human. Who would grant pipes and pumps, even holes, agency? And this list is not limited to these obviously material things but also includes documents, spread sheets, plans, and reports. In the Garibak case the broken pump threatened the entire project. The holes in the pipes, together with the broken pump, became obstacles to closure. The solution of the problem involved a rearrangement of socio-material relations. The pump must be fixed, the holes must be plugged, and an agreement must be signed. Those actors left out of the original agreement had to be brought into the program. Latour would say that these elements that had been originally left out, had to be socialized and the process of socializing them is not merely, or only social. 


\section{Limitations}

There are some obvious limitations to the study that are common to most ethnographic studies. Ethnographies are potentially difficult to replicate and there is no guarantee that any two researchers will agree on what should count as the important variables within a given study. Part of this has to do with the sheer complexity of the research setting. As Latour notes "it is perfectly true to say that any given interaction seems to overflow with elements which are already in the situation coming from some other time, some other place, and generated by some other agency" (2005, p.166). Which threads should a researcher follow? This is largely a personal question that must be answered in the flow of research, and sometimes it's the case that the researcher follows a thread that is a difficult to verify or ultimately only leads to confusion. But this is mostly a kind of abstract limitation. It's simply not possible to know which threads any given researcher will explore. There are, however, some limitations that are more concrete.

One of the difficulties in this particular research had to do with its timing of the research. The PCI program consisted of two-phases and stretched out over five years. For reasons beyond my control I was unable to witness what could be argued is the most interesting part of any development program, the beginning. That moment when a development organization enters a village for the first time or begins the process of community mobilization is an extremely important one. In many ways the actor-network theory methodology is particularly well suited for the study of the innovation that is a necessary part of the start of a project. There is not much that can be done about this particular limitation except to plan future research that can be present for this important phase of the development process. 
Finally, there are serious theoretical and philosophical limitations that must be considered. Actor-network theory is in no way a completed project. While it may offer a much more robust theoretical and philosophical perspective on the methodology and analysis of research data than post-structuralism, this does not mean that it is a complete theory. The perspective has at least two important philosophical limitations and these limitations can be represented by two of the leading lights of object-orientated philosophy, Graham Harman and Levi Bryant. Imagine a line or a spectrum with three points. On the far left of the spectrum there is Graham Harman and his philosophical concern for elaborating a robust and rigorous philosophy of the object. In the middle of the line you have Bruno Latour who is very much a relational scientist or philosopher. After all, Latour calls his brand of sociology, sociology of associations. And for Latour associations are everything. On the far right you have Levi Bryant another objectoriented philosopher who is concerned with elaborating an object-oriented philosophy that can address the issue of mereology, or the relations between parts and whole. On the left you have a kind of quantum philosophy of the object free of its ephemeral affectations, its attributes. On the right you have the philosophical representation of large scale actors, such as organizations, class, culture, etc. In the middle you have Latour carving out a space for a relational perspective that has largely been missing from sociology since the time of Durkheim.

The relational perspective makes two separate arguments that put it atds with these two positions. First, it argues that in a practical sense objects are their relations, a position which Graham Harman vigorously rejects. Second, it argues that to some extent large scale actors such as universities, organizations, class, culture, capitalism, etc exist 
as effects. Which is to say that whenever one asks the question 'when a large scale actor acts who performs the action?' The answer will inevitably involve a long list of intermediaries. For Levi Bryant the notion that large-scale actors are effects is an untenable position, since for him actors at all scales and sizes must be real. Thus there are also two sets of concerns here and also an important division of labor. Harman and Bryant's concerns are primarily philosophical while Latour's concerns are in an important sense practical. Thus the division of labor between these perspectives is one of philosophy on the one hand and research on the other. My own concern is that I do not want to cede this middle ground. In many ways since the time of Durkheim's victory over the now forgotten French sociologist, Gabriel Tarde, sociology has focused too much of its energy on large scale actors, society, class, power, while simultaneously investing itself in an absolute divide of subjects/objects, epistemology/ontology, nature/society. This is the problem of correlationism that is only partially solved in actornetwork theory by an appeal to a rich outside reality. Meillassoux (2010) explains that

Correlationism rests on an argument as simple as it is powerful, and which can be formulated in the following way: No $\mathrm{X}$ without givenness of $\mathrm{X}$, and no theory about $X$ without a positing of $X$. If you speak about something, you speak about something that is given to you, and posited by you. Consequently, the sentence ' $\mathrm{X}$ is', means: ' $\mathrm{X}$ is the correlate of thinking' in a Cartesian sense. That is: $\mathrm{X}$ is the correlate of an affection, or a perception or a conception, or of any given subjective act. To be is to be a correlate, a term of a correlation. (2010 Collapse, Volume III, p.409).

Without diving too deeply into these murky waters suffice it to say that correlationism posits that there can be reality external to our perception of that reality. Thus correlationism is fundamentally anthropomorphic. Actor-network theory and specifically Latour as well as much of object-oriented philosophy or ontology reject this hypothesis in 
favor of what is now being termed post-humanism ${ }^{54}$. There is, as of yet, no absolute solution to this conundrum. One can assert one position or the other, or make argument on behalf of a position, but there are no final proofs. Thus, ANT proceeds on the basis of an incomplete philosophy, but so does everyone else and as has been shown there are certainly degrees of completion. For instance, it has been argued here that postdevelopment fails to offer a robust theory of discourse whereas actor-network theory does. The practical point here is that researchers can only follow philosophers so far, before they must return to more practical concerns. This should not be taken as an argument against philosophy. Michael Reardon once explained to me that anthropology is a form of empirical philosophy. The purpose is to test the limits of our knowledge in the field against the hard objects of our research. Rather than reject philosophy, this research seeks to hold middle ground between large-scale actors and a quantum mechanics of objects.

It might be better to describe these two approaches, Bryant's mereology and Latour's sociology of associations, as comprising separate movements. The movement in actor-network theory is always first towards the parts as a means of avoiding the offer of a totalizing whole. The movement for mereology is towards the notions of autopoiesis and emergence. The tension between these two perspectives rests on the notion of agency. Autopoiesis and emergence move agency up the scale towards a system and then seek to understand the agency of the system as a whole. The movement in ANT is generally towards relations between objects or actants. Bryant seeks an answer to the status of objects, whereas ANT finds the description of relations too productive to

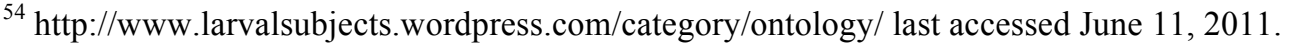


abandon and also too much ignored by the other social sciences. It seems that at just the moment we were authorized to abandon the big actors such as society we are asked to stop and first take into account the status of those large-scale objects we've eschewed in order to provide thick descriptions of their relations.

\section{Next steps and future research}

There remains a great deal to be learned about development and it is my belief that actor-network theory offers the most cogent model for revitalizing a robust critique of development that is based on empirical research and offers a non-idealistic perspective. There are at least three directions for future research. The first, and to me the most obvious, would be to pursue another ethnography of development that would focus on the beginning of a project rather than its end. There is much to be learned from what Norman Long (2001) refers to as the interface between a development organization and its beneficiaries as the one attempts to engage in the mobilization of the other.

The second direction would be to develop an analysis of development based on the differences between development that proceeds by way of deploying a set of facts, and development that proceeds based on the more open principles of community development and that relies more on matters of concern. This would be a kind of explicit test of actor-network theory as critique.

The third option for research would be to focus more intensely on the notion of forms and standards and, if given the opportunity, to review the process of developing a new program or proposal. I know from personal experience some of what this process involves, but it would be interesting and useful to involve a number of different participants in a kind of research experiment. Again, the point would be to elaborate in 
as much detail as possible how a proposal gets put together, with which sets of resources and with which actors and programs. How is the process negotiated and how are documents produced? The design would be somewhat experimental since there are difficult questions of access and trust involved. The results would be useful for further elaborating on a kind quantum-level of discourse.

Finally, I feel that there is a useful affirmation of the principles of community development and the practice of politics that needs to be shared with a practical audience whose concerns are less theoretical and more practical. Thus, it will be important to share the results of this research with Mercy Corps and other development organizations that pursue community based development strategies. 


\section{Bibliography}

Akrich, M. and B. Latour (1992). "A Summary of a Convenient Vocabulary for the Semiotics of Human and Nonhuman Assemblies.” In W. Bijker and J. Law (Eds.) Shaping Technology, Building Society: Studies in Sociotechnical Change. Cambridge, Mass: MIT Press. (1992): 259-264.

Althusser, Louis, with Etienne Balibar. Reading Capital. Translated Ben Brewster. London: New Left Books. 1970.

Alvarez, Claude. "Science" in Wolfgang Sachs, Editor. The Development Dictionary: A Guide to Knowledge as Power. Johannesburg: Witwatersrand University Press. 1999.

Anderson, R. J. "Representations and requirements: The value of ethnography in system design." Human-Computer Interaction 9 (1994): 151-182.

Ashmore, M. (1993). "Behaviour Modification of a Catflap: a contribution to the Sociology of Things." Kennis en Methode 17 (1993): 214-229.

Baran. Paul. The Political Economy of Growth. New York: Monthly Review Press. 1960

Barnes, Barry, David Bloor and John Henry, Scientific Knowledge - A Sociological Analysis. Chicago: The University of Chicago Press. 1996.

Barry, A. "In the middle of the network." In J. Law and A. Mol (Eds.) Complexities in Science, Technology and Medicine. Durham, N. Ca: Duke University Press. 2001.

Berg, Marc. Rationalizing Medical Work: Decision Support Techniques and Medical Practices. Cambridge, Mass: MIT Press. 1997.

Berg, A.-J. “Digital Feminism. PhD.” Senter for Teknologi og Samfunn. Trondheim, Norges Teknisk-Naturvitenskapelige Universitet. 1996.

Bichsel, Christine "In Search of Harmony: Repairing Infrastructure and Social Relations in the Ferghana Valley." Central Asian Survey. Vol 24, No 1. (2005): pp.53-66.

Bijker, Wiebe, E and John Law. Shaping Technology/Building Society: Studies in Sociotechnical Change. Massachusetts: Massachusetts Institute of Technology. 1994.

Bloomfield, B. P. and T. Vurdubakis ."Boundary disputes: Negotiating the boundary between the technical and the social in the development of IT systems." Information Technology \& People 7(1). (1994): 9-24. 
Bloomfield, B. P. "The role of information systems in the UK National Health Service: Action at a distance and the fetish of calculation." Social Studies of Science 21(4) (1991): pp.701-734.

Brenna, B., J. Law, et al. (Eds.). Machines, Agency and Desire. TMV Report Series. Oslo: University of Oslo. 1998.

Brewer, John D. Ethnography. Philadelphia, PA: Open University Press. 2000.

Brown, C. "Organization studies and scientific authority". In M. Reed and M. Hughes (Eds.) Rethinking Organization: New Directions in Organization Theory and Analysis. London, Sage: 67-84. 1992.

Callon, M. "Writing and (Re)writing Devices as Tools for Managing Complexity." In J. Law and A. Mol (Eds.) Complexities in Science, Technology and Medicine. Durham, N. Ca., Duke University Press. 2001.

Callon, M. “Actor-Network Theory: the Market Test." In J. Law and J. Hassard (Eds.) Actor Network and After. Oxford and Keele, Blackwell and the Sociological Review: 181-195. 1999.

Callon, M. "An Essay on Framing and Overflowing: Economic Externalities Revisited by Sociology." In M. Callon (Ed.) The Laws of the Markets. Oxford and Keele: Blackwell and the Sociological Review: 244-269. 1998.

Callon, M. (Ed.). The Laws of the Markets. Oxford: Blackwell and the Sociological Review. 1998.

Callon, M., 'Techno-economic networks and irreversibility', in Law, J., (Eds.), $A$ sociology of monsters: essays on power, technology and domination, , London: Routledge. pp. 132-161. 1991

Callon, Michel. (1986a). "The Sociology of an Actor-Network: The Case of the Electric Vehicle." In Callon, Law \& Rip (eds.) Mapping the Dynamics of Science and Technology: Sociology of Science in the real World. London: MacMillan Press.

Callon, Michel. (1986b) "Some Elements of a Sociology of Translation: The Domestication of the Scallops and the Fishermen of St.Brieuc Bay." In Law, J. (ed.) Power, Action \& Belief: A New Sociology of Knowledge? London: Routledge \& Kegan Paul.

Candea, Matei. Editor. The Social after Gabriel Tarde: Debates and Assessments. New York: Routledge. 2010 
Cardoso, Fernando, and Enzo Faletto. Dependency and Development. Berkeley and Los Angelos: University of Californian Press. 1979.

Chase-Dunn, Christopher. "The Effects of International Economic Dependence on Development and Inequality: a Cross - national Study" American Sociological Review, 40 (1975): 720 - 738.

Cooke, Bill and Uma Kothari. Participation: the New Tyranny. London: Zed Books. 2001.

Cooper, R. "Formal Organization as Representation: Remote Control, Displacement and Abbreviation." In M. Reed and M. Hughes (Eds.) Rethinking Organization. London: Sage. (1992): 254-272.

Cooper, R. and J. Law. "Organization: Distal and Proximal Views." In S. B. Bacharach, P. Gagliardi and B. Mundell (Eds.) Research in the Sociology of Organizations: Studies of Organizations in the European Tradition. Greenwich, Conn: JAI Press. 13 (1995): pp.275-301.

Community Development Team Five. Focus group interview with author. July 8, 2006.

Corbridge, Stuart. "Post-Marxism and Post-Colonialism: The Needs and Rights of Distant Strangers" In Pieterse, Jan Nederveen. Development Theory. London: Sage. 2011.

Cressman, D., “A Brief Overview of Actor-Network Theory: Punctualization, Heterogeneous Engineering \& Translation. Available at http://www.sfu.ca/cprost.reports.html, accessed May 5th, 2011.

Crewe, Emma and Elizabeth Harrison. Whose Development? An Ethnography of Aid. London: Zed Books. 20002

Cussins, Charis. "Ontological Choreography Agency for Women Patients in an Infertility Clinic." In M. Berg and A. Mol (Eds.) Differences in Medicine: Unravelling Practices, Techniques and Bodies. Durham, N Ca., Duke University Press. (1998).: 166-201.

de Laet, Marianne, and Annemarie Mol. "The Zimbabwe Bush Pump: Mechanics of a Fluid Technology." Social Studies of Science. Vol. 30, (2). (2000): pp.225-263.

Deleuze, Gilles and Felix Guattari.. Anti-Oedipus: Volume 1, Capitalism and Schizophrenia. Translated by Robert Hurley, Mark Seem and Helen R. Lane. London and New York: Continuum, 1972 
Denzin, Norman K, and Yvonna S. Lincoln, Editors, Handbook of qualitative research. Thousand Oaks, CA: Sage. 1994.

Dimaggio, Paul J. and Walter W. Powell. "The Iron Cage Revisited:Institutional Isomorphism and Collective Rationality in Organizational Fields." American Sociological Review. Vol 48, No. 2 (1983)

Dugdale, A. "Materiality: Juggling Sameness and Difference." In J. Law and J. Hassard (Eds.) Actor Network and After. Oxford:Blackwell and the Sociological Review. (1999): 113-135.

Ebrahim, Alnoor. NGOs and Organizational Change: Discourse, Reporting, and Learning. Cambridge: Cambridge University Press. 2005.

Edwards, Micheal and David Hulme, editors. Beyond the magic bullet: $N G O$ performance and accountability in the post cold war world 1996 Connecticut: Kumarian Press, Inc.

Engelstad, Ericka and Siri Gerrard. "Challenging Situatedness" pp1-26, In Challenging Situatedness: Gender, Culture, and the Production of Knowledge. Edited by Ericka Engelstad and Siri Gerrard. The Netherlands: Eburon Academic Publishers. 2005.

Engestrom, Y. and V. Escalante. "Postal buddy: Mundane tool or object of affection? The rise and fall of the postal buddy." University of California, San Diego, Mimeo. 1994.

Escobar, Arturo. Territories of Difference: Place, Movements, Life, Redes. US: Duke University Press. 2008

Escobar, Arturo. Power and Visibility: The Invention and Management of Development in the Third World. Ph.D. diss., University of California, Berkeley. 1987.

Escobar, Arturo. "Power and Visibility: Development and the Invention and Management of the Third World." Cultural Anthropology. 3(4) (1988): 377-400.

Escobar, Arturo. Encountering Development: The Making and Unmaking of the Third World. Princeton, New Jersey: Princeton University Press. 1995.

Esteva, Gustavo, “Regenerating People's Space.” Alternatives. 12(1) (1987): 125-152.

Ferguson, James. The Anti-Politics Machine, Cambridge: Cambridge University Press. 1990 .

Ferrarotti, Franco. An invitation to classical sociology: meditations on some great social thinkers. Lanham, MD: Lexington Books, 2003. 
Foucault, Michel. Discipline and Punish: The Birth of the Prison. New York: Vintage. 1979.

Frank, Andre Gunder. Latin America: Underdevelopment or Revolution? New York: Monthly Review Press. 1969a.

Frank, Manfred. What is Neo-Structuralism? Translated by Sabine Wilke and Richard Gray, foreward by Martin Schwab. Minneapolis: University of Minnesota Press. 1988.

Garfinkel, H. Studies in Ethnomethodology. New Jersey: Prentice Hall. 1967.

Gherardi, S. and D. Nicolini. "To Transfer is to Transform: the Circulation of Safety Knowledge." Organization 7. (2000).

Glaser, Barney G, and Anselm L. Strauss. The Discovery of Grounded Theory: Strategies for Qualitative Research. New Jersey: Rutgers. 1967.

Goldenbaum, Mark. Interview by author. Digital recording. Osh, Kyrgyzstan, August 20, 2006.

Grubb, Kevin. Interview by author. Digital recording. Penjikent, Tajikistan, May 26, 2006.

Grubb, Kevin. Interview by author. Digital recording. Penjikent, Tajikistan, July 15, 2006.

Hacking, Ian. The Social Construction of What? Cambridge, Mass: Harvard University Press. 1999.

Hammersley, Martyn and Paul Atkinson, Ethnography 3rd edition. London: Routledge, 2007.

Haraway, Donna. "Reading Buchi Emecheta: Contests for Women's Experience in Women's Studies With Situated Knowledges: The Science Question in Feminism as a Site of Discourse on the Privilege of Partial Perspective." in: Feminist Studies Vol. 14, No. 3, (1988), pp. 575-599.

Harman, Graham. Prince of Networks: Bruno Latour and Metaphysics. Melbourne, AU: re.press. 2009.

Holik, Haji. Personal Interview. Ziddi, Tajikistan. July 4, 2006.

Hopkirk, Peter. The Great Game. New York: Kodansha International. 1994. 
Horký, Ondřej. "Depoliticization, instrumentalization and legitimacy of Czech development cooperation: A case of imposed altruism?" Éthique et économique/Ethics and Economics. 8 (1), (2011).

Hunt, E.K. and Mark Lautzenheiser. History of Economic Thought: A Critical Perspective, 3rd edition. New York: M.E. Sharpe Inc. 2011.

Illich, Ivan. Celebration of Awareness. London: Marion Boyars. 1971.

Investopedia. http://www.investopedia.com/terms/r/request-for-application.asp accessed April 2011.

International Crisis Group. Central Asia: Decay And Decline. Asia Report No 201. February 2011. http://www.crisisgroup.org/en/regions/asia/central-asia/201-central-asiadecay-and-decline.aspx last accessed June 9, 2011.

Jones, Pauline Luong. Editor. The Transformation of Central Asia: State and Societies from Soviet Rule to Independence. Ithaca, New York: Cornell University Press. 2004.

Kaghan, W. and N. Phillips ."Building the Tower of Babel: Communities of Practice and Paradigmatic Pluralism in Organization Studies." Organization(5). (1998): pp.191-216.

Kamat, Sangeeta. "The Privatization of Public Interest: Theorizing NGO Discourse in a Neoliberal Era." Review of International Political Economy, vol 11, no 1. (2004): pp,155-176.

Kanybek, Interview by author. Digital recording. Osh, Kyrgyzstan, August 25, 2006.

Kiely, Ray. "The last refuge of the noble savage? A critical assessment of postdevelopment theory." European Journal of Development Research, 11 (1), (1999): pp3055 .

Kleveman, Lutz C. The New Great Game: Blood and Oil in Central Asia. New York: Grove Press. 2003.

Koichiev, Arslan. "Ethno-Territorial Claims in the Ferghana Valley During the Process of National Delimitation, 1924-7." In Everett-Heath, Tom. Editor. Central Asia: Aspects of Transition. New York: RoutledgeCurzon. 2003. pp.45-56.

Latouche, Serge. Faut-il refuser le développement. Paris: Presses Universitaires de France. 1986

Latour, Bruno Reassembling the Social: an Introduction to Actor-Network Theory. Oxford: Oxford University Press, 2005. 
Latour, Bruno. "What is the style of matters of concern? Two lectures in empirical philosophy", Spinoza Lectures at the University of Amsterdam, April and May 2005, publié sous forme de document indépendant, published as an independent pamphlet, Van Gorcum, Amsterdam, 51 pages, 2008.

Latour, Bruno. Politics of Nature: How to Bring the Sciences into Democracy. Cambridge, Mass: Harvard University Press. 2004.

Latour, Bruno. "From Realpolitik to Dingpolitik - An Introduction" in Making Things Public:Atmospheres of Democracy at ZKM. Massachusetts: MIT Press 2004.

Latour, Bruno. "Which Politics for Artifacts?" in Domus. 2004.

Latour, Bruno. "Gabriel Tarde and the End of the Social" in Patrick Joyce (editor) The Social in Question. New Bearings in History and the Social Sciences, London:Routledge pp.117-132. 2001.

Latour, Bruno. Pandora's hope: Essays on the reality of science studies. Translated by Catherine Porter. Cambridge, Mass.: Harvard University Press. 1999.

Latour, B. Aramis, or the Love of Technology. Cambridge, Mass: MIT Press. 1996.

Latour, Bruno. We Have Never Been Modern. Translated by Catharine Porter. Cambridge, Mass.: Harvard University Press. 1993.

Latour, Bruno. Science in Action: How to Follow Scientists and Engineers Through Society. Cambridge, Mass: Harvard University Press. 1987.

Latour, Bruno, and Steve Woolgar. Laboratory life: The construction of scientific facts. Beverly Hills, CA: Sage. 1979.

John Law 'The Manager and His Powers', published by the Centre for Science Studies, Lancaster University, Lancaster LA1 4YN, UK, at http://www.comp.lancs.ac.uk/sociology/papers/Law-Manager-and-his-Powers.pdf last accessed May 27, 2011. Originally published 2003.

Law, John and Vicky Singleton. "Performing Technology's Stories." Technology and Culture. 41 (2000):pp.765-775, also available at http://www.lancs.ac.uk/fss/sociology/papers/law-singleton-performing-technology'sstories.pdf.

Law, John. "Topology and the Naming of Complexity," published by the Centre for Science Studies, Lancaster University, Lancaster LA1 4YN, UK, at 
http://www.comp.lancs.ac.uk/sociology/papers/Law-Topology-and-Complexity.pdf 1997.

Law, John. "Notes on the theory of the actor-network: Ordering, strategy, and heterogeneity”. Systemic Practice and Action Research. 5(4), (1992): pp379-393.

Lave, Jean and Etienne Wenger. Situated Learning: Legitimate Peripheral Participation. Cambridge: Cambridge University Press. 1991.

Lee, Nick and John. Hassard. "Organization Unbound: Actor-Network Theory, Research Strategy and Institutional Flexibility," Organization, 6 (1999): 391-404.

Leys, Colin. The Rise and Fall of Development Theory. Bloomington, Indiana: Indiana University Press. 1996

Lockie, Stewart. "Deliberation and Actor-Networks: The "Practical" Implications of Social Theory for the Assessment of Large Dams and Other Interventions." Society and Natural Resources. 20, (2007) 785-799.

Long, Norman. Development Sociology: Actor Perspectives. New Jersey: Routledge. 2001.

McKinnon, Katharine. "Taking Post-Development theory to the field: Issues in Development Research, Northern Thailand." Asia Pacific Viewpoint, Vol. 49, No. 3, December. (2008): pp281-293.

Megoran, Nick. "On Researching 'Ethnic Conflict': Epistemology, Politics, and a Central Asian Boundary Dispute.” Europe-Asia Studies Vol. 59, No. 2. March (2007): pp.253 277.

Mercy Corps (Emily Hillenbrand). The Impact of Peaceful Communitis Initiative on Women. Unpublished report. 2007.

Mercy Corps. Vision for Change: Evolution of an Organizational Framework. Prepared by Sarah Wardell, Edited by Anna Young. 2011.

Mercy Corps. Who We Are. Internal Mercy Corps' publication. 2010

Mercy Corps. Guide to Community Mobilization Programming. Internal Mercy Corps' publication. 2008.

Mercy Corps. Sustainability Field Study: Understanding What Promotes Lasting Change at the Community Level. 2007.

Mercy Corps. USAID’s Peaceful Communities Initiative Final Report 2001-2007, 2007. 
Mercy Corps Beyond borders: year one annual report October 2001 to September 2002, 2002.

Mercy Corps. The Heart of Central Asia: Mercy Corps' Multi-Sectoral Assessment of the Ferghana Valley. 1998.

Mercy Corps (Anna Young). Ferghana Valley Field Study: Reducing the Potential for Conflict through Community Mobilization. Mercy Corps Central Asia. 2003.

Meyer, Karl and Shareen Blair Brysac. Tournament of Shadows: The Great Game and the Race for Empire in Central Asia. Washington, DC: Counterpoint. 1999.

Michael, Mike. "Co(a)gency and the car: Attributing Agency in the Case of the 'Road Rage'". In B. Brenna, J. Law and I. Moser (Eds.) Machines, Agency and Desire. Oslo, , University of Oslo: TMV. (1998): 125-141.

Mitchell, Tmothy. Rule of Experts: Egypt, Techno-Politics, Modernity. Berkeley: University of California Press. 2002.

Mol, Anne Marie. The Body Multiple: Artherosclerosis in Practice. Durham, N.Ca. and London: Duke University Press. 2001.

Mosse, David. Cultivating Development: An Ethnography of Aid Policy and Practice. London: Pluto Press. 2005.

Murdoch, John. "Ecologising Sociology: Actor-Network Theory, Co-Construction and the Problem of Human Exemptionalism," Sociology-the Journal of the British Sociological Association, 35, (2001) 111-133.

Nunn, Sam, Barnett, Rubin and Nancy Lubin. Calming the Ferghana Valley: Development and Dialogue in the Heart of Central Asia. New York: The Century Foundation Press. 1999.

Odum, Justin. Interview by author. Digital recording. Khujand, Tajikistan. July 19, 2006.

Ouvry, Adrian Interview by author. Digital recording. Dushanbe, Tajikistan. March 5, 2006.

Palys, Ted, "Purposive Sampling," in The Sage Encyclopedia of Qualitative Research Methods. Edited by in Lisa M. Given. Thousand Oaks, CA: Sage. Vol 2, pp.697-698. CA, Vol.2, pp.697-698.

Peet, Richard, with Elaine Hartwick. Theories of Development. New York: The Guilford Press. 1999. 
Peters, Michael. Poststructuralism, Marxism, and Neoliberalism: Between Theory and Politics. Oxford: Rowman \& Littlefield Publishers, Inc. 2001.

Peters, Michael, A. and Nicholas C. Burbules. Postructuralism and Education Research. United States of America: Rowman \& Littlefield Publishers, INC. 2004.

Pieterse, Jan Nederveen. Development Theory. London: Sage. 2011.

Rahnema, Majid. and Victoria Bawtree (eds). The Post-Development Reader. London: Zed Books. 1997.

Rashid, Ahmed. Taliban: Militant Islam, Oil \& Fundamentalism in Central Asia. New Haven: Yale University Press. 2001.

Renken, Lynn. Interview by author. Digital recording. Portland, Oregon. October 12, 2005.

Westerman, Brandy. Interview by author. Digital recording. Portland, Oregon. October $12,2005$.

Rahnema, Majid. "Poverty" in Wolfgang Sachs, Editor. The Development Dictionary: A Guide to Knowledge as Power. Johannesburg: Witwatersrand University Press. 1999.

Reeves, Madeleine. "Travels in the Margins of the State: Everyday Geography in the Ferghana Valley Borderlands." In Sahadeo, Jeff and Russell Zanca, Editors. Everyday Life in Central Asia: Past and Present. Bloomington: Indiana University Press. 2007.

Reeves, Madeleine. "Locating danger: Konfliktologiia and the Search for Fixity in the Ferghana Valley Borderlands.” Central Asian Survey. 24(1) (2005): pp.1-15.

Rist, Gilbert. The History of Development: From Western Origins to Global Faith, Third Edition. London: Zed Books. 2009

Ritzer, George. Encyclopedia of Social Theory. Thousand Oaks, CA: Sage. 2004.

Roy, Olivier. The New Central Asia: The Creation of Nations. New York: New York University Press. 2000.

Ruming, Kristian. "Following the Actors: mobilizing an actor-network theory methodology in geography." Australian Geographer, Vol. 40, No. 4, (2009): 451-469.

Sachs, Wolfgang. Editor. The Development Dictionary: A Guide to Knowledge as Power. London: Zed Books. 1999. 
Sahadeo, Jeff and Russell Zanca, Editors. Everyday Life in Central Asia: Past and Present. Bloomington: Indiana University Press. 2007.

Sande Lie, Jon Harald. "Post-Development Theory and the Discourse-Agency

Conundrum.” Social Analysis, Volume 52, Issue 3, Winter. (2008): 118-137

Schuurman, Frans J. Beyond the Impasse: New Directions in Development Theory. London: Zed Books Ltd. 2004.

Shapin, Steven and Simon Schaffer. Leviathan and the Air-Pump: Hobbes, Boyle, and the Experimental Life. New Jersey: Princeton University Press. 1985.

Shiva, Vandana. "Resources" in Wolfgang Sachs, Editor. The Development Dictionary: A Guide to Knowledge as Power. Johannesburg: Witwatersrand University Press. 1999.

Simon, David. "Development Revisited: Thinking about, practicing and teaching development after the Cold War" in Development as Theory and Practice. Edited by David Simon and Anders Närman, 17-54, United Kingdom: Addison Wesley Longman United. 1999

Srnicek, Nick "Conflict Networks: Collapsing the Global into the Local." Journal of Critical Globalisation Studies. Issue 2, (2010) 30-64.

Star, S. L. "The Trojan door: Organizations, work, and the 'open Black Box'." Systems Practice 5. (1992): pp.395-410.

Starr, Frederic S. Ferghana Valley: The Heart of Central Asia - Studies of Central Asia \& the Caucasus. New York: M.E. Sharpe. 2011.

Stengers, Isbelle, Cosmopolitiques - Tome 1: la guerre des sciences. 1996 Paris: La de'couverte \& Les Empe^cheurs de penser en rond.

Storey, Andy. "Post-Development Theory: Romanticism: and Pontius Pilate politics." Development, vol. 43, No.4. (2000): pp.40-46.

Strauss, Anselm. Qualitative Analysis for Social Scientists. Cambridge: Cambridge University Press. 1987.

Suchman, Lucy. "Organizaing Alignment: A Case of Bridge-Building." Organization. Volume 7(2) (2000): pp.311-327.

Swanström, Niklas L. P. with Svante Cornell and Anara Tabyshalieva, A Strategic Conflict Analysis of Central Asia with a Focus on Kyrgyzstan and Tajikistan, Report to Swedish Internation Development Cooperation Agency, June 2005. 
Tabyshalieva, Anara. "The Challenge of Regional Cooperation in Central Asia:

Preventing Ethnic Conflict in the Ferghana Valley." Peaceworks No. 28. Washington, D.C.: United States Institute of Peace. 1999.

Thompson, Chad and John Heathershaw. "introduction" Central Asia Survey, Special Issue: Discourses of Danger in Central Asia. 24 (1), 2005:

Thubron, Colin. The Lost Heart of Central Asia. London: Vintage. 2004

Thompson, Chad. \& Heathershaw, John. Editors. "Discourses of Danger in Central Asia." Central Asian Survey, 24, 1, (2005): pp. 1 - 96.

United Nations. The Ferghana Valley: Beyond the Batken Crisis. 1999.

United Nations Development Programme. "Inter-country Programme for the Central Asian Region: The Kyrgyz Republic and the Republic of Tajikistan - Area Development Framework Document" 1999.

Varma, Baidya Nath. The Sociology and Politics of Development: A Theoretical Study. London: Routledge. 1980.

Wallerstein, Immanuel. The Capitalist World Economy. New York: Cambridge University Press. 1979.

Weinthal, Erika. "The Promises and Pitfalls of Environmental Peacemaking in the Aral Sea Basin" in Ken Conca and Geoffrey D. Dabelko, editors. Environmental Peacemaking. Balitmore, MD: The John Hopkins University Press. 2002.

Ziai, Aram, ed. Exploring Post-Development: Theory and Practice, Problems and Perspectives. London and New York: Routledge. 2007. 